\title{
Brain metastases in lung cancer patients
}

Citation for published version (APA):

Hendriks, LEL. (2016). Brain metastases in lung cancer patients: unraveling clinical questions. [Doctoral Thesis, Maastricht University]. Datawyse / Universitaire Pers Maastricht. https://doi.org/10.26481/dis.20160923lh

Document status and date:

Published: 01/01/2016

DOI:

10.26481/dis.20160923lh

Document Version:

Publisher's PDF, also known as Version of record

\section{Please check the document version of this publication:}

- A submitted manuscript is the version of the article upon submission and before peer-review. There can be important differences between the submitted version and the official published version of record.

People interested in the research are advised to contact the author for the final version of the publication, or visit the DOI to the publisher's website.

- The final author version and the galley proof are versions of the publication after peer review.

- The final published version features the final layout of the paper including the volume, issue and page numbers.

Link to publication

\footnotetext{
General rights rights.

- You may freely distribute the URL identifying the publication in the public portal. please follow below link for the End User Agreement:

www.umlib.nl/taverne-license

Take down policy

If you believe that this document breaches copyright please contact us at:

repository@maastrichtuniversity.nl

providing details and we will investigate your claim.
}

Copyright and moral rights for the publications made accessible in the public portal are retained by the authors and/or other copyright owners and it is a condition of accessing publications that users recognise and abide by the legal requirements associated with these

- Users may download and print one copy of any publication from the public portal for the purpose of private study or research.

- You may not further distribute the material or use it for any profit-making activity or commercial gain

If the publication is distributed under the terms of Article $25 \mathrm{fa}$ of the Dutch Copyright Act, indicated by the "Taverne" license above, 


\section{Brain metastases in lung cancer patients: unraveling clinical questions}

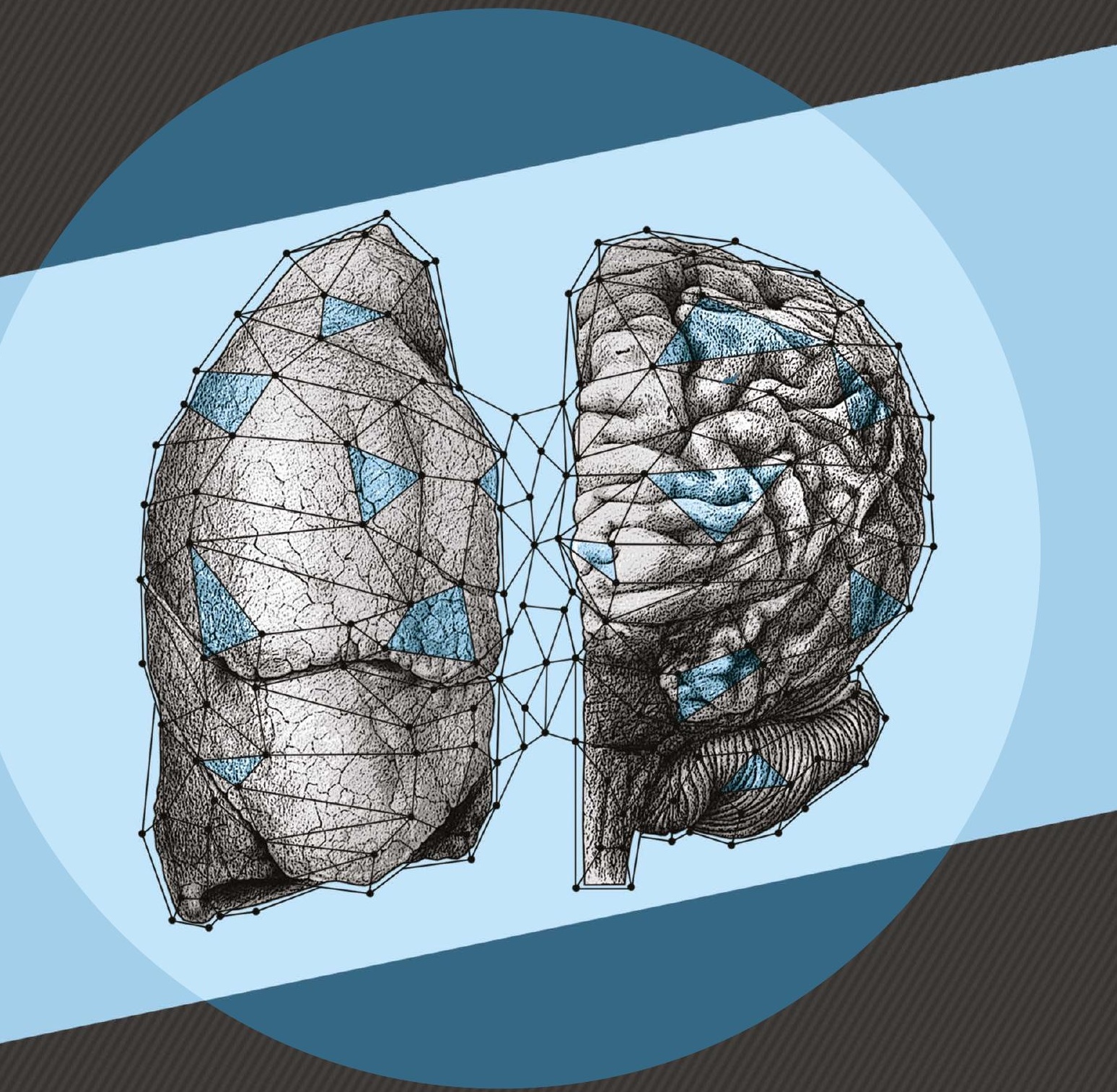

\section{Lizza E.L. Hendriks}


${ }^{\circledR}$ Copyright Lizza E.L. Hendriks, Maastricht 2016

Layout: Tiny Wouters

Cover: Daan Janssen

Printed by: Datawyse | Universitaire Pers Maastricht

ISBN: 9789461595904

Financial support for printing of this thesis was kindly provided by Boehringer Ingelheim, Amgen and Pfizer. 


\section{Brain metastases in lung cancer patients: unraveling clinical questions}

\section{PROEFSCHRIFT}

ter verkrijging van de graad van doctor aan de Universiteit Maastricht, op gezag van de Rector Magnificus, Prof. dr. Rianne M. Letschert, volgens het besluit van het College van Decanen, in het openbaar te verdedigen op vrijdag 23 september 2016 om 10.00 uur

door

Lizzà Elisabeth Lucia Hendriks 


\section{Promotores}

Prof. dr. A-M.C. Dingemans

Prof. dr. E.F.M. Wouters

\section{Beoordelingscommissie}

Prof. dr. V.C.G. Tjan-Heijnen (voorzitter)

Dr. A. Gijtenbeek (Radboud Universiteit Nijmegen, Nijmegen)

Prof. dr. P. Lambin

Prof. dr. J. Van Meerbeeck (Universitair Ziekenhuis Antwerpen, Antwerpen, België)

Prof. dr. F. Ramaekers 


\section{Contents}

Chapter 1 General introduction 7

Chapter 2 Screening for brain metastases in patients with stage III 25 non-small cell lung cancer: Is there additive value of magnetic resonance imaging above a contrast-enhanced computed tomography of the brain? Lung Cancer 2013;80:293-7

Chapter 3 MRI or contrast-enhanced CT screening for brain metastases in patients with stage III non-small cell lung cancer?

A prospective study In preparation

Chapter 4 Development of brain metastases after chemoradiotherapy for stage III non-small cell lung cancer: does the type of chemotherapy regimen matter? Submitted

Chapter 5 Single organ metastatic disease and local disease status, prognostic factors for overall survival in stage IV non-small cell lung cancer: results from a population-based study Eur J Cancer 2015;51:2534-44

Chapter 6 Proposals for the M-descriptors of the eight TNM classification for non-small cell lung cancer: more data needed?

J Thor Oncol 2016;11:e42

Chapter 7 Patient selection for whole brain radiotherapy (WBRT) in a large lung cancer cohort: Impact of a new Dutch guideline on brain metastases

Acta Oncol. 2014;53:945-51

Chapter 8 EGFR-mutated non-small cell lung cancer patients: more prone to development of bone and brain metastases?

Lung Cancer. 2014;84:86-91

Chapter 9 Safety of cranial radiotherapy concurrent with tyrosine kinase inhibitors in non-small cell lung cancer patients:

a systematic review

Cancer Treat Rev. 2015;41:634-45

Chapter 10 Treatment and survival of patients with EGFR-mutated non-small cell lung cancer and leptomeningeal metastasis: a retrospective cohort analysis Lung Cancer. 2015 Sep;89(3):255-61 
Summary

Samenvatting

Valorization

205

Dankwoord

211

Curriculum vitae

217

List of publications

221 


\title{
Chapter 1
}

\author{
General introduction
}




\section{GENERAL INTRODUCTION}

\section{LUNG CANCER; EPIDEMIOLOGY AND PROGNOSIS}

Non-small cell lung cancer (NSCLC) and small cell lung cancer (SCLC) account for $80-85 \%$ and $15-20 \%$ of lung cancer cases, respectively. ${ }^{1}$ In 2013 in the Netherlands, 12.660 patients were diagnosed with lung cancer. ${ }^{2}$ Approximately $30 \%$ is diagnosed in a locally advanced state (i.e. stage III) and $50 \%$ in an already metastatic state (stage IV). ${ }^{3}$ NSCLC can be divided into different histological subtypes: adenocarcinoma, squamous cell carcinoma, large cell carcinoma and several rarer subtypes (for example neuroendocrine carcinomas). Currently, staging is based on the 7th tumor, node and metastases (TNM) classification (Table 1.1). This edition is based on an analysis of a retrospective worldwide database of more than 100.000 cases including data from clinical trials, consortium/surgical series, and registry-series. ${ }^{4}$ The aim of the TNM staging system is to group patients together with the same overall survival (OS), i.e. prognosis. The best OS is found in stage IA (median OS more than nine years, over $70 \%$ five-year survival) and the worst in stage IV disease with extrathoracic metastases (M1b, median OS six months, $22 \%$ one-year survival) (Table 1.2). ${ }^{5,6}$ Besides an advanced stage, other factors have a negative impact on OS. Examples are poor performance status (PS), male gender, comorbidities, weight loss and active smoking. ${ }^{7-9}$ Molecular characteristics can also influence OS. An activating epidermal growth factor receptor (EGFR)-mutation is a good prognostic factor and is predictive for response to EGFRtyrosine kinase inhibitors (TKI). ${ }^{10}$ Activating EGFR-mutations are found in approximately $10-15 \%$ of Caucasian patients with stage IV non-squamous NSCLC ${ }^{11-14}$ and this percentage increases to more than $60 \%$ in non-smoking Asian females. ${ }^{15}$ Anaplastic lymphoma kinase $(A L K)$-fusion genes do not have a prognostic impact but are predictive for response to ALK-TKI. ${ }^{16} A L K$-rearrangements are detected in approximately $5 \%$ of patients. $^{17}$

Table $1.1 \quad 7^{\text {th }}$ TNM classification for lung cancer.

\begin{tabular}{lcccc}
\hline T and $M$ & NO & N1 & N2 & N3 \\
& Stage & Stage & Stage & stage \\
\hline T1a $(\leq 2 \mathrm{~cm})$ & IA & IIA & IIIA & IIIB \\
T1b $(>2-3 \mathrm{~cm})$ & IA & IIA & IIIA & IIIB \\
T2a $(\leq 5 \mathrm{~cm})$ & IB & IIA & IIIA & IIIB \\
T2b $(>5-7 \mathrm{~cm})$ & IIA & IIB & IIIA & IIIB \\
T3 & IIB & IIIA & IIIA & IIIB \\
T4 & IIIA & IIIA & IIIB & IIIB \\
M1a & IV & IV & IV & IV \\
M1b & IV & IV & IV & IV \\
\hline
\end{tabular}

T: tumour; N: node; M: metastases. Adapted from: Groome et al. J Thorac Oncol 2007;2:694-705. 
Table 1.2 Overall survival according to TNM7 stage.

\begin{tabular}{lcccc}
\hline \multirow{2}{*}{ Stage (TNM7) } & \multicolumn{2}{c}{ Clinical stage } & \multicolumn{2}{c}{ Pathological stage } \\
\cline { 2 - 5 } & Median OS (months) & 1-year OS & Median OS (months) & 5 -year OS \\
\hline IA & 60 & $50 \%$ & 119 & $73 \%$ \\
IB & 43 & $43 \%$ & 81 & $58 \%$ \\
IIA & 34 & $36 \%$ & 49 & $46 \%$ \\
IIB & 18 & $25 \%$ & 31 & $36 \%$ \\
IIIA & 14 & $19 \%$ & 22 & $24 \%$ \\
IIIB & 10 & $7 \%$ & 13 & $9 \%$ \\
IV & 6 & $2 \%$ & 17 & $13 \%$ \\
\hline
\end{tabular}

TNM: tumour node metastases; OS: overall survival. Adapted from: Goldstraw et al. J Thorac Oncol 2007; 2:706-714

Currently, there is a lack of data gathered in routine clinical practice regarding the prognostic value of the extent of metastases in population based stage IV NSCLC cohorts and it is not clear whether results are comparable for ${ }^{18}$ fluorodeoxyglucosepositron emission tomography $\left({ }^{18} \mathrm{FDG}-\mathrm{PET}\right)$-staged patients due to possible stage migration, also called the "Will Rogers phenomenon" ${ }^{18-20}$ It is also not known whether local disease status still has a prognostic impact in already metastasized patients.

\section{LUNG CANCER AND BRAIN METASTASES: IMPACT ON OS AND QUALITY OF LIFE}

Approximately $40 \%$ of NSCLC patients will develop brain metastases during the course of their disease. ${ }^{21}$ Brain metastases often have a negative impact on quality of life (QoL). ${ }^{22}$ There are several prognostic classifications available for patients with brain metastases from solid tumours. The Recursive Partitioning Analysis (RPA), the Graded Prognostic Assessment (GPA) and the Diagnosis-Specific-GPA (DS-GPA) are the most commonly used classifications. ${ }^{23-25}$ These classifications are also validated in lung cancer patients (NSCLC as well as SCLC) (Tables 1.3 and 1.4). ${ }^{25-27}$ Median OS for patients with brain metastases from solid tumours ranges from 7.1 months for RPA class I patients, to 4.2 months for RPA class II and 2.3 months for RPA class III. ${ }^{23}$ For lung cancer patients, median OS is 5.2, 4.0 and 2.5 months, respectively. ${ }^{26}$

Table 1.3 RPA classification.

\begin{tabular}{lccc}
\hline RPA class & Description* & Median OS (months) $^{* *}$ & Percentage of patients** \\
\hline I & KPS $\geq 70$ AND & 5.2 & $13 \%$ \\
& Age $<65$ years AND & & \\
No ECM AND & & \\
Primary under control & & $67 \%$ \\
II & All other patients & 4.0 & $20 \%$ \\
III & KPS $<70$ & 2.5 & \\
\hline
\end{tabular}

RPA: recursive partitioning analysis; OS: overall survival; KPS: Karnofsky performance score; ECM: extracranial metastases. * Gaspar et al. Int J Radiat Oncol Biol Phys 2000;46:297-302; ** Kepka et al. Acta Oncol 2005;44:389-98. 
Table 1.4 Ds-GPA classification.

\begin{tabular}{|c|c|c|c|}
\hline \multirow[t]{2}{*}{ Prognostic factor } & \multicolumn{3}{|c|}{ Ds-GPA Scoring Criteria* } \\
\hline & \multirow{2}{*}{$\begin{array}{c}0 \\
>60\end{array}$} & 0.5 & 1 \\
\hline Age (years) & & $50-60$ & $<50$ \\
\hline KPS & $\begin{array}{l}>60 \\
<70\end{array}$ & $70-80$ & $90-100$ \\
\hline ECM & + & $\mathrm{n} / \mathrm{a}$ & - \\
\hline No. of BM & $>3$ & $2-3$ & 1 \\
\hline Total score & \multicolumn{2}{|c|}{ NSCLC, median OS (months)* } & SCLC, median OS (months)* \\
\hline $0-1.0$ & \multicolumn{2}{|c|}{3.0} & 2.8 \\
\hline $1.5-2.0$ & \multicolumn{2}{|c|}{6.5} & 5.3 \\
\hline $2.5-3.0$ & \multicolumn{2}{|c|}{11.3} & 9.6 \\
\hline $3.5-4.0$ & \multicolumn{2}{|c|}{14.8} & 17.1 \\
\hline
\end{tabular}

Ds-GPA: disease specific graded prognostic assessment; KPS: Karnofsky performance score; ECM: extracranial metastases; No: number; BM: brain metastases; NSCLC: non-small cell lung cancer; OS: overall survival; SCLC: small cell lung cancer. * Sperduto et al. Int J Radiat Oncol Biol Phys 2010;77:655-61.

\section{RISK FACTORS FOR BRAIN METASTASES}

Known risk factors for the development of brain metastases are adenocarcinoma histology, advanced nodal status, tumor stage and younger age. ${ }^{28-31}$ It is not clear whether, similar to patients with (EGFR/erB family member) HER2-positive breast cancer, the tumor biology of EGFR-mutated patients results in an increased risk for brain metastases. $^{32}$ In one study evaluating 39 EGFR-mutated, 49 Kirsten rat sarcoma viral oncogene homolog (KRAS)-mutated, 41 ALK-translocated and 80 wildtype NSCLC patients no difference in percentage of patients diagnosed with brain metastases at initial NSCLC diagnosis was found for the different molecular subtypes. ${ }^{33}$ Other studies suggest that the incidence of brain metastases may be higher in EGFR-mutated patients as compared to EGFR-wildtype patients. ${ }^{34-38}$ However, in these studies only patients already diagnosed with brain metastases were enrolled ${ }^{34,36,38}$ and/or mutation status was not known for all included patients. ${ }^{35,37,38}$ Another explanation for a possibly higher incidence of brain metastases in EGFR-mutated patients during treatment is the inability of currently available EGFR-TKI to cross the intact blood-brain barrier (BBB) at recommended doses. ${ }^{39}$

\section{NSCLC: IMAGING REQUIRED FOR STAGING INCLUDING SCREENING FOR BRAIN METASTASES}

The extent of staging work-up advised in guidelines varies according to the (suspected) stage in which the lung cancer is diagnosed. In all patients eligible for therapy with curative intent, not only a computed tomography (CT) of the chest and upper abdomen, but also a whole body ${ }^{18}$ FDG-PET is recommended. ${ }^{40-42}$ When ${ }^{18}$ FDG-PET is added to the $\mathrm{CT}$, more patients are found in an advanced stage due to the upstaging effect of the ${ }^{18}$ FDG-PET. ${ }^{18,19}$ This ${ }^{18}$ FDG-PET scan can be performed with a non- 
diagnostic low dose CT (LD-CT) for attenuation correction or with a diagnostic contrast enhanced CT (CE-CT) of the thorax and upper abdomen. Combination with CE-CT of the brain is also an option and feasible. ${ }^{43}$

In all current NSCLC guidelines it is recommended to exclude asymptomatic brain metastases at least in stage III patients eligible for therapy with curative intent. ${ }^{41,42,44,45}$ Post contrast magnetic resonance imaging (MRI) is preferred, however when this is contra-indicated a CE-CT is mentioned as an alternative option. An example of a current work-up for stage III NSCLC is presented in Figure 1.1, including time limits for each step (based on the Dutch "Stichting Oncologische Samenwerking" (SONCOS) document for 2016). ${ }^{18}$ FDG-PET with or without LD-CT of the brain is not suitable for the detection of brain metastases. ${ }^{46-49}$ Older studies including patients with mixed tumour types and stages show that MRI of the brain is more sensitive than a CE-CT in detecting presence and especially number of brain metastases. ${ }^{50-54}$ However, it is unclear whether this is still the case in the setting of excluding asymptomatic brain metastases in stage III NSCLC patients with up-to-date MRI and CT techniques.

In the follow-up of NSCLC patients treated with curative intent, it is usually not advised to routinely image the brain. ${ }^{41,42}$ Only in the ESMO guideline on locally advanced NSCLC, it is suggested that for selected high risk patients (adenocarcinoma) routine brain imaging is an option for the early detection and possible radical treatment of brain metastases (level of evidence: V, C). ${ }^{44}$ In stage IV NSCLC patients imaging of the brain is only advised for neurologically symptomatic patients. ${ }^{41,42,55}$ Excepted are oligometastatic NSCLC patients eligible for therapy with curative intent: in these patients brain imaging is recommended before commencement of intensive therapy. ${ }^{41}$ 


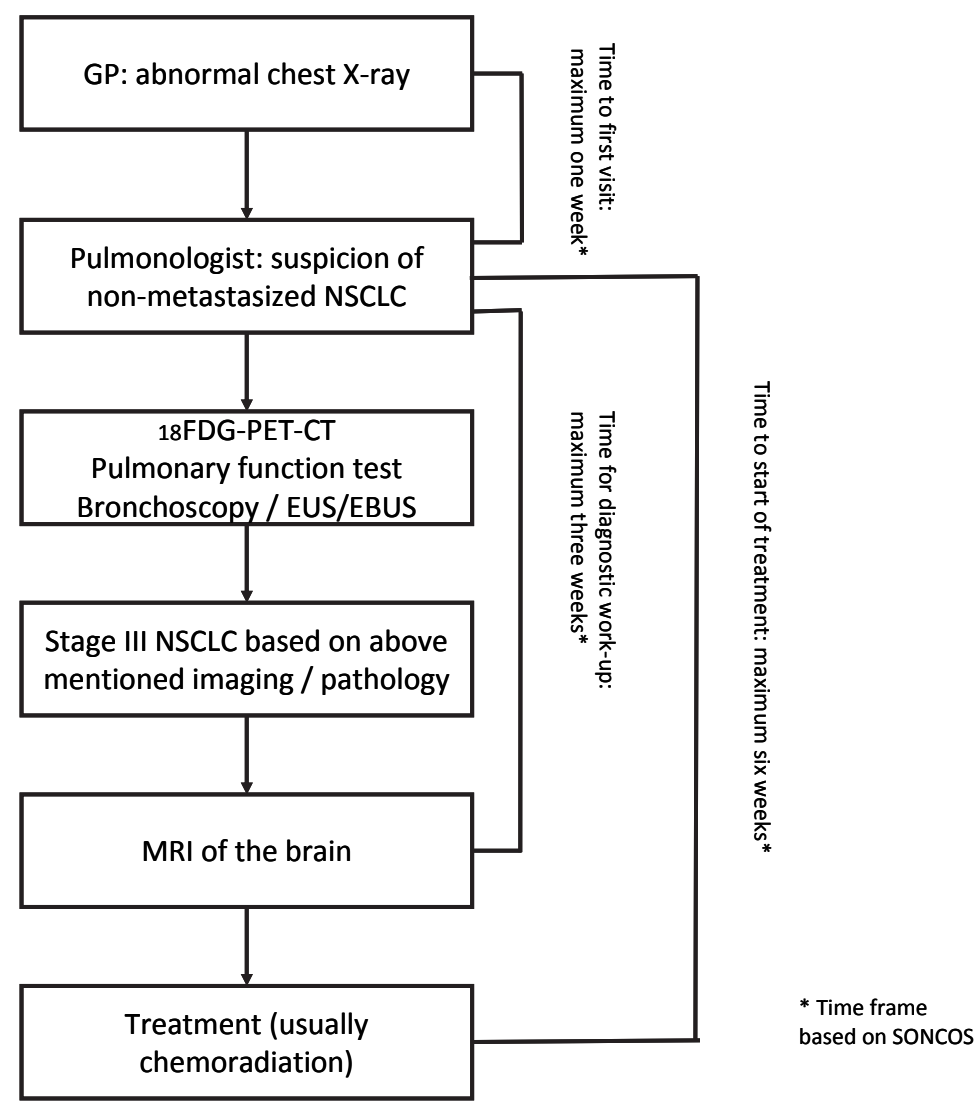

Figure 1.1 Flow chart diagnosis stage III NSCLC

\section{TREATMENT OF STAGE III NSCLC}

Standard treatment for inoperable stage III NSCLC is chemoradiation (CRT). ${ }^{41,42,44}$ In a meta-analysis (2010) a superior OS was found for concurrent CRT (cCRT) compared to sequential CRT (sCRT). ${ }^{56}$ For fit patients, two to four cycles of systemic dose platinum (preferably cisplatin) based doublet chemotherapy are advised concurrent with radiotherapy. Platinum is usually combined with etoposide or vinorelbin. ${ }^{42,44}$ Other chemotherapeutic regimens concurrent with radiotherapy are platinum/pemetrexed (cycle three weeks), ${ }^{57,58}$ weekly carboplatin/paclitaxel, ${ }^{41,59-61}$ weekly platinum/ docetaxel, ${ }^{62}$ weekly platinum/gemcitabine ${ }^{63}$ or daily low dose cisplatin. ${ }^{64}$ There are no phase III head-to-head comparisons of these regimens showing an improved OS with a specific chemotherapeutic regimen. 
Development of brain metastases after radical treatment remains a problem in this patient population. Brain metastases as the first and often only site of progression are diagnosed in $7-34 \%$ of these patients. ${ }^{28,29,31,65,66}$ In older (1990's) retrospective studies $(\mathrm{N}=267$ and $\mathrm{N}=1765)$ without routine ${ }^{18} \mathrm{FDG}-\mathrm{PET}$-scan or brain imaging, the percentage of brain metastases diagnosed in the follow-up did not decrease with the addition of systemic dose, cisplatin based chemotherapy to local radical treatment, although a decrease in extracranial metastases was observed. ${ }^{29,67}$ Using modern staging techniques, it is not known whether the chemotherapy used in a CRT regimen has an impact on the development of brain metastases in the follow-up.

\section{TREATMENT OF STAGE IV NSCLC}

There is no "one-size-fits-all" approach to the treatment of stage IV NSCLC as this is a heterogeneous group of patients clustered together because of the same TNM stage. Extent of disease (oligometastatic versus more wide-spread disease), histology, molecular pathology, PS, comorbidities and patients' preferences are all important and should be taken into account. ${ }^{55}$ It is argued that radical treatment in patients with single/oligometastatic disease improves OS. However, it is not clear whether these patients by nature have a superior OS or that OS can be improved with radical treatment, as was also discussed in a recent review. ${ }^{68}$ Only for a single brain metastasis it is shown in randomized controlled trials that radical treatment improves OS. ${ }^{69}$ When patients are not eligible for radical treatment and when they have a good/acceptable WHO PS (0-2), they are candidates for platinum-based doublet chemotherapy. ${ }^{41,42,55}$ Besides palliative chemotherapy, targeted agents (often tyrosine kinase inhibitors (TKIs)) have become available for a subset of stage IV NSCLC with targetable molecular alterations. Currently, TKI are approved for metastasized NSCLC patients with an activating EGFR-mutation or an ALK-rearrangement, either as first line or beyond. ${ }^{41,55}$ Examples are erlotinib, gefitinib and afatinib for EGFR-mutations, and crizotinib and ceritinib for $A L K$-rearrangements. When compared to chemotherapy, progression free survival (PFS), response rate (RR) and quality of life (QoL) are superior with TKIs. ${ }^{10,70-72}$ For EGFR-mutated patients treated with first line EGFR-TKI (first or second generation), progression free survival (PFS) is 9.2-13.1 months as compared to 4.6-6.3 months for upfront platinum doublet chemotherapy (hazard ratio (HR) 0.37 ) ${ }^{70,73}$ Response rate ranges from $55-82.9 \%$ (EGFR-TKI) as compared to $11.0-36.1 \%$ (chemotherapy). ${ }^{73} \mathrm{~A}$ significant improvement in global QoL as well as lung cancer related symptoms was found for EGFR-TKI compared to chemotherapy. ${ }^{73}$ In the PROFILE1014 study (first line crizotinib versus pemetrexed-platinum in $A L K$-rearranged patients) median ( $95 \% \mathrm{CI}) \mathrm{PFS}$ was 10.9 (8.3-13.9) months for crizotinib versus 7.0 (6.8-8.2) months for chemotherapy (HR 0.45). The RR was $74 \%$ versus $45 \%$ and QoL was superior for the crizotinib arm. ${ }^{72}$ For both EGFR- and ALK-TKI an improvement in OS has not been found, possibly due to crossover from the chemotherapy arm to the TKI arm. 


\section{TREATMENT OF LUNG CANCER BRAIN METASTASES NOT ELIGIBLE FOR RADICAL RADIOTHERAPY OR SURGERY: WHOLE BRAIN RADIOTHERAPY}

In (semi)-recent guidelines (NICE lung cancer 2011, NCCN central nervous system cancer (2012 as well as 2015 version), ESMO NSCLC 2012) it is advised to treat patients with multiple brain metastases with WBRT and best supportive care (BSC) without taking into account the RPA classification or another prognostic classification. ${ }^{74-77}$ Aim is to reduce neurological symptoms caused by the brain metastases. ${ }^{74}$ In the revised Dutch guideline "brain metastases from solid tumours" (version 3.0, July 2011) it is advised to treat patients in RPA class I and selected patients in RPA class II actively with WBRT (30 Gy in 10 fractions or $20 \mathrm{~Gy}$ in 5 fractions) and to treat patients in RPA class III primarily symptomatically with BSC. ${ }^{78}$ The flowchart (adapted for lung cancer) from this guideline is shown in Figure 1.2 (redrawn with permission). The RPA classification is also incorporated in the newest ESMO guideline on NSCLC (2015) and it is recommended to treat RPA class I and II patients actively with WBRT. ${ }^{55}$ In the latest NCCN guideline, it is advised to treat all patients with WBRT (30 Gy in 10 fractions or $37.5 \mathrm{~Gy}$ in 15 fractions) and to give a more rapid course of radiotherapy (20 Gy in 5 fractions) in patients with a poor neurological performance. ${ }^{77}$ Superiority of one of these radiation schemes has never been shown. ${ }^{79}$ Potential benefits of WBRT are improved QoL and PS, improved neurological function, and a reduction in steroid dose needed to control neurological symptoms. However, until recently the benefit of WBRT over BSC alone has never been studied in randomized controlled trials. ${ }^{79}$ At the 2015 ASCO annual meeting, QoL and OS data from the QUARTZ phase III randomised non-inferiority clinical trial (NCT00403065) were presented. In this trial, patients with inoperable brain metastases for whom clinician and patient were uncertain of the benefit of WBRT were included. They were randomised between WBRT and BSC versus BSC only. Primary outcome measure was quality adjusted life years (QALY). It was shown that WBRT provided no additional clinically significant benefit to BSC for this group of patients. ${ }^{80}$ 


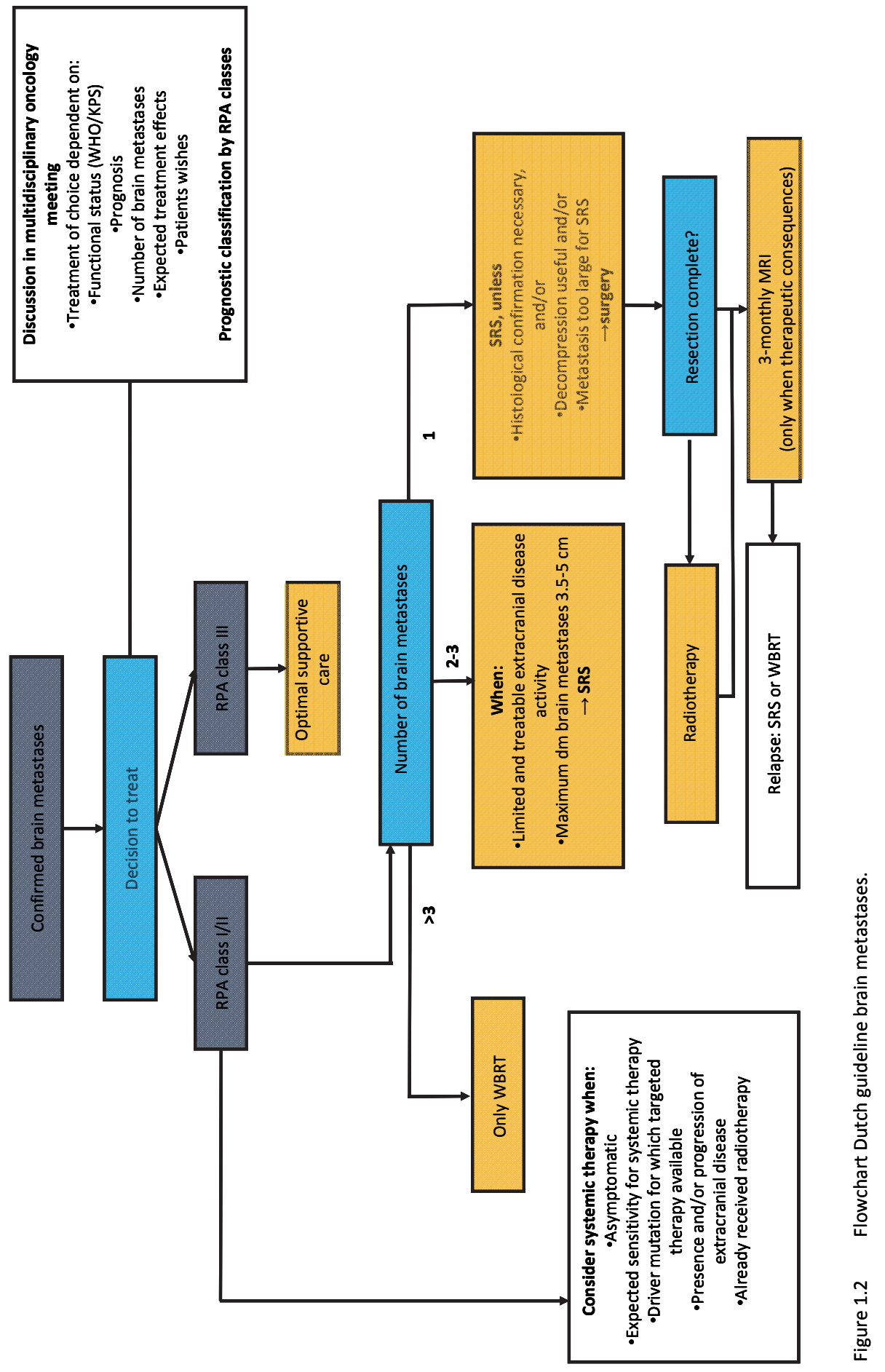




\section{TREATMENT OF LUNG CANCER BRAIN METASTASES NOT ELIGIBLE FOR RADICAL RADIOTHERAPY OR SURGERY: SYSTEMIC THERAPY}

Depending on whether brain metastases are asymptomatic or not, WBRT can be deferred. In asymptomatic patients, upfront chemotherapy results in cranial response rates $(23-50 \%)$ that are comparable/slightly lower than extracranial response rates. ${ }^{81}$ Although in brain metastases patients the cerebrospinal fluid (CSF) penetration rate is low for the EGFR-TKIs erlotinib and gefitinib (mean percentage 1.13 \pm 0.36 and $2.77 \pm 0.45$, respectively), cranial response rates for these two agents are $82-89 \%$ in EGFR-TKI naïve patients with an activating EGFR-mutation. ${ }^{81,82}$ RR as well as response duration are similar to extracranial responses. ${ }^{81}$ For crizotinib, an ALK-TKI, initial disease control rate in the brain is $60 \%$ in patients with brain metastases, however response duration in the brain is shorter than extracranial $\mathrm{RR}^{83}$ CSF penetration rate for crizotinib is only $0.0026 \%{ }^{84}$ Second generation ALK-TKI are more promising in the treatment of brain metastases and brain responses have been described after progression on crizotinib. ${ }^{85,86}$ CSF penetration rate is higher for alectinib (87\%) than for ceritinib (15\%). ${ }^{87}$

\section{PROGNOSIS OF AND TREATMENT OF LEPTOMENINGEAL METASTASES}

Leptomeningeal metastasis occurs in approximately $8 \%$ of NSCLC patients and is the result of spread of malignant cells to the subarachnoid space within the compartment of the CSF. It is associated with a poor prognosis and rapid deterioration of PS. ${ }^{34,88-90}$ Median OS is approximately 3.0 months. ${ }^{90}$ Radiotherapy, surgery and intrathecal chemotherapy all have been described as treatment options for NSCLC patients with leptomeningeal metastasis. However, the efficacy of these treatments is unclear and there is no consensus which (combination) provides the optimal therapeutic strategy. $^{90,91}$ It has been reported that leptomeningeal metastasis are more often diagnosed in EGFR-mutated NSCLC patients compared to EGFR wildtype patients and that survival is superior in this patient group. ${ }^{37,90,92}$ An explanation for the superior survival is that these patients were treated for the first time with EGFR-TKIs after the diagnosis of leptomeningeal metastasis, which does not represent current practice. Data on treatment outcomes of EGFR-mutated patients diagnosed with leptomeningeal metastasis during or after first generation EGFR-TKI treatment are scarce. In small series, high-dose EGFR-TKIs and switch of EGFR-TKI-treatment have been described as treatment options. ${ }^{93-95}$ 


\section{OUTLINE OF THE THESIS}

As is clear from the introduction, brain metastases are an important problem in NSCLC. There are many controversies on both the screening for brain metastases in stage III NSCLC, risk factors for brain metastases (treatment related as well as molecular phenotype related), as well as in the treatment of brain metastases and prognosis after diagnosis of brain and leptomeningeal metastases.

Part 1: brain metastases in stage III NSCLC.

Chapter two is a retrospective single center study investigating whether there is in stage III NSCLC patients a clinically relevant additive value of post contrast MRI to CE-CT of the brain in detecting asymptomatic brain metastases when both are performed in standard work-up, including ${ }^{18}$ FDG-PET-CE-CT.

Chapter three evaluates the same question, but in a prospective multicenter study.

Chapter four explores in a retrospective multicenter study whether a certain CRT regimen for stage III NSCLC (i.e. cyclic dose doublet chemotherapy versus daily low dose chemotherapy) is associated with the development of less (symptomatic) brain metastases during follow-up. Focus is on the development of brain metastases in the first year after diagnosis of stage III NSCLC.

Part $\mathbf{2}$ brain metastases in stage IV disease (all comers).

In chapter five the prognostic impact of single versus multiple organs with metastases, local disease status, and impact of the actual organ affected is evaluated in a nationwide population based stage IV NSCLC cohort.

In chapter six the proposals for the M-descriptors for the forthcoming eight edition of the TNM classification of lung cancer are discussed.

Chapter seven is a retrospective multicenter study evaluating whether the revised Dutch national guideline on brain metastases (2011) has had an impact on the selection of lung cancer patients for WBRT, i.e. whether the percentage of RPA class III patients who underwent WBRT decreased. Furthermore it is evaluated whether there are additional prognostic factors within the lung cancer RPA class II group.

Part 3: brain metastases in stage IV NSCLC patients with driver mutations (especially $E G F R$ ) and central nervous system involvement.

Chapter eight investigates in a retrospective case-control study whether EGFR-mutated NSCLC patients are more prone to development of brain (and bone) metastases as compared to KRAS-mutated and EGFR/KRAS wild type patients, and whether they have a different survival following the detection of these metastases.

Chapter nine reviews the toxicity of combining EGFR- or ALK-TKIs with cranial radiotherapy in NSCLC patients.

Chapter ten evaluates incidence, treatment and treatment outcomes in EGFR-mutated patients with leptomeningeal metastasis in a retrospective multicenter cohort analysis. 
Part 4, chapter eleven contains a general discussion and future perspectives of all afore-mentioned manuscripts.
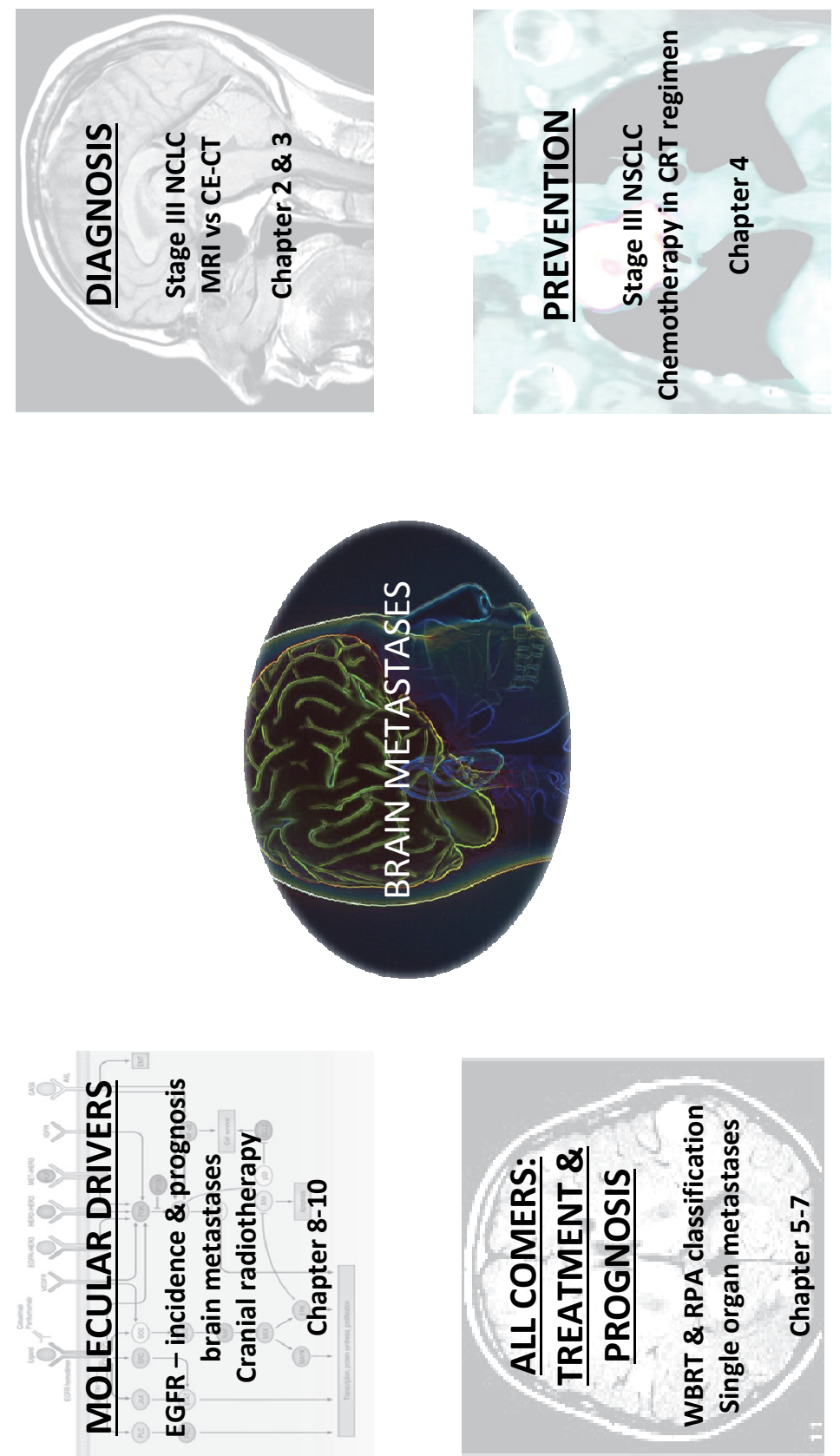

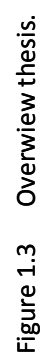




\section{REFERENCES}

1. SEER database table 15.28 Cancer of the Lung and Bronchus (invasive) [Internet]. Available from: seer.cancer.gov/csr/1975_2012/results_single/sect_15_table.28.pdf.

2. www.cijfersoverkanker.nl [Internet]. [cited 27-Oct-2015]. Available from: http://www.cijfersoverkanker.nl/selecties/Incidentie_long_en_luchtpijpkanker/img54d0ecb34ed7b.

3. SEER database: SEER Stat Fact Sheets: Lung and Bronchus Cancer, Percent of Cases \& 5-Year Relative Survival by Stage at Diagnosis: Lung and Bronchus Cancer [Internet]. Available from: http://seer.cancer.gov/statfacts/html/lungb.html.

4. Groome PA, Bolejack V, Crowley JJ, Kennedy C, Krasnik M, Sobin LH, et al. The IASLC Lung Cancer Staging Project: validation of the proposals for revision of the $T, N$, and $M$ descriptors and consequent stage groupings in the forthcoming (seventh) edition of the TNM classification of malignant tumours. J Thorac Oncol. 2007;2:694-705.

5. Postmus PE, Brambilla E, Chansky K, Crowley J, Goldstraw P, Patz EF, Jr., et al. The IASLC Lung Cancer Staging Project: proposals for revision of the $\mathrm{M}$ descriptors in the forthcoming (seventh) edition of the TNM classification of lung cancer. J Thorac Oncol. 2007;2:686-93.

6. Rami-Porta R, Ball D, Crowley J, Giroux DJ, Jett J, Travis WD, et al. The IASLC Lung Cancer Staging Project: proposals for the revision of the T descriptors in the forthcoming (seventh) edition of the TNM classification for lung cancer. J Thorac Oncol. 2007;2:593-602.

7. Kawaguchi T, Takada M, Kubo A, Matsumura A, Fukai S, Tamura A, et al. Performance status and smoking status are independent favorable prognostic factors for survival in non-small cell lung cancer: a comprehensive analysis of 26,957 patients with NSCLC. J Thorac Oncol. 2010;5:620-30.

8. Pirker R, Pereira JR, Szczesna A, von Pawel J, Krzakowski M, Ramlau R, et al. Prognostic factors in patients with advanced non-small cell lung cancer: data from the phase III FLEX study. Lung Cancer. 2012;77:376-82.

9. Dewys WD, Begg C, Lavin PT, Band PR, Bennett JM, Bertino JR, et al. Prognostic effect of weight loss prior to chemotherapy in cancer patients. Eastern Cooperative Oncology Group. Am J Med. 1980;69: 491-7.

10. Mok TS, Wu YL, Thongprasert S, Yang CH, Chu DT, Saijo N, et al. Gefitinib or carboplatin-paclitaxel in pulmonary adenocarcinoma. N Engl J Med. 2009;361:947-57.

11. Rosell R, Carcereny E, Gervais R, Vergnenegre A, Massuti B, Felip E, et al. Erlotinib versus standard chemotherapy as first-line treatment for European patients with advanced EGFR mutation-positive non-small-cell lung cancer (EURTAC): a multicentre, open-label, randomised phase 3 trial. Lancet Oncol. 2012;13:239-46.

12. Rosell R, Moran T, Queralt C, Porta R, Cardenal F, Camps C, et al. Screening for epidermal growth factor receptor mutations in lung cancer. N Engl J Med. 2009;361:958-67.

13. Sequist LV, Heist RS, Shaw AT, Fidias P, Rosovsky R, Temel JS, et al. Implementing multiplexed genotyping of non-small-cell lung cancers into routine clinical practice. Ann Oncol. 2011;22:2616-24.

14. Kerner GS, Schuuring E, Sietsma J, Hiltermann TJ, Pieterman RM, de Leede GP, et al. Common and rare EGFR and KRAS mutations in a Dutch non-small-cell lung cancer population and their clinical outcome. PloS One. 2013;8:e70346.

15. Shi Y, Au JS, Thongprasert S, Srinivasan S, Tsai CM, Khoa MT, et al. A prospective, molecular epidemiology study of EGFR mutations in Asian patients with advanced non-small-cell lung cancer of adenocarcinoma histology (PIONEER). J Thorac Oncol. 2014;9:154-62.

16. Scagliotti G, Stahel RA, Rosell R, Thatcher N, Soria JC. ALK translocation and crizotinib in non-small cell lung cancer: an evolving paradigm in oncology drug development. Eur J Cancer. 2012;48:961-73.

17. Shaw AT, Yeap BY, Mino-Kenudson M, Digumarthy SR, Costa DB, Heist RS, et al. Clinical features and outcome of patients with non-small-cell lung cancer who harbor EML4-ALK. J Clin Oncol. 2009;27: 4247-53.

18. Dinan MA, Curtis LH, Carpenter WR, Biddle AK, Abernethy AP, Patz EF, Jr., et al. Stage migration, selection bias, and survival associated with the adoption of positron emission tomography among medicare beneficiaries with non-small-cell lung cancer, 1998-2003. J Clin Oncol. 2012;30:2725-30. 
19. van Tinteren H, Hoekstra OS, Smit EF, van den Bergh JH, Schreurs AJ, Stallaert RA, et al. Effectiveness of positron emission tomography in the preoperative assessment of patients with suspected non-smallcell lung cancer: the PLUS multicentre randomised trial. Lancet. 2002;359:1388-93.

20. Chee KG, Nguyen DV, Brown M, Gandara DR, Wun T, Lara PN, Jr. Positron emission tomography and improved survival in patients with lung cancer: the Will Rogers phenomenon revisited. Arch Intern Med. 2008;168:1541-9.

21. Yawn BP, Wollan PC, Schroeder C, Gazzuola L, Mehta M. Temporal and gender-related trends in brain metastases from lung and breast cancer. Minn Med. 2003;86:32-7.

22. Steinmann D, Schafer C, van Oorschot B, Wypior HJ, Bruns F, Bolling T, et al. Effects of radiotherapy for brain metastases on quality of life (QoL). Prospective pilot study of the DEGRO QoL working party. Strahlenther Onkol. 2009;185:190-7.

23. Gaspar L, Scott C, Rotman M, Asbell S, Phillips T, Wasserman T, et al. Recursive partitioning analysis (RPA) of prognostic factors in three Radiation Therapy Oncology Group (RTOG) brain metastases trials. Int J Radiat Oncol Biol Phys. 1997;37:745-51.

24. Sperduto PW, Berkey B, Gaspar LE, Mehta M, Curran W. A new prognostic index and comparison to three other indices for patients with brain metastases: an analysis of 1,960 patients in the RTOG database. Int J Radiat Oncol Biol Phys. 2008;70:510-4.

25. Sperduto PW, Chao ST, Sneed PK, Luo X, Suh J, Roberge D, et al. Diagnosis-specific prognostic factors, indexes, and treatment outcomes for patients with newly diagnosed brain metastases: a multiinstitutional analysis of 4,259 patients. Int J Radiat Oncol Biol Phys. 2010;77:655-61.

26. Kepka L, Cieslak E, Bujko K, Fijuth J, Wierzchowski M. Results of the whole-brain radiotherapy for patients with brain metastases from lung cancer: the RTOG RPA intra-classes analysis. Acta Oncol. 2005;44:389-98.

27. Videtic GM, Adelstein DJ, Mekhail TM, Rice TW, Stevens GH, Lee SY, et al. Validation of the RTOG recursive partitioning analysis (RPA) classification for small-cell lung cancer-only brain metastases. Int J Radiat Oncol Biol Phys. 2007;67:240-3.

28. Gaspar LE, Chansky K, Albain KS, Vallieres E, Rusch V, Crowley JJ, et al. Time from treatment to subsequent diagnosis of brain metastases in stage III non-small-cell lung cancer: a retrospective review by the Southwest Oncology Group. J Clin Oncol. 2005;23:2955-61.

29. Andre F, Grunenwald D, Pujol JL, Girard P, Dujon A, Brouchet L, et al. Patterns of relapse of N2 nonsmall-cell lung carcinoma patients treated with preoperative chemotherapy: should prophylactic cranial irradiation be reconsidered? Cancer. 2001;91:2394-400.

30. Carolan H, Sun AY, Bezjak A, Yi QL, Payne D, Kane G, et al. Does the incidence and outcome of brain metastases in locally advanced non-small cell lung cancer justify prophylactic cranial irradiation or early detection? Lung Cancer. 2005;49:109-15.

31. Ceresoli GL, Reni M, Chiesa G, Carretta A, Schipani S, Passoni P, et al. Brain metastases in locally advanced nonsmall cell lung carcinoma after multimodality treatment: risk factors analysis. Cancer. 2002;95:605-12.

32. Lin NU, Winer EP. Brain metastases: the HER2 paradigm. Clin Cancer Res. 2007;13:1648-55.

33. Doebele RC, Lu X, Sumey C, Maxson DA, Weickhardt AJ, Oton AB, et al. Oncogene status predicts patterns of metastatic spread in treatment-naive nonsmall cell lung cancer. Cancer. 2012;118:4502-11.

34. Eichler AF, Kahle KT, Wang DL, Joshi VA, Willers $H$, Engelman JA, et al. EGFR mutation status and survival after diagnosis of brain metastasis in nonsmall cell lung cancer. Neuro Oncol. 2010;12:1193-9.

35. Lee YJ, Choi HJ, Kim SK, Chang J, Moon JW, Park IK, et al. Frequent central nervous system failure after clinical benefit with epidermal growth factor receptor tyrosine kinase inhibitors in Korean patients with nonsmall-cell lung cancer. Cancer. 2010;116:1336-43.

36. Matsumoto S, Takahashi K, Iwakawa R, Matsuno Y, Nakanishi Y, Kohno T, et al. Frequent EGFR mutations in brain metastases of lung adenocarcinoma. Int J Cancer. 2006;119:1491-4.

37. Omuro AM, Kris MG, Miller VA, Franceschi E, Shah N, Milton DT, et al. High incidence of disease recurrence in the brain and leptomeninges in patients with nonsmall cell lung carcinoma after response to gefitinib. Cancer. 2005;103:2344-8.

38. Welsh JW, Komaki R, Amini A, Munsell MF, Unger W, Allen PK, et al. Phase II trial of erlotinib plus concurrent whole-brain radiation therapy for patients with brain metastases from non-small-cell lung cancer. J Clin Oncol. 2013;31:895-902. 
39. Jamal-Hanjani M, Spicer J. Epidermal growth factor receptor tyrosine kinase inhibitors in the treatment of epidermal growth factor receptor-mutant non-small cell lung cancer metastatic to the brain. Clin Cancer Res. 2012;18:938-44.

40. Vansteenkiste J, De Ruysscher D, Eberhardt WE, Lim E, Senan S, Felip E, et al. Early and locally advanced non-small-cell lung cancer (NSCLC): ESMO Clinical Practice Guidelines for diagnosis, treatment and follow-up. Ann Oncol. 2013;24 Suppl 6:vi89-98.

41. NCCN Guidelines version 1.2015 Non-Small Cell Lung Cancer.

42. VIKC. Dutch guideline on non-small cell lung cancer. 2011.

43. Boellaard R, Oyen WJ, Hoekstra CJ, Hoekstra OS, Visser EP, Willemsen AT, et al. The Netherlands protocol for standardisation and quantification of FDG whole body PET studies in multi-centre trials. Eur J Nucl Med Mol Imaging. 2008;35:2320-33.

44. Eberhardt WE, De Ruysscher D, Weder W, Le Pechoux C, De Leyn P, Hoffmann H, et al. 2nd ESMO Consensus Conference in Lung Cancer: locally advanced stage III non-small-cell lung cancer. Ann Oncol. 2015;26:1573-88.

45. Fruh M, De Ruysscher D, Popat S, Crino L, Peters S, Felip E, et al. Small-cell lung cancer (SCLC): ESMO Clinical Practice Guidelines for diagnosis, treatment and follow-up. Ann Oncol. 2013;24 Suppl 6: vi99-105.

46. Kitajima K, Nakamoto Y, Okizuka H, Onishi Y, Senda M, Suganuma N, et al. Accuracy of whole-body FDG$\mathrm{PET} / \mathrm{CT}$ for detecting brain metastases from non-central nervous system tumors. Ann Nucl Med. 2008; 22:595-602.

47. Lee HY, Lee KS, Kim BT, Cho YS, Lee EJ, Yi CA, et al. Diagnostic efficacy of PET/CT plus brain MR imaging for detection of extrathoracic metastases in patients with lung adenocarcinoma. J Korean Med Sci. 2009;24:1132-8.

48. Ohno Y, Koyama H, Nogami M, Takenaka D, Yoshikawa T, Yoshimura M, et al. Whole-body MR imaging vs. FDG-PET: comparison of accuracy of M-stage diagnosis for lung cancer patients. J Magn Reson Imaging. 2007; 26:498-509.

49. Rohren EM, Provenzale JM, Barboriak DP, Coleman RE. Screening for cerebral metastases with FDG PET in patients undergoing whole-body staging of non-central nervous system malignancy. Radiology. 2003;226:181-7.

50. Seute T, Leffers $P$, ten Velde GP, Twijnstra A. Detection of brain metastases from small cell lung cancer: consequences of changing imaging techniques (CT versus MRI). Cancer. 2008;112:1827-34.

51. Suzuki K, Yamamoto M, Hasegawa Y, Ando M, Shima K, Sako C, et al. Magnetic resonance imaging and computed tomography in the diagnoses of brain metastases of lung cancer. Lung Cancer. 2004;46: 357-60.

52. Yokoi K, Kamiya N, Matsuguma H, Machida S, Hirose T, Mori K, et al. Detection of brain metastasis in potentially operable non-small cell lung cancer: a comparison of CT and MRI. Chest. 1999;115(3):714-9.

53. Schellinger PD, Meinck HM, Thron A. Diagnostic accuracy of MRI compared to CCT in patients with brain metastases. J Neurooncol. 1999;44:275-81.

54. Davis PC, Hudgins PA, Peterman SB, Hoffman JC, Jr. Diagnosis of cerebral metastases: double-dose delayed CT vs contrast-enhanced MR imaging. ANJR Am J Neuroradiol. 1991;12:293-300.

55. Reck M, Popat S, Reinmuth N, De Ruysscher D, Kerr KM, Peters S. Metastatic non-small-cell lung cancer (NSCLC): ESMO Clinical Practice Guidelines for diagnosis, treatment and follow-up. Ann Oncol. 2014;25 Suppl 3:iii27-39.

56. Auperin A, Le Pechoux C, Rolland E, Curran WJ, Furuse K, Fournel P, et al. Meta-analysis of concomitant versus sequential radiochemotherapy in locally advanced non-small-cell lung cancer. J Clin Oncol. 2010;28:2181-90.

57. Choy H, Schwartzberg LS, Dakhil SR, Garon EB, Gerber DE, Choksi JK, et al. Phase 2 study of pemetrexed plus carboplatin, or pemetrexed plus cisplatin with concurrent radiation therapy followed by pemetrexed consolidation in patients with favorable-prognosis inoperable stage IIIA/B non-small-cell lung cancer. J Thorac Oncol. 2013;8:1308-16.

58. Senan S, Brade A, L. W, Vansteenkiste J, Dakhil S, Biesma B, et al. Final overall survival (OS) results of the phase III PROCLAIM trial: Pemetrexed (Pem), cisplatin (Cis) or etoposide (Eto), Cis plus thoracic radiation therapy (TRT) followed by consolidation cytotoxic chemotherapy (CTX) in locally advanced nonsquamous non-small cell lung cancer (nsNSCLC). 2015 ASCO Annual Meeting; Chicago2015. 
59. Blumenschein GR, Jr., Paulus R, Curran WJ, Robert F, Fossella F, Werner-Wasik M, et al. Phase II study of cetuximab in combination with chemoradiation in patients with stage IIIA/B non-small-cell lung cancer: RTOG 0324. J Clin Oncol. 2011;29:2312-8.

60. Santana-Davila R, Devisetty K, Szabo A, Sparapani R, Arce-Lara C, Gore EM, et al. Cisplatin and etoposide versus carboplatin and paclitaxel with concurrent radiotherapy for stage III non-small-cell lung cancer: an analysis of Veterans Health Administration data. J Clin Oncol. 2015;33:567-74.

61. Vokes EE, Herndon JE, 2nd, Kelley MJ, Cicchetti MG, Ramnath N, Neill H, et al. Induction chemotherapy followed by chemoradiotherapy compared with chemoradiotherapy alone for regionally advanced unresectable stage III Non-small-cell lung cancer: Cancer and Leukemia Group B. J Clin Oncol. 2007; 25:1698-704.

62. Wu HG, Bang YJ, Choi EK, Ahn YC, Kim YW, Lim TH, et al. Phase I study of weekly docetaxel and cisplatin concurrent with thoracic radiotherapy in Stage III non-small-cell lung cancer. Int J Radiat Oncol Biol Phys. 2002;52:75-80.

63. Oh IJ, Kim KS, Kim YC, Ban HJ, Kwon YS, Kim YI, et al. A phase III concurrent chemoradiotherapy trial with cisplatin and paclitaxel or docetaxel or gemcitabine in unresectable non-small cell lung cancer: KASLC 0401. Cancer Chemother Pharmacol. 2013;72:1247-54.

64. Belderbos J, Uitterhoeve $L$, van Zandwijk N, Belderbos $\mathrm{H}$, Rodrigus $\mathrm{P}$, van de Vaart $\mathrm{P}$, et al. Randomised trial of sequential versus concurrent chemo-radiotherapy in patients with inoperable non-small cell lung cancer (EORTC 08972-22973). Eur J Cancer. 2007;43:114-21.

65. Mamon HJ, Yeap BY, Janne PA, Reblando J, Shrager S, Jaklitsch MT, et al. High risk of brain metastases in surgically staged IIIA non-small-cell lung cancer patients treated with surgery, chemotherapy, and radiation. J Clin Oncol. 2005;23:1530-7.

66. Robnett TJ, Machtay M, Stevenson JP, Algazy KM, Hahn SM. Factors affecting the risk of brain metastases after definitive chemoradiation for locally advanced non-small-cell lung carcinoma. J Clin Oncol. 2001;19:1344-9.

67. Cox JD, Scott CB, Byhardt RW, Emami B, Russell AH, Fu KK, et al. Addition of chemotherapy to radiation therapy alters failure patterns by cell type within non-small cell carcinoma of lung (NSCCL): analysis of radiation therapy oncology group (RTOG) trials. Int J Radiat Oncol Biol Phys. 1999;43:505-9.

68. Palma DA, Salama JK, Lo SS, Senan S, Treasure T, Govindan R, et al. The oligometastatic state-separating truth from wishful thinking. Nat Rev Clin Oncol. 2014;11:549-57.

69. Patil CG, Pricola K, Garg SK, Bryant A, Black KL. Whole brain radiation therapy (WBRT) alone versus WBRT and radiosurgery for the treatment of brain metastases. The Cochrane database of systematic reviews. 2010(6):CD006121.

70. Lee CK, Wu YL, Ding PN, Lord SJ, Inoue A, Zhou C, et al. Impact of Specific Epidermal Growth Factor Receptor (EGFR) Mutations and Clinical Characteristics on Outcomes After Treatment With EGFR Tyrosine Kinase Inhibitors Versus Chemotherapy in EGFR-Mutant Lung Cancer: A Meta-Analysis. J Clin Oncol. 2015;33:1958-65.

71. Yang JC, Hirsh V, Schuler M, Yamamoto N, O'Byrne KJ, Mok TS, et al. Symptom control and quality of life in LUX-Lung 3: a phase III study of afatinib or cisplatin/pemetrexed in patients with advanced lung adenocarcinoma with EGFR mutations. J Clin Oncol. 2013;31:3342-50.

72. Solomon BJ, Mok T, Kim DW, Wu YL, Nakagawa K, Mekhail T, et al. First-line crizotinib versus chemotherapy in ALK-positive lung cancer. N Engl J Med. 2014;371:2167-77.

73. Mok T, Yang JJ, Lam KC. Treating patients with EGFR-sensitizing mutations: first line or second line--is there a difference? J Clin Oncol. 2013;31:1081-8.

74. NICE clinical guideline 121: The diagnosis and treatment of lung cancer. 2011:103-4.

75. NCCN guidelines Non-Small Cell Lung Cancer. version 1.2012. 2012 MS14.

76. Peters S, Adjei AA, Gridelli C, Reck M, Kerr K, Felip E, et al. Metastatic non-small-cell lung cancer (NSCLC): ESMO Clinical Practice Guidelines for diagnosis, treatment and follow-up. Ann Oncol. 2012;23 Suppl 7:vii56-64.

77. NCCN guidelines Central Nervous System Cancers Version 1.2015. 2015.

78. LWNO/ IKL guideline: "brain metastases from solid tumors" version 3.0 July 2011. 2011:17-22.

79. Tsao MN, Lloyd N, Wong RK, Chow E, Rakovitch E, Laperriere N, et al. Whole brain radiotherapy for the treatment of newly diagnosed multiple brain metastases. The Cochrane database of systematic reviews. 2012;4:CD003869. 
80. Mulvenna P, Nankivel M, Barton R, Faivre-Finn C, Wilson P, Moore B, et al. Whole brain radiotherapy for brain metastases from non-small lung cancer: Quality of life (QoL) and overall survival (OS) results from the UK Medical Research Council QUARTZ randomised clinical trial (ISRCTN 3826061). J Clin Oncol. 2015;33( (suppl; abstr 8005)).

81. Zimmermann S, Dziadziuszko R, Peters S. Indications and limitations of chemotherapy and targeted agents in non-small cell lung cancer brain metastases. Cancer treatment reviews. 2014;40(6):716-22.

82. Togashi Y, Masago K, Masuda S, Mizuno T, Fukudo M, Ikemi Y, et al. Cerebrospinal fluid concentration of gefitinib and erlotinib in patients with non-small cell lung cancer. Cancer Chemother Pharmacol. 2012;70:399-405.

83. Costa DB, Shaw AT, Ou SH, Solomon BJ, Riely GJ, Ahn MJ, et al. Clinical experience with crizotinib in patients with advanced ALK-rearranged non-small-cell lung cancer and brain metastases. J Clin Oncol. 2015;33:1881-8.

84. Costa DB, Kobayashi S, Pandya SS, Yeo WL, Shen Z, Tan W, et al. CSF concentration of the anaplastic lymphoma kinase inhibitor crizotinib. J Clin Oncol. 2011;29:e443-5.

85. Zhang I, Zaorsky NG, Palmer JD, Mehra R, Lu B. Targeting brain metastases in ALK-rearranged nonsmall-cell lung cancer. Lancet Oncol. 2015;16:e510-21.

86. Duchemann B, Friboulet L, Besse B. Therapeutic management of ALK+ nonsmall cell lung cancer patients. Eur Respir J. 2015;46:230-42.

87. Baik CS, Chamberlain MC, Chow LQ. Targeted Therapy for Brain Metastases in EGFR-Mutated and ALKRearranged Non-Small-Cell Lung Cancer. J Thorac Oncol. 2015;10:1268-78.

88. Gleissner B, Chamberlain MC. Neoplastic meningitis. Lancet Neurol. 2006;5:443-52.

89. Park JH, Kim YJ, Lee JO, Lee KW, Kim JH, Bang SM, et al. Clinical outcomes of leptomeningeal metastasis in patients with non-small cell lung cancer in the modern chemotherapy era. Lung Cancer. 2012;76: 387-92.

90. Morris PG, Reiner AS, Szenberg OR, Clarke JL, Panageas KS, Perez HR, et al. Leptomeningeal metastasis from non-small cell lung cancer: survival and the impact of whole brain radiotherapy. J Thorac Oncol. 2012;7:382-5.

91. Chamberlain M, Soffietti R, Raizer J, Ruda R, Brandsma D, Boogerd W, et al. Leptomeningeal metastasis: a Response Assessment in Neuro-Oncology critical review of endpoints and response criteria of published randomized clinical trials. Neuro Oncol. 2014;16:1176-85.

92. Umemura S, Tsubouchi K, Yoshioka H, Hotta K, Takigawa N, Fujiwara K, et al. Clinical outcome in patients with leptomeningeal metastasis from non-small cell lung cancer: Okayama Lung Cancer Study Group. Lung Cancer. 2012;77:134-9.

93. Grommes C, Oxnard GR, Kris MG, Miller VA, Pao W, Holodny Al, et al. "Pulsatile" high-dose weekly erlotinib for CNS metastases from EGFR mutant non-small cell lung cancer. Neuro Oncol. 2011;13: 1364-9.

94. Yi HG, Kim HJ, Kim YJ, Han SW, Oh DY, Lee SH, et al. Epidermal growth factor receptor (EGFR) tyrosine kinase inhibitors (TKIs) are effective for leptomeningeal metastasis from non-small cell lung cancer patients with sensitive EGFR mutation or other predictive factors of good response for EGFR TKI. Lung Cancer. 2009;65:80-4.

95. Katayama T, Shimizu J, Suda K, Onozato R, Fukui T, Ito S, et al. Efficacy of erlotinib for brain and leptomeningeal metastases in patients with lung adenocarcinoma who showed initial good response to gefitinib. J Thorac Oncol. 2009;4:1415-9. 


\section{Chapter 2}

Screening for brain metastases in patients with stage III non-small cell lung cancer: Is there additive value of magnetic resonance imaging above a contrast-enhanced computed tomography of the brain?

Lizza E.L. Hendriks, Gerben P. Bootsma, Dirk K.M. De Ruysscher, Nicole A.M. Scheppers, Paul A.M. Hofman, Boudewijn T. Brans, Anne-Marie C. Dingemans Lung Cancer 2013;80:293-7 


\section{ABSTRACT}

\section{Introduction}

Stage III NSCLC patients are candidates for treatment with curative intent. Current guidelines advise post contrast magnetic resonance imaging (MRI) or contrast enhanced computed tomography (CE-CT) of the brain in these patients to exclude brain metastases (BM). In previous small studies MRI was reported to be superior to CE-CT. However, CT and MR technology have evolved and ${ }^{18} \mathrm{~F}$-deoxyglucose-positron-emission-tomography $\left({ }^{18} \mathrm{FDG}\right.$-PET $)$ has been implemented in staging of NSCLC. If CE-CT, performed together with ${ }^{18}$ FDG-PET-CT shows the same yield of BM detection as an additionally performed MRI, substantial gain in time and resources is expected.

\section{Methods}

All NSCLC patients who underwent a staging ${ }^{18}$ FDG-PET-CT between January 2008 and September 2011 were reviewed. Neurological asymptomatic patients with stage III NSCLC who were eligible for treatment with curative intent were selected, without taking into account the results of brain MRI. CT was compared to MRI to investigate whether additional BM were detected on MRI. Development of BM within a year after negative MRI was recorded.

\section{Results}

97/429 NSCLC patients who underwent a PET-CT had stage III disease. Three otherwise stage III patients already had occult BM on CE-CT. 77/97 (79\%) patients underwent MRI, 45/77 (58\%) CECT and 32/77 (42\%) LD-CT. In none of the CE-CT, but in 5/32 (16\%) LD-CT patients BM were detected on MRI. 9/72 patients (13\%) without BM on MRI at diagnosis developed BM within a year.

\section{Conclusions}

This retrospective study suggests that there is no additive value of MRI to ${ }^{18}$ FDG-PET-CT with CE$\mathrm{CT}$ in screening for BM in neurological asymptomatic patients with stage III NSCLC. 


\section{INTRODUCTION}

Around $30 \%$ of patients with non-small cell lung cancer (NSCLC) present with stage III disease and are candidates for intense combined modality treatment with curative intent. ${ }^{1}$ The outcome is however still poor, with a 5 year survival rate of $15.1 \%{ }^{1}$

As the brain is a common site for dissemination, ${ }^{2}$ national and international guidelines advise to exclude brain metastases before starting intense treatment in this patient population. The combined modality treatment with concurrent chemoradiotherapy is frequently associated with morbidity due to radiation esophagitis and pneumonitis. ${ }^{3-5}$ It is estimated that, dependent on disease stage and choice of radiological evaluation, $10-24 \%$ of NSCLC patients have one or more asymptomatic brain metastases at presentation. ${ }^{2,6,7}$ For example, up to $16 \%$ otherwise stage III NSCLC patients were diagnosed with brain metastases on post contrast magnetic resonance imaging (MRI). However, in this study published in 2003 , the number of patients with stage III NSCLC was small (38 of 91 patients) and ${ }^{18} \mathrm{~F}$-deoxyglucose-positron emission tomography $\left({ }^{18}\right.$ FDG-PET) scanning was not performed to exclude extracranial metastases. ${ }^{2}$

A whole body ${ }^{18}$ FDG-PET is in current guidelines advised in the diagnostic work up of all patients eligible for therapy with curative intent to exclude extracranial metastases. ${ }^{3-5}$ ${ }^{18}$ FDG-PET-scanning alone is not effective in detecting (asymptomatic) brain metastases. ${ }^{8,9}$ Nowadays, combined PET-CT scanners are more frequently used. In these scanners a ${ }^{18}$ FDG-PET can be performed with a non-diagnostic low dose computed tomography (LD-CT) for attenuation correction or with a diagnostic contrast enhanced CT (CE-CT) of the thorax and upper abdomen. Combination with CE-CT of the brain is also an option and feasible, but is not common practice. ${ }^{10}{ }^{18}$ FDG-PET-scanning with LD-CT for attenuation correction has already been proven to be not effective in detecting asymptomatic brain metastases when compared to MRI. ${ }^{11}$

Post contrast MRI is reported to be superior to CE-CT in diagnosing occult brain metastases. However, these were mostly older studies, all including patients with mixed tumour types and tumour stages. ${ }^{7,12-14}$

In addition, CT and MR technology both have evolved significantly. Moreover, in none of the studies mentioned above a ${ }^{18}$ FDG-PET(-CT) was part of the diagnostic work up, leading to a less well staged patient population. ${ }^{15}$

Lung cancer guidelines advice routine screening for brain metastases with post contrast MRI or CE-CT in all patients with stage III NSCLC eligible for therapy with curative intent. $^{3-5,15,16}$ In three guidelines, NCCN, ESMO and the Dutch VIKC, a post contrast MRI is advised. ${ }^{4,5,16}$ However, in most hospitals MRI is difficult to arrange within a reasonable time scale. There are also contra-indications for MRI as intracorporal metallic objects, pacemakers and claustrophobia.

The question whether post contrast MRI offers a benefit to CE-CT in the initial staging of patients with NSCLC has become more urgent in view of the increasing wide-spread 
use of ${ }^{18}$ FDG-PET-CT scanners. If dedicated CE-CT of the brain performed in the same setting as ${ }^{18}$ FDG-PET-CT could lead to the same yield of detection of brain metastases as ${ }^{18}$ FDG-PET-CT with a non-diagnostic LD-CT for attenuation correction and a separate post contrast MRI, a substantial gain in time and resources can be expected. In this retrospective study we evaluated whether there is additive value of post contrast MRI to CE-CT for the detection of asymptomatic brain metastases when both are performed in standard work-up including ${ }^{18}$ FDG-PET-CT.

\section{MATERIALS AND METHODS}

\section{PATIENT SELECTION}

The ${ }^{18}$ FDG-PET-CT database of the university hospital Maastricht, The Netherlands, was reviewed. All patients who underwent ${ }^{18}$ FDG-PET-CT in the diagnostic work-up for lung cancer between January 2008 and September 2011 were further evaluated. Patients with stage III NSCLC disease after staging with the ${ }^{18}$ FDG-PET-CT and who were candidates for treatment with curative intent were selected. Patients with neurological symptoms requiring brain imaging were excluded. In our hospital standard work-up of patients admitted with suspicion of lung cancer includes a ${ }^{18}$ FDG-PET according to a specific lung cancer protocol which consists of a CE-CT of the brain, thorax and upperabdomen combined with the ${ }^{18}$ FDG-PET. In case a CE-CT of the chest and upper abdomen is already performed separately the ${ }^{18}$ FDG-PET is combined with a nondiagnostic LD-CT for attenuation correction. As a consequence, in these cases only a non-diagnostic LD-CT of the brain was available. Both patients who underwent a LD-CT together with the PET-CT and patients who underwent a CE-CT were analysed. The policy in our institute is to screen for brain metastases in otherwise stage III NSCLC patients by MRI, also when a CE-CT of the brain is already performed. The results of the MRI were studied to investigate whether additional asymptomatic brain metastases were detected on MRI. In addition development of symptomatic brain metastases within a year after a negative scan was scored.

This study has been approved by the medical ethical committee of the university hospital Maastricht.

\section{IMAGING PROTOCOLS}

\section{MRI protocol}

MRI was performed with a 1.5 Tesla MRI system using a 8-channel Sens head coil (Philips Healthcare, Best, the Netherlands). The protocol included a T1 weighted spinecho sequence with a magnetization prepulse ((MTC) (TR 615, TE 14, NEX 2, matrix 2568154 , with an on resonance prepulse), with and without $0.1 \mathrm{mmol} / \mathrm{kg}$ body weight of Gadobutrol. The addition of the MTC prepulse results in an increased enhancement 
equivalent to a double dose of gadolinium contrast. Additionally a T2 weighted turbospin echo sequence (TR 4632, TE 100, ETL 12, NEX 2, matrix 256x192) and a fluid attenuated inversion recovery sequence (TR 8000, TE 120, TI 2000, ETL 23, NEX 1, matrix 512x138). All sequence had a slice thickness of $5 \mathrm{~mm}$ with a gap of $0.5 \mathrm{~mm}$. Additionally a T1 weighted gradient echo sequence was performed with isotropic voxels of $1 \mathrm{~mm}$ (TR 9, TE 4, NEX 1, matrix 256x256).

\section{PET-CT protocol}

Acquisition of ${ }^{18}$ FDG-PET-CT was performed using a PET camera equipped with time-offlight (Gemini TF PET/64-slice CT scanner, Philips, Best, The Netherlands). PET scans were made from head to pelvis, using 10 bed positions of 2,5 minutes each, after injection of ${ }^{18} \mathrm{FDG}$. In selected cases imaging was continued. Reconstruction was performed using a standard protocol in 3D with a matrix size of 144 resulting in a voxel size of $4.0 \times 4.0 \times 4.0 \mathrm{~mm}^{3}$. PET was preceded by a LD-CT (120 keV, $30 \mathrm{mAs}, 4 \mathrm{~mm}$ slice thickness, 4,0 increment) for attenuation correction of the PET images. Supplementary high-dose, CE-CT was performed according to a protocol with a standardized sequence following injection of $150 \mathrm{ml}$ and a flow rate of $3 \mathrm{ml} / \mathrm{s}$ of jopromide (Ultravist, Bayer, Berlin, Germany): The diagnostic brain CT (120 kV, $400 \mathrm{mAs})$ was performed with a slice thickness of $0.8 \mathrm{~mm}$ and reconstructed to $5 \mathrm{~mm}$ thick slices. The scan was performed 3 minutes after administration of the jopromide.

\section{RESULTS}

$4131{ }^{18}$ FDG-PET-CT scans were reviewed. From the $510{ }^{18}$ FDG-PET-CT's performed in the diagnostic work-up for lung cancer, 429 patients were diagnosed with NSCLC. Three patients with otherwise stage III disease had occult brain metastases on CE-CT. 112 of 429 patients were diagnosed with stage III disease after PET-CT. 97 of 112 (87\%) stage III patients were eligible for therapy with curative treatment. 77 of 97 (79\%) patients underwent MRI (Figure 2.1). Patient characteristics of these 77 patients are shown in Table 2.1. Although the standard work-up consisted of a MRI, the MRI was not performed in 20 patients because of diagnostic work-up elsewhere $(\mathrm{N}=3)$, contraindication for $\mathrm{MRI}(\mathrm{N}=2)$, participation in a study in which MRI of the brain was not a requisite $(\mathrm{N}=5)$, deterioration of clinical condition before $M R I$ was made $(N=2)$ or patient decision not to undergo therapy with curative intent $(\mathrm{N}=2)$. In six patients no reason was found for not performing MRI.

In 45 of 77 (58\%) patients a CE-CT was performed and in 32 of 77 (42\%) patients only a LD-CT was done together with the ${ }^{18}$ FDG-PET. In the LD-CT patient group a CE-CT of the thorax and upper abdomen was already available before the ${ }^{18}$ FDG-PET-CT was made. In these cases only a LD-CT was performed combined with the ${ }^{18}$ FDG-PET for attenuation correction. As a consequence, no diagnostic scan of the brain was available in these patients. 


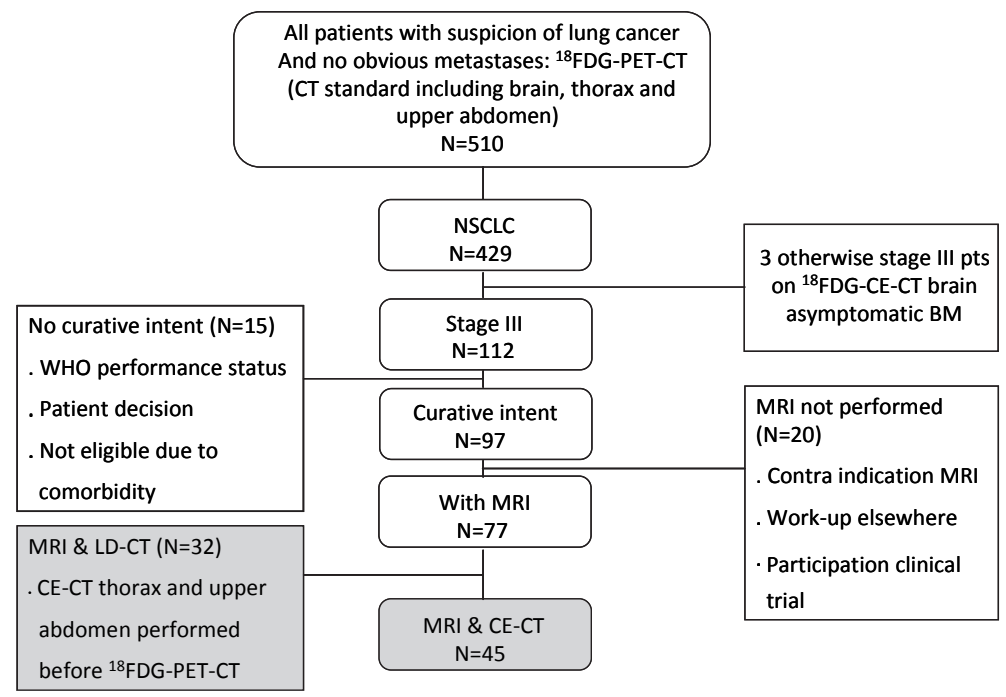

Figure $2.1 \quad$ Flowchart work-up stage III NSCLC.

In the negative CE-CT group, 19 of 45 patients (42\%) had stage IIIA disease and 26 (58\%) had stage IIIB. In the LD-CT group, 18 of 32 patients (56\%) had stage IIIA disease and 14 (44\%) had stage IIIB. (T and $\mathrm{N}$ see Table 2.1 ).

In none of the 45 patients who had a negative CE-CT of the brain together with the ${ }^{18}$ FDG-PET scan, brain metastases were detected on MRI. In contrast, in five of 32 (16\%) LD-CT patients brain metastases were detected on MRI (Figure 2.2). The MRI showed two metastases in 1 patient (largest 16 millimetres $(\mathrm{mm})$ ), three metastases in 1 patient (all around six $\mathrm{mm}$ ) and multiple metastases in the other three patients (largest $12 \mathrm{~mm}$ ). Before MRI, these patients were staged as cT1N3, cT2N2, cT4N0, cT4N2 and cT4N3.

Within 1 year of the diagnosis nine of 72 (13\%) patients without brain metastases on $\mathrm{MRI}$ at diagnosis developed symptomatic brain metastases, in two of nine (22\%) also progressive disease outside of the brain was shown (Figure 2.3 and 2.4). Of these nine patients, two were initially diagnosed with a squamous cell carcinoma (initially cT2N3MO and cT4NOMO), four with an adenocarcinoma (initially cT4N2M0, cT2N2M0, CT4N2MO, cT4NOMO) and in the remaining three patients the NSCLC was not otherwise specified (initially cT2N2M0, cT2N2M0, cT3N2MO). Of these nine patients, three had a CE-CT followed by MRI during their initial work-up for lung cancer, six had a LD-CT followed by MRI during the initial work-up. To evaluate whether these brain metastases were missed during the initial work-up the imaging data of these nine MRI's were reviewed by an experienced neuro-radiologist $(\mathrm{PH})$, but also in retrospect no brain metastases were found. 
Table 2.1 Patient characteristics stage III NSCLC patients in whom MRI was made.

\begin{tabular}{|c|c|}
\hline Sex (Male/Female) & $46 / 31$ \\
\hline Age (years) range & 64.9 range 10.2 \\
\hline \multicolumn{2}{|l|}{ WHO performance score (0-4) } \\
\hline 0 & 41 \\
\hline 1 & 30 \\
\hline 2 & 4 \\
\hline 3 & 2 \\
\hline 4 & 0 \\
\hline \multicolumn{2}{|l|}{ Stage (CE-CT / LD-CT) } \\
\hline IIIA & $37(19$ / 18) \\
\hline cT1N2 & $2(0 / 2)$ \\
\hline cT2N2 & $13(6 / 7)$ \\
\hline cT3N1 & $1(0 / 1)$ \\
\hline cT3N2 & $8(6 / 2)$ \\
\hline cT4NO & $12(6 / 6)$ \\
\hline cT4N1 & $1(1 / 0)$ \\
\hline IIIB & $40(26 / 14)$ \\
\hline cT1N3 & $5(3 / 2)$ \\
\hline cT2N3 & $5(4 / 1)$ \\
\hline cT3N3 & $4(4 / 0)$ \\
\hline cT4N2 & $19(11 / 8)$ \\
\hline cT4N3 & $7(4 / 3)$ \\
\hline \multicolumn{2}{|l|}{ Pathology } \\
\hline Adenocarcinoma & 30 \\
\hline Squamous cell carcinoma & 24 \\
\hline Large cell carcinoma & 3 \\
\hline NSCLC-NOS & 20 \\
\hline \multicolumn{2}{|l|}{ Treatment } \\
\hline Curative intent & 70 \\
\hline Chemoradiotherapy & 67 \\
\hline Surgery followed by chemo- and/or radiotherapy & 3 \\
\hline Palliative/BSC ${ }^{*}$ & 7 \\
\hline Chemotherapy & 3 \\
\hline Radiotherapy & 3 \\
\hline No treatment & 1 \\
\hline
\end{tabular}

SD: standard deviation, WHO: World Health Organisation, NOS: not otherwise specified. ${ }^{*}$ The clinical condition of these patients deteriorated quickly during analysis, so only palliative treatment was offered.

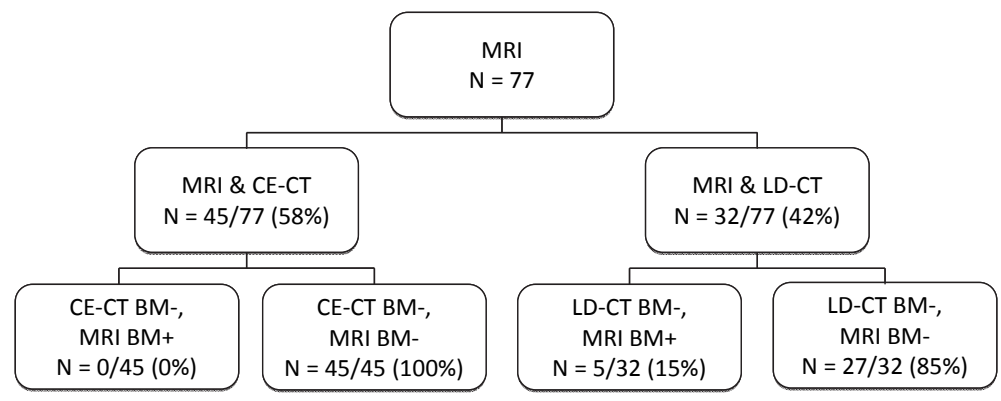

Figure 2.2 Additional brain metastases found on MRI. 


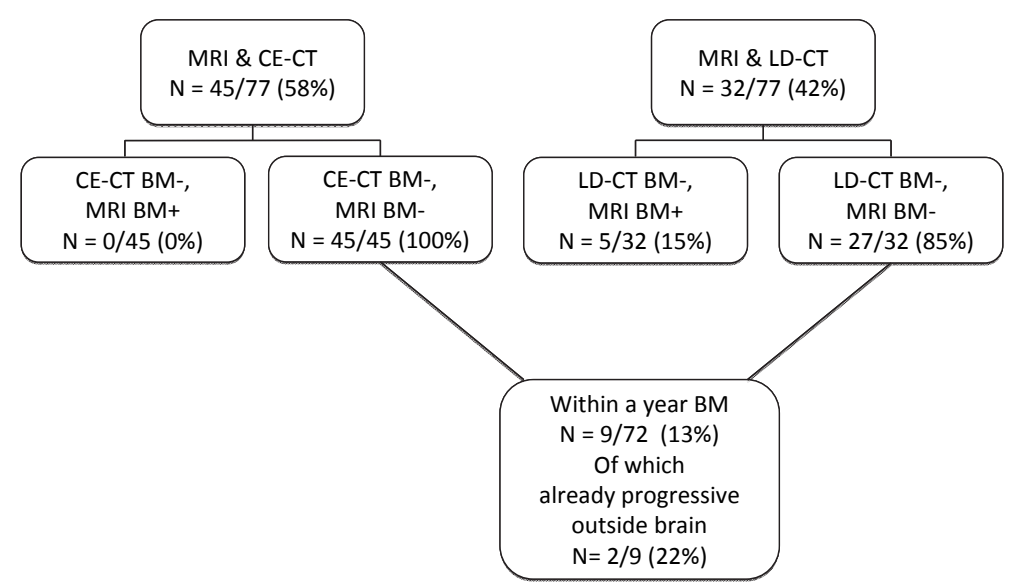

Figure 2.3 Brain metastases within a year after initial negative MRI.

Time to develop symptomatic BM

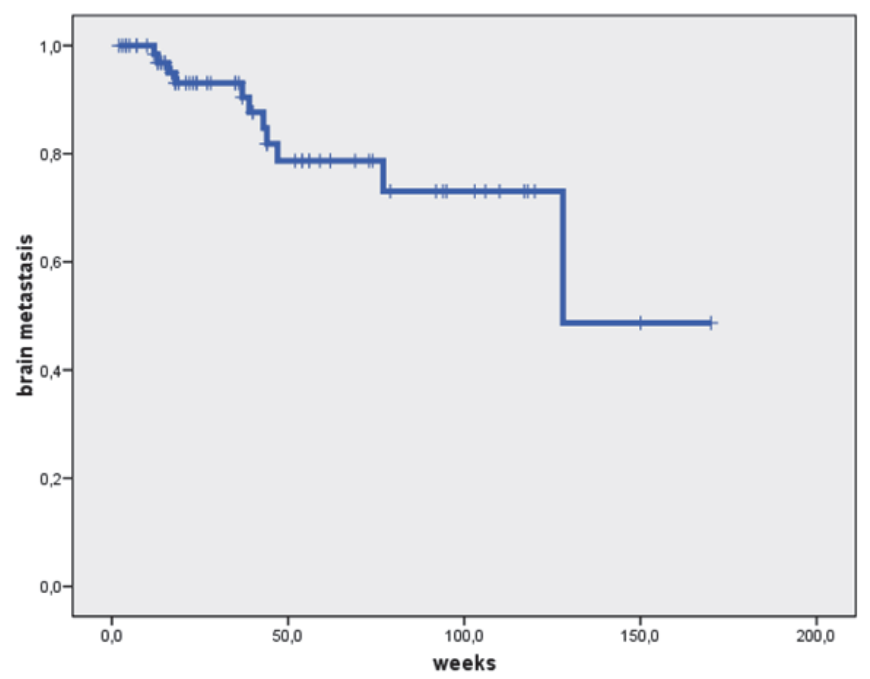

Figure 2.4 Kaplan Meier curve, time to develop symptomatic brain metastases.

\section{DISCUSSION}

Brain metastases are frequent in stage III NSCLC. ${ }^{2}$ Historically MRI is supposed to be superior to CT in detecting brain metastases. ${ }^{2,7,12,14}$ However, the question is whether $\mathrm{MRI}$ has a clinically relevant benefit above CE-CT in detecting asymptomatic brain 
metastases in stage III NSCLC when using up-to-date staging techniques. In this study, up-to-date MRI and CT techniques were used and extra-cranial metastases were excluded by ${ }^{18}$ FDG-PET-CT scanning. In this patient population MRI did not show additional brain metastases after a negative CE-CT of the brain combined with the ${ }^{18}$ FDG-PET-CT, but in three of 48 patients brain metastases were already found on the CE-CT.

Also, this study confirms that adequate imaging of the brain is mandated in these patients as in $16 \%$ of the patients who underwent solely a non diagnostic LD-CT of the brain, brain metastases were detected on MRI. This percentage is comparable to percentages of occult brain metastases found in other studies. ${ }^{2}$

Substantial gain in time and resources can be expected when the whole diagnostic imaging work-up can be performed in one single procedure, this diagnostic work-up consisting of a ${ }^{18}$ FDG-PET directly followed by CE-CT of the brain, thorax and (upper) abdomen. Following this procedure there would also be no delay because of waiting time for MRI before starting therapy with curative intent. Furthermore, in most institutes access to $\mathrm{CT}$ is easier than to MRI.

Brain metastases are still a serious problem in patients with stage III NSCLC: in our series $13 \%$ of patients with an initially negative MRI developed brain metastases within a year. Probably it is worth to investigate whether these brain metastases can be detected at diagnosis when more sensitive MRI techniques are used. It is known that the sensitivity of a post contrast MRI can be increased by using higher dose of contrast or by 3.0 Tesla MRI instead of 1.5 Tesla. However, higher contrast doses also increases false positive findings. ${ }^{17,18}$ Moreover, although 3.0 Tesla MRI scanners seem more sensitive in detecting cerebral lesions, no studies exist that show the increased sensitivity of 3.0 Tesla systems for the detection of cerebral metastases. In our study we used MTC prepulse, this prepulse results in an increased enhancement equivalent to a double dose of gadolinium contrast. ${ }^{19}$ The addition of post-contrast fluid attenuated inversion recovery (FLAIR) sequence (which we used) also improves diagnostic confidence in the evaluation of brain metastases. ${ }^{20}$ Another option is to routinely follow stage III NSCLC patients treated for cure with MRI or CE-CT of the brain on a regular basis to detect brain metastases at a stage where radical treatment is possible. Trying to prevent the development of brain metastases is also an option. A recent phase III study showed that prophylactic cranial irradiation in NSCLC stage III without progressive disease after therapy decreased the rate of BM but no effect on overall survival or disease free survival was found. ${ }^{21}$ Another phase III randomized study addressing the same question is still open for patient enrolment (NVALT11/DLCRG 02). There are some drawbacks of the current study. First, it is a retrospective study with a small sample size. However all consecutive patients were included in the analysis, decreasing the risk of bias. Second, not all stage III patients underwent a MRI. This was especially in 2008 when guidelines did not already advise post contrast MRI of the brain to exclude brain metastases. Third, not all patients were screened by CE-CT before MRI. 
In the LD-CT group a CE-CT of the thorax and upper abdomen was already available before the ${ }^{18}$ FDG-PET-CT was made (most times because the CT of the chest was made for other purposes than suspicion of cancer). In these cases the ${ }^{18}$ FDG-PET was only combined with a non-diagnostic LD-CT for attenuation correction. As a consequence no diagnostic scan of the brain was available. There were no relevant differences in patient characteristics between the patients with LD-CT and CE-CT.

\section{CONCLUSION}

This retrospective study of a consecutive cohort of patients suggests that there is no additive value of post contrast MRI when ${ }^{18} \mathrm{FDG}$-PET-CT with CE-CT is performed in the diagnostic work-up of neurologically asymptomatic stage III NSCLC patients in screening for brain metastases. However, brain metastasis is still an important problem as $13 \%$ of patients developed symptomatic brain metastases within 1 year after treatment with curative intent. Due to the possible impact of these findings on clinical practice a prospective trial (NTR3628) using up-to-date imaging techniques to validate these data has started. 


\section{REFERENCES}

1. Auperin A, Le Pechoux C, Rolland E, Curran WJ, Furuse K, Fournel P, Belderbos J, Clamon G, Ulutin HC, Paulus R, Yamanaka T, Bozonnat MC, Uitterhoeve A, Wang X, Stewart L, Arriagada R, Burdett S, Pignon JP. Meta-analysis of concomitant versus sequential radiochemotherapy in locally advanced non-smallcell lung cancer. J Clin Oncol. 2010;28:2181-90.

2. Hochstenbag MM, Twijnstra A, Hofman P, Wouters EF, ten Velde GP. MR-imaging of the brain of neurologic asymptomatic patients with large cell or adenocarcinoma of the lung. Does it influence prognosis and treatment? Lung Cancer. 2003;42:189-93.

3. NICE clinical guideline 121 2011: Lung cancer, the diagnosis and treatment of lung cancer. 2011.

4. VIKC richtlijn niet-kleincellig longcarcinoom. Landelijke richtlijn, versie 2.0. 2012.

5. NCCN guidelines Non-Small Cell Lung Cancer version 3.2012. 2012.

6. Kim SY, Kim JS, Park HS, Cho MJ, Kim JO, Kim JW, Song CJ, Lim SP, Jung SS. Screening of brain metastasis with limited magnetic resonance imaging (MRI): clinical implications of using limited brain MRI during initial staging for non-small cell lung cancer patients. J Korean Med Sci. 2005;20:121-6.

7. Suzuki K, Yamamoto M, Hasegawa Y, Ando M, Shima K, Sako C, Ito G, Shimokata K. Magnetic resonance imaging and computed tomography in the diagnoses of brain metastases of lung cancer. Lung Cancer. 2004;46:357-360.

8. Marom EM, McAdams HP, Erasmus JJ, Goodman PC, Culhane DK, Coleman RE, Herndon JE, Patz EF, Jr. Staging non-small cell lung cancer with whole-body PET. Radiology. 1999;212:803-9.

9. Palm I, Hellwig D, Leutz M, Rentz K, Hellwig A, Kirsch CM, Ukena D, Sybrecht GW. [Brain metastases of lung cancer: diagnostic accuracy of positron emission tomography with fluorodeoxyglucose (FDG-PET)]. Med Klin (Munich). 1999;94:224-7.

10. Boellaard R, Oyen WJ, Hoekstra CJ, Hoekstra OS, Visser EP, Willemsen AT, Arends B, Verzijlbergen FJ, Zijlstra J, Paans AM, Comans EF, Pruim J. The Netherlands protocol for standardisation and quantification of FDG whole body PET studies in multi-centre trials. Eur J Nucl Med Mol Imaging. 2008;35:2320-33.

11. Yi CA, Shin KM, Lee KS, Kim BT, Kim H, Kwon OJ, Choi JY, Chung MJ. Non-small cell lung cancer staging: efficacy comparison of integrated PET/CT versus 3.0-T whole-body MR imaging. Radiology. 2008;248: 632-42.

12. Schellinger PD, Meinck HM, Thron A. Diagnostic accuracy of MRI compared to CCT in patients with brain metastases. J Neurooncol. 1999;44:275-81.

13. Seute $T$, Leffers $P$, ten Velde GP, Twijnstra A. Detection of brain metastases from small cell lung cancer: consequences of changing imaging techniques (CT versus MRI). Cancer. 2008;112:1827-34.

14. Yokoi K, Kamiya N, Matsuguma H, Machida S, Hirose T, Mori K, Tominaga K. Detection of brain metastasis in potentially operable non-small cell lung cancer: a comparison of CT and MRI. Chest. 1999;115:714-9.

15. Silvestri GA, Gould MK, Margolis ML, Tanoue LT, McCrory D, Toloza E, Detterbeck F. Noninvasive staging of non-small cell lung cancer: ACCP evidenced-based clinical practice guidelines (2nd edition). Chest. 2007;132:178S-201S.

16. Peters S, Adjei AA, Gridelli C, Reck M, Kerr K, Felip E, Group EGW. Metastatic non-small-cell lung cancer (NSCLC): ESMO Clinical Practice Guidelines for diagnosis, treatment and follow-up. Ann Oncol. 2012;23 Suppl 7: vii56-64.

17. Sze G, Johnson C, Kawamura Y, Goldberg SN, Lange R, Friedland RJ, Wolf RJ. Comparison of single- and triple-dose contrast material in the MR screening of brain metastases. AJNR Am J Neuroradiol. 1998;19: 821-8.

18. Yuh WT, Tali ET, Nguyen HD, Simonson TM, Mayr NA, Fisher DJ. The effect of contrast dose, imaging time, and lesion size in the MR detection of intracerebral metastasis. AJNR Am J Neuroradiol. 1995;16: 373-80.

19. Finelli DA, Hurst GC, Gullapali RP, Bellon EM. Improved contrast of enhancing brain lesions on postgadolinium, T1-weighted spin-echo images with use of magnetization transfer. Radiology. 1994;190: 553-9. 
20. Terae S, Yoshida D, Kudo K, Tha KK, Fujino M, Miyasaka K. Contrast-enhanced FLAIR imaging in combination with pre- and postcontrast magnetization transfer T1-weighted imaging: usefulness in the evaluation of brain metastases. J Magn Reson Imaging. 2007;25:479-87.

21. Gore EM, Bae K, Wong SJ, Sun A, Bonner JA, Schild SE, Gaspar LE, Bogart JA, Werner-Wasik M, Choy H. Phase III comparison of prophylactic cranial irradiation versus observation in patients with locally advanced non-small-cell lung cancer: primary analysis of radiation therapy oncology group study RTOG 0214. J Clin Oncol. 2011;29:272-8. 


\title{
Chapter 3
}

MRI or contrast-enhanced CT screening

\author{
for brain metastases in patients with
}

stage III non-small cell lung cancer?

A prospective study

Lizza E.L. Hendriks, Paul A.M. Hofman, Gerben P. Bootsma,

Marcel Westenend, Machiel de Booij, Wendy M.J. Schreurs, Ruud Houben, Dirk K.M. De Ruysscher, Anne-Marie C. Dingemans

In preparation 


\section{ABSTRACT}

\section{Introduction}

In all current non-small cell lung cancer (NSCLC) guidelines it is advised to screen all stage III patients for brain metastases by magnetic resonance imaging (MRI) preferably, or otherwise a contrast-enhanced computed tomography (CE-CT). Access to MRI can be problematic and it is unclear whether there is a benefit of brain MRI after a CE-CT scan that can be incorporated in the staging ${ }^{18}$ Fluodeoxoglucose-positron-emission-tomography $\left({ }^{18} \mathrm{FDG}-\mathrm{PET}\right)-\mathrm{CE}-\mathrm{CT}$ scan.

\section{Patients and methods}

In this observational prospective multicenter study all consecutive stage III NSCLC patients scheduled for treatment with curative intent from three Dutch hospitals were included. Exclusion criteria were: no CE-CT or MRI brain or another primary cancer within two years of NSCLC diagnosis. Data regarding patient characteristics and imaging results were collected. Primary endpoint was the percentage of patients diagnosed with brain metastases on MRI without suspect lesions on CE-CT. 118 patients were needed to show a clinically relevant considered difference of $2 \%$.

\section{Results}

Between December $14^{\text {th }} 2012$ and June $17^{\text {th }} 2015,118$ consecutive stage III NSCLC patients were included. Four other patients already had asymptomatic brain metastases on the ${ }^{18}$ FDG-PET-CECT. $55.9 \%$ of the included patients were male; mean age was 66.6 years, $88.1 \%$ had WHO PS $0-1$, $47.5 \%$ had stage IIIA (before MRI brain) and $38.1 \%$ had an adenocarcinoma. Median time (range) between ${ }^{18}$ FDG-PET-CE-CT and MRI was $2.0(0.0-7.7)$ weeks. $3 / 118$ (2.5\%) patients had a solitary brain metastasis on MRI despite no suspect brain lesions on CE-CT. In retrospect, in one of these three patients a solitary brain metastasis could be identified on the ${ }^{18}$ FDG-PET-CE-CT.

\section{Conclusion}

MRI brain is in daily practice clinically relevant superior to a CE-CT in screening for brain metastases in stage III NSCLC. However, CE-CT alone is a good screening alternative. 


\section{INTRODUCTION}

Central nervous system (CNS) metastases frequently occur in non-small cell lung cancer (NSCLC) patients. ${ }^{1}$ In all current NSCLC guidelines, it is advised to screen for asymptomatic brain metastases in stage III NSCLC patients as usually only patients without brain metastases are eligible for intense combined modality treatment. ${ }^{2-5}$ The preferred imaging modality is post contrast magnetic resonance imaging (MRI) or, when contra-indicated, a contrast enhanced computed tomography (CE-CT). ${ }^{2-5}$ Access to $\mathrm{MRI}$ can be problematic and there are also some contra-indications for MRI (e.g. some pacemakers, claustrophobia). In a recent (2014) survey among lung cancer lead clinicians in the United Kingdom on brain imaging in neurologically asymptomatic lung cancer patients, CE-CT was preferred above MRI, presumably due to lack of access to MRI. ${ }^{6}$ Furthermore, in all patients eligible for therapy with curative intent, a whole body ${ }^{18} \mathrm{~F}$-deoxyglucose-positron emission tomography $\left({ }^{18} \mathrm{FDG}-\mathrm{PET}\right)$ is advised to exclude distant metastases. ${ }^{2-5}$ This ${ }^{18}$ FDG-PET can be performed with a non-diagnostic low dose CT (LD-CT) for attenuation correction or with a diagnostic CE-CT of the thorax and upper abdomen. Combination with CE-CT of the brain is also an option and feasible. ${ }^{7}$ ${ }^{18}$ FDG-PET without a CE-CT of the brain is not suitable for the detection of brain metastases. $^{8-12}$ From older studies including patients with mixed tumour types and tumour stages it is known that MRI of the brain is more sensitive than a CE-CT in detecting presence and especially number of metastases. ${ }^{13-17}$ However, it is unclear whether this is still the case in the setting of excluding asymptomatic brain metastases in ${ }^{18}$ FDG-PET staged stage III NSCLC patients with up-to-date MRI and CT techniques. We recently performed a retrospective study with modern imaging techniques: no additional brain metastases were found on MRI after ${ }^{18}$ FDG-PET-CT with CE-CT of the brain in contrast to only a LD-CT of the brain. ${ }^{12}$ However, brain metastasis is a serious issue in these patients as $13 \%$ of the patients with a negative staging MRI developed symptomatic brain metastases within a year of NSCLC diagnosis. ${ }^{12}$ If CE-CT performed in the same setting as ${ }^{18}$ FDG-PET-CT could lead to the same yield of brain metastases detection as ${ }^{18}$ FDG-PET-CT with LD-CT and separately a post contrast MRI, a substantial gain in time and resources could be expected. In this prospective observational multicenter study, we evaluated whether there is in stage III NSCLC patients a clinically relevant additive value of post contrast MRI to CE-CT of the brain in detecting asymptomatic brain metastases when both are performed in standard work-up, including ${ }^{18}$ FDG-PET-CE-CT. 


\section{MATERIALS AND METHODS}

\section{PATIENT SELECTION}

In the participating hospitals, it is routine practice to perform a ${ }^{18}$ FDG-PET-CE-CT with dedicated CE-CT of the brain and thorax when no recent diagnostic CE-CT of the thorax is available. MRI of the brain is performed in all stage III NSCLC patients eligible for therapy with curative intent to exclude brain metastases (flowchart work-up in Figure 3.1). Patients were included by prospectively screening the agenda of the weekly multidisciplinary lung tumour boards of the three participating Dutch hospitals. As according to Dutch guidelines all lung cancer patients have to be discussed in these tumour boards, no patients are missed. All stage III ( $7^{\text {th }}$ TNM edition) NSCLC patients scheduled for treatment with curative intent were included. Excluded were: patients with a second primary cancer within two years of stage III NSCLC diagnosis (except recurring NSCLC eligible for treatment with curative intent and cervical cancer in situ or non-melanoma skin cancer); no dedicated CE-CT of the brain during the ${ }^{18}$ FDG-PET scan, no brain MRI and mixed histology (i.e. SCLC and NSCLC). Initially, the aim was also to exclude patients with a brain MRI performed more than three weeks after the ${ }^{18} \mathrm{FDG}$ PET-CE-CT scan. However during the study it proved to be very difficult to obtain the MRI within this time period, so all patients fulfilling the other criteria were included, irrespective of timing of MRI.

The following data were collected: age; gender; World Health Organization performance score (WHO PS); smoking status; date of stage III NSCLC diagnosis (defined as date of pathological diagnosis); date of ${ }^{18}$ FDG-PET-CE-CT; date of brain MRI; histology; whether molecular testing was performed and results (Epidermal Growth Factor Receptor (EGFR)/ Kirsten rat sarcoma viral oncogene homolog (KRAS) mutation, Anaplastic Lymphoma Kinase ( $A L K$-) rearrangement or other molecular testing); $\mathrm{T}$ - and $\mathrm{N}$-stage; TNM stage (IIIA/IIIB).

The ethics committee of the MUMC+ evaluated the protocol (METC 12-4-126) and stated that patient informed consent was not mandatory according to the Dutch law "Medical Research (human subjects) Act" as both ${ }^{18}$ FDG-PET-CE-CT and MRI are standard workup according to the Dutch NSCLC guidelines and patients did receive standard workup and treatment which is not influenced by the study protocol. The study was registered on the Dutch Trial Registry (NTR3628).

\section{MRI PROTOCOL}

All patients underwent MRI examination of the brain. After a plan scan the examination consisted of a axial T1-weighted scan (TR 615, TE 14, AV 2, FOV 230, scan\% 80, matrix $256 \times 154$, thickness $5 \mathrm{~mm} / 0.5 \mathrm{~mm}$ ) with an on-resonance pre-pulse. This magnetization transfer contrast enhanced T1-weighted pulse sequence was repeated after a single dose of gadolinium contrast. If magnetization transfer contrast was not available on the 
system a double dose of gadolinium contrast was administered for the post-contrast T1-weighted scan. The examination further consisted of an axial T2-weighted scan (TR 4632, TE 100, ETL 12, AV 2, FOV 230, scan\% 50, matrix 512x192, thickness $5 \mathrm{~mm} / 0.5 \mathrm{~mm}$ ), an axial FLAIR (TR8000, TE 120, TI 2000, ETL 23, AV 1, FOV 230, scan\% 71 , matrix $256 \times 138$, thickness $5 \mathrm{~mm} / 0.5 \mathrm{~mm}$ ) and a sagittal T1-weighted volumetric scan (TR 4, TE 4. Flip 15, AV 1, scan\% 100, matrix 256x256, thickness $1 \mathrm{~mm}$ ). The total examination time was approximately $20 \mathrm{~min}$. For patients with brain metastases on $\mathrm{MRI}$, both MRI and ${ }^{18}$ FDG-PET-CE-CT were reviewed by an experienced neuroradiologist $(\mathrm{PH})$, blinded to local results and outcome of the patient.

\section{BRAIN CE-CT PROTOCOL (DURING ${ }^{18}$ FDG-PET-CE-CT)}

The CT-scan of the brain was a part of a PET-CT examination (pitch 0,4 mm, slice thickness 0,8 mm, 0,4 mm overlap, $120 \mathrm{kV}, 400 \mathrm{mAs}$, FOV 250). The CT scans were acquired after administration of $150 \mathrm{ml}$ iodine contrast with a delay of 3 minutes. The scans were reconstructed with a brain filter and a slice thickness of $5 \mathrm{~mm}$ in the orbitomeatal plane.

\section{SAMPLE SIZE CALCULATION}

The primary endpoint for this study was the percentage of patients who were diagnosed with brain metastases on MRI, but without suspect lesions on CE-CT of the brain. A difference of more than two out of 100 patients (2\%) was considered clinically relevant. With an expected difference of $2 \%$ and a one-sided $95 \%$ confidence interval $(95 \% \mathrm{Cl})$ not exceeding $4 \%$, a total of 118 patients was needed in order to calculate a one-sided $95 \%$ confidence interval around $2 \%$ that excludes the $4 \%$ threshold, given these assumptions. Therefore the sample size for this study was 118 consecutive stage III NSCLC patients eligible for therapy with curative intent.

\section{RESULTS}

\section{PATIENT INCLUSION}

Between December $14^{\text {th }} 2012$ and June $17^{\text {th }}$ 2015, 185 consecutive neurologically asymptomatic, ${ }^{18}$ FDG-PET-staged NSCLC patients were screened (extracranial stage III based on ${ }^{18}$ FDG-PET). Four patients with extracranial stage III NSCLC based on ${ }^{18}$ FDGPET-CE-CT were diagnosed with brain metastases on CE-CT of the brain, these were subsequently confirmed on MRI in three patients. The fourth patient already had multiple brain metastases on CE-CT. These four patients were excluded. 63 other patients were excluded because of a second primary $(\mathrm{N}=15)$, no CE-CT of the brain 
$(\mathrm{N}=32)$ or no $\mathrm{MRI}$ brain $(\mathrm{N}=16)$. As a result, 118 stage III NSCLC patients were evaluable (CONSORT diagram in Figure 3.1).

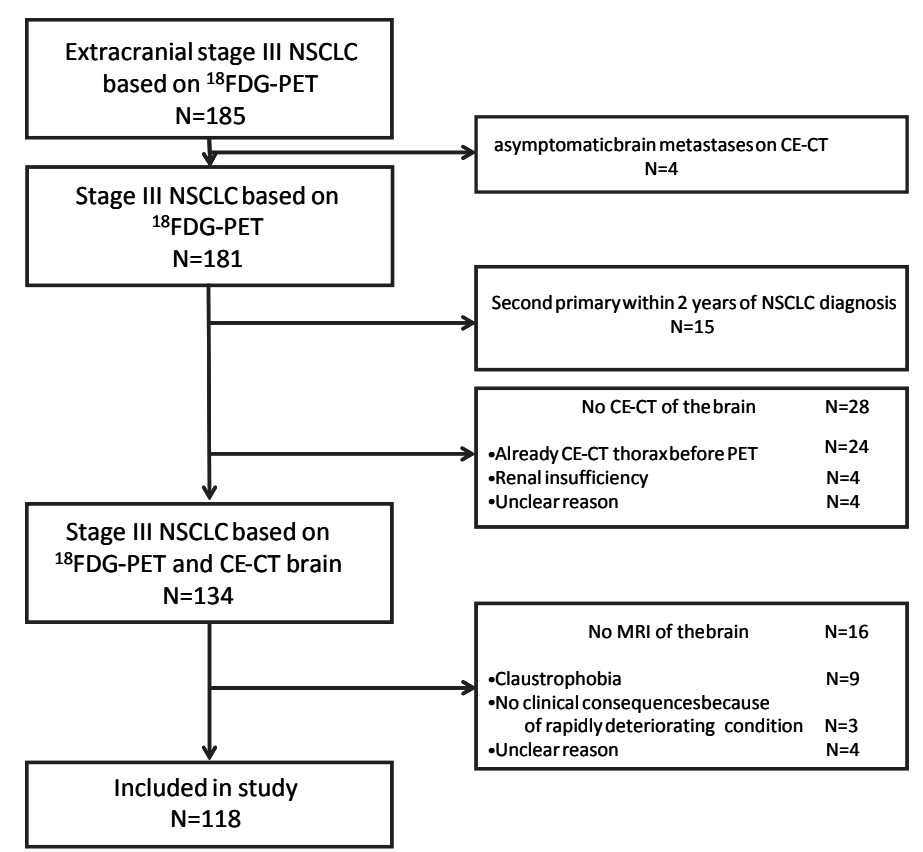

Figure 3.1 CONSORT diagram for inclusion in study.

\section{PATIENT CHARACTERISTICS}

$66(55.9 \%)$ out of these 118 patients were male. The mean age ( \pm standard deviation (SD)) was $66.6 \pm 9.7$ years (range 32.5-88.5). 104 (88.1\%) patients had a good WHO PS (0-1), 56 (47.5\%) were diagnosed with stage IIIA (before MRI brain) and 45 (38.1\%) had an adenocarcinoma. Patient characteristics are shown in Table 3.1.

\section{BRAIN MRI RESULTS}

Median time (range) between ${ }^{18}$ FDG-PET-CE-CT and brain MRI was 2.0 (0.0-7.7) weeks. For $33(28.0 \%)$ patients, the time from ${ }^{18}$ FDG-PET-CE-CT till MRI was more than three weeks.

Three out of 118 (2.5\%) patients without evidence of brain metastases on CE-CT of the brain had evidence of brain metastases on MRI. Time between ${ }^{18}$ FDG-PET-CE-CT and MRI brain for these three patients was respectively three days, 13 days and three weeks. These three MRI's and ${ }^{18}$ FDG-PET-CE-CTs were independently reviewed by an experienced neuroradiologist $(\mathrm{PH})$ and $\mathrm{MRI}$ results were concordant with the original 
report. Two patients had a solitary brain metastasis on $\mathrm{MRI}$, with a maximum diameter of 7 and 9 millimeter. The third patient had a brain metastasis of 15 millimeter and also a suspect very small second lesion. After revision by the neuroradiologist, this patient had in retrospect a single brain metastasis on ${ }^{18}$ FDG-PET-CE-CT. Patient characteristics of these patients are shown in Table 3.2.

Table 3.1 Patient characteristics of included patients.

\begin{tabular}{|c|c|}
\hline Patient characteristic & $\mathrm{N}(\%)$ \\
\hline Male & 66 (55.9) \\
\hline \multicolumn{2}{|l|}{ Age (years) } \\
\hline Median \pm SD & $66.6 \pm 9.7$ \\
\hline range & $32.5-88.5$ \\
\hline \multicolumn{2}{|l|}{ WHO PS } \\
\hline 0 & $48(40.6)$ \\
\hline 1 & $56(47.5)$ \\
\hline 2 & $13(11.0)$ \\
\hline 3 & $1(0.8)$ \\
\hline \multicolumn{2}{|l|}{ cT-stage } \\
\hline $0 / X$ & $2(1.7)$ \\
\hline $1 a$ & $4(3.4)$ \\
\hline $1 b$ & $9(7.6)$ \\
\hline $2 a$ & 20 (16.9) \\
\hline $2 b$ & $8(6.8)$ \\
\hline 3 & $22(18.6)$ \\
\hline 4 & 53 (44.9) \\
\hline \multicolumn{2}{|l|}{ cN-stage } \\
\hline $0 / X$ & $10(8.5)$ \\
\hline 1 & $6(5.1)$ \\
\hline 2 & $68(57.6)$ \\
\hline 3 & $34(28.8)$ \\
\hline \multicolumn{2}{|l|}{ Stage (before MRI brain) } \\
\hline IIIA & $56(47.5)$ \\
\hline IIIB & $62(52.5)$ \\
\hline \multicolumn{2}{|l|}{ Histology } \\
\hline Adenocarcinoma & $45(38.1)$ \\
\hline Squamous cell carcinoma & $46(39.0)$ \\
\hline Large cell carcinoma/NOS & 27 (22.9) \\
\hline \multicolumn{2}{|l|}{ Molecular analysis } \\
\hline Not performed & 79 (66.9) \\
\hline$E G F R / K R A S \mathrm{wt}, A L K-$ & $21(17.8)$ \\
\hline EGFR mutation & $1(0.8)$ \\
\hline KRAS mutation & $16(13.6)$ \\
\hline$A L K$ translocation & $1(0.8)$ \\
\hline
\end{tabular}


Table 3.2 Patient characteristics of patients with brain metastases on MRI despite no suspect lesions on CE-CT.

\begin{tabular}{lccc}
\hline Patient characteristic & Patient 1 & Patient 2 & Patient 3 \\
\hline Gender & male & male & female \\
Age (years) & 64 & 59 & 66 \\
WHO PS & 1 & 1 & 0 \\
cT-stage & 3 & 3 & $\mathrm{x}$ \\
cN-stage & 1 & 2 & 2 \\
Stage (before MRI brain) & IIIA & IIIA & IIIA \\
Histology & Squamous cell carcinoma & Adenocarcinoma & Adenocarcinoma \\
Molecular analysis & Not performed & Not performed & EGFR/KRAS wt ALK- \\
Time between 18FDG-PET-CE-CT & 3 & 13 & 21 \\
and MRI brain (days) & & & 1 \\
Number of brain metastases & 1 & & 1 (and dubious second \\
found on MRI (original report) & & 7 & lesion) \\
$\begin{array}{l}\text { Diameter metastasis on MRI (mm) } \\
\text { (original report) }\end{array}$ & 9 & Concordant & millimetric) \\
MRI review neuroradiologist & Concordant & No metastasis & One metastasis \\
18FDG-PET-CE-CT review & No metastasis & & (11 mm) \\
neuroradiologist & & &
\end{tabular}

\section{DISCUSSION}

In this prospective multicenter study, with up-to-date imaging protocols and staging, $2.5 \%$ of neurologically asymptomatic extracranial stage III NSCLC patients were diagnosed with brain metastases on brain MRI after a negative CE-CT of the brain, performed during ${ }^{18} \mathrm{FDG}$-PET-CE-CT. However, one of these patients had in retrospect a solitary brain metastasis on ${ }^{18}$ FDG-PET-CE-CT. We defined a difference of more than $2 \%$ clinically relevant. In daily practice, without review of the ${ }^{18}$ FDG-PET-CE-CTs, MRI is superior to CE-CT in detecting asymptomatic brain metastases in stage III NSCLC. This study also shows that adequate brain imaging is necessary in this patient population, as four patients were already diagnosed with asymptomatic brain metastases on CE-CT of the brain, and in retrospect one of the lesions on MRI brain could be identified on the ${ }^{18}$ FDG-PET-CE-CT. Moreover, in patients with only a LD-CT of the brain, MRI detected brain metastases in $14.6 \%$ of the patients (results not shown). This percentage of asymptomatic brain metastases diagnosis is comparable to previous studies. ${ }^{1,12}$

Detecting brain metastases in this patient population is important as combined modality treatment is intense with a high incidence of important side effects. ${ }^{18,19}$ Despite this intense treatment, the 5-year overall survival is about $30 \%$ in recent series. $^{20-22}$ Most patients diagnosed with brain metastases will not be eligible for this intensive treatment regimen. Moreover, some patients will be diagnosed with single or oligo- brain metastases, potentially amenable to treatment with curative intent (surgery or radical radiotherapy). ${ }^{23}$ In the participating hospitals, performing a MRI brain within a reasonable time period after ${ }^{18}$ FDG-PET proved difficult, as in $29.8 \%$ of 
patients time from ${ }^{18}$ FDG-PET to MRI was more than three weeks. This is not a problem unique for the participating hospitals, as in a United Kingdom survey (2014) CE-CT was preferred above MRI, presumably due to lack of access to MRI. ${ }^{6}$ However, delay from ${ }^{18}$ FDG-PET-CE-CT to MRI with subsequent growth of a microscopic brain metastasis does not seem to be the explanation for the lesions found on MRI for the three patients in the present study. Time to MRI was only three to 21 days for these three patients. In general, an additional MRI of the brain can cause a delay in the workup of stage III NSCLC which is not desirable as, for example, according to the Dutch SONCOS document (SONCOS: "Foundation for Oncological Collaboration") treatment has to start within six weeks (counted from general practitioner referral to start of treatment). ${ }^{24}$ Another important issue is that $13-15 \%$ of stage III NSCLC patients will develop (mostly symptomatic) brain metastases within a year of NSCLC diagnosis. ${ }^{12,25}$ It is not known whether these metastases were already present at initial stage III diagnosis and were not detected by MRI or that these were newly developing metastases. Maybe some of these metastases could have been detected with more sensitive MRI-techniques e.g. with higher contrast doses. However, higher contrast doses also increase the possibility for false positive findings. ${ }^{26,27}$ It is possible that a 3.0 Tesla scanner would have detected brain metastases in more patients, but no studies exist showing increased sensitivity of these scanners in detecting the presence or absence of brain metastases.

Regular brain imaging in the follow up is also an option to detect brain metastases at a stage in which they are possibly still eligible for therapy with radical intent. Regular follow up is not recommended in NSCLC guidelines except in the ESMO guideline on locally advanced NSCLC. In this guideline it is suggested that for selected high risk patients (adenocarcinoma) routine brain imaging is an option for the early detection and possible radical treatment of brain metastases (level of evidence: $\mathrm{V}, \mathrm{C}$ ). ${ }^{3}$ However, as not only adenocarcinoma patients develop brain metastases, a better risk stratification tool would be useful. As far as we known, to date there are no reliable serum or tissue biomarkers predictive for the development of brain metastases. In a recent study, Single Nucleotide Polymorphisms in the PI3K-PTEN-AKT-mTOR pathway were associated with the development of brain metastases in the follow-up. ${ }^{28}$ In another study, serum tumor markers such as CEA, CYFRA21-1 and CA-125 were not associated with the development of brain metastases. ${ }^{29}$ Some micro-RNA's were associated with the development of brain metastases in small series of mostly early stage NSCLC patients but this still needs validation. ${ }^{30}$

Prophylactic cranial irradiation ( $\mathrm{PCl}$ ) to prevent the development of brain metastases is also an option. This is currently tested in the phase III randomized NVALT11/DLCRG 02 study (NCT01282437) with as a primary endpoint the proportion of patients developing symptomatic brain metastases. The study is closed for accrual and results are awaited for

In conclusion, brain metastases remain a problem in this patient population, and imaging of the brain is needed before commencement of intensive treatment. MRI is in 
daily practice, without review of the ${ }^{18}$ FDG-PET-CE-CT by an experienced neuroradiologist, clinically relevant superior in detecting brain metastases. However, access to MRI is often difficult and CE-CT is a good screening alternative. 


\section{REFERENCES}

1. Hochstenbag MM, Twijnstra A, Hofman P, Wouters EF, ten Velde GP. MR-imaging of the brain of neurologic asymptomatic patients with large cell or adenocarcinoma of the lung. Does it influence prognosis and treatment? Lung Cancer. 2003;42:189-93.

2. VIKC. Dutch guideline on non-small cell lung cancer. 2011.

3. Eberhardt WE, De Ruysscher D, Weder W, Le Pechoux C, De Leyn P, Hoffmann H, et al. 2nd ESMO Consensus Conference in Lung Cancer: locally advanced stage III non-small-cell lung cancer. Ann Oncol 2015;26:1573-88.

4. NCCN Guidelines version 1.2015 Non-Small Cell Lung Cancer. 2014.

5. NICE clinical guideline 121: The diagnosis and treatment of lung cancer. 2011:103-4.

6. Hudson BJ, Crawford MB, Curtin JJ. Brain imaging in lung cancer patients without symptoms of brain metastases: a national survey of current practice in England. Clin Radiol. 2015;70:610-3.

7. Boellaard R, Oyen WJ, Hoekstra CJ, Hoekstra OS, Visser EP, Willemsen AT, et al. The Netherlands protocol for standardisation and quantification of FDG whole body PET studies in multi-centre trials. Eur J Nucl Med Mol Imaging. 2008;35:2320-33.

8. Kitajima K, Nakamoto Y, Okizuka H, Onishi Y, Senda M, Suganuma N, et al. Accuracy of whole-body FDG$\mathrm{PET} / \mathrm{CT}$ for detecting brain metastases from non-central nervous system tumors. Ann Nucl Med. 2008;22:595-602.

9. Lee HY, Lee KS, Kim BT, Cho YS, Lee EJ, Yi CA, et al. Diagnostic efficacy of PET/CT plus brain MR imaging for detection of extrathoracic metastases in patients with lung adenocarcinoma. J Korean Med Sci. 2009;24:1132-8.

10. Ohno Y, Koyama H, Nogami M, Takenaka D, Yoshikawa T, Yoshimura M, et al. Whole-body MR imaging vs. FDG-PET: comparison of accuracy of M-stage diagnosis for lung cancer patients. J Magn Reson Imaging. 2007;26:498-509.

11. Rohren EM, Provenzale JM, Barboriak DP, Coleman RE. Screening for cerebral metastases with FDG PET in patients undergoing whole-body staging of non-central nervous system malignancy. Radiology. 2003;226:181-7.

12. Hendriks LE, Bootsma GP, de Ruysscher DK, Scheppers NA, Hofman PA, Brans BT, et al. Screening for brain metastases in patients with stage III non-small cell lung cancer: Is there additive value of magnetic resonance imaging above a contrast-enhanced computed tomography of the brain? Lung Cancer. 2013;80:293-7.

13. Kruger S, Mottaghy FM, Buck AK, Maschke S, Kley H, Frechen D, et al. Brain metastasis in lung cancer. Comparison of cerebral MRI and 18F-FDG-PET/CT for diagnosis in the initial staging. Nuklearmedizin. 2011;50:101-6.

14. Seute T, Leffers $P$, ten Velde GP, Twijnstra A. Detection of brain metastases from small cell lung cancer: consequences of changing imaging techniques (CT versus MRI). Cancer. 2008;112:1827-34.

15. Suzuki K, Yamamoto M, Hasegawa Y, Ando M, Shima K, Sako C, et al. Magnetic resonance imaging and computed tomography in the diagnoses of brain metastases of lung cancer. Lung Cancer. 2004;46: 357-60.

16. Yokoi K, Kamiya N, Matsuguma H, Machida S, Hirose T, Mori K, et al. Detection of brain metastasis in potentially operable non-small cell lung cancer: a comparison of CT and MRI. Chest. 1999;115:714-9.

17. Davis PC, Hudgins PA, Peterman SB, Hoffman JC, Jr. Diagnosis of cerebral metastases: double-dose delayed CT vs contrast-enhanced MR imaging. Am J Neuroradiol. 1991;12:293-300.

18. Govaert SL, Troost EG, Schuurbiers OC, de Geus-Oei LF, Termeer A, Span PN, et al. Treatment outcome and toxicity of intensity-modulated (chemo) radiotherapy in stage III non-small cell lung cancer patients. Radiat Oncol. 2012;7:150.

19. Topkan E, Parlak C, Selek U. Impact of weight change during the course of concurrent chemoradiation therapy on outcomes in stage IIIB non-small cell lung cancer patients: retrospective analysis of 425 patients. Int J Radiat Oncol Biol Phys. 2013;87:697-704.

20. Pless M, Stupp R, Ris HB, Stahel RA, Weder W, Thierstein S, et al. Induction chemoradiation in stage IIIA/N2 non-small-cell lung cancer: a phase 3 randomised trial. Lancet. 2015;386:1049-56. 
21. Eberhardt WE, Pottgen C, Gauler TC, Friedel G, Veit S, Heinrich V, et al. Phase III Study of Surgery Versus Definitive Concurrent Chemoradiotherapy Boost in Patients With Resectable Stage IIIA(N2) and Selected IIIB Non-Small-Cell Lung Cancer After Induction Chemotherapy and Concurrent Chemoradiotherapy (ESPATUE). J Clin Oncol. 2015;33:4194-201.

22. Senan S, Brade A, Wang LH, Vansteenkiste J, Dakhil S, Biesma B, et al. PROCLAIM: Randomized phase III trial of pemetrexed-cisplatin or etoposide-cisplatin plus thoracic radiation therapy followed by consolidation chemotherapy in locally advanced nonsquamous non-small-cell lung cancer. J Clin Oncol. 2016 Jan 25.

23. Reck M, Popat S, Reinmuth N, De Ruysscher D, Kerr KM, Peters S. Metastatic non-small-cell lung cancer (NSCLC): ESMO Clinical Practice Guidelines for diagnosis, treatment and follow-up. Ann Oncol. 2014;25 Suppl 3:iii27-39.

24. SONCOS normeringsrapport 4 2016, (2016).

25. Gaspar LE, Chansky K, Albain KS, Vallieres E, Rusch V, Crowley JJ, et al. Time from treatment to subsequent diagnosis of brain metastases in stage III non-small-cell lung cancer: a retrospective review by the Southwest Oncology Group. J Clin Oncol. 2005;23:2955-61.

26. Sze G, Johnson C, Kawamura Y, Goldberg SN, Lange R, Friedland RJ, et al. Comparison of single- and triple-dose contrast material in the MR screening of brain metastases. Am J Neuroradiol. 1998;19: 821-8.

27. Yuh WT, Tali ET, Nguyen HD, Simonson TM, Mayr NA, Fisher DJ. The effect of contrast dose, imaging time, and lesion size in the MR detection of intracerebral metastasis. Am J Neuroradiol. 1995;16: 373-80.

28. Li Q, Yang J, Yu Q, Wu H, Liu B, Xiong H, et al. Associations between single-nucleotide polymorphisms in the PI3K-PTEN-AKT-mTOR pathway and increased risk of brain metastasis in patients with non-small cell lung cancer. Clinical cancer research : an official journal of the American Association for Cancer Research. 2013;19(22):6252-60.

29. Cedres S, Nunez I, Longo M, Martinez P, Checa E, Torrejon D, et al. Serum tumor markers CEA, CYFRA21-1, and CA-125 are associated with worse prognosis in advanced non-small-cell lung cancer (NSCLC). Clin Lung Cancer. 2011;12:172-9.

30. Lu Y, Govindan R, Wang L, Liu PY, Goodgame B, Wen W, et al. MicroRNA profiling and prediction of recurrence/relapse-free survival in stage I lung cancer. Carcinogenesis. 2012;33:1046-54. 


\section{Chapter 4}

Development of brain metastases after chemoradiotherapy for stage III non-small cell lung cancer: does the type of chemotherapy regimen matter?

Lizza E.L. Hendriks, Anita J.W.M. Brouns, Mohammad Amini, Wilma Uyterlinde, Robin Wijsman, Jan Bussink, Bonne Biesma, S. Bing Oei, Jos A. Stigt, Gerben P. Bootsma, José S.A. Belderbos, Dirk K.M. De Ruysscher, Michel M. van den Heuvel, Anne-Marie C. Dingemans 


\section{ABSTRACT}

\section{Introduction}

Most brain metastases (BM) occur within one year after chemoradiotherapy (CRT) for stage III NSCLC. Whether the specific chemotherapy used influences BM development is unknown.

\section{Methods}

Retrospective multicenter study including all consecutive stage III NSCLC patients who completed CRT. Primary endpoints: BM development within the 1st year, BM as only site of first relapse. Differences between treatment regimens were assessed with a logistic regression model.

\section{Results}

Between January 2006 and June 2014, 838 patients were eligible (737 concurrent (cCRT), 101 sequential (sCRT)). $11 \%$ developed BM within a year, $5 \%$ had BM as only site of first relapse. BM patients were significantly younger, female, and had adenocarcinoma histology. In both cyclic doublet chemotherapy $\mathrm{CCRT}(\mathrm{N}=346)$ and daily low dose cisplatin (LDC) cCRT ( $N=391)$ BM were found in $11 \%$ within one year $(p=0.927)$. In $4 \%$ and $5 \%$, respectively, BM were the only site of first relapse $(p=0.399)$. The chemotherapy regimen used (cCRT versus SCRT) had no influence on BM development, neither within one year nor as only site of first relapse (OR 0.87 ( $p=0.695)$, OR 0.89 $(p=0.838)$, respectively). LDC versus cyclic cCRT was not significantly different: neither within one year nor as only site of first relapse (OR $0.96(p=0.861)$, OR $1.36 \quad(p=0.404)$, respectively). Comparable results were found for LDC versus cyclic non-taxane $(\mathrm{N}=277)$ and cyclic taxane regimens $(\mathrm{N}=69)$ and for $C$ CRT regimens with $\geq 50$ patients (LDC versus cisplatin/etoposide $(\mathrm{N}=188)$, cisplatin/vinorelbine $(\mathrm{N}=65)$, weekly cisplatin/docetaxel $(\mathrm{N}=60))$.

\section{Conclusion}

$11 \%$ developed BM within one year after stage III diagnosis, not dependent on the type of chemotherapy regimen used within a CRT treatment. 


\section{INTRODUCTION}

The standard treatment for most patients with stage III non-small cell lung cancer (NSCLC) is combined chemoradiation (CRT). Concurrent CRT (CCRT) results in a superior overall survival (OS) compared to sequential CRT (SCRT). ${ }^{1}$ As brain metastases frequently occur in locally advanced NSCLC it is routine practice to perform brain imaging during staging. ${ }^{2,3}$ The brain is still a frequent site of relapse after CRT, as $13-15 \%$ of patients develop symptomatic brain metastases within the first year after NSCLC diagnosis. ${ }^{4,5}$ Most brain relapses are diagnosed in this first year, but over $30 \%$ occur later. ${ }^{4,5}$ Brain metastases have a negative impact on quality of life (QoL) and are associated with a worse OS. ${ }^{6,7}$ Known risk factors for brain metastases are adenocarcinoma histology and younger age. ${ }^{4,8}$ Several chemotherapy regimens are used as part of CRT. In the European Society for Medical Oncology (ESMO) NSCLC guideline, two to four cycles of cyclic dosed platinum based doublet chemotherapy are recommended. ${ }^{3}$ Platinum is usually combined with etoposide or vinorelbine. ${ }^{3}$ An alternative schedule often used in the United States is weekly carboplatin/paclitaxel. ${ }^{9}$ Other concurrent regimens are cyclic dose platinum/pemetrexed, ${ }^{10}$ weekly platinum/docetaxel ${ }^{11}$ or daily low dose cisplatin. ${ }^{12}$

To our knowledge, there are no phase III head-to-head comparisons of these regimens showing an improved OS with a specific regimen. A recent retrospective study $(\mathrm{N}=1842)$ compared outcomes of stage III NSCLC patients treated with cisplatin/etoposide or carboplatin/paclitaxel concurrent with radiotherapy within the Veterans Health Administration and no significant OS differences were found. ${ }^{9}$

The impact of the specific chemotherapy regimen used during CRT on the development of brain metastases is still unclear. To answer the question whether there is any influence of the CRT chemotherapy regimen used on the development of brain metastases, we performed a retrospective multicenter study in stage III NSCLC treated with CRT.

\section{METHODS}

\section{STUDY SUBJECTS}

Data of all consecutive stage III NSCLC patients from five Dutch teaching hospitals, treated with definitive CRT (with/without surgery) between January $1^{\text {st }} 2006$ and June $30^{\text {th }} 2014$ were retrospectively analyzed. Exclusion criteria were: diagnosis of another malignancy within two years of stage III NSCLC (except cervical cancer in situ, nonmelanoma skin cancer, previously diagnosed NSCLC treated with curative intent); no ${ }^{18}$ fluorodeoxyglucose-positron emission tomography ( ${ }^{18} \mathrm{FDG}$-PET)-scan; no adequate brain imaging (i.e. no magnetic resonance imaging (MRI) or contrast-enhanced 
computed tomography (CE-CT)) during staging; no CRT completion (in order to exclude bias from suboptimal treatment); prophylactic cranial irradiation (PCI) treatment.

The following details were extracted from the medical records: age; gender; world health organization performance status (WHO PS); smoking status; date of pathology diagnosis; staging brain imaging modality; histology; molecular testing (yes/no, results); $\mathrm{T}$ - and N-stage; TNM stage; cCRT or SCRT; chemotherapy regimen; dose radiotherapy (Gy); treatment completion (i.e. all planned cycles chemotherapy (delay/dose reductions allowed) and radiotherapy completion); surgery post CRT; date progressive disease and first site of progression (brain only, extracranial only, both); date brain metastases diagnosis, symptoms; whether regular brain imaging was performed during follow-up; date of death/last follow-up. CRT regimens were classified as daily low dose cisplatin and cyclic dose doublet chemotherapy. Within the cyclic dose doublet chemotherapy group, subgroups were made for taxane and non-taxane based regimens. Patients treated with sequential cyclic dose doublet chemotherapy followed by radiotherapy or cCRT were classified as "cyclic dose" regardless of the concurrent chemotherapy regimen used. Last date of follow-up was June $30^{\text {th }}, 2015$.

The ethics committee of the MUMC+ evaluated the protocol (METC 14-5-054) and stated that study approval was not mandatory according to the Dutch law "Medical Research (human subjects) Act". ${ }^{13}$

\section{STATISTICAL ANALYSIS}

Statistical analysis was performed with SPSS (version 20; SPSS Inc., Chicago, IL). Patient characteristics were described for the total group and according to treatment regimen. Significant differences between regimens were assessed by $X^{2}$-test, Fisher's exact test, Mann-Whitney-U test or ANOVA when applicable. Primary endpoints were development of brain metastases within the first year after stage III NSCLC diagnosis and whether the brain was the only site of first relapse within this year, these were compared with the $\mathrm{X}^{2}$-test. Secondary endpoint was development of brain metastases regardless of timing (within a year as well as later), this was also compared with the $\mathrm{X}^{2}$-test. A binary logistic regression model for brain metastases development was constructed including covariates that are known risk factors for brain metastases (age, gender, histology, stage). Chemotherapy regimens (sCRT versus CCRT and in the cCRT group daily low dose cisplatin versus cyclic dose regimens) were added to this regression model. Also, subgroup analyses were performed in the cCRT subgroup for low dose cisplatin versus non-taxane and taxane based regimens respectively. For the cCRT subgroup, logistic regression analysis was also performed for subgroups of chemotherapy with $\geq 50$ patients.

Progression free survival (PFS) was defined as time from stage III diagnosis till disease progression or death; OS was defined as the time from stage III diagnosis till death. Patients who were alive at last follow-up or who were lost-to-follow-up were censored at last date of follow-up. The Kaplan-Meier method was used to estimate distribution 
of survival. Log-rank test was used to test difference in survival between subgroups. $P$-values $\leq 0.05$ for two-sided tests were considered statistically significant.

\section{RESULTS}

\section{PATIENT CHARACTERISTICS}

Between January $1^{\text {st }} 2006$ and June $30^{\text {th }} 2014,1026$ patients were treated with CRT. 188 patients were excluded for the following reasons: second primary $(N=32)$, no adequate baseline brain imaging $(\mathrm{N}=81)$, CRT not completed $(\mathrm{N}=66)$ or $\mathrm{PCl}(\mathrm{N}=9)$ (CONSORT diagram in Figure 4.1).

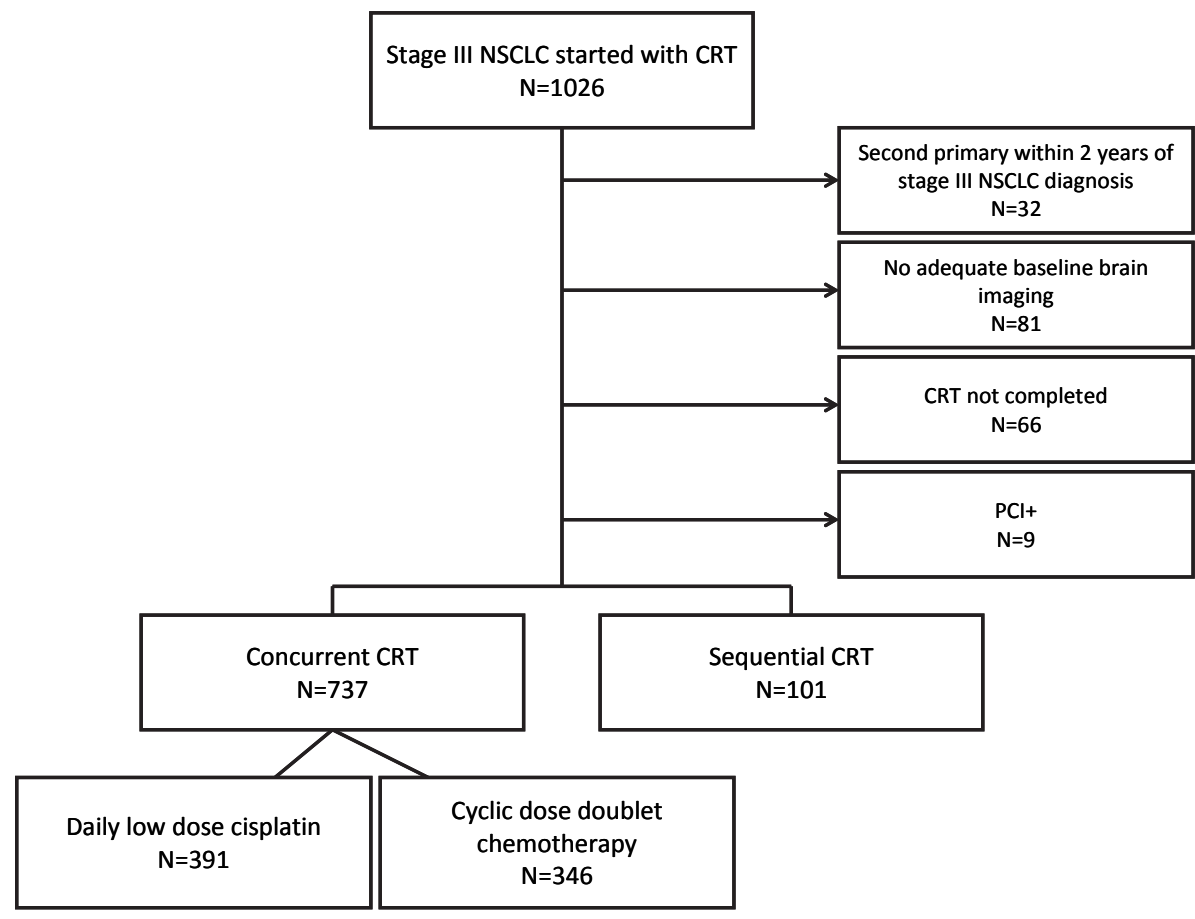

Figure 4.1 Consort study inclusion.

Hence, 838 patients were eligible: 737 cCRT and 101 sCRT treated. Patient characteristics for all patients and CCRT/SCRT subgroups are shown in Table 4.1. Characteristics for the CCRT patients treated with cyclic dose doublet chemotherapy versus daily low dose cisplatin are depicted in Table 4.2 (chemotherapy regimens further specified in Table S4.1). 
Table 4.1 Patient characteristics for all eligible patients.

\begin{tabular}{|c|c|c|c|}
\hline Patient characteristic & $\begin{array}{c}\text { Total group } \\
\mathrm{N}=838\end{array}$ & $\begin{array}{c}\text { cCRT group } \\
\mathrm{N}=737\end{array}$ & $\begin{array}{c}\text { sCRT group } \\
\mathrm{N}=101\end{array}$ \\
\hline Mean age $\pm S D$ & $62 \pm 10$ & $62 \pm 10$ & $66 \pm 11$ \\
\hline (range) & $30-84$ & $(30-84)$ & $(34-83)$ \\
\hline Male N (\%) & $535(64)$ & $468(64)$ & $67(66)$ \\
\hline \multicolumn{4}{|l|}{ WHO PS N (\%) } \\
\hline $0-1$ & $779(93)$ & $691(94)$ & $88(87)$ \\
\hline 2 & $34(4)$ & $23(3)$ & $11(11)$ \\
\hline Missing & $25(3)$ & $23(3)$ & $2(2)$ \\
\hline \multicolumn{4}{|l|}{ Smoking status N (\%) } \\
\hline Current & 239 (29) & $201(27)$ & $38(38)$ \\
\hline Former & $344(41)$ & $291(40)$ & $53(52)$ \\
\hline Never & $8(1)$ & $6(1)$ & $2(2)$ \\
\hline Unknown & 247 (29) & $239(32)$ & $8(8)$ \\
\hline \multicolumn{4}{|l|}{ Histology N (\%) } \\
\hline Adenocarcinoma & 324 (39) & $283(38)$ & $41(41)$ \\
\hline Squamous cell carcinoma & $281(33)$ & $237(32)$ & $44(44)$ \\
\hline Other / NOS & $233(28)$ & $217(29)$ & $16(16)$ \\
\hline \multicolumn{4}{|c|}{ Brain imaging initial diagnosis N (\%) } \\
\hline $\mathrm{MRI}$ & $720(86)$ & $635(86)$ & $85(84)$ \\
\hline CE-CT & $118(14)$ & $102(14)$ & $16(16)$ \\
\hline \multicolumn{4}{|l|}{ Stage N (\%) } \\
\hline IIIA & $494(59)$ & $441(60)$ & $53(52)$ \\
\hline IIIB & $344(41)$ & $296(40)$ & $48(48)$ \\
\hline \multicolumn{4}{|l|}{ T-stage N (\%) } \\
\hline T0-2 & 412 (49) & $358(49)$ & $54(54)$ \\
\hline T3-4 & $426(51)$ & $379(51)$ & $47(47)$ \\
\hline \multicolumn{4}{|l|}{ N-stage N (\%) } \\
\hline No-1 & $109(13)$ & $101(14)$ & $8(8)$ \\
\hline $\mathrm{N} 2-3$ & $729(87)$ & $636(86)$ & $93(92)$ \\
\hline \multicolumn{4}{|l|}{ CRT chemo used N (\%) } \\
\hline Cyclic dose & & $339(46)$ & $101(100)$ \\
\hline Low dose cisplatin & & $398(54)$ & $0(0)$ \\
\hline \multicolumn{4}{|l|}{ Radiotherapy (Gy) } \\
\hline Mean \pm SD & $65.4 \pm 3.4$ & $65.5 \pm 3.2$ & $64.6 \pm 4.8$ \\
\hline Range & $45-89.3$ & $45-89.3$ & $45-79.2$ \\
\hline \multicolumn{4}{|c|}{ Surgery as part of multimodality treatment $\mathrm{N}(\%)$} \\
\hline Yes & $93(11)$ & $92(13)$ & $1(1)$ \\
\hline \multicolumn{4}{|l|}{ Type induction/sequential } \\
\hline Platinum/Gemcitabine & & $133(18)$ & $67(66)$ \\
\hline Platinum/Paclitaxel & & $8(1)$ & $2(2)$ \\
\hline Platinum/Pemetrexed & & $41(6)$ & $23(23)$ \\
\hline Platinum/Etoposide & & $41(6)$ & $0(0)$ \\
\hline Cisplatinum/Vinorelbine & & $3(0.4)$ & $1(1)$ \\
\hline Unknown & & $0(0)$ & $7(7)$ \\
\hline None & & $508(69)$ & $0(0)$ \\
\hline \multicolumn{4}{|l|}{ Dose reduction $\mathrm{N}(\%)$} \\
\hline Yes & $45(5)$ & $36(5)$ & $9(9)$ \\
\hline
\end{tabular}

$\mathrm{N}$ : number; cCRT: concurrent chemoradiation; SCRT: sequential chemoradiation; SD: standard deviation; WHO PS: world health organization performance score; NOS: not otherwise specified; MRI: magnetic resonance imaging; CE-CT: contrast enhanced computed tomography; T: tumour; N: node; CRT: chemoradiation; Gy: gray. 
Table 4.2 Patient characteristics for patients treated with concurrent chemo-radiation.

\begin{tabular}{|c|c|c|c|}
\hline Patient characteristic & $\begin{array}{c}\text { Cyclic dose doublet } \\
\text { chemotherapy } \\
\mathrm{N}=346\end{array}$ & $\begin{array}{c}\text { Daily low dose } \\
\text { cisplatin } \\
\mathrm{N}=391 \\
\end{array}$ & $p$-value \\
\hline Mean age $\pm S D$ & $62 \pm 10$ & $62 \pm 10$ & 0.746 \\
\hline (range) & $31-84$ & $30-83$ & \\
\hline Male N (\%) & $223(65)$ & $245(63)$ & 0.646 \\
\hline WHO PS N (\%)* & & & 0.463 \\
\hline $0-1$ & $324(93)$ & $367(93)$ & \\
\hline 2 & $9(3)$ & $14(4)$ & \\
\hline Smoking status N (\%)* & & & 0.035 \\
\hline Current & $125(37)$ & $76(49)$ & \\
\hline Former & $213(62)$ & $78(50)$ & \\
\hline Never & $4(1)$ & $2(1)$ & \\
\hline Histology N (\%) & & & 0.036 \\
\hline Adenocarcinoma & $146(42)$ & $137(35)$ & \\
\hline Squamous cell carcinoma & $113(33)$ & $124(32)$ & \\
\hline Other / NOS & $87(25)$ & $130(33)$ & \\
\hline EGFR mutation $\mathrm{N}(\%)^{*}$ & & & 0.439 \\
\hline Yes & $2(2)$ & $3(4)$ & \\
\hline No & $101(98)$ & $75(96)$ & \\
\hline KRAS mutation $\mathrm{N}(\%)^{*}$ & & & 0.472 \\
\hline Yes & $38(35)$ & $26(31)$ & \\
\hline No & $69(65)$ & $59(69)$ & \\
\hline \multicolumn{4}{|l|}{$A L K$ rearrangement $\mathrm{N}(\%)^{*}$} \\
\hline Yes & $3(12)$ & $4(13)$ & 0.919 \\
\hline No & $22(88)$ & $27(87)$ & \\
\hline Brain imaging initial diagnosis $\mathrm{N}(\%)$ & & & 0.083 \\
\hline $\mathrm{MRI}$ & $290(84)$ & $345(88)$ & \\
\hline CE-CT & $56(16)$ & $46(12)$ & \\
\hline Stage N (\%) & & & 0.226 \\
\hline IIIA & $199(58)$ & $242(62)$ & \\
\hline IIIB & $147(42)$ & $149(38)$ & \\
\hline T-stage N (\%) & & & 0.941 \\
\hline TO-2 & 169 (49) & $189(48)$ & \\
\hline T3-4 & $177(51)$ & $202(52)$ & \\
\hline N-stage N (\%) & & & 0.604 \\
\hline N0-1 & $45(13)$ & $56(14)$ & \\
\hline $\mathrm{N} 2-3$ & $301(87)$ & $335(86)$ & \\
\hline Type concurrent chemotherapy N (\%) & & & N/A \\
\hline Cisplatin/etoposide & $188(54)$ & - & \\
\hline Carboplatin/etoposide & $22(6)$ & - & \\
\hline Cisplatin/vinorelbin \pm cetuximab & $65(19)$ & - & \\
\hline Carboplatin/vinorelbin & $4(1)$ & - & \\
\hline Cisplatin/pemetrexed & $6(2)$ & - & \\
\hline $\begin{array}{l}\text { Weekly platinum/docetaxel ( } \pm \text { induction high } \\
\text { dose chemotherapy) }\end{array}$ & $61(18)$ & - & \\
\hline Cisplatin low dose daily & - & $391(100)$ & \\
\hline Radiotherapy (Gy) Mean ( $\pm S D$ ) & $65( \pm 5)$ & $66( \pm 1)$ & $<0.001$ \\
\hline Range & $45-89$ & $52-68$ & \\
\hline Surgery after cCRT N (\%) & & & 0.686 \\
\hline Yes & $45(13)$ & $47(12)$ & \\
\hline
\end{tabular}


Table 4.2 (continued)

\begin{tabular}{lccc}
\hline Patient characteristic & $\begin{array}{c}\text { Cyclic dose doublet } \\
\text { chemotherapy } \\
\mathrm{N}=346\end{array}$ & $\begin{array}{c}\text { Daily low dose } \\
\text { cisplatin } \\
\mathrm{N}=391\end{array}$ & $p$-value \\
\hline $\begin{array}{l}\text { Dose reduction N (\%) } \\
\text { Yes }\end{array}$ & $36(10)$ & $0(0)$ & $<0.001$ \\
$\begin{array}{l}\text { Routine brain imaging in follow-up N (\%) } \\
\text { Yes }\end{array}$ & $0(0)$ & $0(0)$ & - \\
\hline
\end{tabular}

$\mathrm{N}$ : number; SD: standard deviation; WHO PS: world health organization performance score; NOS: not otherwise specified; EGFR: epidermal growth factor receptor; KRAS: Kirsten rat sarcoma viral antigen; ALK: anaplastic lymphoma kinase; MRI: magnetic resonance imaging; CE-CT: contrast enhanced computed tomography; T: tumour; N: node; CRT: chemoradiation; Gy: gray; CCRT: concurrent chemoradiation.

\section{DEVELOPMENT OF BRAIN METASTASES}

$153 / 838$ patients (18\%) were diagnosed with brain metastases in the follow-up, of which 143 (93\%) were symptomatic. The percentage of brain metastases diagnosis was not significantly different for SCRT and CCRT patients (18/101 (18\%) versus 135/737 $(18 \%, p=0.904)$. The median time $(95 \%$ confidence interval $(\mathrm{CI}))$ from stage III NSCLC diagnosis to brain metastases diagnosis was 11.8 (7.4-16.3) months for sCRT and 10.4 (9.2-11.7) months for cCRT patients $(p=0.453)$. As compared to patients not developing brain metastases, those with metastases were significantly younger (mean age 59 versus 63 years, $p<0.001)$, had female gender $(44 \%$ versus $34 \%, p=0.018)$, had adenocarcinoma histology (57\% versus 35\%, $p<0.001)$ and had a more advanced $\mathrm{N}^{-}$ stage (93\% versus $86 \%, p=0.018$ ) (Table 54.2 ).

\section{BRAIN METASTASES DIAGNOSIS WITHIN A YEAR OF NSCLC DIAGNOSIS}

88/838 (11\%) patients developed brain metastases within a year. Patients diagnosed with brain metastases were significantly younger (mean age 59 versus 63 years, $p<0.001)$, female ( $49 \%$ versus $35 \%, p=0.009)$, and had adenocarcinoma histology $(51 \%$ versus $37 \%, p<0.001$ ) compared to patients not diagnosed with brain metastases (Table 4.3). No significant difference in percentage of patients diagnosed with brain metastases was found for SCRT (10/101 ( $10 \%)$ ) versus cCRT (78/737 (11\%), $p=0.834)$. In $4 / 101(4.0 \%)$ and $35 / 737(5 \%)$, respectively, the brain was the only site of first relapse, this was not significantly different $(p=0.724)$.

Within the cCRT subgroup, no significant differences were observed between cyclic dose doublet chemotherapy $(\mathrm{N}=346)$ and daily low dose cisplatin $(\mathrm{N}=391) .37(11 \%)$ and $41(11 \%)$ patients were diagnosed with brain metastases, respectively ( $p=0.927)$. In 14 (4\%) cyclic dose doublet chemotherapy and 21 (5\%) daily low dose cisplatin patients respectively, the brain was the only site of first relapse $(p=0.399)$. 
Table 4.3 Patient characteristics for patients developing brain metastases within a year of NSCLC diagnosis, compared to those without brain metastases within a year.

\begin{tabular}{|c|c|c|c|}
\hline Patient characteristic & $\begin{array}{l}\text { Brain metastases } \\
\qquad \mathrm{N}=88\end{array}$ & $\begin{array}{l}\text { No brain metastases } \\
\qquad \mathrm{N}=750\end{array}$ & $p$-value \\
\hline Mean age \pm SD & $59 \pm 10$ & $63 \pm 10$ & $<0.001$ \\
\hline (range) & $36-80$ & $30-84$ & \\
\hline Male N (\%) & $45(51)$ & $490(65)$ & 0.009 \\
\hline \multicolumn{4}{|l|}{ WHO PS N (\%)* } \\
\hline $0-1$ & $77(96)$ & $702(96)$ & 0.839 \\
\hline 2 & $3(4)$ & $31(4)$ & \\
\hline \multicolumn{4}{|l|}{ Smoking status N (\%)* } \\
\hline Current & $26(41)$ & $213(40)$ & 0.973 \\
\hline Former & $36(57)$ & $308(58)$ & \\
\hline Never & $1(2)$ & $7(2)$ & \\
\hline \multicolumn{4}{|l|}{ Histology N (\%) } \\
\hline Adenocarcinoma & $45(51)$ & $279(37)$ & $<0.001$ \\
\hline Squamous cell carcinoma & $10(11)$ & $271(36)$ & \\
\hline Other / NOS & $33(38)$ & $200(27)$ & \\
\hline \multicolumn{4}{|l|}{ EGFR mutation $\mathrm{N}(\%)^{*}$} \\
\hline Yes & $1(4)$ & $5(3)$ & 0.811 \\
\hline No & $27(96)$ & $176(97)$ & \\
\hline \multicolumn{4}{|l|}{ KRAS mutation $\mathrm{N}(\%)^{*}$} \\
\hline Yes & $18(53)$ & $57(30)$ & 0.010 \\
\hline No & $16(47)$ & $132(70)$ & \\
\hline \multicolumn{4}{|l|}{$A L K$ rearrangement $\mathrm{N}(\%)^{*}$} \\
\hline Yes & $2(18)$ & $5(10)$ & 0.426 \\
\hline No & $9(82)$ & $46(90)$ & \\
\hline \multicolumn{4}{|c|}{ Brain imaging initial diagnosis $\mathrm{N}(\%)$} \\
\hline $\mathrm{MRI}$ & $71(81)$ & $649(87)$ & 0.135 \\
\hline CE-CT & $17(19)$ & $101(13)$ & \\
\hline \multicolumn{4}{|l|}{ Stage N (\%) } \\
\hline IIIA & $47(53)$ & $447(69)$ & 0.264 \\
\hline IIIB & $41(47)$ & $303(40)$ & \\
\hline \multicolumn{4}{|l|}{ T-stage N (\%) } \\
\hline T0-2 & $38(43)$ & $374(50)$ & 0.235 \\
\hline T3-4 & $50(57)$ & $376(50)$ & \\
\hline \multicolumn{4}{|l|}{ N-stage N (\%) } \\
\hline N0-1 & $8(9)$ & $101(13)$ & 0.248 \\
\hline $\mathrm{N} 2-3$ & $80(91)$ & $649(87)$ & \\
\hline Radiotherapy (Gy) Mean \pm SD & $66 \pm 4$ & $65 \pm 3$ & 0.842 \\
\hline Range & $45-79$ & $45-89$ & \\
\hline \multicolumn{4}{|l|}{ Surgery after cCRT N (\%) } \\
\hline Yes & $7(8)$ & $86(12)$ & 0.321 \\
\hline \multicolumn{4}{|l|}{ Dose reduction N (\%) } \\
\hline Yes & $3(3)$ & $42(6)$ & 0.342 \\
\hline
\end{tabular}

* computed only for patients with known data. N: number; SD: standard deviation; WHO PS: world health organization performance score; NOS: not otherwise specified; EGFR: epidermal growth factor receptor; KRAS: Kirsten rat sarcoma viral antigen; ALK: anaplastic lymphoma kinase; MRI: magnetic resonance imaging; CE-CT: contrast enhanced computed tomography; T: tumour; N: node; CRT: chemoradiation; Gy: gray; cCRT: concurrent chemoradiation. 


\section{PREDICTORS FOR BRAIN METASTASES DEVELOPMENT}

In the total group ( $\mathrm{N}=838)$, a lower risk of developing brain metastases within a year was seen in older patients (age as continuous variable, odds ratio (OR) $(95 \% \mathrm{Cl}) 0.97$ (0.95-0.99), $p=0.011$ ) and squamous carcinoma histology (OR 0.28 (0.14-0.59), $p=0.001$ ). The chemotherapy regimen used (cCRT versus SCRT) did not influence the brain metastases risk (OR $0.87(0.42-1.78), p=0.695)$. Comparable results were found for the brain as the only site of first relapse: OR of $0.96(0.96-0.99, p=0.011)$ for increasing age, OR $0.12(0.03-0.54, p=0.006)$ for squamous versus adenocarcinoma histology, OR $0.89(0.30-2.68, p=0.838)$ for cCRT versus sCRT. Advanced T-stage (T3-4 versus T0-2) was also associated with an increased risk of brain metastases (OR 2.31 $(1.12-4.79), p=0.024)$. Comparable results were found for all brain relapses regardless of timing (Table 4.4).

In the cCRT group ( $\mathrm{N}=737)$, a lower risk of developing brain metastases within a year was found for squamous versus adenocarcinoma histology (OR 0.22 (0.09-0.51), $p<0.001$ ). For the brain as the only site of first relapse, older patients (OR 0.97 (0.93-0.10), $p=0.045)$ and patients with squamous histology (OR 0.14 (0.03-0.62), $p=0.010$ ) had a lower risk; patients with a more advanced T-stage had a higher risk (OR 3.45 (1.12-5.35), $p=0.024)$. For all brain relapses regardless of timing, older age (OR 0.98 (0.96-0.99), $p=0.037$ ) and squamous histology (OR $0.19(0.10-0.36), p<0.001$ ) decreased the brain metastases risk. In none of these subgroup analyses, chemotherapy regimen (daily low dose cisplatin versus cyclic dose doublet chemotherapy) had an impact on brain metastases development (Table 4.4). Comparable results were found for daily low dose cisplatin ( $\mathrm{N}=391)$ versus cyclic dose non-taxane $(\mathrm{N}=277)$ and cyclic dose taxane based regimens $(\mathrm{N}=69)$. There was also no significant difference in brain metastases development for the subgroups of cCRT regimens with $\geq 50$ patients (daily low dose cisplatin ( $N=391)$ versus cisplatin/etoposide $(\mathrm{N}=188)$, cisplatin/vinorelbine \pm cetuximab $(\mathrm{N}=65)$, weekly cisplatin/docetaxel $(\mathrm{N}=60)$ respectively. This was regardless of timing and whether the brain was the first and only site of relapse (Tables S4.3 and S4.4).

\section{PROGRESSION FREE SURVIVAL AND OVERALL SURVIVAL}

The median follow-up (95\% Cl) for patients being alive was 45.1 (42.3-47.8) months. PFS (95\% Cl) was 16.7 (14.1-19.4) months for cCRT and 13.3 (10.9-15.7) months for SCRT (hazard ratio (HR) $0.82(0.64-1.06, p=0.122)$. The OS was $24.5(21.9-27.2)$ and 16.8 (13.7-19.8) months, respectively (HR 0.76 (0.59-0.98), $p=0.034)$. One-year survival was $70 \%$ and $66 \%$, respectively ( $p=0.451$ ). For daily low dose cisplatin cCRT, PFS was 15.1 (11.0-19.3) months compared to 17.2 (14.0-20.3) months for cyclic dose cCRT (HR 1.11 (0.92-1.33), $p=0.270)$. OS was 23.7 (19.9-27.5) months for daily low dose cisplatin cCRT and 25.5 (21.9-29.0) months for cyclic dose cCRT, respectively (HR 1.08 (0.90-1.30, $p=0.397)$. One-year survival was $68 \%$ and $73 \%$, respectively $(p=0.116)$. 
Table 4.4 Multivariate logistic regression analysis for brain metastases development.

\begin{tabular}{|c|c|c|}
\hline \multicolumn{3}{|l|}{ All chemoradiation patients ( $\mathrm{N}=838$ ) } \\
\hline Brain relapse pattern & OR $(95 \% \mathrm{Cl})$ & $p$-value \\
\hline \multicolumn{3}{|l|}{ All brain relapses } \\
\hline Gender (female vs male) & $1.05(0.72-1.53)$ & 0.807 \\
\hline Age (continuous, older vs younger) & $0.97(0.95-0.99)$ & 0.002 \\
\hline T-stage (T3-4 vs T0-2) & $1.19(0.81-1.74)$ & 0.375 \\
\hline $\mathrm{N}$-stage (N2-3 vs N0-1) & $1.80(0.89-3.64)$ & 0.102 \\
\hline Treatment regimen (concurrent vs sequential) & $0.88(0.50-1.57)$ & 0.669 \\
\hline Histology (squamous vs adenocarcinoma) & $0.24(0.14-0.42)$ & $<0.001$ \\
\hline Histology (NOS vs adenocarcinoma) & $0.75(0.50-1.14)$ & 0.174 \\
\hline \multicolumn{3}{|l|}{ All brain relapses within one year } \\
\hline Gender (female vs male) & $1.29(0.81-2.06)$ & 0.282 \\
\hline Age (continuous, older vs younger) & $0.97(0.95-0.99)$ & 0.011 \\
\hline T-stage (T3-4 vs T0-2) & $1.64(1.02-2.64)$ & 0.043 \\
\hline $\mathrm{N}$-stage (N2-3 vs N0-1) & $1.58(0.70-3.58)$ & 0.269 \\
\hline Treatment regimen (concurrent vs sequential) & $0.87(0.42-1.78)$ & 0.695 \\
\hline Histology (squamous vs adenocarcinoma) & $0.28(0.14-0.59)$ & 0.001 \\
\hline Histology (NOS vs adenocarcinoma) & $1.11(0.67-1.83)$ & 0.674 \\
\hline \multicolumn{3}{|l|}{ Brain as the only site of first relapse within one year } \\
\hline Gender (female vs male) & $1.61(0.81-3.18)$ & 0.173 \\
\hline Age (continuous, older vs younger) & $0.96(0.96-0.99)$ & 0.011 \\
\hline T-stage (T3-4 vs T0-2) & $2.31(1.12-4.79)$ & 0.024 \\
\hline $\mathrm{N}$-stage (N2-3 vs N0-1) & $0.81(0.30-2.19)$ & 0.681 \\
\hline Treatment regimen (concurrent vs sequential) & $0.89(0.30-2.68)$ & 0.838 \\
\hline Histology (squamous vs adenocarcinoma) & $0.12(0.03-0.54)$ & 0.006 \\
\hline Histology (NOS vs adenocarcinoma) & $0.97(0.48-1.97)$ & 0.931 \\
\hline \multicolumn{3}{|l|}{ Only concurrent chemoradiation patients $(\mathrm{N}=737)$} \\
\hline Brain relapse pattern & OR $(95 \% \mathrm{Cl})$ & $p$-value \\
\hline \multicolumn{3}{|l|}{ All brain relapses } \\
\hline Gender (female vs male) & $1.01(0.67-1.51)$ & 0.974 \\
\hline Age (continuous, older vs younger) & $0.98(0.96-0.99)$ & 0.037 \\
\hline T-stage (T3-4 vs T0-2) & $1.18(0.78-1.77)$ & 0.431 \\
\hline $\mathrm{N}$-stage (N2-3 vs N0-1) & $1.88(0.90-3.93)$ & 0.095 \\
\hline Treatment regimen (low dose cisplatin vs cyclic dose) & $0.96(0.65-1.41)$ & 0.819 \\
\hline Histology (squamous vs adenocarcinoma) & $0.19(0.10-0.36)$ & $<0.001$ \\
\hline Histology (NOS vs adenocarcinoma) & $0.73(0.47-1.12)$ & 0.153 \\
\hline \multicolumn{3}{|l|}{ All brain relapses within one year } \\
\hline Gender (female vs male) & $1.28(0.78-2.10)$ & 0.325 \\
\hline Age (continuous, older vs younger) & $0.98(0.95-1.00)$ & 0.071 \\
\hline T-stage (T3-4 vs TO-2) & $1.52(0.91-2.52)$ & 0.107 \\
\hline $\mathrm{N}$-stage (N2-3 vs N0-1) & $1.67(0.70-3.98)$ & 0.248 \\
\hline Treatment regimen (low dose cisplatin vs cyclic dose) & $0.96(0.59-1.55)$ & 0.861 \\
\hline Histology (squamous vs adenocarcinoma) & $0.22(0.09-0.51)$ & $<0.001$ \\
\hline Histology (NOS vs adenocarcinoma) & $1.08(0.64-1.82)$ & 0.768 \\
\hline \multicolumn{3}{|l|}{ Brain as the only site of first relapse within one year } \\
\hline Gender (female vs male) & $1.77(0.87-3.63)$ & 0.117 \\
\hline Age (continuous, older vs younger) & $0.97(0.93-1.00)$ & 0.045 \\
\hline T-stage (T3-4 vs T0-2) & $2.45(1.12-5.35)$ & 0.024 \\
\hline $\mathrm{N}$-stage (N2-3 vs N0-1) & $0.78(0.29-2.17)$ & 0.655 \\
\hline Treatment regimen (low dose cisplatin vs cyclic dose) & $1.36(0.66-2.76)$ & 0.404 \\
\hline Histology (squamous vs adenocarcinoma) & $0.14(0.03-0.62)$ & 0.010 \\
\hline Histology (NOS vs adenocarcinoma) & $0.92(0.46-1.93)$ & 0.817 \\
\hline
\end{tabular}

$N$ : number; OR: odds ratio; $\mathrm{Cl}$ : confidence interval; T: tumour; N: node; NOS: not otherwise specified. 


\section{DISCUSSION}

The brain is a frequent site of relapse after CRT and this has a negative impact on QoL and $\mathrm{OS}^{4-7}$ In this retrospective multicenter study the type of chemotherapy did not have an impact on the incidence of brain metastases in stage III NSCLC patients treated with CRT. Also, no significant differences were found for SCRT versus CCRT treated patients. Although brain metastases before treatment start were excluded by brain $\mathrm{MRI} / \mathrm{CT}$ and all patients were ${ }^{18}$ FDG-PET-CT staged, still $11 \%$ was diagnosed with brain metastases within one year, and for half of them the brain was the only site of first relapse. As demonstrated in previous studies, adenocarcinoma histology and younger age were significant predictors for brain metastases development. ${ }^{4,8}$

An explanation for our findings is that subclinical brain metastases are already present at staging and that the type of chemotherapy regimens does not differ in the effect to eradicate these tumor deposits. This is likely due to the fact that these chemotherapies have almost no penetration through an intact blood-brain barrier and/or are substrates for brain efflux pumps. ${ }^{14}$ In general, chemotherapy added to local radical treatment improves OS, as was found in a recent meta-analysis (HR 0.88 ( $p=0.0009), 4 \%$ increase in 5-year survival). ${ }^{15}$ Impact on brain metastases development was not evaluated. The finding that the chemotherapy regime does not influence brain metastases incidence is not entirely new. For example, the early RTOG 88-08/ECOG 4588 trial randomizing 490 stage III NSCLC patients between radical radiotherapy (standard or hyperfractionated) and SCRT revealed no difference in brain metastases incidence in the follow up (but significantly less distant metastases other than brain for SCRT compared to the radiotherapy alone arms $(p=0.04)) .{ }^{16}$ However, it is likely that due to inadequate brain imaging metastases at initial staging were missed. Indeed, in a recent study using brain MRI up to $16 \%$ had asymptomatic metastases at initial staging. ${ }^{5}$

Strong points of this study are that it is a multi-center study including over 800 consecutive stage III NSCLC patients, all with up-to-date staging and all treated with CRT, which represents current practice. In order to exclude bias from suboptimal treatment only patients who completed treatment were included.

Limitations of our study are that within the cyclic dose doublet chemotherapy group different chemotherapy regimens were used, and that the number of patients per cyclic dose regimen was relatively small for comparing these regimens. However, when we compared the major subgroups of chemotherapy within the CCRT group no differences were found regarding brain metastases development. Comparable results were found for daily low dose cisplatin versus cyclic dose taxane and non-taxane based regimens, respectively. Some patients did receive weekly platinum/docetaxel concurrent with radiotherapy (often preceded by full dose platinum based doubled chemotherapy) and these patients were grouped within the cyclic dose group. One can argue that this regimen has some low dose components. When we excluded these patients from our analyses, results did not change significantly (data not shown). Adenocarcinoma 
histology is a risk factor for brain metastases and it is possible that the chemotherapeutic regimens used have a different impact on adenocarcinoma histology compared to other histologies. When the analyses above were repeated with only adenocarcinoma patients, results did not change significantly (data not shown). Furthermore, it is a retrospective study and as such follow up was not standardized but according to local practice (i.e. PFS data difficult to compare). Only patients who completed their CRT treatment were included (no intention-to-treat-analysis) and patient selection for CRT eligibility was according to local protocols. This may have caused an imbalance in favor of the patients treated with SCRT regarding prognosis in the different subgroups. It is not common practice to perform regular brain imaging in the follow-up of radically treated stage III NSCLC patients. ${ }^{3}$ This results in underdiagnosis of asymptomatic brain metastases. One can argue the relevance of asymptomatic metastases when a patient dies of extracranial disease. Furthermore, bias regarding different regimes for cerebral metastases screening did not occur because brain imaging was only performed when a patient had symptoms indicative for brain metastases or when brain imaging was required for renewed staging. As it is not common practice to perform molecular screening in stage III NSCLC, molecular characteristics were mostly unknown. However, as especially patients with an ALKrearrangement are prone to develop brain metastases and percentage of $A L K$ rearranged patients is low in the literature $( \pm 5 \%)$ it is unlikely that this has caused any bias. ${ }^{17}$ Finally, the time period chosen for the primary endpoints (brain metastases within one year) is arbitrary. However, we chose this time period as in a previous study brain metastases were most frequently diagnosed within this year and were often the only site of progression. ${ }^{4}$ When we expanded our analyses to all patients diagnosed with brain metastases irrespective of timing, comparable results were found. Treatment factors that can reduce brain metastases development are important to identify, for these metastases are often associated with reduced QoL and poor prognosis. ${ }^{6,7}$ Prophylactic cranial irradiation $(\mathrm{PCl})$ to eradicate microscopic brain metastases is a possible treatment option. $\mathrm{PCl}$ is currently evaluated in the phase III randomized NVALT11/DLCRG 02 study (NCT01282437). It is closed for accrual and results are awaited.

In conclusion, the specific chemotherapy regimen used during CRT for stage III NSCLC has no impact on the subsequent development of clinically manifest brain metastases. It remains important to identify modifiable factors in order to reduce the development of brain metastases. 


\section{REFERENCES}

1. Auperin A, Le Pechoux C, Rolland E, et al. Meta-analysis of concomitant versus sequential radiochemotherapy in locally advanced non-small-cell lung cancer. J Clin Oncol. 2010;28:2181-90.

2. NCCN Guidelines version 1.2015 Non-Small Cell Lung Cancer.

3. Eberhardt WE, De Ruysscher D, Weder W, et al. 2nd ESMO Consensus Conference in Lung Cancer: locally advanced stage III non-small-cell lung cancer. Ann Oncol. 2015;26:1573-88.

4. Gaspar LE, Chansky K, Albain KS, et al. Time from treatment to subsequent diagnosis of brain metastases in stage III non-small-cell lung cancer: a retrospective review by the Southwest Oncology Group. J Clin Oncol. 2005;23:2955-61.

5. Hendriks LE, Bootsma GP, de Ruysscher DK, et al. Screening for brain metastases in patients with stage III non-small cell lung cancer: Is there additive value of magnetic resonance imaging above a contrastenhanced computed tomography of the brain? Lung Cancer 2013;80:293-7.

6. Kepka L, Cieslak E, Bujko K, et al. Results of the whole-brain radiotherapy for patients with brain metastases from lung cancer: the RTOG RPA intra-classes analysis. Acta Oncol. 2005;44:389-98.

7. Steinmann D, Schafer C, van Oorschot B, et al. Effects of radiotherapy for brain metastases on quality of life (QoL). Prospective pilot study of the DEGRO QoL working party. Strahlenther Onkol. 2009;185: 190-7.

8. Andre F, Grunenwald D, Pujol JL, et al. Patterns of relapse of N2 nonsmall-cell lung carcinoma patients treated with preoperative chemotherapy: should prophylactic cranial irradiation be reconsidered? Cancer 2001;91:2394-400.

9. Santana-Davila R, Devisetty K, Szabo A, et al. Cisplatin and etoposide versus carboplatin and paclitaxel with concurrent radiotherapy for stage III non-small-cell lung cancer: an analysis of Veterans Health Administration data. J Clin Oncol. 2015;33:567-74.

10. Senan S, Brade A, L. W, et al. Final overall survival (OS) results of the phase III PROCLAIM trial: Pemetrexed (Pem), cisplatin (Cis) or etoposide (Eto), Cis plus thoracic radiation therapy (TRT) followed by consolidation cytotoxic chemotherapy (CTX) in locally advanced nonsquamous non-small cell lung cancer (nsNSCLC). 2015 ASCO Annual Meeting. Chicago: 2015. J Clin Oncol 33, 2015 (suppl; abstr 7506)

11. Wu HG, Bang YJ, Choi EK, et al. Phase I study of weekly docetaxel and cisplatin concurrent with thoracic radiotherapy in Stage III non-small-cell lung cancer. Int J Radiat Oncol Biol Phys. 2002;52:75-80.

12. Belderbos J, Uitterhoeve L, van Zandwijk N, et al. Randomised trial of sequential versus concurrent chemo-radiotherapy in patients with inoperable non-small cell lung cancer (EORTC 08972-22973). Eur J Cancer 2007;43:114-21.

13. Act of 26 February 1998, containing rules on medical research involving human subjects (Medical Research (Human Subjects) Act). 1998 Available at http://www.ccmo.nl/attachments/files/wmoengelse-vertaling-29-7-2013-afkomstig-van-vws.pdf.

14. Steeg PS, Camphausen KA, Smith QR. Brain metastases as preventive and therapeutic targets. Nat Rev Cancer 2011;11:352-363.

15. Burdett S, Pignon JP, Tierney J, et al. Adjuvant chemotherapy for resected early-stage non-small cell lung cancer. The Cochrane database of systematic reviews 2015;3:CD011430.

16. Komaki R, Scott CB, Sause WT, et al. Induction cisplatin/vinblastine and irradiation vs. irradiation in unresectable squamous cell lung cancer: failure patterns by cell type in RTOG 88-08/ECOG 4588. Radiation Therapy Oncology Group. Eastern Cooperative Oncology Group. Int J Radiat Oncol Biol Phys. 1997;39:537-44.

17. Shaw AT, Kim DW, Nakagawa K, et al. Crizotinib versus chemotherapy in advanced ALK-positive lung cancer. N Engl J Med. 2013;368:2385-94. 
Table S4.1 Overview of chemotherapy regimens used within a chemo-radiation regimen.

\begin{tabular}{|c|c|}
\hline \multicolumn{2}{|l|}{ Sequential/induction } \\
\hline \multicolumn{2}{|l|}{ Cycle: 21 days } \\
\hline \multirow[t]{3}{*}{ Cisplatin/gemcitabin } & cisplatin 75 milligram $(\mathrm{mg}) / \mathrm{m}^{2}$ day $(\mathrm{d}) 1$ \\
\hline & gemcitabine $1250 \mathrm{mg} / \mathrm{m}^{2} \mathrm{~d} 1,8$ \\
\hline & $3-4$ cycles (sequential) \\
\hline \multirow[t]{3}{*}{ Carboplatin/gemcitabin } & carboplatin area under the curve (AUC) $5 \mathrm{~d} 1$ \\
\hline & gemcitabine $1250 \mathrm{mg} / \mathrm{m}^{2} \mathrm{~d} 1,8$ \\
\hline & 3-4 cycles (sequential) \\
\hline \multirow[t]{3}{*}{ Carboplatin/paclitaxel } & carboplatin AUC7 d1 \\
\hline & paclitaxel $175 \mathrm{mg} / \mathrm{m}^{2} \mathrm{~d} 1$ \\
\hline & 3-4 cycles (sequential) \\
\hline \multirow[t]{3}{*}{ Cisplatin/pemetrexed } & cisplatin $75 \mathrm{mg} / \mathrm{m}^{2} \mathrm{~d} 1$ \\
\hline & pemetrexed $500 \mathrm{mg} / \mathrm{m}^{2} \mathrm{~d} 1$ \\
\hline & 3-4 cycles (sequential) \\
\hline \multirow[t]{3}{*}{ Carboplatin/pemetrexed } & carboplatin AUC5 d1 \\
\hline & pemetrexed $500 \mathrm{mg} / \mathrm{m}^{2} \mathrm{~d} 1$ \\
\hline & 3-4 cycles (sequential) \\
\hline \multirow[t]{3}{*}{ Cisplatin/vinorelbin } & cisplatin $50 \mathrm{mg} / \mathrm{m}^{2} \mathrm{~d} 1,8$ \\
\hline & vinorelbin $20 \mathrm{mg} / \mathrm{m}^{2} \mathrm{~d} 1-8$ \\
\hline & 1-2 cycles (induction) \\
\hline \multirow[t]{3}{*}{ Cisplatin/etoposide } & cisplatin $75 \mathrm{mg} / \mathrm{m}^{2} \mathrm{~d} 1$ \\
\hline & etoposide $100 \mathrm{mg} / \mathrm{m}^{2} \mathrm{~d} 1-3$ \\
\hline & $1-2$ cycles (induction) \\
\hline \multirow[t]{3}{*}{ Carboplatin/etoposide } & carboplatin AUC5 d1 \\
\hline & etoposide $100 \mathrm{mg} / \mathrm{m}^{2} \mathrm{~d} 1-3$ \\
\hline & 1-2 cycles (induction) \\
\hline \multicolumn{2}{|l|}{ Concurrent } \\
\hline \multicolumn{2}{|l|}{ Cycle: 21 days } \\
\hline \multirow[t]{3}{*}{ Cisplatin/etoposide } & cisplatin $75 \mathrm{mg} / \mathrm{m}^{2} \mathrm{~d} 1$ \\
\hline & etoposide $100 \mathrm{mg} / \mathrm{m}^{2} \mathrm{~d} 1-3$ \\
\hline & $2-3$ cycles \\
\hline \multirow[t]{3}{*}{ Carboplatin/etoposide } & carboplatin AUC5 d1 \\
\hline & etoposide $100 \mathrm{mg} / \mathrm{m}^{2} \mathrm{~d} 1-3$ \\
\hline & $2-3$ cycles \\
\hline \multirow[t]{3}{*}{ Cisplatin/vinorelbin } & cisplatin $50 \mathrm{mg} / \mathrm{m}^{2} \mathrm{~d} 1,8$ \\
\hline & vinorelbin $20 \mathrm{mg} / \mathrm{m}^{2} \mathrm{~d} 1-8$ \\
\hline & 2-3 cycles \\
\hline \multirow[t]{5}{*}{ Cisplatin/vinorelbin + cetuximab } & cetuximab $250 \mathrm{mg} / \mathrm{kg} \mathrm{d} 1$ \\
\hline & $\begin{array}{l}\text { before start radiotherapy one gift of cetuximab } 400 \mathrm{mg} / \mathrm{kg} \\
\text { cisplatin } 50 \mathrm{mg} / \mathrm{m}^{2} \mathrm{~d} 1.840 \mathrm{mg} / \mathrm{m}^{2} \mathrm{~d} 22\end{array}$ \\
\hline & Vinorelbine escalated in three steps; (1) $10 \mathrm{mg} / \mathrm{m}^{2} \mathrm{~d} 1,8$ and \\
\hline & $\begin{array}{l}\left.8 \mathrm{mg} / \mathrm{m}^{2} \mathrm{~d} 22,29 ;(2) 20 \mathrm{mg} / \mathrm{m}^{2} \mathrm{~d} 1,8 \text { and } 8 \mathrm{mg} / \mathrm{m}^{2} \mathrm{~d} 22,29 ; 3\right) 20 \\
\mathrm{mg} / \mathrm{m}^{2} \mathrm{~d} 1,8 ; 15 \mathrm{mg} / \mathrm{m}^{2} \mathrm{~d} 22,29\end{array}$ \\
\hline & 5 cycles \\
\hline \multirow[t]{3}{*}{ Carboplatin/vinorelbin } & carboplatin AUC3 d1,8 \\
\hline & vinorelbin $20 \mathrm{mg} / \mathrm{m}^{2} \mathrm{~d} 1-8$ \\
\hline & 2-3 cycles \\
\hline \multirow[t]{3}{*}{ Cisplatin/pemetrexed } & cisplatin $75 \mathrm{mg} / \mathrm{m}^{2} \mathrm{~d} 1$ \\
\hline & pemetrexed $500 \mathrm{mg} / \mathrm{m}^{2} \mathrm{~d} 1$ \\
\hline & 3 cycles \\
\hline \multicolumn{2}{|l|}{ Cycle: 7 days } \\
\hline Weekly cisplatin/docetaxel & cisplatin $20 \mathrm{mg} / \mathrm{m}^{2} \mathrm{~d} 1$ - docetaxel $20 \mathrm{mg} / \mathrm{m}^{2} \mathrm{~d} 1,6$ cycles \\
\hline Weekly carboplatin/docetaxel & carboplatin AUC2 d1 - docetaxel $20 \mathrm{mg} / \mathrm{m}^{2} \mathrm{~d} 1,6$ cycles \\
\hline
\end{tabular}


Table S4.2 Patient characteristics for patients developing brain metastases regardless of timing, compared to those without brain metastases.

\begin{tabular}{|c|c|c|c|}
\hline Patient characteristic & $\begin{array}{l}\text { Brain metastases } \\
\qquad \mathrm{N}=153\end{array}$ & $\begin{array}{l}\text { No brain metastases } \\
\qquad \mathrm{N}=685\end{array}$ & $p$-value \\
\hline Mean age $\pm S D$ & $59 \pm 9$ & $63 \pm 10$ & $<0.001$ \\
\hline (range) & $36-80$ & $30-84$ & \\
\hline Male N (\%) & $85(56)$ & $450(66)$ & 0.018 \\
\hline \multicolumn{4}{|l|}{ WHO PS N (\%)* } \\
\hline $0-1$ & $141(98)$ & $638(95)$ & 0.165 \\
\hline 2 & $3(2)$ & $31(5)$ & \\
\hline \multicolumn{4}{|l|}{ Smoking status N (\%)* } \\
\hline Current & $51(46)$ & $188(39)$ & 0.400 \\
\hline Former & $59(53)$ & $285(59)$ & \\
\hline Never & $1(1)$ & $7(1)$ & \\
\hline \multicolumn{4}{|l|}{ Histology N (\%) } \\
\hline Adenocarcinoma & $87(57)$ & $237(35)$ & $<0.001$ \\
\hline Squamous cell carcinoma & $19(12)$ & $262(38)$ & \\
\hline Other / NOS & $47(31)$ & $186(27)$ & \\
\hline \multicolumn{4}{|l|}{ EGFR mutation $\mathrm{N}(\%)^{*}$} \\
\hline Yes & $3(5)$ & $3(2)$ & 0.357 \\
\hline No & $57(95)$ & $146(98)$ & \\
\hline \multicolumn{4}{|l|}{ KRAS mutation $\mathrm{N}(\%)^{*}$} \\
\hline Yes & $28(40)$ & $47(31)$ & 0.173 \\
\hline No & $42(60)$ & $106(69)$ & \\
\hline \multicolumn{4}{|l|}{$A L K$ rearrangement $\mathrm{N}(\%)^{*}$} \\
\hline Yes & $2(10)$ & $5(12)$ & 0.825 \\
\hline No & $18(90)$ & $37(88)$ & \\
\hline \multicolumn{4}{|c|}{ Brain imaging initial diagnosis $\mathrm{N}(\%)$} \\
\hline $\mathrm{MRI}$ & $130(85)$ & $590(86)$ & 0.708 \\
\hline CE-CT & $23(15)$ & $95(14)$ & \\
\hline \multicolumn{4}{|l|}{ Stage N (\%) } \\
\hline IIIA & $86(56)$ & $408(60)$ & 0.446 \\
\hline IIIB & $67(44)$ & $277(40)$ & \\
\hline \multicolumn{4}{|l|}{ T-stage N (\%) } \\
\hline T0-2 & $78(51)$ & 334 (49) & 0.619 \\
\hline T3-4 & 75 (49) & $351(51)$ & \\
\hline \multicolumn{4}{|l|}{ N-stage N (\%) } \\
\hline No-1 & $11(7)$ & $98(14)$ & 0.018 \\
\hline $\mathrm{N} 2-3$ & $142(93)$ & $587(86)$ & \\
\hline Radiotherapy (Gy) Mean \pm SD & $65 \pm 3$ & $65 \pm 4$ & 0.875 \\
\hline Range & $45-79$ & $45-89$ & \\
\hline \multicolumn{4}{|l|}{ Surgery after cCRT N (\%) } \\
\hline Yes & $20(13)$ & $73(11)$ & 0.390 \\
\hline \multicolumn{4}{|l|}{ Dose reduction $\mathrm{N}(\%)$} \\
\hline Yes & $5(3)$ & $40(6)$ & 0.319 \\
\hline
\end{tabular}

*: computed only for patients with known data. N: number; SD: standard deviation; WHO PS: world health organization performance score; NOS: not otherwise specified; EGFR: epidermal growth factor receptor; KRAS: Kirsten rat sarcoma viral antigen; ALK: anaplastic lymphoma kinase; MRI: magnetic resonance imaging; CE-CT: contrast enhanced computed tomography; T: tumour; N: node; CRT: chemoradiation; Gy: gray; cCRT: concurrent chemoradiation. 
Table S4.3 Multivariate logistic regression analysis for brain metastases development including taxane based and non-taxane based regimens versus daily low dose cisplatin.

\begin{tabular}{|c|c|c|}
\hline \multicolumn{3}{|l|}{ All chemoradiation patients $(\mathrm{N}=838)$} \\
\hline Brain relapse pattern & OR $(95 \% \mathrm{Cl})$ & $p$-value \\
\hline \multicolumn{3}{|l|}{ All brain relapses } \\
\hline Gender (female vs male) & $1.05(0.72-1.53)$ & 0.811 \\
\hline Age (continuous, older vs younger) & $0.97(0.95-0.99)$ & 0.003 \\
\hline T-stage (T3-4 vs T0-2) & $1.18(0.80-1.73)$ & 0.398 \\
\hline $\mathrm{N}$-stage (N2-3 vs N0-1) & $1.78(0.88-3.60)$ & 0.108 \\
\hline Histology (squamous vs adenocarcinoma) & $0.24(0.14-0.41)$ & $<0.001$ \\
\hline Histology (NOS vs adenocarcinoma) & $0.74(0.49-1.12)$ & 0.157 \\
\hline Treatment regimen (non-taxane vs low dose cisplatin) & $1.12(0.77-1.64)$ & 0.547 \\
\hline Treatment regimen (taxane vs low dose cisplatin) & $0.80(0.38-1.69)$ & 0.552 \\
\hline \multicolumn{3}{|l|}{ All brain relapses within one year } \\
\hline Gender (female vs male) & $1.30(0.81-2.07)$ & 0.279 \\
\hline Age (continuous, older vs younger) & $0.97(0.95-0.99)$ & 0.013 \\
\hline T-stage (T3-4 vs T0-2) & $1.62(1.00-2.61)$ & 0.049 \\
\hline $\mathrm{N}$-stage (N2-3 vs N0-1) & $1.53(0.68-3.46)$ & 0.306 \\
\hline Histology (squamous vs adenocarcinoma) & $0.28(0.13-0.58)$ & 0.001 \\
\hline Histology (NOS vs adenocarcinoma) & $1.08(0.65-1.78)$ & 0.769 \\
\hline Treatment regimen (non-taxane vs low dose cisplatin) & $1.19(0.75-1.90)$ & 0.462 \\
\hline Treatment regimen (taxane vs low dose cisplatin) & $0.43(0.13-1.45)$ & 0.174 \\
\hline \multicolumn{3}{|l|}{ Brain as the only site of first relapse within one year } \\
\hline Gender (female vs male) & $1.62(0.82-3.21)$ & 0.163 \\
\hline Age (continuous, older vs younger) & $0.96(0.93-0.99)$ & 0.010 \\
\hline T-stage (T3-4 vs T0-2) & $2.29(1.11-4.75)$ & 0.026 \\
\hline $\mathrm{N}$-stage (N2-3 vs N0-1) & $0.80(0.30-2.15)$ & 0.652 \\
\hline Histology (squamous vs adenocarcinoma) & $0.12(0.03-0.54)$ & 0.006 \\
\hline Histology (NOS vs adenocarcinoma) & $0.92(0.45-1.86)$ & 0.807 \\
\hline Treatment regimen (non-taxane vs low dose cisplatin) & $0.87(0.44-1.72)$ & 0.695 \\
\hline Treatment regimen (taxane vs low dose cisplatin) & $0.27(0.04-2.11)$ & 0.212 \\
\hline \multicolumn{3}{|l|}{ Only concurrent chemoradiation patients $(\mathrm{N}=737)$} \\
\hline Brain relapse pattern & OR $(95 \% \mathrm{Cl})$ & $p$-value \\
\hline \multicolumn{3}{|l|}{ All brain relapses } \\
\hline Gender (female vs male) & $1.01(0.67-1.50)$ & 0.981 \\
\hline Age (continuous, older vs younger) & $0.98(0.96-0.99)$ & 0.040 \\
\hline T-stage (T3-4 vs T0-2) & $1.17(0.78-1.76)$ & 0.454 \\
\hline $\mathrm{N}$-stage (N2-3 vs N0-1) & $1.86(0.89-3.89)$ & 0.101 \\
\hline Histology (squamous vs adenocarcinoma) & $0.19(0.10-0.36)$ & $<0.001$ \\
\hline Histology (NOS vs adenocarcinoma) & $0.72(0.47-1.11)$ & 0.136 \\
\hline Treatment regimen (non-taxane vs low dose cisplatin) & $1.10(0.73-1.65)$ & 0.652 \\
\hline Treatment regimen (taxane vs low dose cisplatin) & $0.83(0.39-1.75)$ & 0.617 \\
\hline \multicolumn{3}{|l|}{ All brain relapses within one year } \\
\hline Gender (female vs male) & $1.28(0.78-2.10)$ & 0.329 \\
\hline Age (continuous, older vs younger) & $0.98(0.95-1.00)$ & 0.077 \\
\hline T-stage (T3-4 vs T0-2) & $1.49(0.90-2.48)$ & 0.122 \\
\hline $\mathrm{N}$-stage (N2-3 vs N0-1) & $1.62(0.68-3.86)$ & 0.279 \\
\hline Histology (squamous vs adenocarcinoma) & $0.22(0.09-0.51)$ & $<0.001$ \\
\hline Histology (NOS vs adenocarcinoma) & $1.04(0.62-1.76)$ & 0.872 \\
\hline Treatment regimen (non-taxane vs low dose cisplatin) & $1.18(0.72-1.94)$ & 0.508 \\
\hline Treatment regimen (taxane vs low dose cisplatin) & $0.44(0.13-1.50)$ & 0.191 \\
\hline
\end{tabular}


Table S4.3 (continued)

\begin{tabular}{lll}
\hline Brain as the only site of first relapse within one year & & \\
Gender (female vs male) & $1.78(0.87-3.63)$ & 0.117 \\
Age (continuous, older vs younger) & $0.96(0.93-1.00)$ & 0.043 \\
T-stage (T3-4 vs TO-2) & $2.42(1.11-5.28)$ & 0.027 \\
N-stage (N2-3 vs N0-1) & $0.77(0.28-2.11)$ & 0.613 \\
Histology (squamous vs adenocarcinoma) & $0.14(0.03-0.62)$ & 0.010 \\
Histology (NOS vs adenocarcinoma) & $0.90(0.43-1.90)$ & 0.784 \\
Treatment regimen (non-taxane vs low dose cisplatin) & $0.84(0.41-1.74)$ & 0.641 \\
Treatment regimen (taxane vs low dose cisplatin) & $0.28(0.04-2.19)$ & 0.226 \\
\hline
\end{tabular}

$\mathrm{N}$ : number; OR: odds ratio; $\mathrm{Cl}$ : confidence interval; T: tumour; $\mathrm{N}$ : node; NOS: not otherwise specified.

Table S4.4 Multivariate logistic regression analysis for brain metastases development including only concurrent chemo-radiation patients and comparison for the largest chemotherapy subgroups.

\begin{tabular}{|c|c|c|}
\hline \multicolumn{3}{|l|}{ Only concurrent chemoradiation patients $(\mathrm{N}=737)$} \\
\hline Brain relapse pattern & OR $(95 \% \mathrm{Cl})$ & $p$-value \\
\hline \multicolumn{3}{|l|}{ All brain relapses } \\
\hline Gender (female vs male) & $1.03(0.68-1.55)$ & 0.887 \\
\hline Age (continuous, older vs younger) & $0.98(0.96-1.00)$ & 0.065 \\
\hline T-stage (T3-4 vs T0-2) & $1.12(0.78-1.80)$ & 0.417 \\
\hline $\mathrm{N}$-stage (N2-3 vs N0-1) & $1.91(0.91-4.02)$ & 0.089 \\
\hline Histology (squamous vs adenocarcinoma) & $0.19(0.10-0.35)$ & $<0.001$ \\
\hline Histology (NOS vs adenocarcinoma) & $0.68(0.44-1.07)$ & 0.092 \\
\hline Treatment regimen (cis/vino \pm cetuximab vs low dose cisplatin) & $1.06(0.52-2.16)$ & 0.870 \\
\hline Treatment regimen (cis/eto vs low dose cisplatin) & $1.28(0.82-2.00)$ & 0.285 \\
\hline Treatment regimen (cis/docetaxel vs low dose cisplatin) & $0.73(0.32-1.68)$ & 0.459 \\
\hline \multicolumn{3}{|l|}{ All brain relapses within one year } \\
\hline Gender (female vs male) & $1.35(0.82-2.23)$ & 0.245 \\
\hline Age (continuous, older vs younger) & $0.98(0.95-1.00)$ & 0.093 \\
\hline T-stage (T3-4 vs T0-2) & $1.50(0.90-2.51)$ & 0.124 \\
\hline $\mathrm{N}$-stage (N2-3 vs N0-1) & $1.71(0.71-4.09)$ & 0.230 \\
\hline Histology (sqamous vs adenocarcinoma) & $0.22(0.09-0.51)$ & $<0.001$ \\
\hline Histology (NOS vs adenocarcinoma) & $1.02(0.60-1.73)$ & 0.950 \\
\hline Treatment regimen (cis/vino \pm cetuximab vs low dose cisplatin) & $1.28(0.57-2.87)$ & 0.544 \\
\hline Treatment regimen (cis/eto vs low dose cisplatin) & $1.23(0.71-2.14)$ & 0.468 \\
\hline Treatment regimen (cis/docetaxel vs low dose cisplatin) & $0.53(0.16-1.84)$ & 0.319 \\
\hline \multicolumn{3}{|l|}{ Brain as the only site of first relapse within one year } \\
\hline Gender (female vs male) & $1.91(0.92-3.98)$ & 0.084 \\
\hline Age (continuous, older vs younger) & $0.96(0.93-1.00)$ & 0.027 \\
\hline T-stage (T3-4 vs T0-2) & $2.67(1.19-6.00)$ & 0.017 \\
\hline $\mathrm{N}$-stage (N2-3 vs N0-1) & $0.77(0.28-2.12)$ & 0.616 \\
\hline Histology (squamous vs adenocarcinoma) & $0.14(0.03-0.62)$ & 0.010 \\
\hline Histology (NOS vs adenocarcinoma) & $0.84(0.39-1.82)$ & 0.666 \\
\hline Treatment regimen (cis/vino \pm cetuximab vs low dose cisplatin) & $0.65(0.18-2.33)$ & 0.511 \\
\hline Treatment regimen (cis/eto vs low dose cisplatin) & $0.86(0.37-1.97)$ & 0.715 \\
\hline Treatment regimen (cis/docetaxel vs low dose cisplatin) & $0.35(0.04-2.76)$ & 0.317 \\
\hline
\end{tabular}

$\mathrm{N}$ : number; OR: odds ratio; $\mathrm{Cl}$ : confidence interval; $\mathrm{T}$ : tumour; $\mathrm{N}$ : node; NOS: not otherwise specified; cis: cisplatin; vino: vinorelbin; eto: etoposide 


\title{
Chapter 5
}

\section{Single organ metastatic disease and local}

\author{
disease status, prognostic factors for overall
}

survival in stage IV non-small cell lung cancer:

results from a population-based study

Lizza E.L. Hendriks*, Jules L. Derks*, Piet E. Postmus, Ronald A. Damhuis, Ruud M.A. Houben, Esther G.C. Troost, Monique M. Hochstenbag, Egbert F. Smit, Anne-Marie C. Dingemans

* authors contributed equally to the manuscript 


\section{ABSTRACT}

\section{Purpose}

To analyze the prognostic impact on overall survival (OS) of single versus multiple organ metastases, organ affected, and local disease status in a population based stage IV NSCLC cohort.

\section{Methods}

In this observational study, data were analyzed of all histologically confirmed stage IV NSCLC patients diagnosed between 1-1-2006 and 31-12-2012 registered in the Netherlands Cancer Registry. Location of metastases before treatment was registered. Multivariable survival analyses [age, gender, histology, M-status, local disease status, number of involved organs, actual organ affected] were performed for all patients and for an ${ }^{18}$ FDG-PET-staged subgroup.

\section{Results}

11094 patients were selected: $60 \%$ male, mean age 65 years, $73 \%$ adenocarcinoma. Median OS for $1(\mathrm{~N}=5676), 2(\mathrm{~N}=3280)$, and $\geq 3(\mathrm{~N}=2138)$ metastatically affected organs was $6.7,4.3,2.8$ months, respectively $(p<0.001)$. Hazard ratio (HR) for 2 versus 1 organ(s) was $1.33(p<0.001)$, for $\geq 3$ versus 1 organ(s) 1.91 ( $p<0.001)$. Results were confirmed in the ${ }^{18}$ FDG-PET-staged cohort $(\mathrm{N}=1517)$ : patients with single organ versus 2 and $\geq 3$ organ metastases had higher OS $(8.6,5.7$, 3.8 months, HR 1.40 and 2.17 , respectively, $p<0.001$ ). In single organ metastases, OS for low versus high TN-status was 8.5 versus 6.5 months [HR $1.40(p<0.001)] .{ }^{18} \mathrm{FDG}$-PET-staged single organ metastases patients with low TN-status had a superior OS than those with high TN-status (11.6 versus 8.2 months, HR 1.62, $p<0.001$ ).

\section{Conclusion}

Patients with single organ metastases stage IV NSCLC have a favorable prognosis, especially in combination with low TN status. They have to be regarded as a separate subgroup of stage IV disease. 


\section{INTRODUCTION}

The tumor, node, and metastasis (TNM) classification of non-small cell lung cancer (NSCLC) is a prognostic tool to stratify patients. The current $7^{\text {th }}$ edition is based on an analysis of a retrospective worldwide database of more than 100,000 cases including data from clinical trials, consortium/surgical series, and registry-series. ${ }^{1,2}$ Currently, within stage IV two prognostically different subgroups are distinguished; M1a (intrathoracic: pleural and/or pericardial dissemination and/or metastasis to contralateral lung) and M1b (distant metastasis), with median overall survival (OS) of 8 and 6 months, respectively. ${ }^{1,2}$ In the $M 1 b$ group $(\mathrm{N}=4350)$, median OS was slightly worse for patients with multiple distant metastatic sites compared to a single site. No OS difference regarding the actual organ affected was encountered in the single organ metastases subgroup ( $\mathrm{N}=2480)$; it was not possible to analyze impact of single versus multiple sites in a specific organ. ${ }^{2}$ Currently, there is a lack of data gathered in routine clinical practice regarding the prognostic value of the extent of metastases in population based stage IV NSCLC cohorts and it is not clear whether results are comparable for ${ }^{18}$ fluorodeoxyglucose-positron emission tomography ( ${ }^{18}$ FDG-PET)staged patients, due to possible upstaging. ${ }^{3}$

The Netherlands Cancer Registry (NCR) has registered all patients diagnosed with cancer in the Netherlands since 1989 and has $98 \%$ nationwide coverage. In contrast to TNM7, metastatic sites at time of NSCLC diagnosis are standardly recorded according to clinical data. ${ }^{4}$ Here, we analyzed the prognostic impact of single versus multiple organs with metastases, local disease status, and impact of the actual organ affected in stage IV NSCLC.

\section{MATERIALS AND METHODS}

\section{PATIENT SELECTION: NCR}

All patients diagnosed between 1-1-2006 and 31-12-2012 with NSCLC (adenocarcinoma $(\mathrm{AdC})$ and squamous cell carcinoma (SqCC)) were selected. Only histology was selected to avoid cytological classification bias. Large cell carcinoma (LCC) was not selected because of recent evidence separating $80 \%$ of LCC into AdC/SqCC, possibly introducing classification bias. ${ }^{5}$ Data retrieval was on 21-03-2014.

Data have been actively collected by data managers according to standardized formats and have been linked to the Dutch Pathology Registry and National Civil Registry for follow-up and histology confirmation. ${ }^{4}$ Information includes: gender; age; diagnosis year; morphology code; stage (until 2009 TNM6, 22010 TNM7); first-line treatment; diagnosis of previous malignancy, and metastases localization at diagnosis. Metastases sites are recorded according to documented clinical data with maximal three separate 
locations. In cases with more than three locations, the first two are recorded and the last is coded as $\geq 3$ metastases. Organ count is irrespective of number of metastases within this organ. Reporting of staging procedures as ${ }^{18}$ FDG-PET or magnetic resonance imaging (MRI) brain is not mandatory.

Excluded were: no TNM recorded, previous malignancy within five years of NSCLC, metachronous NSCLC, stage IV NSCLC according to TNM6 solely based on pulmonary metastases (possibly TNM7 T4, i.e. no stage IV), no metastases sites documentation, and no Civil Registry linkage.

Subgroup analyses were performed in patients in whom an ${ }^{18}$ FDG-PET-scan was documented to investigate upstaging effects. ${ }^{3}$ Separate subgroup analyses were performed for TNM6 and TNM7 when required, as some changes in TNM7 T-classification occurred. To analyze impact of anticancer treatment an exploratory analysis was performed in patients receiving active anticancer treatments as opposed to best supportive care (BSC) only. Palliative radiotherapy without systemic treatment was classified as BSC. Study approval was by the NCR data monitoring committee and procedures were performed according to national privacy regulations.

\section{STATISTICAL ANALYSIS}

Statistical analysis was conducted with SPSS (v20; SPSS Inc., Chicago, IL). OS was calculated from day of diagnosis till death and analysed according to the Kaplan-Meier method and tested for significance with log-rank test. Patients who were alive at closing date (31-12-2012) or who were lost-to-follow-up were censored at last date of follow-up. A multivariate Cox regression model was constructed including covariates that were found significant in univariate analyses. Covariates tested were: age, gender, histology, TNM7 M1b versus M1a and TNM6 M1, low TN-stage versus high TN-stage (i.e., T1-2 and N0-1 versus T3-4 and/or N2-3), number of organs with metastases (i.e., 1, 2 or $\geq 3$ ) and within single organ metastases also actual organ affected. Proportional hazard assumption was tested using visual inspection of Log (minus Log) survival plots. Continuous variables were compared with the Mann Whitney U-test; categorical data were tested according to the chi-square test. $P$ values of $\leq 0.05$ for two-sided tests were considered statistically significant.

\section{RESULTS}

\section{PATIENT CHARACTERISTICS}

Between 01-01-2006 and 31-12-2012, 11094 stage IV patients were eligible for analysis (CONSORT diagram, Figure 5.1).

Patient characteristic are described in Table 5.1. 5676 (51.2\%) had single organ metastases. Median follow up [95\% Cl] was 28.1 [26.7-29.5] months. At time of analysis 
$1742(15.7 \%)$ patients were alive and 5 were lost-to-follow-up. Bone was the most frequent metastatic site at diagnosis. Significantly more common in AdC than in SqCC were: bone $(43.0 \%$ versus $36.5 \%, p<0.001)$, brain $(22.0 \%$ versus $15.1 \%, p<0.001)$, pleura (15.9\% versus $12.6 \%, p<0.001$ ), and lymph node metastases (only current M1b lymph nodes included) ( $11.6 \%$ versus $10.1 \%, p=0.03$ ) (Figure $5.2 \mathrm{~A}$ ).

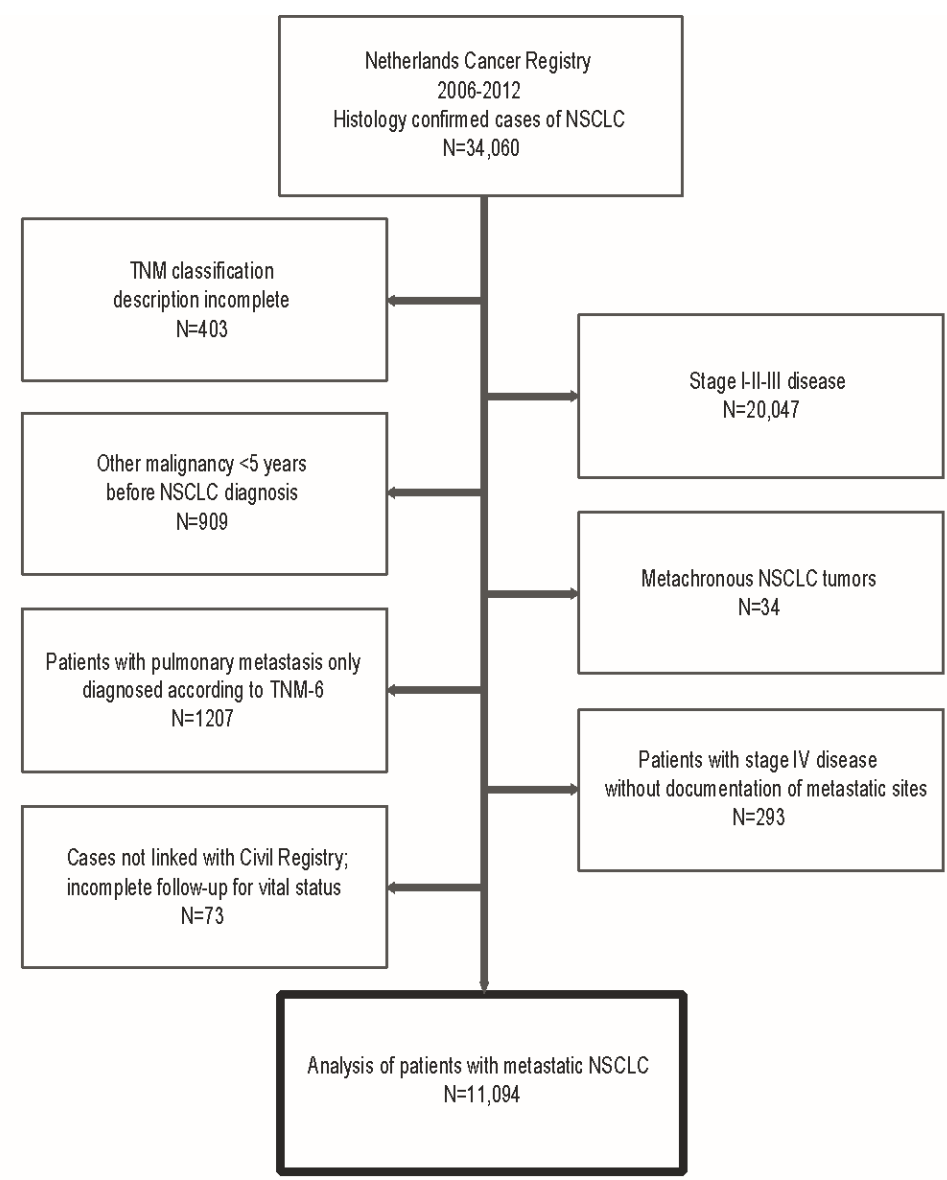

Figure 5.1 CONSORT diagram presenting the selection of stage IV NSCLC patients between 2006 and 2012 from the Netherlands Cancer Registry database. NSCLC: non-small cell lung cancer. 
Table 5.1 Patient characteristics stage IV NSCLC.

\begin{tabular}{|c|c|c|c|c|c|c|}
\hline \multirow{2}{*}{$\begin{array}{l}\text { Patient characteristic } \\
\text { Subgroup }\end{array}$} & \multicolumn{3}{|c|}{ Total group } & \multicolumn{3}{|c|}{ Single organ metastases } \\
\hline & Total & AdC & $\mathrm{SqCC}$ & Total & AdC & $\mathrm{SqCC}$ \\
\hline Patient number $(\mathrm{N})$ & 11094 & 8134 & 2960 & 5676 & 3915 & 1761 \\
\hline Age (years) Mean \pm SD & $65.4 \pm 10.7$ & $64.2 \pm 10.8$ & $68.7 \pm 9.9$ & $66.1 \pm 10.8$ & $64.7 \pm 10.9$ & $69.2 \pm 9.9$ \\
\hline \multicolumn{7}{|l|}{ Categories (N (\%)) } \\
\hline$<50$ years & 877 (7.9) & 775 (9.5) & $102(3.4)$ & $419(7.4)$ & $359(9.2)$ & $60(3.4)$ \\
\hline$\geq 50$ and $<60$ years & $2325(21.0)$ & $1904(23.4)$ & $421(14.2)$ & $1113(19.6)$ & $881(22.5)$ & $232(13.2)$ \\
\hline$\geq 60$ and $<70$ years & $3721(33.5)$ & $2767(34.0)$ & $954(32.2)$ & $1836(32.3)$ & 1289 (32.9) & $547(31.1)$ \\
\hline$\geq 70$ & $4171(37.6)$ & $2688(33.0)$ & $1483(50.1)$ & $2308(40.7)$ & $1386(35.4)$ & $922(52.4)$ \\
\hline \multicolumn{7}{|l|}{ Gender (N (\%)) } \\
\hline Male & $6625(59.7)$ & $4464(54.9)$ & $2171(73.0)$ & 3389 (59.7) & $2089(53.4)$ & $1300(73.8)$ \\
\hline \multicolumn{7}{|l|}{ T-stage (N (\%)) } \\
\hline TNM6 & $4584(100.0)$ & $3321(100.0)$ & $1263(100.0)$ & $2089(100.0)$ & $1433(100.0)$ & $656(100.0)$ \\
\hline $0 / X$ & $525(11.5)$ & $417(12.6)$ & $108(8.6)$ & $244(11.7)$ & $194(13.5)$ & $50(7.6)$ \\
\hline 1 & $481(10.5)$ & $417(12.6)$ & $64(5.1)$ & 270 (12.9) & $231(16.1)$ & $39(5.9)$ \\
\hline 2 & $1476(32.2)$ & 1025 (30.9) & $451(35.7)$ & 729 (34.9) & $464(32.4)$ & $265(40.4)$ \\
\hline 3 & $314(6.8)$ & $186(5.5)$ & $128(10.1)$ & 164 (7.9) & $100(7.0)$ & $64(9.8)$ \\
\hline 4 & $1788(39.0)$ & $1276(38.4)$ & $512(40.5)$ & $682(32.6)$ & $444(31.0)$ & $238(36.3)$ \\
\hline TNM7 & $6510(100.0)$ & $4813(100.0)$ & $1697(100.0)$ & $3587(100.0)$ & $2482(100.0)$ & $1105(100.0)$ \\
\hline $0 / X$ & $608(9.3)$ & $509(10.6)$ & $99(5.8)$ & $338(9.4)$ & $283(11.4)$ & $55(5.0)$ \\
\hline $1 a$ & $312(4.8)$ & 285 (5.9) & $27(1.6)$ & $186(5.2)$ & $167(6.7)$ & $19(1.7)$ \\
\hline $1 b$ & $383(5.9)$ & 330 (6.9) & $53(3.1)$ & $237(6.6)$ & $196(7.9)$ & $41(3.7)$ \\
\hline $2 a$ & $1205(18.5)$ & 910 (18.9) & 295 (17.4) & $718(20.0)$ & $509(20.5)$ & 209 (18.9) \\
\hline $2 b$ & 439 (6.7) & $305(6.3)$ & $134(7.9)$ & $257(7.2)$ & $161(6.5)$ & $96(8.7)$ \\
\hline 3 & $1257(19.3)$ & 851 (17.7) & 406 (23.9) & $727(20.3)$ & $467(18.8)$ & $260(23.5)$ \\
\hline 4 & $2306(35.5)$ & $1623(33.7)$ & $683(40.3)$ & $1124(31.3)$ & $699(28.2)$ & 425 (38.5) \\
\hline \multicolumn{7}{|l|}{$\mathrm{N}$-stage (N (\%)) } \\
\hline $0 / x$ & $2769(25.0)$ & $2036(25.0)$ & $733(24.8)$ & $1733(30.5)$ & 1250 (31.9) & $483(27.4)$ \\
\hline 1 & $732(6.6)$ & $527(6.5)$ & $205(6.9)$ & $421(7.4)$ & $292(7.5)$ & $129(7.3)$ \\
\hline 2 & 4418 (39.8) & 3138 (38.6) & $1280(43.2)$ & $2155(38.0)$ & $1403(35.8)$ & $752(42.7)$ \\
\hline 3 & 3175 (28.6) & 2433 (29.9) & $742(25.1)$ & $1367(24.1)$ & $970(24.8)$ & $397(22.5)$ \\
\hline \multicolumn{7}{|l|}{ M-stage (N (\%)) } \\
\hline \multicolumn{7}{|l|}{ TNM6 } \\
\hline 1 & $4584(100.0)$ & $3321(100.0)$ & $1263(100.0)$ & $2089(100.0)$ & $1433(100.0)$ & $656(100.0)$ \\
\hline TNM7 & $6500(100.0)$ & $4813(100.0)$ & $1697(100.0)$ & $3587(100.0)$ & $2482(100.0)$ & $1105(100.0)$ \\
\hline $1 a$ & $1419(21.8)$ & 957 (19.9) & $462(27.2)$ & 1323 (36.9) & $872(35.1)$ & $451(40.8)$ \\
\hline $1 b$ & $5091(78.2)$ & $3856(80.1)$ & $1235(72.8)$ & $2264(63.1)$ & $1610(64.9)$ & $654(59.2)$ \\
\hline \multirow{2}{*}{\multicolumn{7}{|c|}{$\begin{array}{l}\text { No of organs with } \\
\text { metastases (N (\%)) }\end{array}$}} \\
\hline & & & & & & \\
\hline 1 & $5676(51.2)$ & $3859(47.4)$ & $1761(59.5)$ & N/A & N/A & $\mathrm{N} / \mathrm{A}$ \\
\hline 2 & $3280(29.6)$ & $2480(30.5)$ & $798(27.0)$ & & & \\
\hline$\geq 3$ & $2138(19.3)$ & $1795(22.1)$ & $401(13.5)$ & & & \\
\hline
\end{tabular}

TNM: tumour, node, metastasis; N; number; SD: standard deviation; AdC: adenocarcinoma; SqCC: squamous cell carcinoma; No: number; N/A; not applicable

Single organ metastases patients $(\mathrm{N}=5676)$ were significantly older (mean age 66.1 versus 64.7 years, $p<0.001)$ and more often had SqCC (31.0\% versus $22.1 \%, p<0.001)$ and lower TN-status (18.3\% versus 9.8\%, $p<0.001$, Table 5.1 ) than patients with $\geq 2$ organ metastases $(\mathrm{N}=5418)$. In single organ metastases patients, bone $(28.7 \%$ versus 
$25.9 \%, p=0.031)$, brain $(21.4 \%$ versus $14.1 \%, p<0.001)$, and pleural metastases $(15.1 \%$ versus $11.9 \%, p=0.010$ ) were significantly more common in AdC compared to SqCC, liver $(7.7 \%$ versus $11.3 \%, p<0.001)$, adrenal $(7.1 \%$ versus $9.3 \%, p=0.006)$, and lung metastases $(12.3 \%$ versus $18.2 \%, p<0.001)$ were significantly less common in AdC (Figure 5.2B).
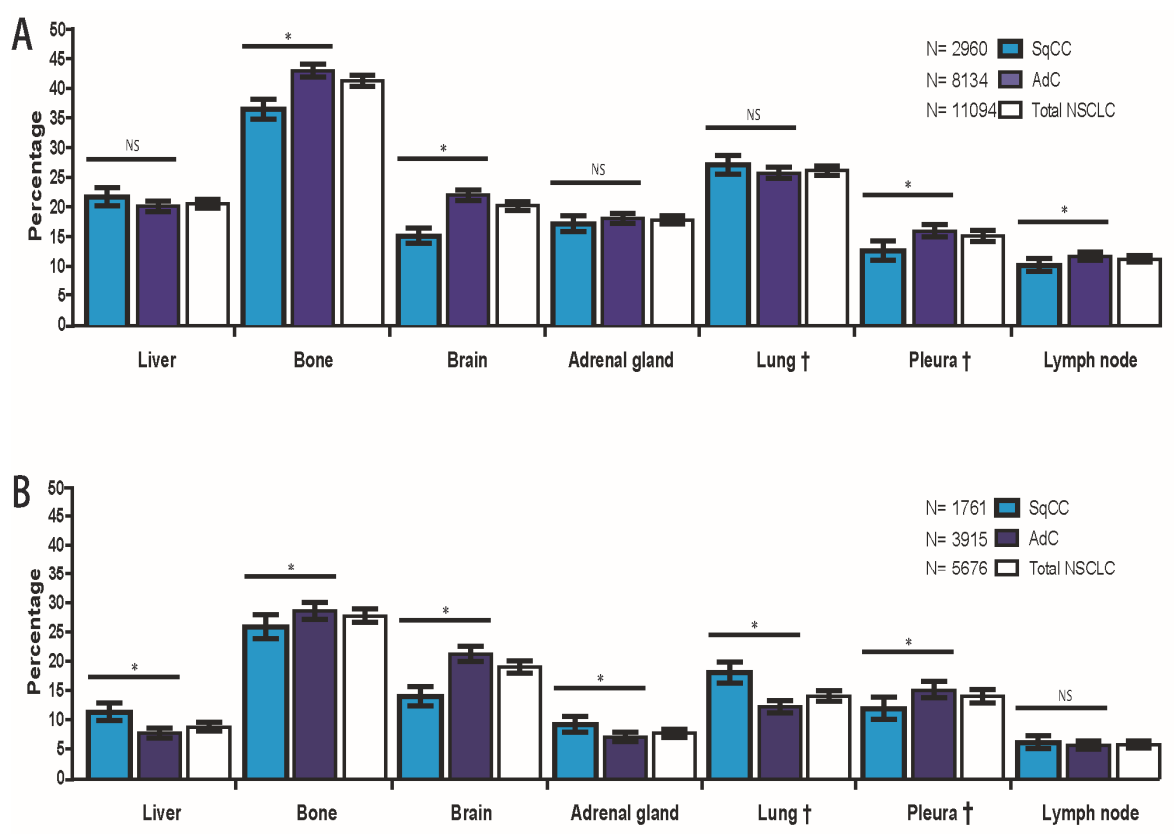

Figure 5.2 A. Prevalence of actual organ with metastases in the total group, and the AdC and SqCC subgroups (one patient can have more than one organ metastases). AdC is compared with SqCC.

B. Prevalence of actual organ with metastases in the single organ metastases group, and the AdC and SqCC subgroups. AdC is compared with SqCC. + Analyzed only in TNM-7; * Significant, $p<0.05$ Chi-square test. AdC: adenocarcinoma; SqCC: squamous cell carcinoma; N: number; NSCLC: non-small cell lung cancer;

\section{TNM6 AND TNM7 OVERALL SURVIVAL}

Median OS for TNM6 ( $\mathrm{N}=4584)$ did not significantly differ from TNM7 M1b ( $N=5091)$ (4.6 [4.4-4.8] versus 4.7 [4.4-4.9] months; $p=0.13$ ). Median OS was significantly higher in TNM7 M1a (N=1419) (8.3 [7.6-9.0] months; $p<0.001)$ than in TNM6 and TNM7 M1b.

\section{OVERALL SURVIVAL ACCORDING TO NUMBER OF ORGANS AFFECTED}

Median OS was significantly longer in single organ metastases patients $(\mathrm{N}=5676)$ compared to patients with $2(\mathrm{~N}=3280)$ or $\geq 3$ organs with metastases $(\mathrm{N}=2138)$ (6.7 [6.4-7.0], 4.3 [4.1-4.6], and 2.8 [2.6-3.0] months, respectively; $p<0.001$; Figure 
5.3A). In multivariate analysis this remained significant. $\mathrm{HR}[95 \% \mathrm{Cl}]$ for 2 organs versus 1 was 1.38 [1.31-1.44] $(p<0.001)$ and 1.97 [1.86-2.09] for $\geq 3$ organs versus $1(p<0.001)$. Other independent favorable factors for OS were younger age, female gender, AdC, TNM7 M1a, and low TN-status (Suppl. Figure S5.1A).
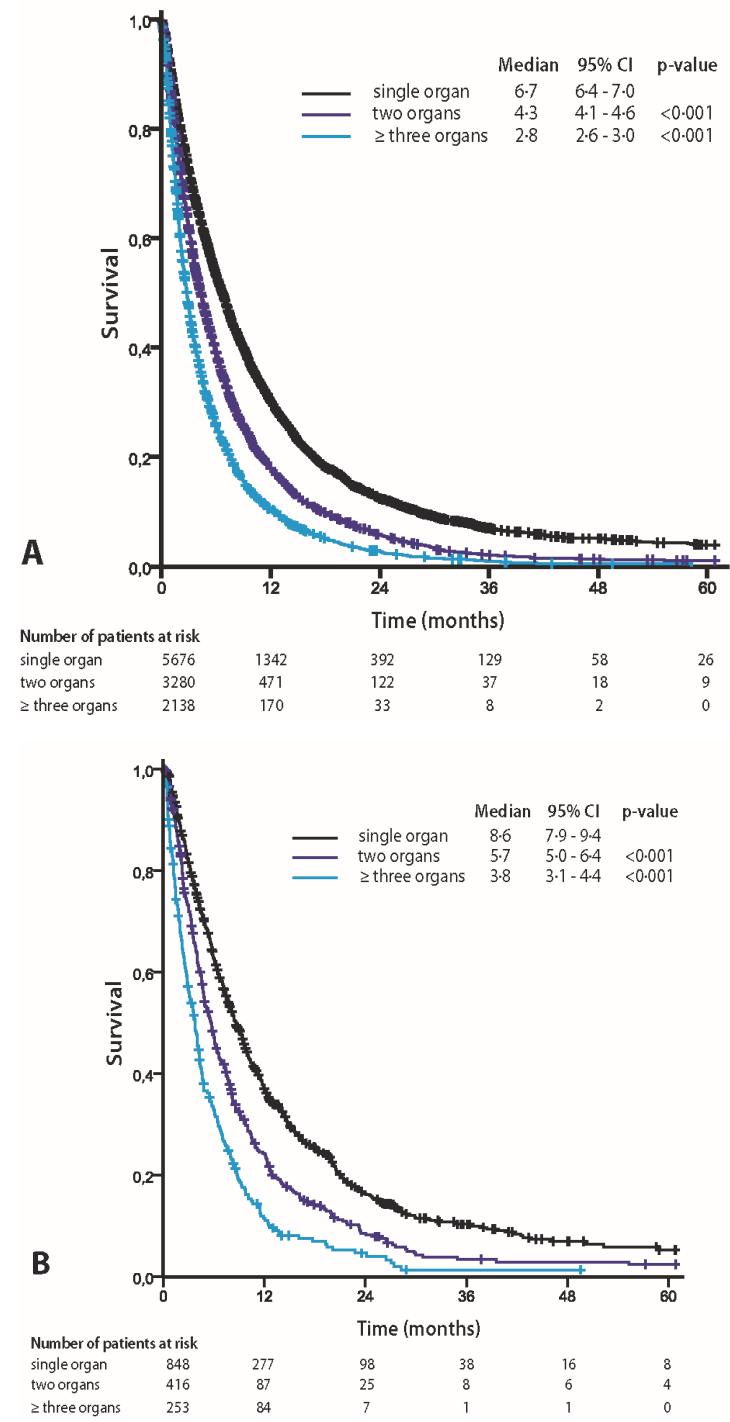

Figure 5.3 A. Kaplan Meier curves for the overall cohort according to number of organs with metastases $(1,2$, and $\geq 3)$.

B. Kaplan Meier curves for the ${ }^{18}$ FDG-PET-staged subgroup according to number of organs with metastases $(1,2$, and $\geq 3)$. 
In patients with a documented staging ${ }^{18}$ FDG-PET-scan ( $\left.\mathrm{N}=1517\right)$, OS was superior to that of the group in which it was not documented whether a staging ${ }^{18}$ FDG-PET-scan was performed ( $\mathrm{N}=9577)$. For the latter group, OS was 6.4 [6.1-6.7], 4.1 [3.9-4.4] and 2.7 [2.6-2.9] months $(p<0.001)$ for single organ, 2 organs and $\geq 3$ organs with metastases, respectively. For the documented ${ }^{18}$ FDG-PET-scan group OS was 8.6 [7.9-9.4], 5.7 [5.0-6.4], and 3.8 [3.1-4.4] months, respectively; $p<0.001$, Figure 5.3B). In multivariate analysis HR for 2 versus 1 organ(s) $\{1.40$ [1.23-1.60] $(p<0.001)\}$, and for $\geq 3$ versus 1 organ(s) $\{2.17$ [1.85-2.55] $(p<0.001)\}$ remained significant. Other independent favorable factors for OS were identical to those for no documented ${ }^{18}$ FDG-PET-scan group (Suppl. Figure S5.1B).

\section{OVERALL SURVIVAL IN SINGLE ORGAN METASTASES PATIENTS ACCORDING TO LOCAL DISEASE STATUS AND IMPACT OF SPECIFIC ORGAN AFFECTED}

Median OS was significantly higher in patients with low TN-status ( $N=1043)$ and was 8.5 [7.6-9.3] months compared to 6.5 [6.2-6.8] months for high TN-status ( $\mathrm{N}=4375)$ $(p<0.001$, Figure 5.4A). In multivariate analysis, this retained its prognostic value: high versus low TN-status HR 1.40 [1.29-1.51] $(p<0.001)$. Other independent favorable factors were younger age, female gender, and AdC. Liver metastases were an unfavorable prognostic factor, whereas adrenal, pulmonary, and pleural disease as well as lymph node metastases were favorable factors (Figure 5.5A).

When TNM6 $(\mathrm{N}=2089)$ and TNM7 $(\mathrm{N}=3587)$ classified patients were analyzed separately, low TN-status had a superior median OS compared to high TN-status in both TNM6 (7.5 [6.2-8.8] versus 5.8 [5.3-6.2] months, respectively; $p<0.001)$ and TNM7 (9.6 [8.3-10.8] versus 7.0 [6.5-7.4] months, respectively; $p<0.001$ ).

Patients with documented ${ }^{18}$ FDG-PET-scans $(\mathrm{N}=848)$ had superior OS compared to the total single organ metastases group $(p<0.001)$. Median OS differences for low versus high TN-status remained significant (11.6 [8.1-15.1] months and 8.2 [7.3-9.1] months, respectively; $p<0.001$, Figure $5.4 \mathrm{~B}$ ). In multivariate analysis, $\mathrm{TN}$-status remained of prognostic significance (high versus low TN-status: HR 1.62 [1.31-1.99], $p<0.001$ ). Other independent favorable factors were younger age and female gender. Metastatic disease in brain, lungs, pleura or lymph nodes was a favorable prognostic factor (Figure 5.5B).

When TNM6 and TNM7 classified patients were analyzed separately, median OS for TNM6 low TN-status ( $\mathrm{N}=81$ ) was 12.5 [8.4-16.5] months compared to 7.0 [6.2-7.8] months for high TN-status $(\mathrm{N}=300)(p<0.001)$. For TNM7 median OS was 10.1 [5.6-14.6] months for low $(\mathrm{N}=83)$ and 9.7 [8.1-11.2] months for high TN-status $(\mathrm{N}=357)(p=0.121)$. 

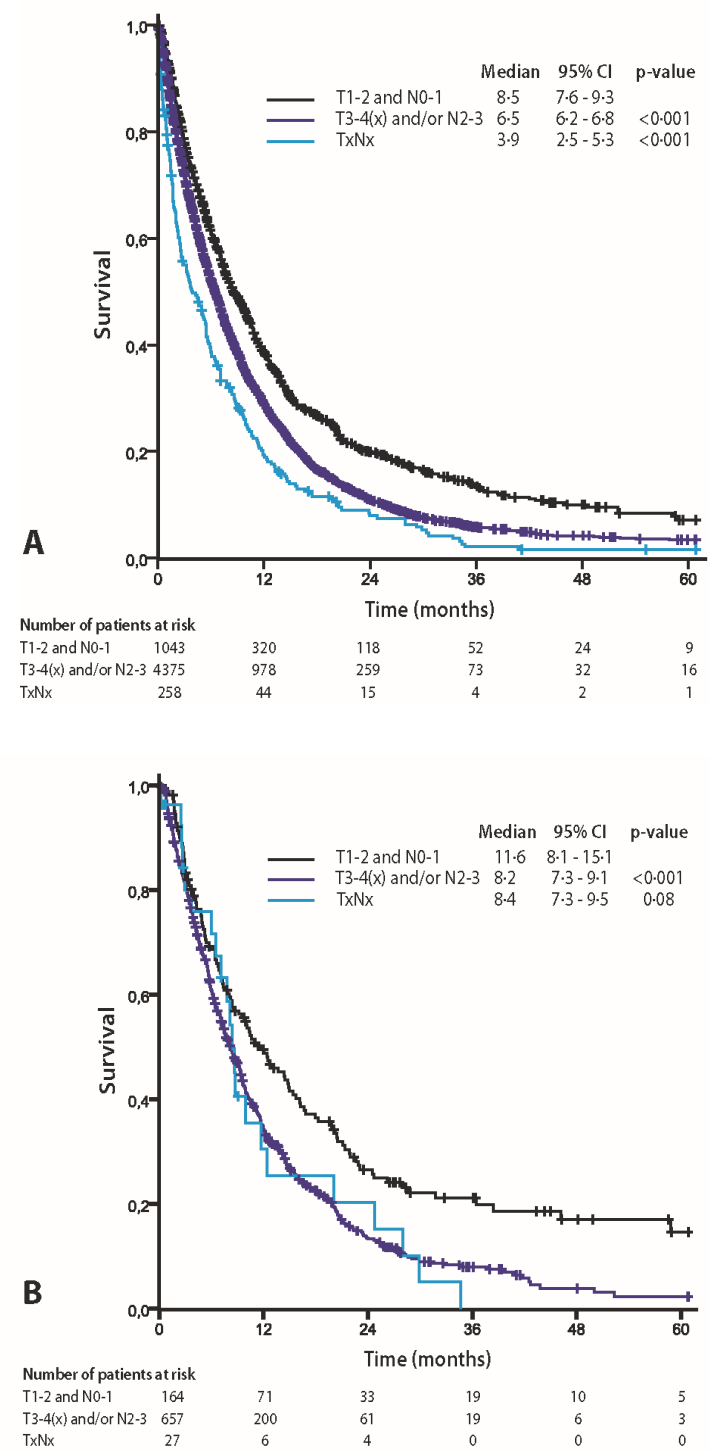

Figure 5.4 A. Kaplan Meier curves for the single organ metastases group according to local disease status. B. Kaplan Meier curves for the single organ metastases ${ }^{18}$ FDG-PET-staged subgroup according to local disease status. T: tumour; $\mathrm{N}$ : node; $\mathrm{Cl}$ : confidence interval. 


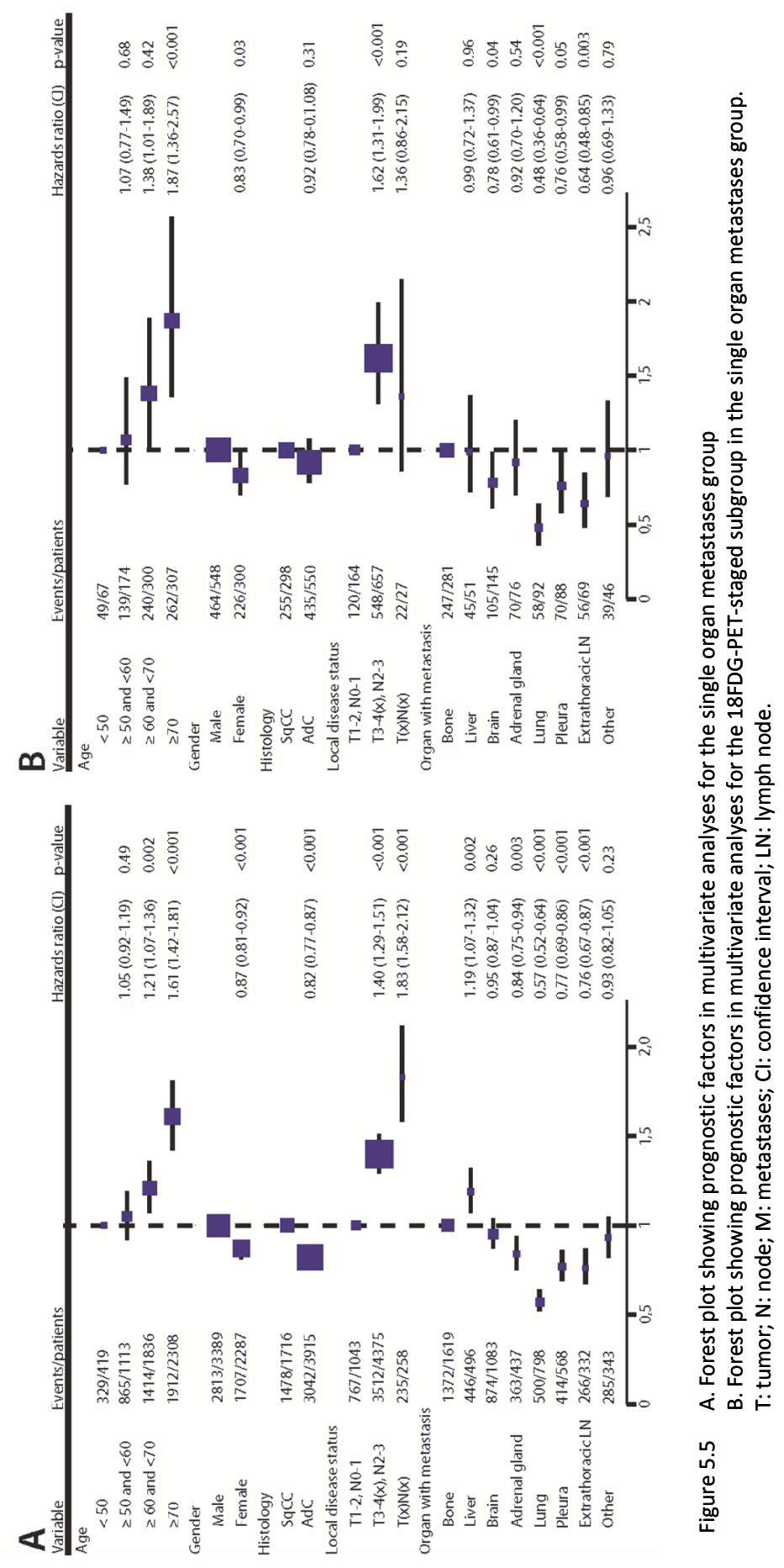




\section{SUBGROUP OF PATIENTS RECEIVING ACTIVE ANTICANCER TREATMENT}

Patients receiving active anticancer treatment $(\mathrm{N}=6022)$ had a superior median OS compared to the BSC group (median 8.4 versus 2.2 months, $p<0.001$ ).

Single organ metastases patients $(\mathrm{N}=3206)$ had a significantly superior OS compared to patients with $2(\mathrm{~N}=1791)$ or $\geq 3$ organs $(\mathrm{N}=1025)$ involved. Median OS was 10.4 [10.010.8], 7.3 [7.0-7.7], and 5.7 [5.3-6.1] months, respectively $(p<0.001$, Suppl. Figure S5.2A). For the ${ }^{18}$ FDG-PET-staged subgroup this was 11.7 [10.5-12.9], 8.1 [7.2-9.0] and 6.4 [5.2-7.6] months, respectively $(p<0.001)$.

Single organ metastases patients with low TN-status $(\mathrm{N}=547)$ had significantly higher median OS compared to high TN-status ( $\mathrm{N}=2581)$ : 13.7 [12.5-14.9] versus 9.9 [9.4-10.3] months, respectively ( $p<0.001$, Suppl. Figure S5.2B). For the ${ }^{18}$ FDG-PET-staged subgroup this was 14.4 [11.2-17.5] and 9.2 [8.6-9.8] months, respectively $(p<0.001)$.

\section{DISCUSSION}

In this large population-based study NSCLC patients with single organ metastases, in particular with low TN-status, had a superior median OS compared to those with multiple organs with metastases. These results add to results obtained by Albain et al. ${ }^{6}\left(\mathrm{~N}=2531\right.$, retrospective multicenter study), Jeremic et al. ${ }^{7}(\mathrm{~N}=285$, retrospective single center study), Sanchez de Cos Esquin et al. ${ }^{8}$ ( $\mathrm{N}=640$ (18\% ${ }^{18}$ FDG-PET staged), prospective observational multiregional study), Oh et $a l^{9}{ }^{9}(\mathrm{~N}=1284$, retrospective single center study), Paralkar et al. ${ }^{10}\left(\mathrm{~N}=172\left(10 \%{ }^{18} \mathrm{FDG}-\mathrm{PET}\right.\right.$ staged), retrospective single tertiary center study), Pirker et al. ${ }^{11}$ ( $N=1125$, FLEX study: chemotherapy with/without cetuximab) and Parikh et al. ${ }^{12}(\mathrm{~N}=186$, prospective single center study including only oligometastatic ${ }^{18}$ FDG-PET-staged NSCLC patients). However, compared to these studies, our study is population-based and includes the largest ${ }^{18}$ FDG-PET staged subgroup ( $\mathrm{N}=1517)$. Also in this subgroup the same prognostic factors were found.

In all previously reported studies, patients with single organ metastases had a better prognosis than those with metastasis to more than one organ. Only in one study impact of N-status was evaluated: patients with N0-1 disease had better outcome. ${ }^{12}$ In two other studies ( $\mathrm{N}=67149$ and $\mathrm{N}=850) \mathrm{N}$-status was evaluated, in one in the current $\mathrm{M} 1 \mathrm{a}$ group only. ${ }^{13,14}$ Nodal disease was a negative prognostic factor. However, number of metastatic sites was not (extensively) evaluated. ${ }^{13,14}$ Other favorable prognostic factors for OS found in our study (female gender, AdC, intrapulmonary metastases) were also identified in other studies. ${ }^{6,8,12,15-17}$

Potential explanations for better OS in single organ metastases patients is that smaller tumor load contributes to longer survival, or that the disease is found in an earlier stage, i.e. lead time bias. ${ }^{18}$ 
It is suggested that patients with single or oligometastatic brain metastases or adrenal gland metastases have a favorable prognosis with reported median OS of 12-31 months. ${ }^{15,19,20}$ In our study, patients with single organ brain or adrenal metastases did not persistently have better OS compared to patients with other organs affected. A possible explanation for the lack of survival advantage in the brain metastases group is that we were not able to differentiate between single, oligo- and multiple brain metastases. In addition, for both brain and adrenal glands data collected in the NCR do not allow for differentiation between radical versus palliative local treatment.

Local disease status was another prognostic factor for OS. In this context a recently developed Markov chain/Monte Carlo stochastic mathematical model for cancer progression is of interest. ${ }^{21}$ In this model, cancer progression is regarded as a multidirectional process instead of the commonly accepted unidirectional cancer progression (i.e. initiated at the primary tumour and stepwise progression to distant metastatic sites). For lung cancer, three types of tumor seeding were proposed: primary tumor self-seeding, metastatic location to primary tumor reseeding and metastasis reseeding with the most important metastatic pathway being lung to regional lymph nodes and adrenals. Furthermore, lymph nodes (and adrenals) were considered active re-seeders promoting dissemination. One can imagine that in this model low TN-status represents a tumor behaving less aggressively. ${ }^{21}$ Another possibility is that patients with bulky central thoracic disease die sooner because of respiratory complications. $^{22}$

As patients with single organ metastases and low TN-status had the highest OS, it is tempting to speculate whether a subgroup of these patients would achieve an even better OS when treated radically. Radical treatment is often aimed at in patients with oligometastasis in the brain or adrenal(s). However, it is not clear whether these patients by nature have a superior OS or that OS can be improved with radical treatment, as was also discussed in a recent review. ${ }^{23}$

A strong aspect of this study is that it is based on a population-based registry with over $98 \%$ case ascertainment. ${ }^{4}$ Data were collected by trained data managers including an extensive evaluation of TN-status, site specific metastases and first line treatment. Moreover, the same prognostic factors were found in the ${ }^{18}$ FDG-PET-staged subgroup and in the $\left({ }^{18}\right.$ FDG-PET-staged) active treatment subgroup.

Limitations are that although data were prospectively collected this was a retrospective analysis. Some established prognostic factors (performance status, smoking status, comorbidities), which may have influenced reported data, were not recorded in the registry. Also, only first line treatment was recorded. Second, median OS in this dataset is lower than usually reported in clinical trials reflecting the outcome of the general population. Third, the effect of ${ }^{18}$ FDG-PET-scanning could only be evaluated in a subset of patients. Fourth, under-diagnosis of brain metastases may have occurred for brain imaging has not been mandatory in the stage IV NSCLC workup. Fifth, as in other 
published studies, ${ }^{8,15-17}$ patients reported here with intrapulmonary metastases only have a relatively good prognosis. A caveat is that some of these may in fact have two primary tumours and were thus misclassified as stage IV. However, this study reflects daily practice and these patients were regarded stage IV. Moreover, when we repeated all analyses performed excluding these patients results remained comparable. Sixth, data regarding mutation analysis (e.g. EGFR) were not available. However, as percentage of non-squamous NSCLC patients with an activating EGFR-mutation is approximately $9 \%$ in the Dutch population, and the percentage of other targetable mutations or translocations is even lower, it is not likely that this has influenced our results. ${ }^{24,25}$ Seventh, the definition for the low versus high TN-groups is arbitrary, especially whether N1 should be included in the low TN-group. However, when the multivariate analyses were repeated with NO and N1 as separate groups, prognosis for the N1 group was not significantly different from the NO group (data not shown). Finally, for the TNM classification slightly changed in the $7^{\text {th }}$ edition, these changes might have influenced our results. Data to recode TNM6 into TNM7 were not available. However, results did not change significantly when we analysed TNM6 and 7 separately.

In conclusion, this hypothesis generating study shows that stage IV NSCLC patients with single organ metastases have a favorable prognosis, especially in combination with a low TN-status. Recently, the IASLC has started with the prospective collection of more detailed patient data in order to refine the TNM7. ${ }^{26}$ It would be of interest to validate our results in this dataset, as data regarding number of (organs with) metastases are collected for the new TNM classification. We suggest that, besides the already existing M1a category, patients in the M1b category are subdivided according to one versus more organs with metastases, as the largest difference in OS is found between one and two organs with metastases. If validated, this should also be considered as stratification factor in clinical trials. 


\section{REFERENCES}

1. Groome PA, Bolejack V, Crowley JJ, et al. The IASLC Lung Cancer Staging Project: validation of the proposals for revision of the $\mathrm{T}, \mathrm{N}$, and $\mathrm{M}$ descriptors and consequent stage groupings in the forthcoming (seventh) edition of the TNM classification of malignant tumours. J Thorac Oncol. 2007;2:694-705.

2. Postmus PE, Brambilla E, Chansky K, et al. The IASLC Lung Cancer Staging Project: proposals for revision of the $\mathrm{M}$ descriptors in the forthcoming (seventh) edition of the TNM classification of lung cancer. J Thorac Oncol. 2007;2:686-93.

3. Dinan MA, Curtis LH, Carpenter WR, et al. Stage migration, selection bias, and survival associated with the adoption of positron emission tomography among medicare beneficiaries with non-small-cell lung cancer, 1998-2003. J Clin Oncol. 2012;30:2725-30.

4. Visser O SS, Dijck JAAM van (editors). Incidence of cancer in the Netherlands 1999/2000, eleventh report of the Netherlands Cancer Registry. The Netherlands Cancer Registry (NCR),Vereniging van Integrale Kankercentra; 2003.

5. Rossi G, Mengoli MC, Cavazza A, et al. Large cell carcinoma of the lung: clinically oriented classification integrating immunohistochemistry and molecular biology. Virchows Arch. 2014;464:61-8.

6. Albain KS, Crowley JJ, LeBlanc M, et al. Survival determinants in extensive-stage non-small-cell lung cancer: the Southwest Oncology Group experience. J Clin Oncol. 1991;9:1618-26.

7. Jeremic B, Milicic B, Dagovic A, et al. Pretreatment clinical prognostic factors in patients with stage IV non-small cell lung cancer (NSCLC) treated with chemotherapy. J Cancer Res Clin Oncol. 2003;129: 114-22.

8. Sanchez de Cos Escuin J, Abal Arca J, Melchor Iniguez R, et al. Tumor, node and metastasis classification of lung cancer--M1a versus M1b--analysis of M descriptors and other prognostic factors. Lung Cancer. 2014;84:182-9.

9. Oh Y, Taylor S, Bekele BN, et al. Number of metastatic sites is a strong predictor of survival in patients with nonsmall cell lung cancer with or without brain metastases. Cancer. 2009;115:2930-2938.

10. Paralkar VR, Li T, Langer CJ. Population characteristics and prognostic factors in metastatic non-smallcell lung cancer: a Fox Chase Cancer Center retrospective. Clin Lung Cancer. 2008;9:116-121.

11. Pirker R, Pereira JR, Szczesna A, et al. Prognostic factors in patients with advanced non-small cell lung cancer: data from the phase III FLEX study. Lung Cancer. 2012;77:376-382.

12. Parikh RB, Cronin AM, Kozono DE, et al. Definitive primary therapy in patients presenting with oligometastatic non-small cell lung cancer. Int J Radiat Oncol Biol Phys. 2014;89:880-887.

13. William WN, Jr., Lin HY, Lee JJ, et al. Revisiting stage IIIB and IV non-small cell lung cancer: analysis of the surveillance, epidemiology, and end results data. Chest. 2009;136:701-709.

14. Hoang $T$, Dahlberg SE, Sandler AB, et al. Prognostic models to predict survival in non-small-cell lung cancer patients treated with first-line paclitaxel and carboplatin with or without bevacizumab. J Thorac Oncol. 2012;7:1361-1368.

15. Collaud S, Stahel R, Inci I, et al. Survival of patients treated surgically for synchronous single-organ metastatic NSCLC and advanced pathologic TN stage. Lung Cancer. 2012;78:234-238.

16. Peng $\mathrm{H}, \mathrm{Ma} \mathrm{M}, \mathrm{Han}$ B. [Survival analysis of 1,742 patients with stage IV non-small cell lung cancer]. Zhongguo fei ai za zhi. 2011;14:362-366.

17. Tonnies M, Pfannschmidt J, Bauer TT, et al. Metastasectomy for synchronous solitary non-small cell lung cancer metastases. Ann Thorac Surg. 2014;98:249-256.

18. Liao S, Penney $\mathrm{BC}$, Zhang $\mathrm{H}$, et al. Prognostic value of the quantitative metabolic volumetric measurement on 18F-FDG PET/CT in Stage IV nonsurgical small-cell lung cancer. Acad Radiol. 2012;19:69-77.

19. Maclean J, Fersht N, Singhera M, et al. Multi-disciplinary management for patients with oligometastases to the brain: results of a 5 year cohort study. Radiat Oncol. 2013;8:156.

20. Gray PJ, Mak RH, Yeap BY, et al. Aggressive therapy for patients with non-small cell lung carcinoma and synchronous brain-only oligometastatic disease is associated with long-term survival. Lung Cancer. 2014;85:239-44. 
21. Newton PK, Mason J, Bethel K, et al. Spreaders and sponges define metastasis in lung cancer: a Markov chain Monte Carlo mathematical model. Cancer Res. 2013;73:2760-9.

22. Higginson DS, Chen RC, Tracton G, et al. The impact of local and regional disease extent on overall survival in patients with advanced stage IIIB/IV non-small cell lung carcinoma. Int J Radiat Oncol Biol Phys. 2012;84:e385-92.

23. Palma DA, Salama JK, Lo SS, et al. The oligometastatic state-separating truth from wishful thinking. Nat Rev Clin Oncol. 2014;11:549-57.

24. Sequist LV, Heist RS, Shaw AT, et al. Implementing multiplexed genotyping of non-small-cell lung cancers into routine clinical practice. Ann Oncol. 2011;22:2616-24.

25. Kerner GS, Schuuring E, Sietsma J, et al. Common and rare EGFR and KRAS mutations in a Dutch nonsmall-cell lung cancer population and their clinical outcome. PloS One. 2013;8:e70346.

26. Rami-Porta R, Bolejack V, Giroux DJ, et al. The IASLC lung cancer staging project: the new database to inform the eighth edition of the TNM classification of lung cancer. J Thorac Oncol. 2014;9:1618-24. 


\section{SUPPLEMENTARY FIGURES}

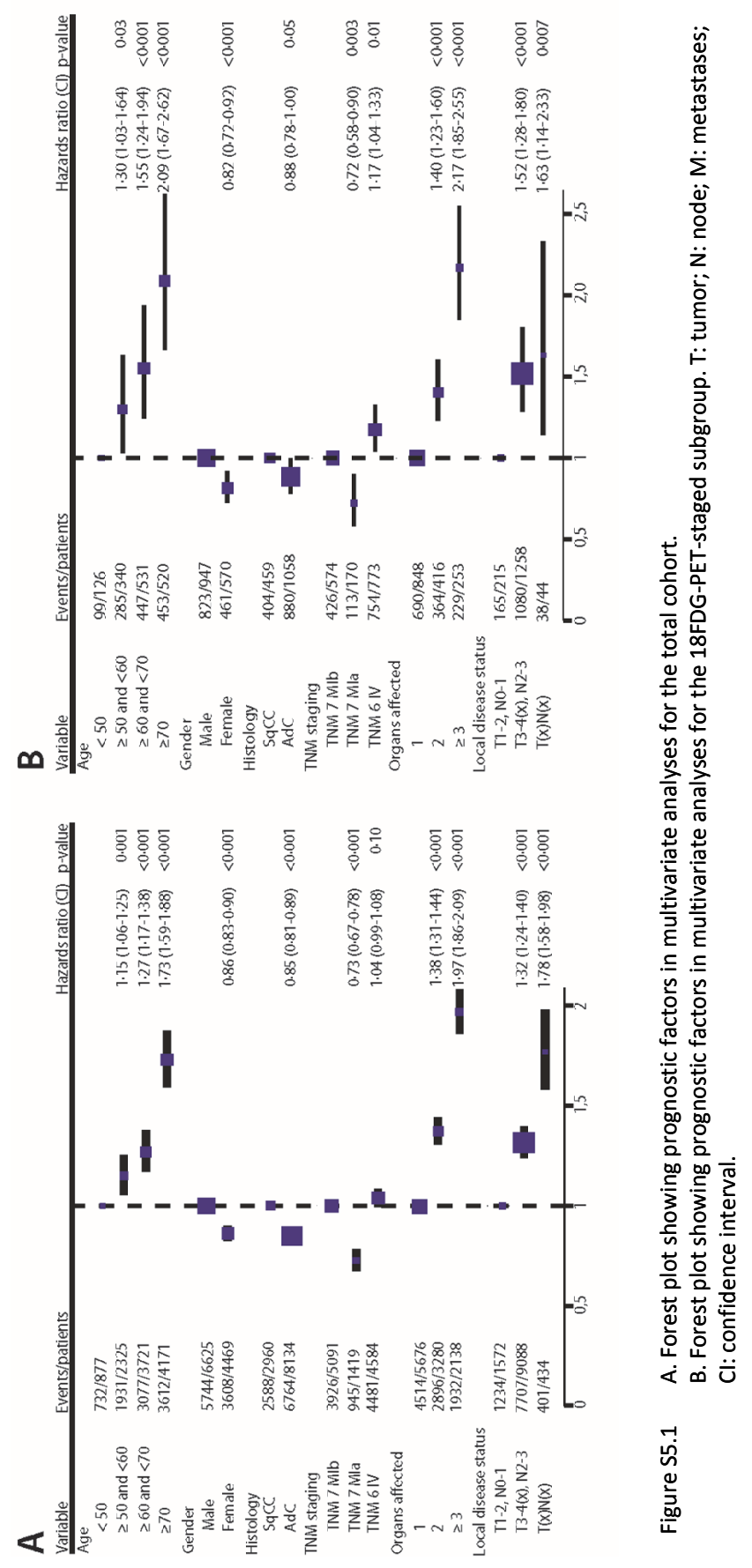



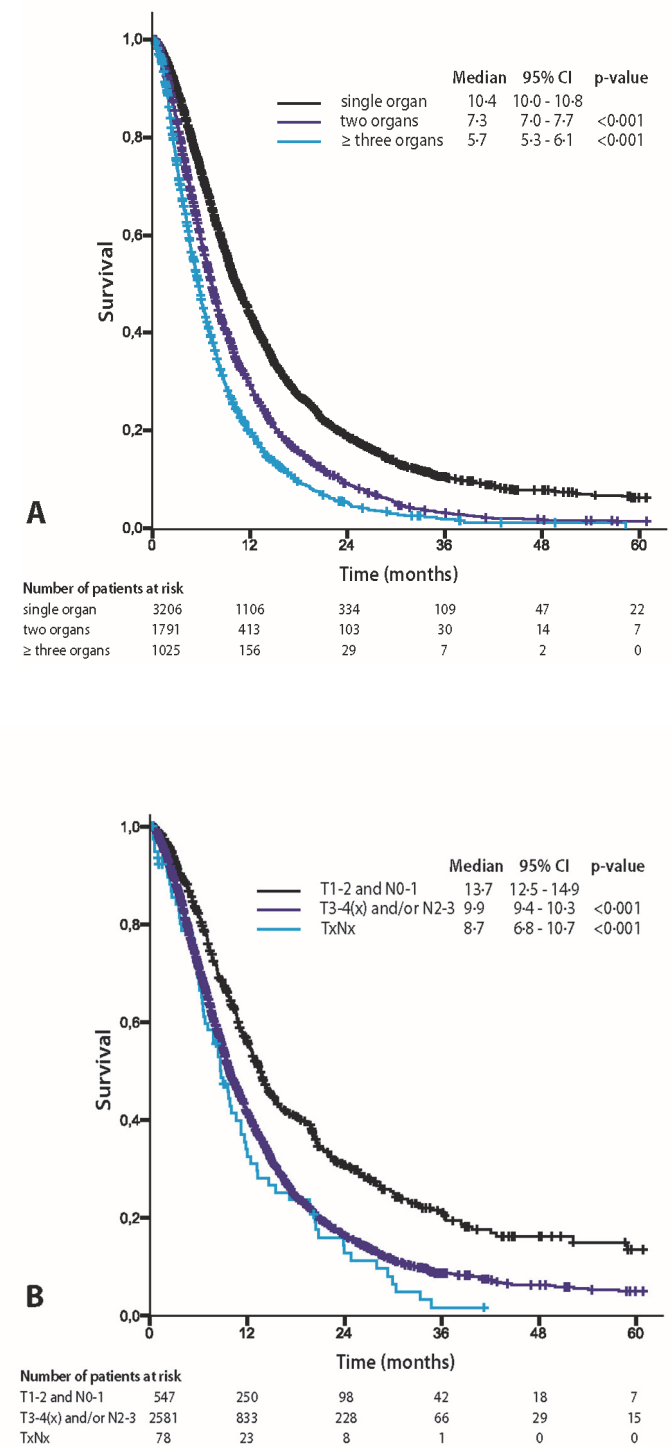

Figure S5.2 A. Kaplan Meier curves for the subgroup receiving active anticancer treatment according to number of organs with metastases $(1,2$, and $\geq 3$ ).

B. Kaplan Meier curves for the single organ metastases patients receiving active anticancer treatment according to local disease status. $\mathrm{T}$ : tumour; $\mathrm{N}$ : node; $\mathrm{Cl}$ : confidence interval. 


\section{Chapter 6}

Proposals for the M-descriptors of the eight INM classification for non-small cell lung cancer: more data needed?

Lizza E.L. Hendriks, Anne-Marie C. Dingemans, Dirk K.M. De Ruysscher J Thor Oncol 2016;11:e42 


\section{TO THE EDITOR}

We were looking forward to the proposals for the eight TNM classification for nonsmall cell lung cancer (NSCLC), as these were supposed to be based on a prospective database including data regarding staging techniques (e.g. use of ${ }^{18}$ fluorodeoxyglucosepositron-emission-tomography $\left({ }^{18} \mathrm{FDG}-\mathrm{PET}\right)$ scanning or brain magnetic resonance imaging (MRI)). ${ }^{1}$ This could be of interest because of possible upstaging. ${ }^{2}$ We read with interest the article by Eberhardt et al. ${ }^{3}$ in which proposals for the M-descriptor revision were made. Data from 2411 NSCLC patients registered between 1999 and 2012 were collected. For the final analysis, data from the electronic data capture (EDC) system were used ( $E D C N=1059,1025$ patients used). We wonder whether selection bias could have influenced the data as number of patients included per hospital was small. In addition it is possible that the large subgroup (25.6\%) of Chinese patients has influenced the analyses. It is expected that approximately half of these patients have targetable driver mutations, resulting in a superior OS. Subgroup analyses evaluating impact of the specific organ affected were performed within the proposed $M 1 \mathrm{~b}$ and M1c categories excluding the Chinese patients. These analyses showed a decreased OS for most of the organs analysed when excluding these Chinese patients. We hope the authors can provide us the OS data of the M1a (unchanged from current M1a category), $\mathrm{M} 1 \mathrm{~b}$ (single metastasis in a single organ) and $\mathrm{M} 1 \mathrm{c}$ (metastases in multiple organs/ multiple metastases in a single organ) categories of the subgroup of patients excluding the Chinese patients. Moreover, patients should be split into different prognostic groups including race (Caucasian versus Asian) and histology (squamous versus non-squamous). Although we are aware that the TNM classification is merely based on anatomical criteria, these additional analyses are necessary to ensure extrapolation of the results globally.

From the data presented it is not clear how many patients were staged by ${ }^{18}$ FDG-PETscanning and MRI brain. As this might impact staging we would like to ask the authors what percentage of patients was PET/MRI staged and whether the M-descriptors proposal changed if only these patients were included.

Moreover, in other studies it is suggested that an advanced ( $\mathrm{T}$ - as well as) $\mathrm{N}$-stage still has a negative prognostic impact in the metastasized setting. ${ }^{4,5}$ Do the authors have information regarding the prognostic impact of local disease status or will this information be used in the eight TNM classification stage proposal?

We hope that by answering our questions the interpretation of the subdivision of the $\mathrm{M}$-categories improves and we look forward to the answer of the authors. 


\section{REFERENCES}

1. Giroux DJ, Rami-Porta R, Chansky K, et al. The IASLC Lung Cancer Staging Project: data elements for the prospective project. J Thorac Oncol 2009;4:679-683.

2. Dinan MA, Curtis LH, Carpenter WR, et al. Stage migration, selection bias, and survival associated with the adoption of positron emission tomography among medicare beneficiaries with non-small-cell lung cancer, 1998-2003. J Clin Oncol 2012;30:2725-2730.

3. Eberhardt W, Mitchell A, Crowley J, et al. The IASLC Lung Cancer Staging Project: Proposals for the Revision of the M Descriptors in the Forthcoming Eighth Edition of the TNM Classification of Lung Cancer. J Thorac Oncol 2015;10:1515-1522.

4. Hendriks LE, Derks JL, Postmus PE, et al. Single organ metastatic disease and local disease status, prognostic factors for overall survival in stage IV non-small cell lung cancer: Results from a populationbased study. Eur J Cancer 2015;51:2534-2544..

5. Ashworth AB, Senan S, Palma DA, et al. An individual patient data metaanalysis of outcomes and prognostic factors after treatment of oligometastatic non-small-cell lung cancer. Clin Lung Cancer 2014;15:346-355. 


\title{
Chapter 7
}

\author{
Patient selection for whole brain
}

radiotherapy (WBRT) in a large lung

cancer cohort: Impact of a new Dutch

guideline on brain metastases

Lizza E.L. Hendriks, Esther G.C. Troost, Allan Steward, Gerben P. Bootsma,

Katrien De Jaeger, Ben E.E.M. van den Borne, Anne-Marie C. Dingemans

Acta Oncol. 2014;53:945-51 


\section{ABSTRACT}

\section{Introduction}

Median survival after diagnosis of brain metastases is, depending on the Recursive Partitioning Analysis (RPA) classes, 7.1 (class I) to 2.3 months (class III). In 2011 the Dutch guideline on brain metastases was revised, advising to withhold whole brain radiotherapy (WBRT) in RPA class III. In this large retrospective study, we evaluated the guideline's use in daily practice.

\section{Material and methods}

Data of 428 lung cancer patients undergoing WBRT for brain metastases (2004-2012) referred from three Dutch hospitals were retrospectively analyzed. Details on Karnofsky performance score (KPS), age, control of primary tumour, extracranial metastases, histology and survival after diagnosis of brain metastases were collected. RPA class was determined using the first four items.

\section{Results}

327 patients had non-small cell lung cancer (NSCLC) and 101 small cell lung cancer (SCLC). For NSCLC, $6.1 \%, 71.9 \%$ and $16.2 \%$ were classified as RPA I, II, and III respectively. $5.8 \%$ could not be classified. For SCLC this was $8.9 \%, 66.3 \%, 14.9 \%$, and $9.9 \%$, respectively. Before the revised guideline was implemented, $11.3-21.3 \%$ of WBRT patients were annually classified as RPA III. In the year thereafter, this was $13.0 \%(p=0.646)$. Median survival $[95 \% \mathrm{Cl}$ ] for NSCLC RPA class I, II, and III was 11.4 [9.9-12.9], 4.0 [3.4-4.7], and 1.7 [1.3-2.0] months, respectively. For SCLC this was 7.9 [4.1-11.7], 4.7 [3.3-6.1], and 1.7 [1.5-1.8] months.

\section{Conclusions}

Although it is advised to withhold WBRT in RPA class III patients, in daily practice $11.3-21.3 \%$ of WBRT treated patients were classified as RPA III. The new guideline did not result in a decrease. Reasons for referral of RPA III patients despite a low KPS were not found. Despite WBRT, survival of RPA III patients remains poor and this poor outcome should be stressed in practice guidelines. Therefore, better awareness amongst physicians would prevent some patients from being treated unnecessarily. 


\section{INTRODUCTION}

More than $50 \%$ of all intracranial tumours are metastases from extracranial primary tumour sites. ${ }^{1}$ Of these primary tumours, lung cancer is the most frequent ${ }^{2}$ and $30-60 \%$ of lung cancer patients will develop brain metastases. ${ }^{3,4}$ The Radiation Therapy Oncology Group (RTOG) has identified pre-treatment variables that determine survival after the diagnosis of brain metastases including age, Karnofsky performance status (KPS), control of primary tumour, absence of extracranial metastases and primary tumour site (e.g., breast cancer versus lung cancer). ${ }^{5}$ Based on the Recursive Partitioning Analysis (RPA) classification using the above mentioned variables (except for primary tumour site) patients can be divided into three categories: class I with good prognosis, class II with intermediate and class III with poor prognosis (see Table 7.1). ${ }^{5}$ RPA classification has been validated in both non-small cell lung cancer (NSCLC) and small cell lung cancer (SCLC). Survival ranges from a median of 7.1 months for RPA class I to 2.3 months for RPA class III. ${ }^{5-7}$ Whole Brain Radiotherapy (WBRT) is considered the standard treatment for patients with brain metastases not eligible for (radio)surgery or stereotactic radiotherapy. ${ }^{8}$ Potential benefits of WBRT are improved quality of life and performance status, improved neurological function, and a reduction in steroid dose needed to control neurological symptoms. However, the benefit of WBRT as compared to best supportive care (BSC) alone has not been studied in randomized controlled trials. ${ }^{9}$

Table 7.1 RPA class and survival.

\begin{tabular}{|c|c|c|c|c|}
\hline \multirow[t]{2}{*}{$\begin{array}{l}\text { RPA } \\
\text { class }\end{array}$} & \multirow[t]{2}{*}{ Description } & \multicolumn{2}{|c|}{$\begin{array}{c}\text { Current study } \\
\text { Median survival (months) }\end{array}$} & \multirow[t]{2}{*}{$\begin{array}{l}\text { RTOG analysis[5] } \\
\text { Median survival (months) }\end{array}$} \\
\hline & & NSCLC & SCLC & \\
\hline \multirow[t]{4}{*}{1} & KPS $\geq 70$ AND & 11.4 & 7.9 & 7.1 \\
\hline & Age $<65$ years AND & & & \\
\hline & Controlled systemic disease AND & & & \\
\hline & Metastases to brain only & & & \\
\hline II & all other patients & 4.0 & 4.7 & 4.2 \\
\hline III & KPS $<70$ & 1.7 & 1.7 & 2.3 \\
\hline
\end{tabular}

RPA: recursive partitioning analysis; KPS: Karnofsky performance score

Moreover, data of an unplanned interim analysis (due to poor accrual) of the phase III QUARTZ trial (NCT00403065) comparing BSC with BSC plus WBRT in inoperable brain metastases from NSCLC indicate that, with BSC only, there is no evidence of worsening quality of life or overall survival in patients for whom clinician and patient are uncertain of the benefit of WBRT. ${ }^{10}$

Current practice is that most guidelines (European Society of Medical Oncology, National Institute for Health and Clinical Excellence, National Comprehensive Cancer Network) advise WBRT combined with BSC without taking into account the RPA 
classification or another prognostic classification. ${ }^{11-13}$ However, in the revised Dutch guideline 'brain metastases from solid tumours' (version 3.0, July 2011) it is advised to treat patients with more than three metastatic lesions in RPA class I and the majority of the patients in RPA class II actively with WBRT and to treat patients in RPA class III primarily symptomatically with BSC. ${ }^{14}$ The performance score is often implemented in decision-making in other guidelines but RPA classification, although validated, is not implemented in these guidelines. As RPA class seems strong in predicting early death, ${ }^{15}$ its use was advised in the revised Dutch guideline.

The aim of this study was to analyze whether the revised Dutch national guideline had impact on the selection of patients for WBRT, i.e. whether the percentage of RPA III patients who underwent WBRT decreased. Results for referral of RPA III patients despite a low performance score were also studied. Furthermore the survival data of the studied patient cohort were compared to the survival reported in the RTOG validation studies. $^{5}$

\section{MATERIALS AND METHODS}

\section{PATIENT SELECTION}

Data of 428 lung cancer patients from 3 teaching hospitals in the South of the Netherlands who underwent WBRT for brain metastases between March 2004 and July 2012 were retrospectively analyzed. WBRT was delivered at MAASTRO Clinic (Maastricht) and the Catharina Hospital (Eindhoven). Details on age, gender, performance score (according to WHO/KPS), histology, local (intrathoracic) disease control, presence of extracranial metastases, time from diagnosis of lung cancer to development of brain metastases, and date of death or last follow-up visit were collected. Control of the primary tumour was defined as a complete tumour response or lack of local progression for at least three months before WBRT [based on chest X-ray or computed tomography (CT) of the chest]. Diagnosis of extracranial metastases was based on CTs of the chest and upper-abdomen, bone scintigraphy or ultrasound of the abdomen within one month of diagnosis of brain metastases. When only a chest X-ray was performed, the presence of extracranial metastases was stated as unknown. Brain metastases were defined as synchronous if discovered at the time of diagnosis of the primary cancer or within two months thereafter. ${ }^{2}$ The RPA class was determined using the following four items: KPS, age, local disease control and presence of extracranial metastases. Histology was divided into NSCLC and SCLC, whereby NSCLC was further sub-grouped in squamous cell carcinoma, adenocarcinoma, large cell carcinoma and "not otherwise specified" (NOS). Survival time was assessed from the date of diagnosis of brain metastases on imaging till death. Last date of follow-up was February 2013. The study was approved by the local science committee and was 
conducted according to the Code of Conduct for the use of data in Health Research and the Dutch "use of patient data" law.

\section{STATISTICAL METHODS}

All analyses were performed using SPSS statistical software (SPSS for Windows, version 20.0, IBM). Overall survival from time of diagnosis of brain metastases till death was calculated for all included NSCLC and SCLC patients per RPA class using the KaplanMeier method. A log rank test was performed to compare survival times between RPA classes. Pearson Chi-Square test was used to evaluate whether there was a difference in RPA class III before and after implementation of the revised guideline.

\section{RESULTS}

\section{PATIENT CHARACTERISTICS}

Between 2004 and 2012, a total of 327 NSCLC and 101 SCLC patients underwent WBRT at two radiotherapy departments. All patients received WBRT delivered with a $6 \mathrm{MV}$ linear accelerator using two lateral fields. The prescribed dose was $5 \times 4 \mathrm{~Gy}$. In the NSCLC patient group, the mean age (range) was 62.2 years (40.4-85.2), $55.4 \%$ was male and 266 patients (81.3\%) had a KPS of at least 70. In 208 patients (63.6\%) the primary tumour was uncontrolled, 139 (42.5\%) had extracranial metastases and 157 (48.0\%) had brain metastases at primary diagnosis. (Table 7.2)

In the SCLC patient group, the mean age was 64.0 years (44.7-85.7), 58.2\% was male and $81(80.2 \%)$ had a KPS of at least 70 . In 60 patients $(59.4 \%)$ the primary tumour was not controlled, 43 patients (42.6\%) had extracranial metastases and 41 patients $(40.6 \%)$ had brain metastases at primary diagnosis. (Table 7.2)

\section{RPA CLASSIFICATION}

For NSCLC, 20 of 327 patients (6.1\%) were classified as RPA I, 235 patients (71.9\%) as RPA II, and 53 (16.2\%) as RPA III. RPA could not be defined in 19 patients (5.8\%).

For SCLC the corresponding numbers were 9 (8.9\%), 67 (66.3\%), 15 (14.9\%), and $10(9.9 \%)$, respectively. 
Table 7.2 Patient characteristics.

\begin{tabular}{lcc}
\hline Patient characteristics & NSCLC N=327 & SCLC N=101 \\
\hline Mean age (range) & $62.2(40.4-85.2)$ & $62.1(44.7-83.5)$ \\
$\%$ male & 55.4 & 64.0 \\
Histology & $145(44.3 \%)$ & \\
Adenocarcinoma & $37(11.3 \%)$ & \\
Squamous cell carcinoma & $60(18.3 \%)$ & \\
Large cell carcinoma & $85(26.1 \%)$ & \\
Not otherwise specified & & $81(80.1 \%)$ \\
Performance (KPS) & $266(81.3 \%)$ & $5(14.9 \%)$ \\
$\geq 70$ & $53(16.2 \%)$ & \\
$<70$ & $8(2.5 \%)$ & $41(40.6 \%)$ \\
Missing & & $60(59.4 \%)$ \\
Diagnosis of primary to development of BM & $157(48.0 \%)$ & \\
Synchronous & $170(52.0 \%)$ & $17(21.0 \%)$ \\
Metachronous & & $60(74.1 \%)$ \\
KPS $\geq 70$, control of primary & $41(15.4 \%)$ & $4(4.9 \%)$ \\
Under control & $208(78.2 \%)$ & \\
Uncontrolled & $17(6.4 \%)$ & $32(39.5 \%)$ \\
Unknown & & $44(54.3 \%)$ \\
KPS $\geq 70$, extracranial metastases & $104(39.1 \%)$ & $5(6.2 \%)$ \\
No & $146(54.8 \%)$ & \\
Yes & $16(6.1 \%)$ & \\
Unknown & & \\
\hline
\end{tabular}

NSCLC: non-small cell lung cancer: SCLC: small cell lung cancer; KPS: Karnofsky performance score; BM: brain metastases

\section{SURVIVAL}

The majority of patients were dead at the time of analysis. Nine NSCLC patients (2.8\%) and two SCLC patients (2.0\%) were alive. For one NSCLC patient the date of death was unknown. These patients were classified as censored observations at the time of last follow-up. Eight NSCLC (five RPA II, three RPA III) and two SCLC (one RPA II, one RPA III) patients did not start or complete radiotherapy due to progressively deteriorating KPS. Since these patients were first considered eligible for WBRT, they were included in the analysis with the intention to treat principle.

Median survival [95\% Cl] for NSCLC RPA class I, II and III was 11.4 [9.9-12.9], 4.0 [3.4-4.7] and 1.7 [1.3-2.0] months, respectively. This difference was statistically significant $(p<0.0001)$. (Figure $7.1 \mathrm{~A})$ For the NSCLC patients with an unknown RPA classification, median survival was 2.7 [2.4-3.0] months.

For SCLC median survival [95\% Cl] for RPA class I, II and III was statistically significant different at 7.9 [4.1-11.7], 4.7 [3.3-6.1], and 1.7 [1.5-1.8] months, respectively $(p<0.0001)$. (Figure 7.1B) For the SCLC patients with an unknown RPA class median survival was 4.2 [3.5-5.0] months.

In the large group of RPA class II patients a subgroup analysis was performed to evaluate whether there were patient groups with different survival. Patients with 
extracranial metastases had a significantly worse median survival compared to patients without (3.7 [2.8-4.5] versus 5.7 [4.7-6.7] months ( $p=0.004$, Figure 7.1C). Age under or over 65 years had no impact, median survival was respectively 4.6 [3.9-5.2] and 3.5 [2.8-4.1] months $(p=0.472)$. The same was found for control or no control of primary tumour, median survival was respectively 3.5 [1.6-5.4] and 4.3 [3.6-4.9] months $(p=0.912)$.

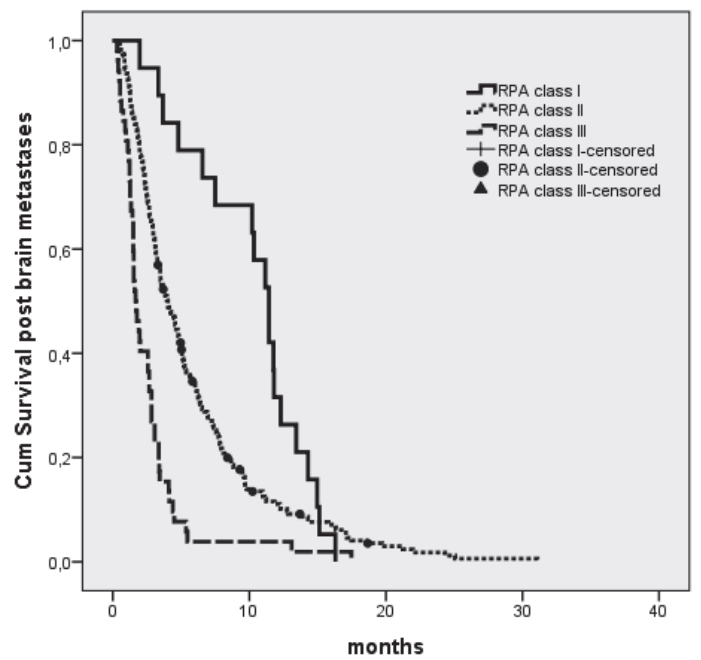

Figure 7.1A Survival post brain metastases in NSCLC patients per RPA class.

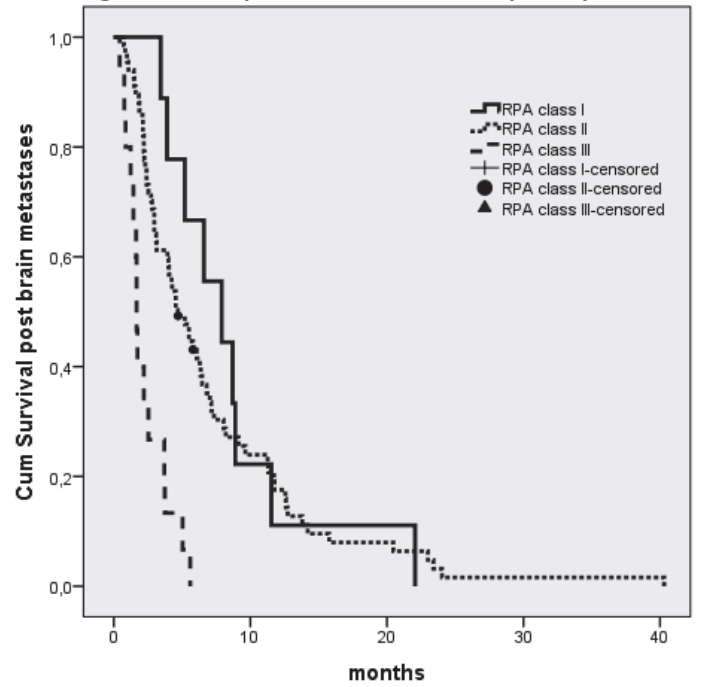

Figure 7.1B Survival post brain metastases in SCLC patients per RPA class. 


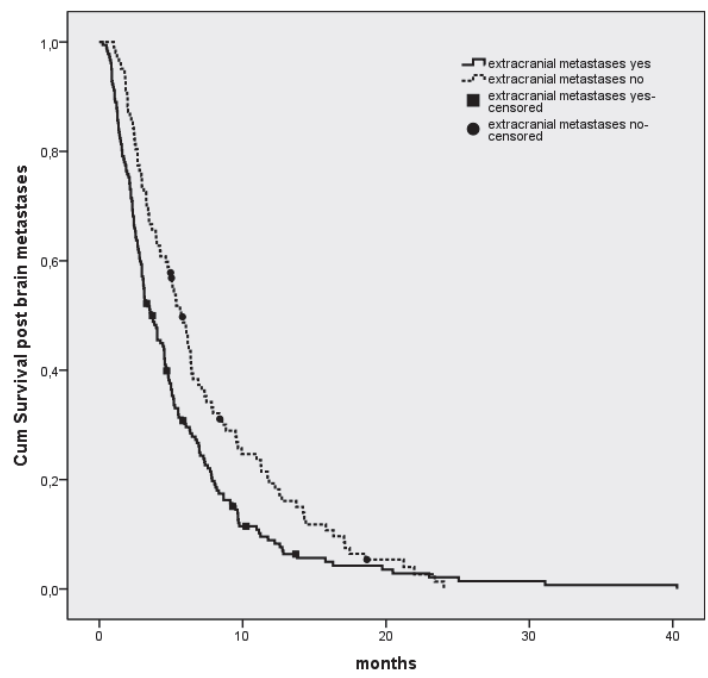

Figure 7.1C Survival in RPA class II subgroups with and without extracranial metastases.

\section{RPA CLASS III PATIENTS}

In order to evaluate why RPA class III patients were treated despite a low KPS, a more detailed analysis was performed.

RPA class III patients were divided according to the presence or absence of extracranial metastases and to the presence of synchronous or metachronous brain metastases. Regarding the first, it was hypothesized that RPA class III patients with solely brain metastases and no extracranial metastases at diagnosis were treated with WBRT despite a low KPS.

Regarding the latter, it was postulated that having a first line systemic treatment option available could also be a reason to treat these patients (although palliative systemic treatment is not recommended in patients with a low KPS, with a possible exception of SCLC patients because of high response rates to first line chemotherapy).

However, the majority (60.0\% of NSCLC and $67.3 \%$ of SCLC) of RPA III patients was diagnosed with extracranial metastases, and $50.0 \%$ of NSCLC and $66.6 \%$ of SCLC patients had metachronous brain metastases. With the exception of SCLC patients diagnosed with synchronous brain metastases (only three patients, median survival 5.0 [0.0-10.3] months), median survival for NSCLC and SCLC was 1.2-2.8 months. (Table 7.3) Because of the low number of patients, groups were not further subdivided into controlled versus uncontrolled primary tumour. 
Table 7.3 RPA class III characteristics and survival.

\begin{tabular}{|c|c|c|c|c|}
\hline $\begin{array}{l}\text { RPA class III } \\
(\mathrm{N}(\%)) \\
\end{array}$ & $\begin{array}{c}\text { Synchronous } \\
\text { BM (N (\%)) }\end{array}$ & $\begin{array}{l}\text { Median survival } \\
{[95 \% \mathrm{Cl}] \text {, months }}\end{array}$ & $\begin{array}{c}\text { Metachronous } \\
\text { BM (N (\%)) }\end{array}$ & $\begin{array}{c}\text { Median survival, } \\
\text { months }\end{array}$ \\
\hline \multicolumn{5}{|l|}{$N S C L C(\mathrm{~N}=52)$} \\
\hline With ECM & $14(40.0)$ & 1.7 [1.5-1.9] & $21(60.0)$ & $1.5[1.2-1.8]$ \\
\hline $\mathrm{N}=35(67.3 \%)$ & & & & \\
\hline Without ECM & $6(54.5)$ & $2.0[0.1-3.8]$ & $5(45.5)$ & $2.8[0.0-7.7]$ \\
\hline $\mathrm{N}=11(21.2 \%)$ & & & & \\
\hline $\begin{array}{l}\text { Unknown ECM } \\
\mathrm{N}=6(11.5 \%)\end{array}$ & $3(50.0)$ & $1.7[1.0-2.6]$ & $3(50.0)$ & $1.5[0.9-2.1]$ \\
\hline \multicolumn{5}{|l|}{$\operatorname{SCLC}(\mathrm{N}=15)$} \\
\hline $\begin{array}{l}\text { With ECM } \\
N=9(60.0 \%)\end{array}$ & $3(33.3)$ & $5.0[0.0-10.3]$ & $6(66.6)$ & $1.7[0.1-3.3]$ \\
\hline $\begin{array}{l}\text { Without ECM } \\
\mathrm{N}=3(20.0 \%)\end{array}$ & $1(33.3)$ & $1.4[\mathrm{~N} / \mathrm{A}]$ & $2(66.6)$ & $1.6[\mathrm{~N} / \mathrm{A}]$ \\
\hline $\begin{array}{l}\text { Unknown ECM } \\
\mathrm{N}=3(20.0 \%)\end{array}$ & $0(0.0)$ & N/A & $3(100)$ & $1.2[0.5-2.0]$ \\
\hline
\end{tabular}

RPA: recursive partitioning analysis; $B M$ : brain metastases; NSCLC: non-small cell lung cancer; ECM: extracranial metastases; SCLC: small cell lung cancer.

\section{EFFECT OF THE REVISED GUIDELINE}

Before the revised Dutch national guideline was implemented in 2011, 11.3 to $21.3 \%$ of WBRT patients was annually classified as RPA III (on average 9 patients per year). In the year after implementing the guideline, this number only slightly dropped to $13.0 \%$ (6 patients per year) $(p=0.646)$.

\section{DISCUSSION}

Brain metastasis frequently occurs in lung cancer patients and is related with a poor outcome. $^{3,4}$

Despite the recommendations in the Dutch national guideline, in our cohort $16.2 \%$ of NSCLC and $14.9 \%$ of SCLC patients treated with WBRT were RPA class III. Despite the release/implementation of the new national guideline in 2011, no substantial decrease in class III patients as percentage of the total of patients treated with WBRT was observed.

It is still largely unknown whether a poor overall prognosis is not only a poor prognostic factor for survival, but also predictive factor for the poor effects of WBRT. In older studies (in which all patients were treated with WBRT) a poor performance score was found to be a poor prognostic factor. In two recent studies (one interim-analysis only), this appeared to be also a poor predictive factor as there was no difference in survival between patients treated with and without WBRT. ${ }^{10,16}$ 
Our study confirms the dismal outcome of these RPA III patients. A possible explanation for (continuing) treating RPA class III patients is that physicians overestimate the benefit of WBRT. ${ }^{17}$ Furthermore, cancer patients and their relatives may have unrealistic expectations and are more often than non-cancer patients willing to accept an aggressive potentially toxic treatment with little or no benefit on survival or quality of life. ${ }^{18}$

In our study no explanation was found for treating RPA class III patients despite their poor performance score. Most of these patients were already treated with first line chemotherapy and were not diagnosed with brain metastases as the only site of disease activity. (i.e., they did not have a more favourable prognosis).

Potential benefits of WBRT are not well studied and there are no completed randomized trials of WBRT versus BSC with adequately defined endpoints. In older WBRT studies, ${ }^{19}$ symptomatic responses following WBRT of more than $60 \%$ were noted, but quality of life was not the primary endpoint. Also, response was not well defined, without any separation between response to corticosteroids or WBRT, and with measurement techniques that were neither standardized nor validated. More recent studies and a Cochrane review suggest that there is either only a modest effect of WBRT on quality of life and/or survival, or that no conclusion can be drawn. ${ }^{20-23}$ Moreover, there is evidence that in NSCLC patients for whom the clinician (i.e., multidisciplinary lung/neuro-oncology team) and/or patient are uncertain of the benefit of WBRT, withholding WBRT does not harm the patient. An unplanned interim analysis of the QUARTZ trial $(\mathrm{N}=151)$ indicated that there is no early evidence of worsening quality-adjusted life years (primary endpoint) for these NSCLC patients when treated with BSC only. ${ }^{10}$ The total accrual of 534 patients in this study with a highly relevant primary endpoint for these patients is expected mid-2014. A recent retrospective study $(\mathrm{N}=113)$ in patients with brain metastases and adverse prognostic factors reported comparable results. ${ }^{16}$ Another recent prospective non-randomized study ( $\mathrm{N}=91$ ) found no additive value of WBRT to optimal supportive care in RPA class III patients (predominantly NSCLC). ${ }^{23}$

However, current practice is that most guidelines advise WBRT in addition to optimal supportive care. ${ }^{11-13}$ Although the performance score is used for decision-making in other guidelines, RPA classification is not mentioned. Furthermore, according to our study, presence or absence of extracranial metastases could be used in RPA class II to further refine the prognostic classification in this group. In the original RTOG analysis, this retained no significance, but it is possible that for lung cancer patients the presence of extracranial metastases is also a poor prognostic factor.

There are some drawbacks to this study. First of all, due to the retrospective design we were unable to collect all data (e.g., on performance status, control of primary tumour or extracranial metastases). In clinical routine, the evaluation of the extent of the intrathoracic disease is somewhat arbitrary and the effort to evaluate the extent of extrathoracic disease is typically modest once the diagnosis of brain metastases is 
established. Despite this, evaluation of extracranial disease is important because of the prognostic implications as we have shown in the subgroup of RPA class II patients. Due to these missing data we were unable to determine the RPA class for all patients $(5,8 \%$ of NSCLC patients, 9,9 \% of SCLC patients). Second, the retrospective nature led to a slightly different distribution of patients in the RPA classes compared to the original RTOG analysis. ${ }^{5}$ In our study, less patients were classified as RPA class I and more as RPA class II. In the only study validating RPA classification for SCLC-only patients with brain metastases, more patients were classified as RPA III (33\% compared to $14.9 \%$ in our series). ${ }^{7}$

Except for NSCLC RPA class I, survival data were comparable to the original RTOG analysis (Table 7.1), ${ }^{5}$ as well as to three lung cancer only studies. ${ }^{6,7,24}$ It is possible that due to the small sample size our NSCLC RPA class I cohort is a highly selected group with a favourable histology and thus longer survival. Third, we did not have full data regarding patients who were evaluated by the radiation oncologist but were considered ineligible for WBRT. For those evaluated, low performance score was the main reason for ineligibility. Data regarding patients who were never considered candidates for WBRT by the treating pulmonologist or multidisciplinary team were not retrievable. It would be interesting to investigate why some RPA class III patients are considered candidates for WBRT and some are not.

Fourth, only two radiotherapy departments (easily accessed by the three referral hospitals) were included in our analysis. This may not be representative for the whole country, however the lack of use of RPA class in other guidelines suggests that the use of RPA III class is not common sense in selection of patients for WBRT.

Fifth, we did not have data regarding neurological outcome or quality of life after WBRT. However, other studies found no additive value of WBRT in RPA class III patients/patients with adverse prognostic factors. ${ }^{10,16,23}$ Considering the results in our study and bearing in mind the poor outcome of RPA class III patients use of RPA class for selection of lung cancer patients for WBRT should be stressed. At the moment the latter is most precisely described in the Dutch guideline, but in our opinion other guidelines should also stress the importance of selecting the right patients. To facilitate this, a prognostic classification and not only performance status should be implemented in other guidelines. Physicians should be aware of their overestimation of the effect of WBRT on quality of life for the patient or even survival. Discussing disease prognosis, the effects and the side effects of WBRT with patients having brain metastases by their referring physicians is important. These patients should also be discussed in multidisciplinary meetings. 


\section{CONCLUSION}

Although the Dutch guideline does not advise WBRT in RPA class III patients, 14.9-16.2\% of the studied WBRT patients were class RPA III. Despite the release/implementation of the new multidisciplinary national guideline in 2011, no decrease in referral of RPA class III patients for WBRT was observed. Reasons for referral despite a low performance score were not found. The survival of RPA class III patients is poor and in agreement with the RTOG validation studies. In our view, guidelines should be implemented more precisely and a prognostic classification should also be implemented in other guidelines. Better awareness amongst physicians and correct information of patients on treatment expectations would prevent some patients from being treated unnecessarily. 


\section{REFERENCES}

1. Gavrilovic IT, Posner JB. Brain metastases: epidemiology and pathophysiology. J Neurooncol. 2005;75: 5-14.

2. Lagerwaard FJ, Levendag PC, Nowak PJ, Eijkenboom WM, Hanssens PE, Schmitz PI. Identification of prognostic factors in patients with brain metastases: a review of 1292 patients. Int J Radiat Oncol Biol Phys. 1999;43:795-803.

3. Ceresoli GL, Reni M, Chiesa G, Carretta A, Schipani S, Passoni P, et al. Brain metastases in locally advanced nonsmall cell lung carcinoma after multimodality treatment: risk factors analysis. Cancer. 2002;95:605-12.

4. Quan AL, Videtic GM, Suh JH. Brain metastases in small cell lung cancer. Oncology (Williston Park, NY). 2004;18:961-72; discussion 74, 79-80, 87.

5. Gaspar L, Scott C, Rotman M, Asbell S, Phillips T, Wasserman T, et al. Recursive partitioning analysis (RPA) of prognostic factors in three Radiation Therapy Oncology Group (RTOG) brain metastases trials. Int J Radiat Oncol Biol Phys. 1997;37:745-51.

6. Kepka L, Cieslak E, Bujko K, Fijuth J, Wierzchowski M. Results of the whole-brain radiotherapy for patients with brain metastases from lung cancer: the RTOG RPA intra-classes analysis. Acta Oncol. 2005;44:389-98.

7. Videtic GM, Adelstein DJ, Mekhail TM, Rice TW, Stevens GH, Lee SY, et al. Validation of the RTOG recursive partitioning analysis (RPA) classification for small-cell lung cancer-only brain metastases. Int J Radiat Oncol Biol Phys. 2007;67:240-3.

8. Chu FC, Hilaris BB. Value of radiation therapy in the management of intracranial metastases. Cancer. 1961;14:577-81.

9. Tsao MN, Lloyd N, Wong R, Chow E, Rakovitch E, Laperriere N. Whole brain radiotherapy for the treatment of multiple brain metastases. The Cochrane database of systematic reviews. 2006(3):CD003869.

10. Langley RE, Stephens RJ, Nankivell M, Pugh C, Moore B, Navani N, et al. Interim data from the Medical Research Council QUARTZ Trial: does whole brain radiotherapy affect the survival and quality of life of patients with brain metastases from non-small cell lung cancer? Clin Oncol. 2013;25:e23-30.

11. NICE clinical guideline 121: The diagnosis and treatment of lung cancer. 2011:103-4.

12. NCCN guidelines: Central Nervous System Cancers. version 2.2012. 2012:MS-25.

13. Peters S, Adjei AA, Gridelli C, Reck M, Kerr K, Felip E, et al. Metastatic non-small-cell lung cancer (NSCLC): ESMO Clinical Practice Guidelines for diagnosis, treatment and follow-up. Ann Oncol. 2012;23 Suppl 7:vii56-64.

14. LWNO/ IKL guideline: "brain metastases from solid tumours" version 3.0 July 2011. 2011:17-22.

15. Zindler JD, Rodrigues G, Haasbeek CJ, De Haan PF, Meijer OW, Slotman BJ, et al. The clinical utility of prognostic scoring systems in patients with brain metastases treated with radiosurgery. Radiother Oncol. 2013;106:370-4.

16. Nieder C, Norum J, Dalhaug A, Aandahl G, Pawinski A. Radiotherapy versus best supportive care in patients with brain metastases and adverse prognostic factors. Clin Exp Metastasis. 2013;30:723-9.

17. Barnes EA, Chow E, Tsao MN, Bradley NM, Doyle M, Li K, et al. Physician expectations of treatment outcomes for patients with brain metastases referred for whole brain radiotherapy. Int J Radiat Oncol Biol Phys. 2010;76:187-92.

18. Extermann M, Albrand G, Chen H, Zanetta S, Schonwetter R, Zulian GB, et al. Are older French patients as willing as older American patients to undertake chemotherapy? J Clin Oncol. 2003;21:3214-9.

19. Cairncross JG, Kim JH, Posner JB. Radiation therapy for brain metastases. Ann Neurol. 1980;7:529-41.

20. Bezjak A, Adam J, Barton R, Panzarella T, Laperriere N, Wong CS, et al. Symptom response after palliative radiotherapy for patients with brain metastases. Eur J Cancer. 2002;38:487-96.

21. Tsao MN, Lloyd N, Wong RK, Chow E, Rakovitch E, Laperriere N, et al. Whole brain radiotherapy for the treatment of newly diagnosed multiple brain metastases. The Cochrane database of systematic reviews. 2012;4:CD003869. 
22. Wong J, Hird A, Zhang L, Tsao M, Sinclair E, Barnes E, et al. Symptoms and quality of life in cancer patients with brain metastases following palliative radiotherapy. Int J Radiat Oncol Biol Phys. 2009;75:1125-31.

23. Komosinska K, Kepka L, Niwinska A, Pietrzak L, Wierzchowski M, Tyc-Szczepaniak D, et al. Prospective evaluation of the palliative effect of whole-brain radiotherapy in patients with brain metastases and poor performance status. Acta Oncol. 2010;49:382-8.

24. Rodrigus $P$, de Brouwer $P$, Raaymakers $E$. Brain metastases and non-small cell lung cancer. Prognostic factors and correlation with survival after irradiation. Lung Cancer. 2001;32:129-36. 


\title{
Chapter 8
}

\section{EGFR-mutated non-small cell lung cancer} patients: more prone to development of

\author{
bone and brain metastases?
}

Lizza E.L. Hendriks, Egbert F. Smit, Bettine A.H. Vosse, Wouter W. Mellema, Danielle A.M. Heideman, Gerben P. Bootsma, Marcel Westenend, Cordula Pitz, Michiel J. de Vries, Ruud Houben, Katrien Grünberg, Matthyas Bendek, Ernst-Jan M. Speel, Anne-Marie C. Dingemans 


\section{ABSTRACT}

\section{Objectives}

Both bone and brain are frequent sites of metastasis in non-small cell lung cancer (NSCLC). Conflicting data exist whether EGFR mutant (+) patients are more prone to develop brain metastases or have a better outcome with brain metastases compared to EGFR/KRAS wildtype (WT) or KRAS+ patients. For bone metastases this has not been studied.

\section{Methods}

In this retrospective case-control study all EGFR+ (exon 19 and 21) patients diagnosed at two pathology departments were selected (2004/2008 to 2012). For every EGFR+ patient a consecutive KRAS+ and WT patient with metastatic NSCLC (mNSCLC) was identified. Patients with another malignancy within 2 years of mNSCLC diagnosis were excluded. Data regarding age, gender, performance score, histology, treatment, bone/brain metastases diagnosis, skeletal related events (SRE) and subsequent survival were collected.

\section{Results}

189 patients were included: 62 EGFR+, 65 KRAS+, 62 WT. 32\%, 35\% and $40 \%$ respectively had brain metastases $(p=0.645)$. Mean time to brain metastases was $20.8[ \pm 12.0], 10.8[ \pm 9.8], 16.4[ \pm 10.2]$ months (EGFR+-KRAS+ $p=0.020, E G F R+-W T p=0.321)$. Median post brain metastases survival was 12.1 [5.0-19.1], 7.6 [1.2-14.0], 10.7 [1.5-19.8] months ( $p=0.674) .60 \%, 52 \%$ and $50 \%$ had metastatic bone disease $(p=0.528)$. Mean time to development of metastatic bone disease was $13.4[ \pm 10.6], 23.3[ \pm 19.4], 16.4[ \pm 9.6]$ months $(p=0.201)$. Median post metastatic bone disease survival was 15.0 [10.6-20.3], 9.0 [5.2-12.9], 3.2 [0.0-6.9] months $(p=0.010)$. Time to 1 st SRE was not significantly different.

\section{Conclusions}

Incidence of brain and bone metastases was not different between EGFR+, KRAS+ and WT patients. Post brain metastases survival, time from mNSCLC diagnosis to metastatic bone disease and $1^{\text {st }}$ SRE did not differ either. Post metastatic bone disease survival was significantly longer in EGFR+ patients. Although prevention of SRE'S is important for all patients, the latter finding calls for a separate study for SRE preventing agents in EGFR+ patients. 


\section{INTRODUCTION}

Metastatic non-small cell lung cancer ( $\mathrm{mNSCLC}$ ) patients with activating epidermal growth factor receptor mutations (EGFR+) have, compared to KRAS mutated (KRAS+) or EGFR/KRAS wild type (WT) patients, a longer progression free survival (PFS) and overall survival (OS) when treated with EGFR-tyrosine kinase inhibitors (TKI). ${ }^{1-3}$ Differences in tumor biology may also reflect metastatic pattern. Similar to patients with (EGFR/erB family member) HER2 positive breast cancer, ${ }^{4}$ the incidence of brain metastases may be higher in EGFR+ patients as compared to EGFR- patients. ${ }^{5-9}$ One explanation is the inability of currently available EGFR-TKI to cross the intact blood-brain barrier at recommended doses. ${ }^{10}$ In the above mentioned studies only patients with brain metastases were enrolled ${ }^{5,7,9}$ and/or mutation status was not known for all included patients. ${ }^{6,8,9}$ Thus, the question whether the time to development of brain metastases and outcome is different between EGFR+, KRAS+ or WT patients could not be answered. Next to brain, bone is a frequent site of metastasis in NSCLC exerting a negative impact on quality of life. ${ }^{11-13}$ Brain metastases have also a negative impact on survival. ${ }^{14}$ Different metastatic patterns may have implications for diagnostic strategies (e.g. screening) and treatment decisions (e.g. prophylactic treatment).

In this retrospective case-control study we compared EGFR+ to KRAS+ and WT mNSCLC patients to determine whether EGFR+ patients are more prone to develop brain metastases and/or metastatic bone disease, and whether they have a different survival following the detection of these metastases.

\section{MATERIALS AND METHODS}

This study was designed as a retrospective case-control study, using a prospectively collected database.

\section{PATIENT SELECTION}

All EGFR+ patients who were diagnosed at the pathology departments of two university hospitals (MUMC+ and VUMC) were selected. For every EGFR+ patient the consecutive $K R A S+$ and WT NSCLC patient was selected. The MUMC+ database covers the period 01-10-2008 to 01-08-2012 and the VUMC database 01-11-2004 to 01-01-2012. The MUMC+ pathology department performs mutation analysis for the MUMC+ (both general and referral hospital) and four surrounding general hospitals. From the VUMC database only patients who underwent treatment at VUMC (mainly referral hospital) were selected in order to obtain sufficient follow-up data.

Inclusion criteria: mNSCLC and known mutation status (activating EGFR+: exon 19 deletion or exon 21 mutation, KRAS+ or WT (defined as: no EGFR or KRAS mutation)). 
Exclusion criteria: exon 18 or 20 EGFR mutation, other active malignancy within 2 years of diagnosis of mNSCLC, mixed histology, EML4-ALK translocation positive (when testing was performed) or no follow-up data available (at least one visit after diagnosis of $\mathrm{mNSCLC}$ required).

The in- and outpatient medical records of all patients were retrieved and the following data were collected: age at diagnosis of mNSCLC; gender; smoking status; date of first diagnosis NSCLC and of mNSCLC; histology; treatment; development, number, symptoms and treatment of brain metastases; development, and treatment of metastatic bone disease, skeletal related event (SRE) and time of death. Last date of follow-up was August 2013.

Medical ethical committee approval was not obtained in accordance with local regulations, as it is a retrospective study with no interventions.

\section{MUTATION ANALYSIS}

Mutation analysis for EGFR (exon 18-21) and KRAS (exon 2-3) was performed as part of standard of care with high resolution melting as pre-screening followed by Sanger sequencing to confirm genotype. ${ }^{15}$

\section{STATISTICAL ANALYSIS}

Statistics were performed using SPSS (IBM statistics, version 20). Descriptive statistics of demographic and clinical variables were obtained. Categorical variables were compared using chi-square tests, continuous variables were compared using ANOVA. For patients without metastatic bone disease or brain metastases at first diagnosis of mNSCLC, time to diagnosis of these metastases was calculated from diagnosis of mNSCLC and was expressed as mean with standard deviation (SD). Means were compared using ANOVA with, if statistically significant, post-hoc Student's-T-tests for pair wise comparisons. OS was defined as time from diagnosis of mNSCLC to death and post metastatic bone disease and post brain metastases survival was calculated from diagnosis of these metastases to death (patients without event were censored at last visit). Both were estimated using the Kaplan-Meier method. Survival curves were compared using the log-rank test. To estimate the hazard ratio (HR), Cox regression analysis was used.

\section{RESULTS}

\section{PATIENT CHARACTERISTICS}

Respectively 59/603 (9.8\%) and 26/346 (7.5\%) NSCLC patients included in the MUMC+ and VUMC database carried an EGFR mutation. These 85 EGFR+ patients were paired 
with the consecutive KRAS+ and WT patients. The medical records of these 255 patients were analyzed. Three EGFR+ patients had an exon 18 mutation and 8 had an exon 20 mutation; these patients were excluded together with the consecutive KRAS+ and EGFR/KRAS WT patient. In addition, 33 patients were excluded because of: no metastatic disease $(\mathrm{N}=13)$, another malignancy diagnosed within 2 years of mNSCLC diagnosis $(\mathrm{N}=10)$, no follow up data $(\mathrm{N}=8)$ or $A L K$ translocation $(\mathrm{N}=2)$. Finally, 189 patients were included in the analysis: 62 EGFR+, 65 KRAS+ and 62 EGFR/KRAS WT (WT). Patient characteristics are shown in Table 8.1. Most EGFR+ patients $(58 / 62$ (93.5\%)) received an EGFR-TKI during the course of their disease, $41 / 58$ (70.7\%) as first line treatment.

Of the 62 EGFR+ patients, 41 had exon 19 deletions and 21 had exon 21 mutations (of which one combined with an exon 19 deletion).

Table 8.1 Patient characteristics.

\begin{tabular}{|c|c|c|c|c|}
\hline Characteristics & $\begin{array}{c}E G F R+ \\
N=62\end{array}$ & $\begin{array}{c}\text { KRAS+ } \\
\mathrm{N}=65\end{array}$ & $\begin{array}{c}\text { Wildtype } \\
\mathrm{N}=62\end{array}$ & $p$-value \\
\hline Female N (\%) & $46(74.2)$ & $38(58.5)$ & $26(41.9)$ & 0.001 \\
\hline Mean age, years (range) & $60.7(29.3-90.7)$ & $61.0(35.1-83.3)$ & $63.0(39.6-81.8)$ & 0.532 \\
\hline Never smoker N (\%) & $25(40.3)$ & $2(3.1)$ & $9(14.5)$ & $<0.001$ \\
\hline WHO PS 0-2 N (\%) & $59(95.2)$ & $62(95.4)$ & $60(96.8)$ & 0.164 \\
\hline Adenocarcinoma N (\%) & 57 (91.9) & $53(81.5)$ & $52(83.9)$ & 0.217 \\
\hline $\begin{array}{l}\text { Stage IV disease at first diagnosis } \\
\mathrm{N}(\%)\end{array}$ & $54(87.1)$ & $49(75.4)$ & $61(83.9)$ & 0.205 \\
\hline $\begin{array}{l}\text { PET-CT at first diagnosis of } \\
\text { metastatic disease } \mathrm{N}(\%)^{*}\end{array}$ & $38(61.3)$ & $46(70.8)$ & $48(77.4)$ & 0.232 \\
\hline $\begin{array}{l}\text { Mutation analysis performed at } \\
\text { first diagnosis of metastatic } \\
\text { disease } N(\%) \\
\text { 1st line treatment N (\%) }\end{array}$ & $42(67.7)$ & $45(69.2)$ & $47(75.8)$ & 0.480 \\
\hline None & $3(4.8)$ & $8(12.3)$ & $11(17.7)$ & 0.080 \\
\hline Chemotherapy & $18(29.0)$ & $55(84.6)$ & $46(74.2)$ & $<0.001$ \\
\hline EGFR-TKI & $41(66.2)$ & $2(3.1)$ & $5(8.1)$ & $<0.001$ \\
\hline $\begin{array}{l}\text { EGFR-TKI during course of } \\
\text { disease } N(\%)\end{array}$ & $58(93.5)$ & $16(24.6)$ & $15(24.2)$ & $<0.001$ \\
\hline
\end{tabular}

EGFR: epidermal growth factor receptor; WHO PS: world health organisation performance score; TKI: tyrosine kinase inhibitor. * except for one wildtype patient and for four EGFR+ patients with missing data: all other patients Ct-thorax/upper abdomen

\section{OVERALL SURVIVAL}

Median OS [95\% Cl] was significantly longer for EGFR+ patients compared to KRAS+ and WT patients: 26.7 [20.4-32.9]; 11.0 [6.8-15.1] and 11.5 [7.6-15.3] months respectively (HR 1.379 [1.135-1.677], $p<0.0001$, Figure 8.1).Within the EGFR+ group, median OS was significantly longer for exon 19 than in exon 21 mutated patients: 29.8 [22.1-37.5] and 15.5 [9.4-22.6] months, respectively (HR 1.550 [1.122-2.141], $p=0.006$ ). 


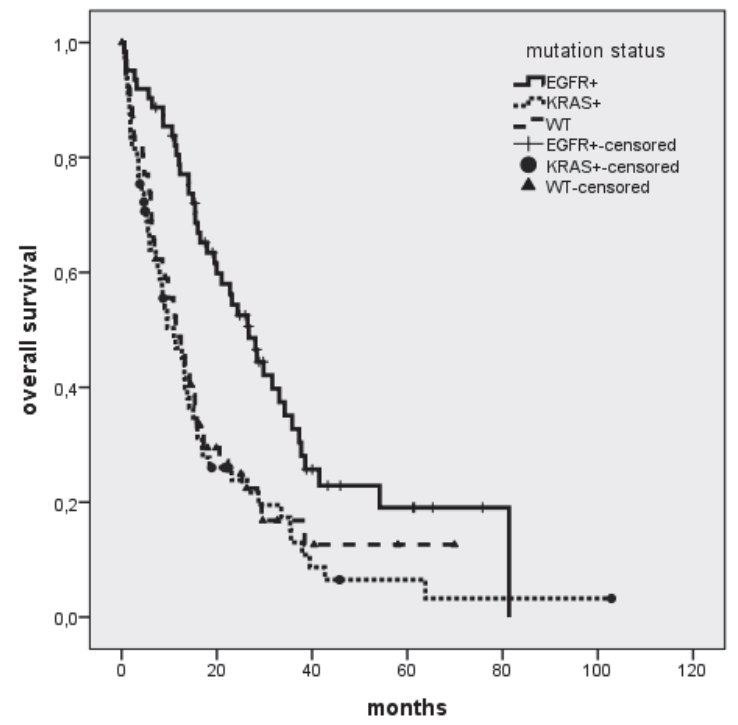

Figure 8.1 Overall survival for EGFR+, KRAS and WT patients.

\section{BRAIN METASTASES}

Incidence of brain metastases was not different between the 3 groups: 20/62 (32.3\%) EGFR+, 23/65 (35.4\%) KRAS+ and 25/62 (40.3\%) WT patients had brain metastases $(p=0.645)$. At diagnosis of mNSCLC brain metastases were present in $5 / 20(25.0 \%), 9 / 23$ $(39.1 \%)$ and $13 / 25(52.0 \%)$ patients $(p=0.184)$. Mean time [SD] to diagnosis of brain metastases for patients without brain metastases at initial diagnosis of mNSCLC was $20.8[ \pm 12.0] ; 10.8[ \pm 9.8]$ and $16.4[ \pm 10.2]$ months respectively. $E G F R+$ patients had a significantly longer time to development of brain metastases than $K R A S+(p=0.020)$ but not compared to WT patients $(p=0.321)$. No significant difference in median $[95 \% \mathrm{Cl}]$ post brain metastases survival was observed: 12.1 [5.0-19.1]; 7.6 [1.2-14.0] and 10.7 [1.5-19.8] months (HR 1.119 [0.801-1.565], $p=0.674$, Table 8.2, Figure 8.2).

All 15 EGFR+ patients who developed brain metastases after initial diagnosis of mNSCLC were treated with an EGFR-TKI during the course of their disease $(9 / 15$ (60\%) first line, $12 / 15$ (80\%) before development of brain metastases). Mean time [SD] to development of brain metastases was not significantly different between EGFR+ patients who were in first line treated with an EGFR-TKI versus patients who received it in a later line (21.3 [ \pm 12.9$]$ months versus $18.8[ \pm 9.2]$ months, $p=0.760$ ) nor was there a significant difference in time to brain metastases for patients who received an EGFR-TKI or only chemotherapy before development of brain metastases $(21.4[ \pm 12.4]$ months versus $17.3[ \pm 12.5]$ months, $p=0.675)$. In the latter group $(\mathrm{N}=3)$ EGFR-TKI treatment was started after diagnosis of brain metastases. Median survival $[95 \% \mathrm{Cl}]$ post brain metastases was not significantly different between patients receiving an EGFR-TKI 
before or after development of brain metastases (6.8 [0.0-18.9] months compared to 11.0 [9.1-12.8] months) ( $p=0.808)$. In addition no difference in OS was observed (37.3 [16.5-58.1] months and 31.6 [12.2-51.1] months respectively, $p=0.861$ ).

Table $8.2 \quad$ Mutation status and bone / brain metastases.

\begin{tabular}{|c|c|c|c|c|}
\hline & $\begin{array}{l}\text { EGFR+ } \\
\mathrm{N}=62\end{array}$ & $\begin{array}{l}\text { KRAS+ } \\
\mathrm{N}=65\end{array}$ & $\begin{array}{l}\text { Wildtype } \\
\mathrm{N}=62\end{array}$ & $p$-value \\
\hline \multicolumn{5}{|l|}{$\begin{array}{l}\text { Imaging at } 1^{\text {st }} \text { diagnosis of } \\
\text { mNSCLC } N(\%)\end{array}$} \\
\hline$-\mathrm{MRI}$ & $15(24.2)$ & $19(29.2)$ & $18(29.0)$ & 0.417 \\
\hline - CT & $20(32.3)$ & $25(38.5)$ & $28(45.2)$ & \\
\hline - None** & $25(40.3)$ & $19(29.2)$ & $16(25.8)$ & \\
\hline - Missing & $2(3.2)$ & $2(3.1)$ & $0(0.0)$ & \\
\hline \multicolumn{5}{|l|}{ BM N (\%) } \\
\hline - Yes & $20(32.3)$ & $23(35.4)$ & $25(40.3)$ & 0.645 \\
\hline -At diagnosis & $-5(25.0)$ & $-9(39.1)$ & $-13(52.0)$ & 0.184 \\
\hline -During follow up & $-15(75.0)$ & $-14(60.9)$ & $-12(48.0)$ & \\
\hline$-\mathrm{No}$ & $42(67.7)$ & $42(64.6)$ & $37(59.7)$ & \\
\hline Time to BM months [SD] & $20.8[ \pm 12.0]$ & $10.8[ \pm 9.8]$ & $16.4[ \pm 10.2]$ & $\begin{array}{l}\text { EGFR/KRAS } 0.020 \text {, } \\
\text { EGFR/WT } 0.321\end{array}$ \\
\hline EGFR-TKI before BM N (\%) & $15(100.0)$ & $1(7.1)$ & $4(33.3)$ & $<0.001$ \\
\hline - First line & $-12(80)$ & & & \\
\hline Symptomatic N (\%) & $16(80.0)$ & 17 (73.9) & $24(96.0)$ & 0.097 \\
\hline \multicolumn{5}{|l|}{ Treatment } \\
\hline - WBRT N (\%) & $12(60.0)$ & $11(47.8)$ & $20(80.0)$ & 0.028 \\
\hline - SRS N (\%) & $2(10.0)$ & $8(34.8)$ & $6(24.0)$ & 0.161 \\
\hline - Surgery N (\%) & $0(0.0)$ & $3(13.0)$ & $1(4.0)$ & 0.260 \\
\hline \multicolumn{5}{|l|}{ Post BM survival } \\
\hline months [95\% Cl] & $12.1[5.0-19.1]$ & $7.6[1.2-14.0]$ & $10.7[1.5-19.8]$ & 0.674 \\
\hline \multicolumn{5}{|l|}{ Bone metastases } \\
\hline \multicolumn{5}{|l|}{$\begin{array}{l}\text { Imaging at 1st diagnosis of } \\
\text { mNSCLC } N(\%)\end{array}$} \\
\hline - PET-CT & $38(61.3)$ & $46(70.8)$ & $48(77.4)$ & 0.232 \\
\hline$-\mathrm{CT}^{*}$ & $17(27.4)$ & $13(20.0)$ & $11(17.7)$ & \\
\hline - Bone scintigraphy§ & $5(8.1)$ & $4(6.2)$ & $2(3.3)$ & \\
\hline - Missing & $2(3.2)$ & $2(3.0)$ & $1(1.6)$ & \\
\hline \multicolumn{5}{|l|}{ Bone mets $\mathrm{N}(\%)$} \\
\hline - Yes & $37(59.7)$ & $34(52.3)$ & $31(50.0)$ & 0.528 \\
\hline - At diagnosis & $-20(54.1)$ & $-26(76.5)$ & $-18(58.1)$ & 0.121 \\
\hline - During follow up & $-17(45.9)$ & $-8(23.5)$ & $-13(41.9)$ & \\
\hline - No & $25(40.3)$ & $31(47.7)$ & $31(50.0)$ & \\
\hline \multicolumn{5}{|l|}{ Time to bone mets months } \\
\hline$[S D]$ & $13.4[ \pm 10.6]$ & $23.3[ \pm 19.4]$ & $16.4[ \pm 9.6]$ & 0.201 \\
\hline $\mathrm{SRE}+\mathrm{N}(\%)$ & $19(51.4)$ & $22(64.7)$ & $15(48.4)$ & 0.361 \\
\hline \multicolumn{5}{|l|}{ Time to 1 st SRE months [95\% } \\
\hline $\mathrm{Cl}]$ & $12.9[5.0-20.7]$ & $7.3[0.0-14.9]$ & $3.5[0-7.7]$ & 0.213 \\
\hline Post bone mets survival & & & & $E G F R / K R A S 0.049$ \\
\hline months $[95 \% \mathrm{Cl}]$ & 15.5 [10.6-20.3] & $9.0[5.2-12.9]$ & $3.2[0-6.9]$ & EGFR/WT 0.004 \\
\hline
\end{tabular}

EGFR: epidermal growth factor receptor; $95 \% \mathrm{Cl}=95 \%$ confidence interval; $\mathrm{SD}=$ standard deviation; SRE= skeletal related event; EGFR-TKI=epidermal growth factor receptor; WBRT=whole brain radiotherapy; SRS= stereotactic radiosurgery. ${ }^{*} \mathrm{CT}$-thorax/upper abdomen; $\S$ when both PET-CT and bone scintigraphy were performed, patients were scored for "PET-CT"; ** only low dose CT brain during PET-CT was scored as "none". 


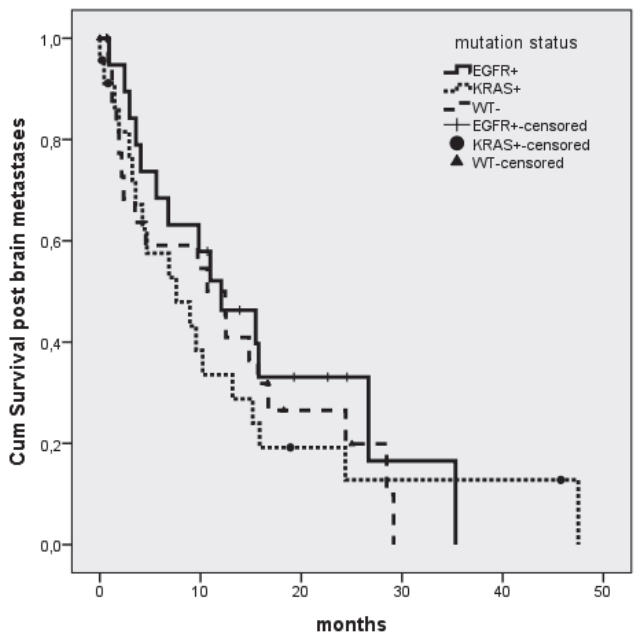

Figure 8.2 Survival post brain metastases for EGFR+, KRAS+ and WT patients.

\section{METASTATIC BONE DISEASE}

Incidence of bone metastases was also not different between EGFR, KRAS+ and WT patients: $37 / 62$ (59.7\%) EGFR+, 34/65 (52.3\%) KRAS+ and 31/62 (50.0\%) WT patients were diagnosed with or developed metastatic bone disease during the course of their disease $(p=0.528)$. Of these 20/37 (54.1\%), 26/34 (76.5\%) and 18/31 (58.1\%) respectively had metastatic bone disease at diagnosis of $\operatorname{mNSCLC}(p=0.121)$. Mean time [SD] to first diagnosis of metastatic bone disease for patients without metastatic bone disease at initial diagnosis of mNSCLC was respectively $13.4[ \pm 10.6] ; 23.3[ \pm 19.4]$ and 16.4 [ \pm 9.6 ] months for EGFR+, KRAS+ and WT patients, $(p=0.201)$. No difference in SRE's was observed: $19 / 37$ (51.4\%), 22/34 (64.7\%) and 15/31 (48.4\%) respectively ( $p=0.361)$. Also, time to first SRE was equal $(p=0.213)$. However, post metastatic bone disease survival was significantly longer in the EGFR+ group: median [95\% Cl] of 15.5 [10.6-20.3] months compared to 9.0 [5.2-12.9] months for KRAS+ and 3.2 [0-6.9] months for WT patients. (EGFR+-KRAS+ $p=0.049, E G F R+-W T p=0.004$ ), Table 8.2, Figure 8.3). Mean time [SD] to development of metastatic bone disease was longer, however not significant, for EGFR+ patients first line treated with EGFR-TKI (15.9 [ \pm 11.1$]$ months) compared to those treated initially with chemotherapy (7.3 $[ \pm 6.7]$ months) $(p=0.380)$. 


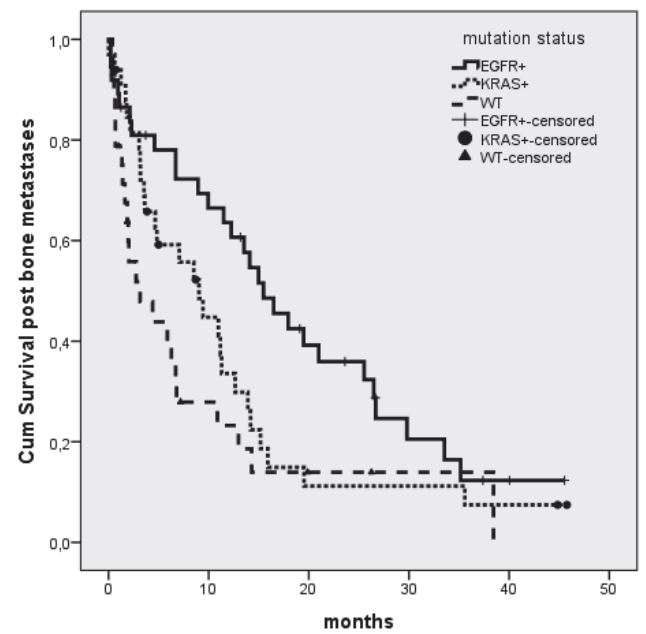

Figure 8.3 Survival post bone metastases for EGFR+, KRAS+ and WT patients.

\section{DISCUSSION}

It is well known that patients presenting with an activating EGFR mutation have a better prognosis than KRAS+ or WT patients. ${ }^{1-3}$ Although it is frequently suggested that EGFR+ patients, like HER2 positive breast cancer patients, are more prone to develop brain metastases during the course of their disease, ${ }^{5-9}$ this could not be confirmed in our retrospective case-control study. To our knowledge, this is the first case control study of EGFR+, KRAS+ and WT patients with follow-up from first diagnosis of mNSCLC to evaluate incidence of brain and bone metastases and survival thereafter. Although this was a retrospective study, bias regarding staging and treatment has been minimized by not selecting exclusively patients with brain metastases at diagnosis, but including all consecutive patients with an activating EGFR mutation and comparing the pattern of metastasis with consecutive KRAS+ and EGFR/KRAS WT patients. In the literature, one study is available that investigated the prevalence of metastases at first diagnosis of mNSCLC however without follow-up data. ${ }^{16}$ In this study (209 consecutive non-squamous mNSCLC patients, 39 EGFR+, $49 K R A S+, 41 A L K+$ and 80 triple negative) comparable results were obtained. The percentage of bone and brain metastases was not significantly different between $E G F R+, K R A S+, A L K+$ and triple negative patients at initial diagnosis of mNSCLC. ${ }^{4}$

In our study time to development of brain metastases was significantly longer in EGFR+ patients compared to KRAS+ patients, but survival post brain metastases was not significantly different. Although different treatments (EGFR-TKI versus chemotherapy) might influence development of and survival after brain metastases in EGFR+ patients 
in our study time to development of brain metastases was not significantly different for EGFR+ patients treated with EGFR-TKI compared to chemotherapy. However, with only 15 EGFR+ patients developing brain metastases after initial diagnosis of mNSCLC, numbers are too small to draw firm conclusions. In contrast, in a retrospective study of Heon et al., including 155 EGFR+ patients, time to central nervous system progression was significantly longer in the EGFR-TKI than in the chemotherapy group (median of 56 versus 31.6 months). ${ }^{17}$ In this study CNS progression was defined not only as newly diagnosed brain metastases, but also as growth of pre-existing metastases. Brain metastases in EGFR+ patients respond to treatment with EGFR-TKIs s, $^{5,18-22}$ and radiation therapy, ${ }^{22,23}$ with median survival post brain metastases of 12-19 months. ${ }^{5,9,20,22}$ Little is known of post brain metastases survival in EGFR+ patients treated with EGFR-TKI who develop brain metastases. In two retrospective studies $(\mathrm{N}=100$ and $\mathrm{N}=155)$, median survival after diagnosis of brain metastases was $5.5^{24}$ and 5.9 months. ${ }^{17}$ Although not significant, in our study survival after diagnosis of brain metastases was shorter when a patient was on EGFR-TKI treatment compared to starting EGFR-TKI treatment after diagnosis of brain metastases (6.8 versus 11.0 months).

More aggressive treatment of EGFR+ patients developing brain metastases while on EGFR-TKI treatment might prolong post brain metastases survival. For example, treatment with irreversible EGFR-TKIs or pulse therapy EGFR-TKI has been studied. ${ }^{25-27}$ In a phase I trial with afatinib, a NSCLC patient developed brain metastases during treatment with afatinib $10 \mathrm{mg}$ once daily, but had a 10 month lasting intracranial response on afatinib $40 \mathrm{mg}$ once daily. ${ }^{27}$ In another study, 6/9 patients with EGFR mutant lung cancer who developed brain metastases during treatment with regular doses of EGFR-TKI had a partial response to pulse therapy erlotinib (median of $1500 \mathrm{mg}$ weekly), another 2 had stable disease. Median time to central nervous system (CNS) progression was 2.8 months (range 0.8-14.5). ${ }^{26}$ Another option is radiotherapy and continuation of EGFR-TKI, especially when the brain is the only site of progressive disease. $^{28,29}$ In one study, CNS response rate and disease control rate were $41 \%$ and $76 \%$ respectively. Median OS was 408 days. ${ }^{28}$ In another study, PFS was 1.7-11.1 months, OS was not mentioned. ${ }^{29}$

Our study did also not show a different incidence and time to development of metastatic bone disease between EGFR+, KRAS+ and WT patients. Survival post metastatic bone disease was significantly longer in the EGFR+ group, but incidence of first SRE and time to first SRE was not different. Based on these results, it seems that EGFR+ patients have a longer survival with SREs. Prevention of metastatic bone disease and subsequent development of SREs (for example with bisphosphonates or denosumab) is important for all patients, but may be especially important in this subgroup of patients due to a longer survival with metastatic bone disease and the higher change of developing a SRE. This calls for a separate study of the effects of SRE 
preventing agents in EGFR+ patients. Strengths of the presented study include its multicenter character, the prospectively collected database and the case-control design. Limitations include its retrospective nature and the small number of patients with brain or bone metastases. As not all EGFR mutations confer the same sensitivity to TKIs, only patients with exon 19 and 21 mutations were included. Some patients only received best supportive care, but results did not change when we performed a subgroup analysis excluding these patients (data not shown). Finally, as current practice is not to screen for metastatic bone disease or brain metastases in mNSCLC, in our series patients did not undergo standard imaging at first diagnosis of metastasized disease or during follow-up, leading to a possible underdiagnosis of metastatic bone disease and brain metastases. Since the lack of brain and/or bone imaging at first diagnosis of mNSCLC was similar for the three groups, bias is less likely. To determine whether this influenced our data at first diagnosis of $\mathrm{mNSCLC}$, we reanalyzed the data excluding patients who had no brain or bone imaging at first diagnosis of mNSCLC. Results were similar (data not shown).

\section{CONCLUSION}

Incidence of metastatic bone disease and brain metastases was not different between EGFR+, KRAS+ and WT patients. Furthermore, survival post metastatic bone disease was significantly longer in the EGFR+ group, which stresses the impact of bone management especially in these patients and probably warrant more intense screening for metastatic bone disease. 


\section{REFERENCES}

1. Lynch TJ, Bell DW, Sordella R, Gurubhagavatula S, Okimoto RA, Brannigan BW, Harris PL, Haserlat SM, Supko JG, Haluska FG, Louis DN, Christiani DC, Settleman J, Haber DA. Activating mutations in the epidermal growth factor receptor underlying responsiveness of non-small-cell lung cancer to gefitinib. N Engl J Med. 2004;350:2129-39.

2. Mok TS, Wu YL, Thongprasert S, Yang CH, Chu DT, Saijo N, Sunpaweravong P, Han B, Margono B, Ichinose $Y$, Nishiwaki $Y$, Ohe $Y$, Yang JJ, Chewaskulyong B, Jiang H, Duffield EL, Watkins CL, Armour AA, Fukuoka M. Gefitinib or carboplatin-paclitaxel in pulmonary adenocarcinoma. N Engl J Med. 2009;361: 947-57.

3. Johnson ML, Sima CS, Chaft J, Paik PK, Pao W, Kris MG, Ladanyi M, Riely GJ. Association of KRAS and EGFR mutations with survival in patients with advanced lung adenocarcinomas. Cancer. 2013;119: 356-62.

4. Lin NU, Winer EP. Brain metastases: the HER2 paradigm. Clin Cancer Res. 2007;13:1648-55.

5. Eichler AF, Kahle KT, Wang DL, Joshi VA, Willers H, Engelman JA, Lynch TJ, Sequist LV. EGFR mutation status and survival after diagnosis of brain metastasis in nonsmall cell lung cancer. Neuro Oncol. 2010;12: 1193-9.

6. Lee YJ, Choi HJ, Kim SK, Chang J, Moon JW, Park IK, Kim JH, Cho BC. Frequent central nervous system failure after clinical benefit with epidermal growth factor receptor tyrosine kinase inhibitors in Korean patients with nonsmall-cell lung cancer. Cancer. 2010;116:1336-43.

7. Matsumoto S, Takahashi K, Iwakawa R, Matsuno Y, Nakanishi Y, Kohno T, Shimizu E, Yokota J. Frequent EGFR mutations in brain metastases of lung adenocarcinoma. Int J Cancer. 2006;119:1491-4.

8. Omuro AM, Kris MG, Miller VA, Franceschi E, Shah N, Milton DT, Abrey LE. High incidence of disease recurrence in the brain and leptomeninges in patients with nonsmall cell lung carcinoma after response to gefitinib. Cancer. 2005;103:2344-8.

9. Welsh JW, Komaki R, Amini A, Munsell MF, Unger W, Allen PK, Chang JY, Wefel JS, McGovern SL, Garland LL, Chen SS, Holt J, Liao Z, Brown P, Sulman E, Heymach JV, Kim ES, Stea B. Phase II trial of erlotinib plus concurrent whole-brain radiation therapy for patients with brain metastases from nonsmall-cell lung cancer. J Clin Oncol. 2013;31:895-902.

10. Jamal-Hanjani M, Spicer J. Epidermal growth factor receptor tyrosine kinase inhibitors in the treatment of epidermal growth factor receptor-mutant non-small cell lung cancer metastatic to the brain. Clin Cancer Res. 2012;18:938-44.

11. Coleman RE. Metastatic bone disease: clinical features, pathophysiology and treatment strategies. Cancer Treat Rev. 2001;27:165-76.

12. Langer C, Hirsh V. Skeletal morbidity in lung cancer patients with bone metastases: demonstrating the need for early diagnosis and treatment with bisphosphonates. Lung Cancer. 2010;67: 4-11.

13. Langer CJ, Mehta MP. Current management of brain metastases, with a focus on systemic options. J Clin Oncol. 2005;23:6207-19.

14. Kepka L, Cieslak E, Bujko K, Fijuth J, Wierzchowski M. Results of the whole-brain radiotherapy for patients with brain metastases from lung cancer: the RTOG RPA intra-classes analysis. Acta Oncol. 2005;44:389-98.

15. Heideman DA, Thunnissen FB, Doeleman M, Kramer D, Verheul HM, Smit EF, Postmus PE, Meijer CJ, Meijer GA, Snijders PJ. A panel of high resolution melting (HRM) technology-based assays with direct sequencing possibility for effective mutation screening of EGFR and K-ras genes. Cell Oncol. 2009;31: 329-33.

16. Doebele RC, Lu X, Sumey C, Maxson DA, Weickhardt AJ, Oton AB, Bunn PA, Jr., Baron AE, Franklin WA, Aisner DL, Varella-Garcia M, Camidge DR. Oncogene status predicts patterns of metastatic spread in treatment-naive nonsmall cell lung cancer. Cancer 2012;118:4502-11.

17. Heon S, Yeap BY, Lindeman NI, Joshi VA, Butaney M, Britt GJ, Costa DB, Rabin MS, Jackman DM, Johnson BE. The Impact of Initial Gefitinib or Erlotinib versus Chemotherapy on Central Nervous System Progression in Advanced Non-Small Cell Lung Cancer with EGFR Mutations. Clin Cancer Res. 2012;18: 4406-14. 
18. Park SJ, Kim HT, Lee DH, Kim KP, Kim SW, Suh C, Lee JS. Efficacy of epidermal growth factor receptor tyrosine kinase inhibitors for brain metastasis in non-small cell lung cancer patients harboring either exon 19 or 21 mutation. Lung Cancer. 2012;77:556-60.

19. Bai H, Han B. The effectiveness of erlotinib against brain metastases in non-small cell lung cancer patients. Am J Clin Oncol 2013;36:110-5.

20. Porta R, Sanchez-Torres JM, Paz-Ares L, Massuti B, Reguart N, Mayo C, Lianes P, Queralt C, Guillem V, Salinas P, Catot S, Isla D, Pradas A, Gurpide A, de Castro J, Polo E, Puig T, Taron M, Colomer R, Rosell R. Brain metastases from lung cancer responding to erlotinib: the importance of EGFR mutation. Eur Respir J. 2011;37:624-31.

21. Soffietti R, Trevisan E, Ruda R. Targeted therapy in brain metastasis. Curr Opin Oncol. 2012;24:679-86.

22. Hsiao SH, Lin HC, Chou YT, Lin SE, Kuo CC, Yu MC, Chung CL. Impact of epidermal growth factor receptor mutations on intracranial treatment response and survival after brain metastases in lung adenocarcinoma patients. Lung Cancer. 2013;81:455-61.

23. Gow CH, Chien CR, Chang YL, Chiu YH, Kuo SH, Shih JY, Chang YC, Yu CJ, Yang CH, Yang PC. Radiotherapy in lung adenocarcinoma with brain metastases: effects of activating epidermal growth factor receptor mutations on clinical response. Clin Cancer Res. 2008;14:162-8.

24. Heon S, Yeap BY, Britt GJ, Costa DB, Rabin MS, Jackman DM, Johnson BE. Development of central nervous system metastases in patients with advanced non-small cell lung cancer and somatic EGFR mutations treated with gefitinib or erlotinib. Clin Cancer Res. 2010;16:5873-82.

25. Clarke JL, Pao W, Wu N, Miller VA, Lassman AB. High dose weekly erlotinib achieves therapeutic concentrations in CSF and is effective in leptomeningeal metastases from epidermal growth factor receptor mutant lung cancer. J Neurooncol. 2010;99: 283-6.

26. Grommes C, Oxnard GR, Kris MG, Miller VA, Pao W, Holodny Al, Clarke JL, Lassman AB. "Pulsatile" highdose weekly erlotinib for CNS metastases from EGFR mutant non-small cell lung cancer. Neuro Oncol. 2011;13: 1364-9.

27. Yap TA, Vidal L, Adam J, Stephens P, Spicer J, Shaw H, Ang J, Temple G, Bell S, Shahidi M, UttenreutherFischer M, Stopfer P, Futreal A, Calvert H, de Bono JS, Plummer R. Phase I trial of the irreversible EGFR and HER2 kinase inhibitor BIBW 2992 in patients with advanced solid tumors. J Clin Oncol. 2010;28: 3965-72.

28. Shukuya T, Takahashi T, Naito T, Kaira R, Ono A, Nakamura Y, Tsuya A, Kenmotsu H, Murakami H, Harada H, Mitsuya K, Endo M, Nakasu Y, Takahashi K, Yamamoto N. Continuous EGFR-TKI administration following radiotherapy for non-small cell lung cancer patients with isolated CNS failure. Lung Cancer. 2011;74:457-61.

29. Weickhardt AJ, Scheier B, Burke JM, Gan G, Lu X, Bunn PA, Jr., Aisner DL, Gaspar LE, Kavanagh BD, Doebele RC, Camidge DR. Local ablative therapy of oligoprogressive disease prolongs disease control by tyrosine kinase inhibitors in oncogene-addicted non-small-cell lung cancer. J Thorac Oncol. 2012;7: 1807-14. 


\title{
Chapter 9
}

\section{Safety of cranial radiotherapy}

\author{
concurrent with tyrosine kinase
}

Thibitors in non-small cell lung cancer

patients: a systematic review

Lizza E.L. Hendriks, Janna Schoenmaekers, Jaap D. Zindler, Danielle B. Eekers, Ann Hoeben, Dirk K.M. De Ruysscher, A-M.C. Dingemans Cancer Treat Rev. 2015;41:634-45 


\section{ABSTRACT}

Recently, non-small cell lung cancer (NSCLC) has been partly subclassified into molecularlydefined oncogene "addicted" tumours for which targeted agents are available. Tyrosine kinase inhibitors (TKI) are currently approved for patients with an activating epidermal growth factor receptor $(E G F R)$ mutation or anaplastic lymphoma kinase $(A L K)$ rearrangement. In these patients, brain metastases are often the first site of progression while on TKI treatment. The TKI may however still be active on extra-cranial sites and clinicians are thus faced with the question if the TKI may be continued during cranial radiotherapy. Advantages of combining TKI with cranial radiotherapy would be a possible synergistic effect on the brain metastases and the prevention of a systemic disease flare-up. A disadvantage is the possibly increased risk of (neuro)toxicity. The present systematic review addresses the toxicity of combining TKI with cranial radiotherapy in NSCLC patients. 


\section{INTRODUCTION}

Increasingly, new molecular features of non-small cell lung cancer (NSCLC) are being discovered, leading to an unprecedented growth of targeted agents. These are often tyrosine kinase inhibitors (TKI). ${ }^{1}$ Currently, TKI are approved for metastasized NSCLC patients with an activating epidermal growth factor receptor (EGFR) mutation or an anaplastic lymphoma kinase $(A L K)$ rearrangement, either as first line or beyond. ${ }^{2,3}$ Examples are erlotinib, gefitinib, afatinib and icotinib (China only) for EGFR-mutations, and crizotinib and ceritinib (USA only) for $A L K$-rearrangements. Approximately $20-35 \%$ of these patients are diagnosed with brain metastasis at initial diagnosis and these patients are often amenable for initial treatment with TKI. ${ }^{4-8}$ However, a substantial part will develop new brain metastasis or progression of brain metastasis during treatment. On erlotinib and gefitinib treatment $14-33 \%$ of patients develop (progression of) brain metastasis. ${ }^{9-15}$ In patients with a survival beyond five years, this percentage increases to $52.9 \%{ }^{6}$ On crizotinib treatment $70 \%$ of patients experience progression of brain metastases after an initial cerebral disease control rate of $60 \%$ (median time to intracranial progression: 7 months). $20 \%$ of patients without brain metastasis at initial NSCLC diagnosis develop brain metastasis during crizotinib treatment and this increases to about $58 \%$ in patients with a survival beyond three years. $^{6,8}$ In these patients, the brain is often the first and/or only site of progression (oligo-progression). ${ }^{8,12,14,16}$

The TKI may however still be active on extra-cranial sites and clinicians are thus faced with the question if the TKI may be continued during cranial radiotherapy. Although there are pre-clinical studies suggesting that TKIs enhance radiation effects, the effects on normal tissues are unclear. ${ }^{17-20}$ Data show that some molecular features of the tumour are not only related to response to TKI but also to radiation susceptibility of the tumour. As an example, tumours with activating EGFR-mutations not only show a high probability to respond to EGFR-TKI but also to radiation. ${ }^{21}$ In current guidelines (ESMO 2014, NCCN 2014, ASTRO 2012) no recommendations are made regarding the concurrent use of TKI's and cranial radiotherapy in NSCLC patients with an activating mutation. ${ }^{2,3,22,23}$ Frequently, TKI's are discontinued during cranial radiation because of (neuro)toxicity concerns. However, toxicity (e.g. radiation pneumonitis) does not seem to increase when EGFR-TKI are combined with thoracic radiotherapy in the majority of studies although some did report a higher incidence of grade 3-5 radiation pneumonitis. ${ }^{24-27}$ Advantages of combining TKI with cranial radiotherapy would be a possible synergistic effect on the brain metastases and the prevention of a systemic disease flare-up. The latter has been described in both EGFR-mutated patients ( $23 \%$ of patients, median time to disease flare-up 8 days, range 3-21 days) and in an $A L K$ translocated patient (time to disease flare-up 15 days). ${ }^{28,29}$ Among the factors associated with an increased risk for a disease flare-up was the presence of central nervous system (CNS) disease. ${ }^{28}$ 
The aim of the present systematic review is to address the toxicity of combining TKI with cranial radiotherapy in NSCLC patients as, to the best of our knowledge, there is no systematic review on this topic. The focus will be on neurotoxicity. When possible, a daily practice advice will be formulated.

\section{METHODS}

\section{SEARCH STRATEGY AND SELECTION CRITERIA}

The literature search was performed following the PICO method ${ }^{30}$ and is shown in Appendix 9.1. This search was used to identify studies in Pub Med, EMBASE, Web of Science and the Cochrane Library from 2001 until the search date in November 2014. Additionally, clinicaltrials.gov was searched to identify unpublished or ongoing clinical trials.

Selection criteria were established prior to the search and selection of articles. These included human only studies, including a minimum of 5 NSCLC patients treated with concurrent cranial radiotherapy and TKI's (EGFR: erlotinib, gefitinib, afatinib, icotinib, $A L K$ : crizotinib, ceritinib and alectinib). As safety was the primary endpoint there was no restriction on the presence of a targetable mutation. Studies with whole brain radiotherapy (WBRT) as well as stereotactic radiosurgery/stereotactic radiotherapy (SRS/SRT) were included. Language was restricted to English, German and Dutch. Original articles and conference proceedings were included, reviews were excluded. Additionally, references of eligible articles were manually searched to find other relevant studies. All inclusion and exclusion criteria are summarized in Table 9.1.

Table 9.1 Inclusion criteria for review.

\begin{tabular}{ll}
\hline Subjects included & Human only \\
\hline Language & English, German, Dutch \\
Article type & Original article, conference proceeding \\
Number of patients & $\geq 5$ \\
Site of primary tumour & NSCLC \\
Tumour stage & IV \\
Treatment & WBRT and/or SRS/SRT concurrent with TKI (EGFR- or ALK-TKI) \\
Follow up period & All \\
Outcome & Safety / adverse events one of the outcomes measured \\
\hline
\end{tabular}

NSCLC: non-small cell lung cancer; WBRT: whole brain radiotherapy; SRS: stereotactic radiosurgery; SRT: stereotactic radiotherapy; TKI: tyrosine kinase inhibitor; EGFR: epidermal growth factor receptor; $A L K$ : anaplastic lymphoma kinase.

\section{OUTCOMES}

One researcher (LH) conducted the search and selection of eligible studies. All articles were then evaluated by another independent reviewer (JS). When available, the 
following data were extracted from eligible studies by one researcher (LH) and independently by another researcher (JS): author, year of publication, original article or conference proceeding only, type of study, duration of study, number of included patients, EGFR mutation/ALK-translocation status available (yes/no) and results of mutation testing, dose cranial radiotherapy (WBRT and/or SRS/SRT), description of TKI used (including dosing and timing), safety and efficacy outcomes.

Data were extracted and tabulated independently (Appendix 9.2). Consensus was reached by discussion between reviewers when outcomes differed.

\section{RESULTS}

\section{SEARCH RESULTS}

The initial search in the four databases included 710 articles in total. Using Endnote and manual screening, 179 duplicate articles were excluded. Another 461 articles were excluded based on not relevant titles for this study, 70 articles were further screened. After reading of the abstracts, another 43 articles were excluded based on the exclusion criteria. Of the 27 remaining articles and conference proceedings, the whole article was read (not possible for conference proceeding). Based on the exclusion criteria, 11 articles and 3 conference proceedings were eligible to include in this review. With a manual search of the reference list of the included articles one other relevant article was found (flowchart in Figure 9.1).

\section{DESCRIPTION AND QUALITY OF THE STUDIES}

Of the 12 original articles and 3 conference proceedings that matched the selection criteria and were included in this review, 6 evaluated erlotinib concurrent with WBRT (one study combined WBRT with SRS), ${ }^{31-36} 4$ evaluated gefitinib concurrent with WBRT $^{37-40}$ and in 3 studies both drugs were studied. ${ }^{41-43}$ In 2 studies icotinib concurrent with WBRT was studied. ${ }^{44,45}$ For afatinib, crizotinib, ceritinib and alectinib no studies were found concurrent with cranial radiotherapy.

Five studies were retrospective. ${ }^{33,40-43} 2$ studies were phase I, ${ }^{32,45} 7$ were phase II, ${ }^{31,35-39,44}$ and there was only one phase III trial. ${ }^{34}$ The phase III trial was a randomized, but not placebo controlled study. ${ }^{34} 4$ out of 7 phase II studies consisted of 2 arms. $^{31,36,38,39}$ In one of these studies patients were not randomized to one of the arms, but treatment allocation was based on whether EGFR-mutation status was determined. These patients (irrespective of EGFR-testing results) were allocated within the concurrent arm, the patients in which mutation analysis was not performed were allocated within the WBRT only arm. ${ }^{36}$ Of the 4 phase II, 2 arm-studies only one study was a double blind, placebo controlled study. ${ }^{31}$ 


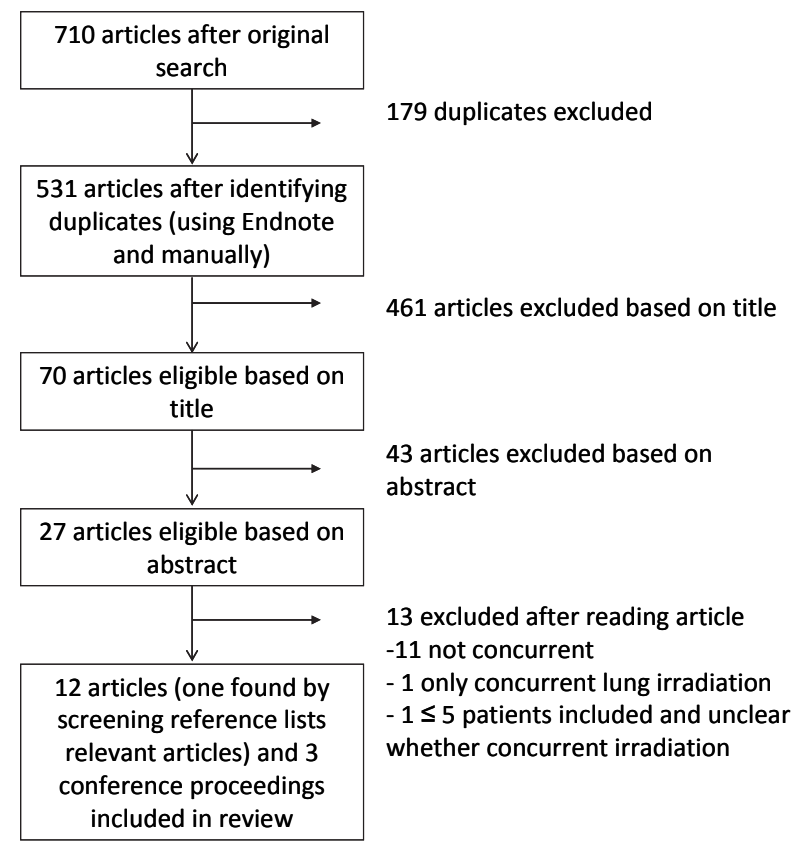

Figure 9.1 Flowchart article selection.

There was one study in which only patients with an activating EGFR mutation were included $^{45}$ and there were 8 other studies in which at least part of the included patients were tested for activating EGFR mutations. $31,35,36,39-41,43,44$ In these studies, percentage of EGFR-mutated patients (computed as number EGFR-mutated/total number of patients included) varied between 1.3 and $69.8 \%$.

For WBRT, the total radiation dose varied between 20 and $50 \mathrm{~Gy}$ in 4 (20Gy) to 25 (50Gy) fractions. EGFR-TKI were initiated from one week before the onset of cranial radiation to the first day of radiotherapy. In most studies, after WBRT, investigators could continue the EGFR-TKI at their own discretion. ${ }^{31-35,37-45}$ Only in one study the EGFR-TKI was discontinued one month after completion of WBRT. ${ }^{36}$ In the two-arm studies, the treatments that were compared varied between WBRT only (or combined with temozolomide or chemotherapy) and WBRT concurrent with EGFR-TKI, and EGFRTKI only compared to WBRT concurrent with EGFR-TKI. ${ }^{31,34,36,38-41}$ Primary outcomes ranged between overall survival (OS), (neurological) progression free survival ((n)PFS), local PFS (LPFS), intracranial response rate, toxicity and quality of life (QoL). All studies are summarized in Table 9.2. For the retrospective studies, all outcomes are listed as primary. 


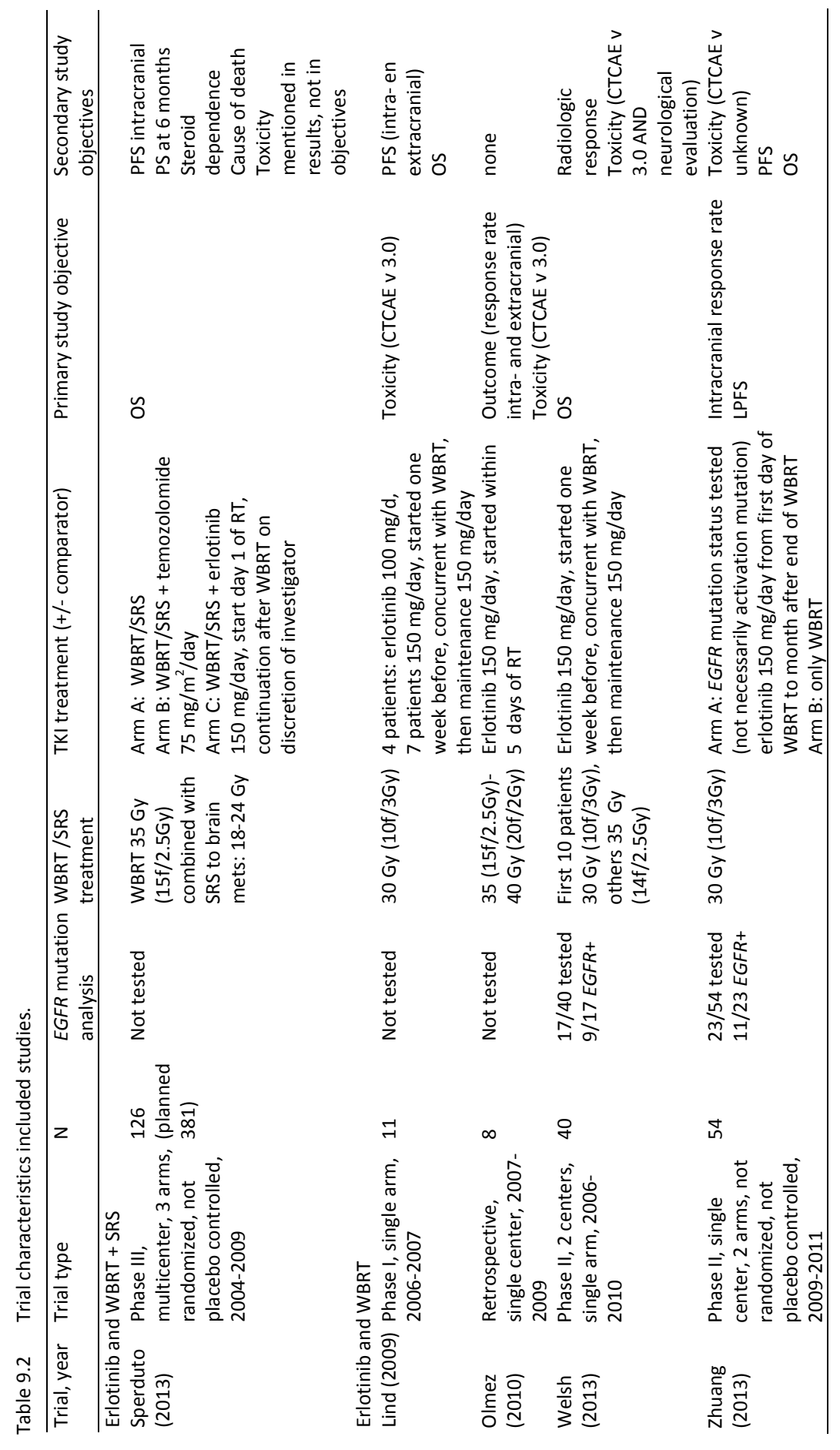




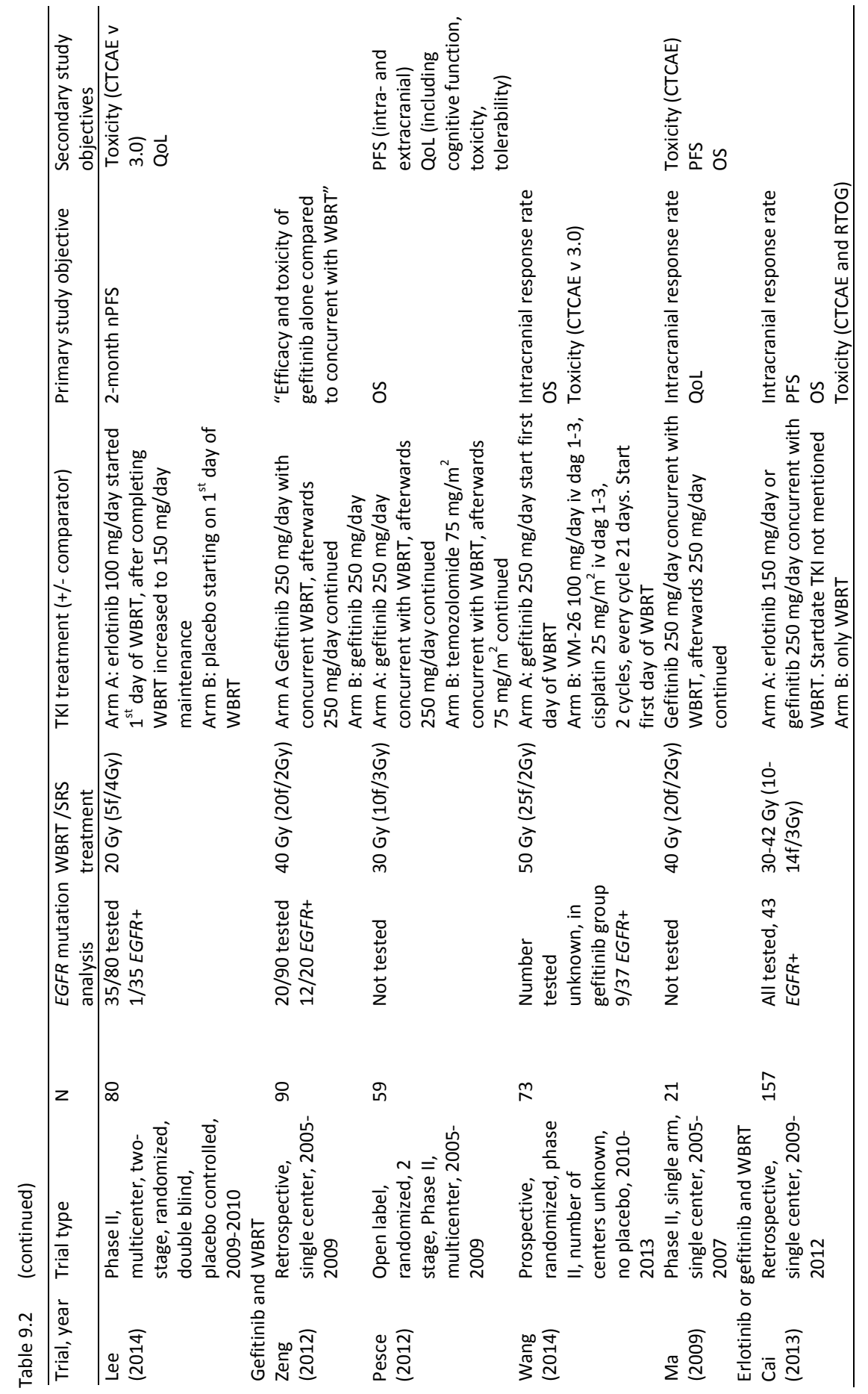




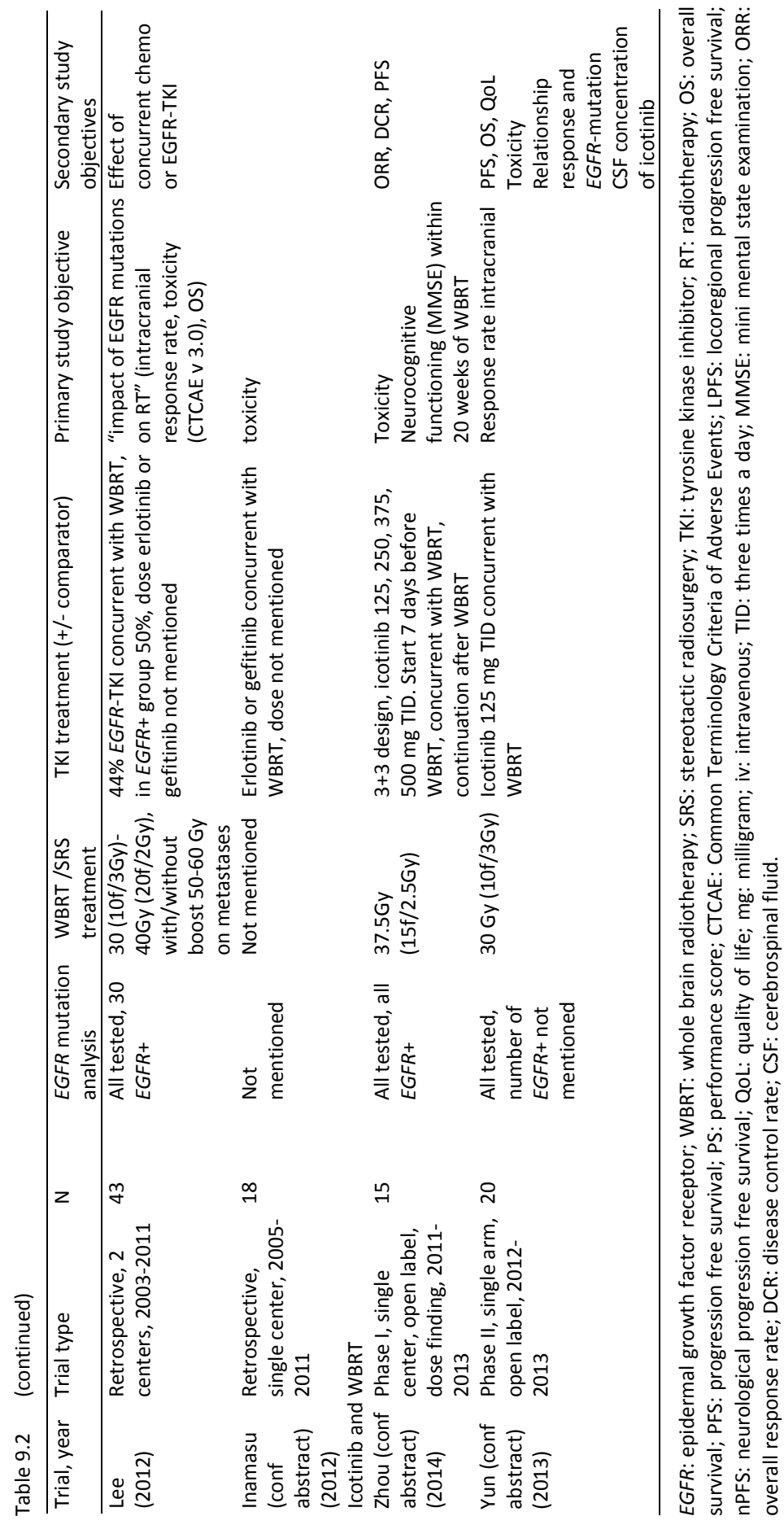




\section{FREQUENCY AND METHODS OF TOXICITY EVALUATION}

In 3 out of 10 (30\%) prospective studies, toxicity was the primary objective. ${ }^{32,39,45}$ In the study of Lind et al., neurotoxicity was not an end point of the trial; neurological examination was performed at baseline and was not specified during the follow-up although adverse events were recorded according to the Common Terminology Criteria of Adverse Events (CTCAE) criteria. ${ }^{32}$ Wang et al did not include specific neurocognitive functioning tests. ${ }^{39}$ Zhou et al (abstract only) only performed Mini Mental State Examinations (MMSE) up to 20 weeks after WBRT. ${ }^{45}$ In the study of Lee et al, toxicity itself was not a primary objective, however nPFS was. This consisted of a clinical (MMSE, assessment of motor strength, visual acuity and gait) and radiological assessment. Adverse events according to the Common Terminology Criteria of Adverse Events (CTCAE) criteria were only recorded up to 28 days after finalizing the treatment. ${ }^{31}$ From the other 6 prospective studies, Welsh et al. did the most extensive neurotoxicity evaluation. Neurological examination and MMSE were performed at baseline, at 6 months and at 12 months after treatment. Patients had also formal cognitive testing (neurological examination, Hopkins Verbal Learning Test-Revised, Trail Making Test Part $A$ and B, Multilingual Aphasia Examination Controlled Oral Word Association) before enrolment, within 14 days of WBRT completion and at each follow-up visit (at 1 month and then every 3 months). ${ }^{35}$ In the study of Pesce et al., cognitive function (MMSE, Trail Making Test part B, EORTC QLQ-C30 cognitive function subscale) was assessed prior to start and on day one of cycles 2, 3 and $5 .^{38}$ In the study of Ma et al., neurological examination was performed weekly during concurrent treatment. ${ }^{37}$ In the other studies, neurotoxicity was not a specific item and toxicity was scored according to the CTCAE criteria. ${ }^{34,36,37,44}$ Methods and frequency of toxicity assessment are summarized in Table 9.3. Only prospective studies are summarized, as in the retrospective studies there was no specified protocol for follow-up.

\section{TOXICITY OUTCOMES}

All outcomes are summarized in Table 9.4. 9 trials (3 retrospective) specifically mentioned neurotoxicity $32-35,37,40,41,45$ of which 5 reported that there was no increased neurotoxicity of the concurrent treatment. ${ }^{32,35,40,41,45}$ However, in one of these studies 2 questionable late neurotoxicity events were reported: one 74-year old male developed dementia two years after study completion and one 56-year old female had 5 months after study completion intracranial progression for which she received SRS, she developed brain necrosis thereafter. Other contributing factors for these events were older age (possibly unrecognized cognitive impairment) in the first patient and the use of SRS in the second. ${ }^{35}$ In one study $5 \%$ grade 3 dizziness for both the WBRT only and the WBRT + erlotinib group was reported but no late neurotoxicity. Duration of dizziness was not mentioned. ${ }^{36}$ In one retrospective study $(N=8) 3$ patients had mental status change. 


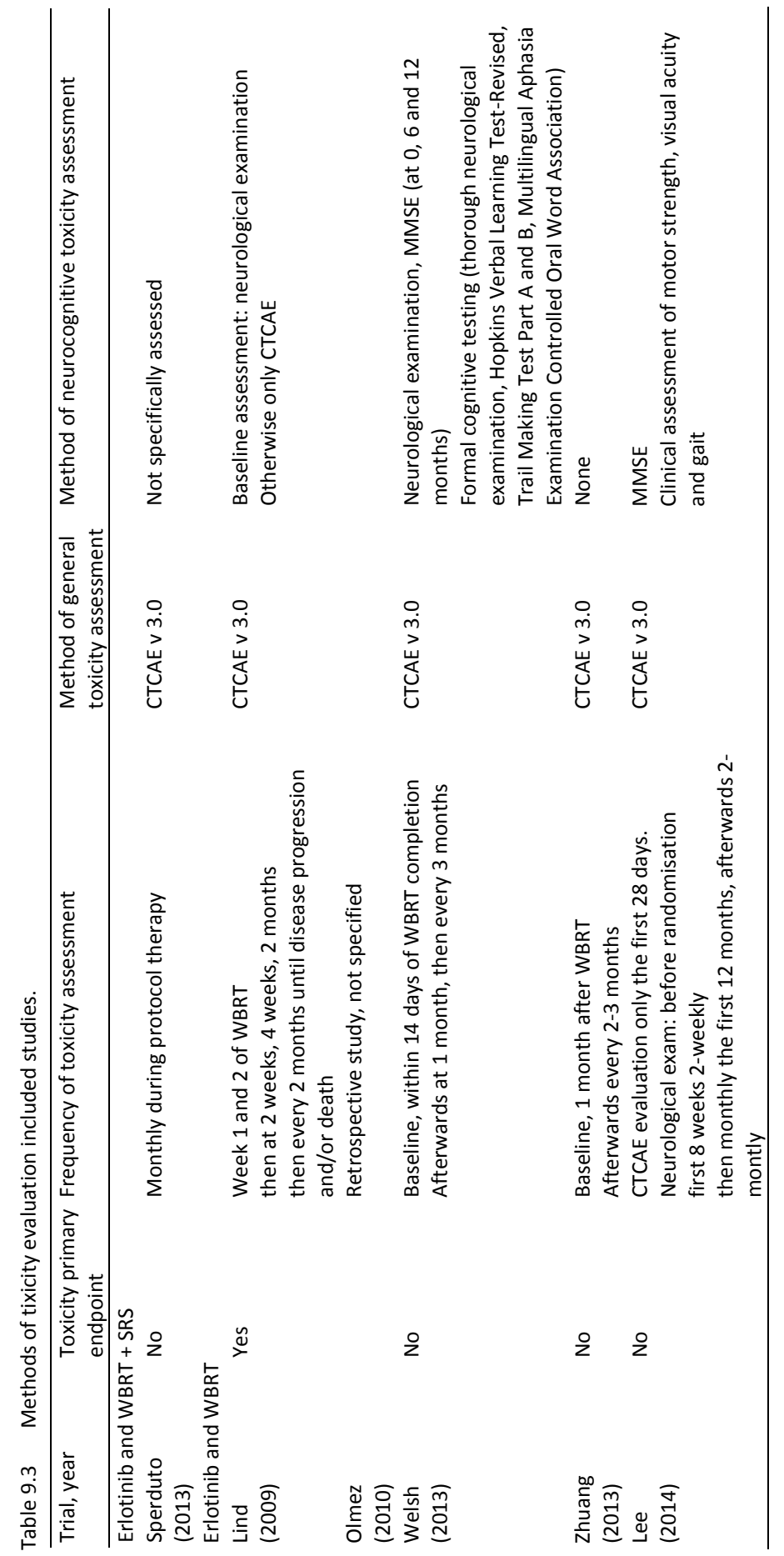




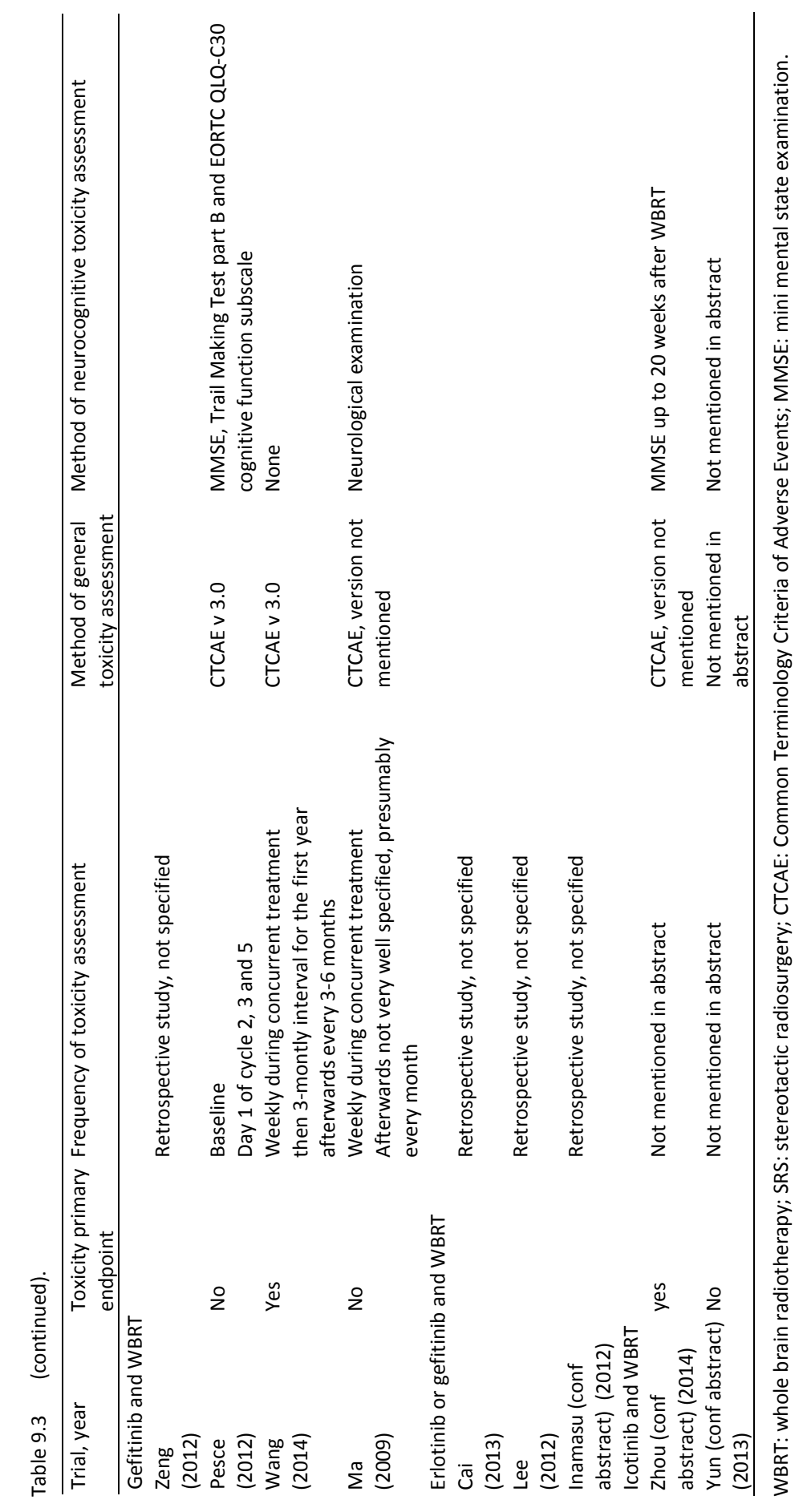




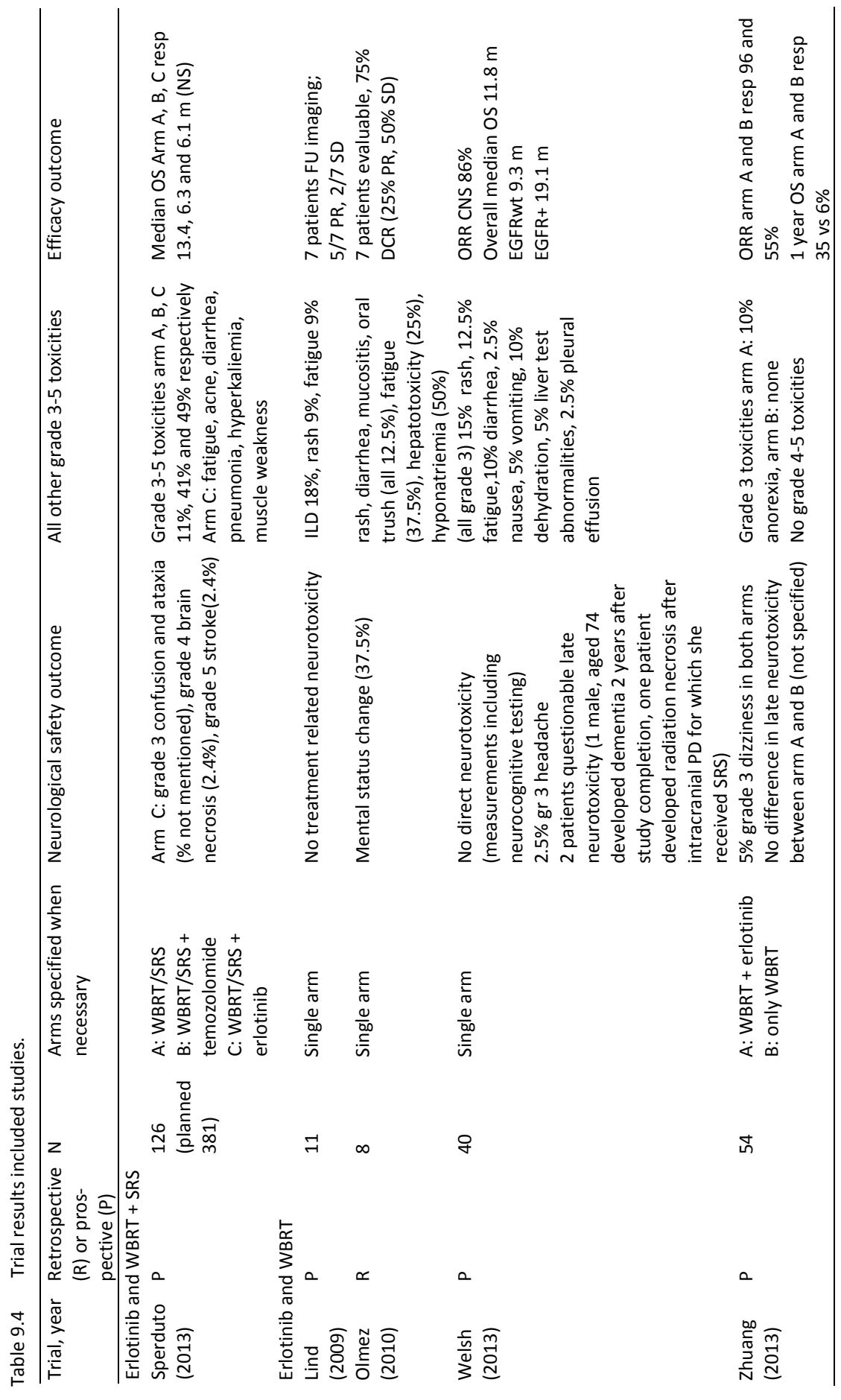




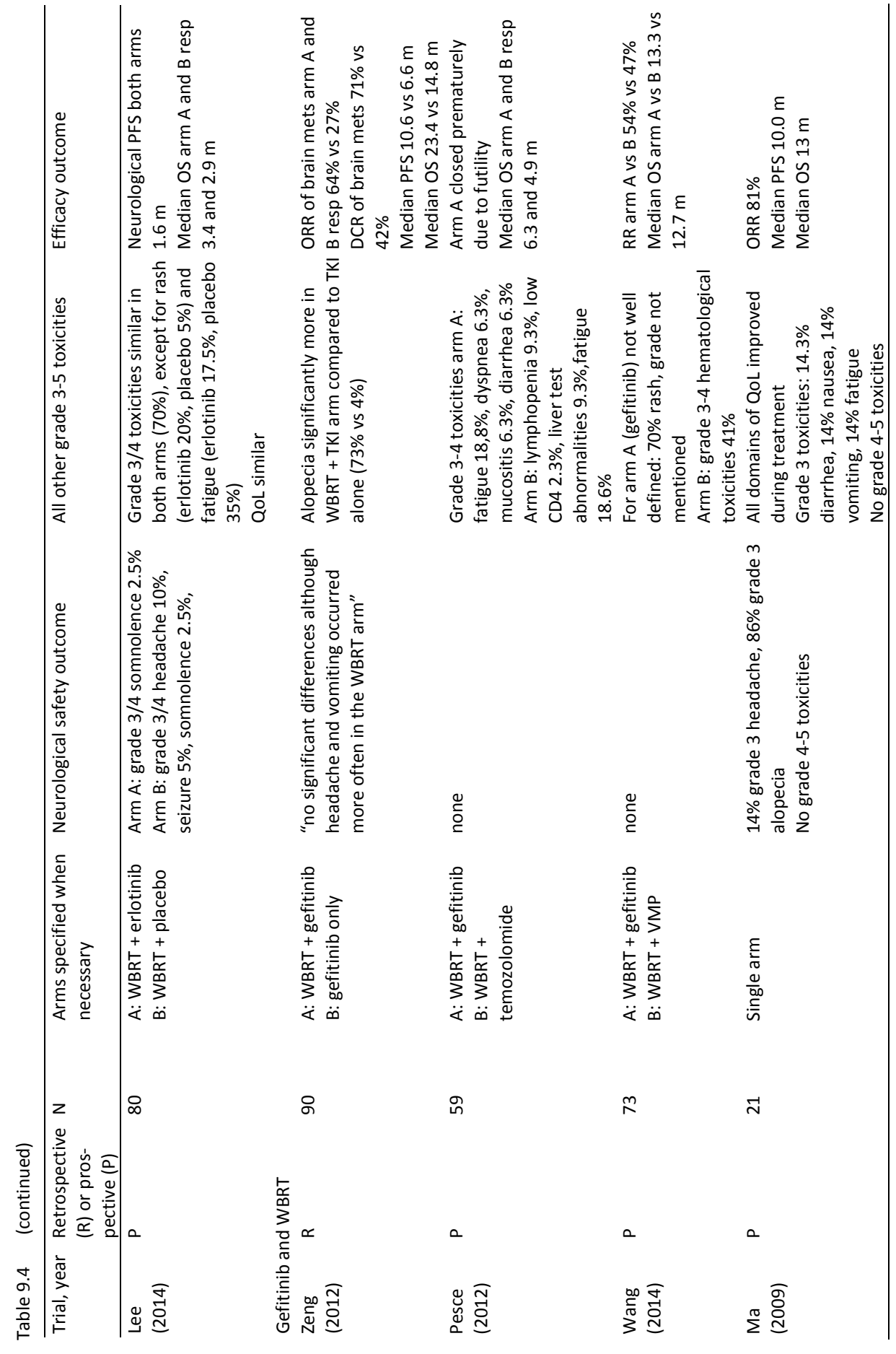




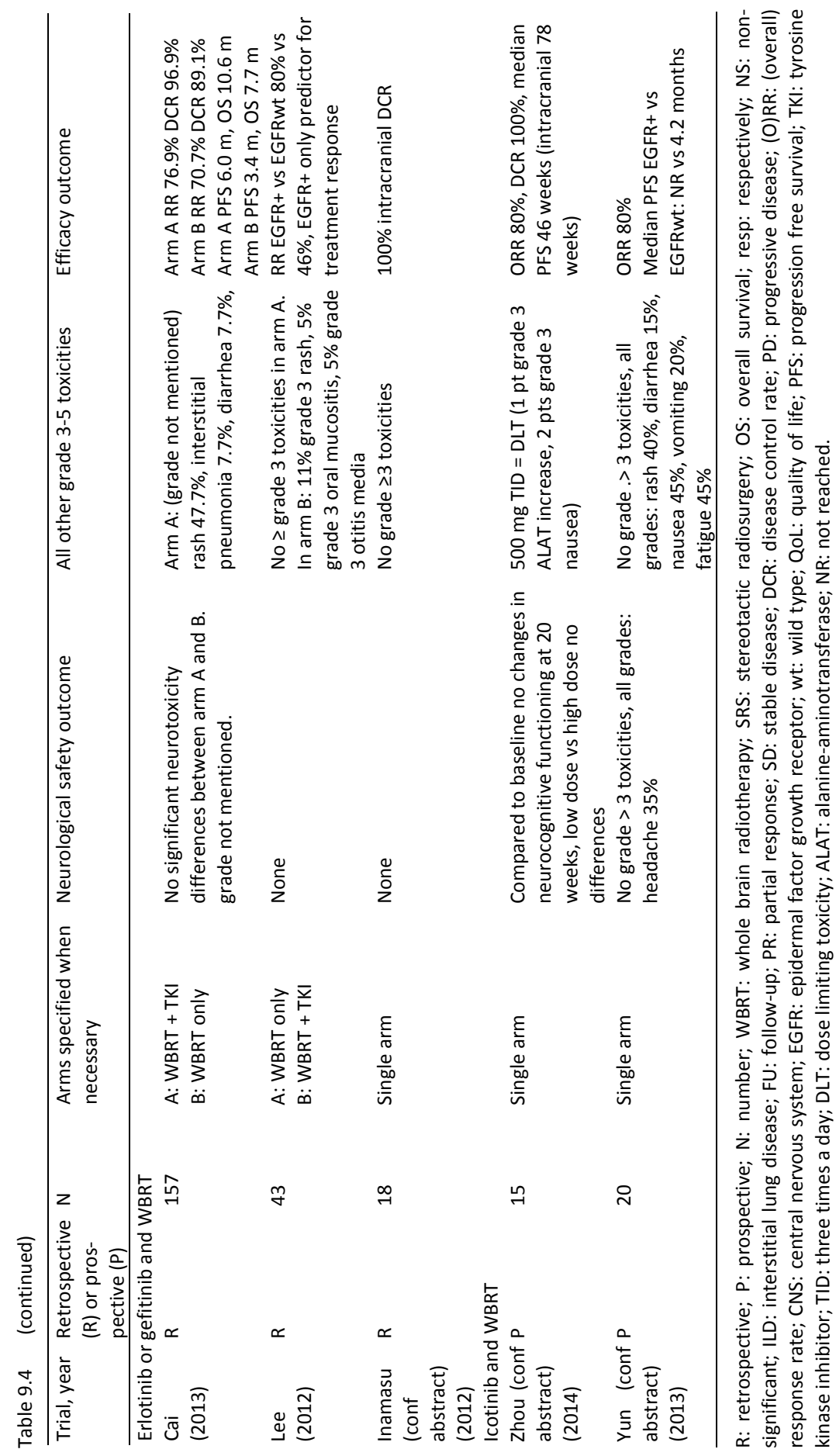


Two of these patients also had grade 3 hyponatremia and an intercurrent infection as a possible contributing factor for the mental status change. ${ }^{33}$ In a prospective randomized study of WBRT together with SRS and combined with erlotinib, temozolomide or no systemic treatment, grade 4 brain necrosis and grade 5 haemorrhagic stroke both occurred in 1/41 patients in the erlotinib arm. Grade 3 confusion and ataxia were also found, but number of patients was not specifically mentioned. $^{34}$ In a single arm prospective study $(\mathrm{N}=21) 14 \%$ grade 3 headache was reported, but grade 4-5 toxicities did not occur. ${ }^{37}$ In the other 6 studies neurotoxicities were not specifically described. However, all grade/ grade 3-5 toxicities were mentioned and these did not include grade 3-5 neurotoxicities. Time to resolution of toxicities was not mentioned. . $^{31,38,39,42-44}$

\section{DISCUSSION}

A relatively high percentage of $E G F R$-mutated and $A L K$-rearranged patients will develop brain metastases during the course of their disease, often while on TKI treatment. ${ }^{9-15,46}$ A possible explanation for this high percentage is that the first generation TKI's do not achieve therapeutic concentrations in the brain due to (relative) inability to cross the blood-brain barrier. ${ }^{47-49}$ In this situation, extra cranially located cancer cells are often still dependent on EGFR- or ALK-signalling and are responding to TKI's. ${ }^{12}$ In patients with brain metastases both WBRT and SRS/SRT can be considered, mainly dependent on the number/volume of brain metastases and the performance status of the patient. ${ }^{3}$ In current guidelines, no advice regarding TKI use during cranial radiotherapy is given. $^{2,3,22,23}$ To our knowledge, the present study was the first to systematically review the literature in order to evaluate the safety of concurrent cranial radiotherapy and TKI. For ALK-TKI, no studies were found. For EGFR-TKI, 15 studies were found of which 5 were retrospective. ${ }^{31-45}$ In only 9 studies, presence of an activating EGFR-mutation was evaluated with varying percentages $(1.3-100 \%) .^{31,35,36,39-41,43-45}$ Only one study was a phase III study ${ }^{34}$ and only 3 out of 7 phase II studies were randomized 2 arm studies. $^{31,38,39}$ In the identified papers, treatments studied varied between WBRT only, WBRT concurrent with EGFR-TKI (in one study also combined with SRS) and EGFR-TKI only. No studies were found for SRS without WBRT concurrently with TKI. No studies were identified in which patients with an activating mutation/translocation developed brain metastases while on TKI treatment and were subsequently randomized to cranial radiotherapy with concurrent TKI or cranial radiotherapy with temporarily discontinuation of the TKI. Primary outcomes varied and outcome data were measured and reported in a non-uniform way. Based on these data, WBRT concurrent with EGFRTKI does not seem to increase neurotoxicity, although no firm conclusions can be made. However, one should be cautious in interpreting the neurological toxicity data from most of these studies, as in only two studies extensive neurocognitive tests were 
performed. ${ }^{35,38}$ In both of these studies neurotoxicity was not the primary endpoint; one study was a single arm study and the other was not powered to detect neurotoxicity differences. Moreover, in the two arm study there was no comparator arm without an active systemic drug (one arm gefitinib concurrently with WBRT, the other temozolomide concurrently with WBRT). ${ }^{38}$ As such, subtle changes in neurocognitive functioning due to concurrent TKI and cranial radiotherapy cannot be excluded. Furthermore, WBRT combined with SRS, concurrent with EGFR-TKI does seem to increase neurotoxicity when compared to historical data for WBRT and SRS without concurrent systemic treatment. In the study with concurrent EGFR-TKI, grade 3 confusion and ataxia (percentage not mentioned), grade 4 brain necrosis $(2.4 \%)$ and grade 5 stroke $(2.4 \%)$ were reported. ${ }^{34}$ In the study without systemic treatment, acute toxicities were grade 3 in $2 \%$ of patients, grade 4 in $1 \%$ and none had grade 5 toxicities. $^{50}$ Non-neurological toxicities seem to increase with the concurrent use of EGFR-TKI when compared to monotherapy EGFR-TKI or WBRT. EGFR-TKI's are known to cause grade $\geq 3$ toxicities, like rash (3-13\%), diarrhoea (0-25\%), fatigue (0-19\%), nausea $(3-6 \%)$, vomiting $(3-5 \%)$ and interstitial lung disease $\left(1.2 \%\right.$, all grades). ${ }^{51-53}$ When compared to the $3-13 \%$ grade $\geq 3$ rash encountered with monotherapy EGFR-TKI, this percentage is slightly higher in the concurrent treated patients in this review (9-20\%). ${ }^{31-35,43}$ Grade $\geq 3$ rash was more often encountered with erlotinib than with gefitinib as is also known from literature, possibly because erlotinib is given at the maximum tolerated dose (MTD) and gefitinib is given at approximately one third of the MTD. ${ }^{54}$ Although location of rash was not described, it is possible that this occurred on the scalp due to the concurrent WBRT. The same holds true for grade $\geq 3$ mucositis, as this is seldom encountered with first generation EGFR-TKI, ${ }^{53}$ and was observed in $5-12.5 \%$ in the studies described in this review. ${ }^{33,38,43}$ However, only one of these studies was randomized and in this trial, in both arms a systemic agent was given (temozolomide or gefitinib). ${ }^{38}$ Moreover, the technique of WBRT was very simple, thus including some mucosa in the irradiated volumes. Percentages of grade $\geq 3$ fatigue, nausea and vomiting do not seem to increase with EGFR-TKI concurrent with WBRT compared to monotherapy EGFR-TKI, although WBRT itself also can also cause fatigue, nausea and vomiting (usually $\leq$ grade 2 ). ${ }^{55}$

As safety was the focus of our review there was no restriction on the presence of a targetable mutation. As such, the question whether the potential increase in local CNS response rate and the prevention of tumour flare when the TKI is continued during cranial radiation outweighs the potential risk of clinically significant side effects is not answered. To date, there are no studies addressing this specific question in patients with an activating mutation. In two out of four studies that compare WBRT to concurrent EGFR-TKI and WBRT, the response rate and OS were higher in patients that were treated with the combined treatment. However, in these trials EGFR mutation status was not tested or known only for a subset of patients. It was also unclear 
whether EGFR-mutated patients treated with WBRT only were afterwards treated with EGFR-TKI (i.e. possible undertreatment of these WBRT only patients). ${ }^{31,34,36,41}$

As mentioned above, no studies were identified in which patients with an activating mutation/translocation developed brain metastases while on TKI treatment and were subsequently randomized to cranial radiotherapy with/without concurrent TKI. In current guidelines, no advice regarding TKI use during cranial radiotherapy is given. ${ }^{2,3,22,23}$ In daily practice, the TKI is often discontinued for 4-5 times the half-life $(T 1 / 2)$ of the drug before start of cranial radiotherapy and is reinitiated a couple of days after cranial radiotherapy because of (neuro)toxicity concerns. For the first generation TKI's, T1 $1 \frac{2}{2}$ is 36 hours (erlotinib) to $40-42$ hours (gefitinib- crizotinib). ${ }^{56-58} \mathrm{~T} 1 / 2$ of icotinib is only six to eight hours. ${ }^{58}$ As a result, TKI's are discontinued approximately two to three weeks because of cranial radiotherapy with the risk of a systemic disease flare-up. The 4-5 times the $T 1 / 2$ is based on the finding that after this time drugs are eliminated from the blood. However, it is unclear whether there are still remaining biological effects of the drug. Moreover, it is also unknown whether there is a dose-dependent effect for radiosensitisation. Furthermore, for other drugs like monoclonal antibodies $T 1 / 2$ is often more than one week (e.g. ipilimumab T1/2 15 days) which makes it impossible due to the need for systemic disease control to discontinue these drugs for $4-5$ times the $T 1 / 2 .{ }^{59}$ As there is a lack of pre-clinical data for e.g. radiosensitisation and dose-dependency as well as remaining biological effects after discontinuation of the drug (TKI as well as monoclonal antibodies), this should be subjected to further research. Another question that is not evaluated in this review is what the best treatment sequence is for patients with an activating EGFR mutation or $A L K$-rearrangement with already a diagnosis of asymptomatic brain metastasis before commencement of a TKI. Based on available literature, patients with an activating EGFR mutation can start directly with an EGFRTKI, as, despite the poor blood-brain-barrier penetration of first generation EGFR-TKIs, the cerebral response rate is more than $80 \%{ }^{7}$ For $A L K$-rearranged patients, data are less clear. In the retrospective pooled analysis of the subgroup of patients with previously untreated brain metastases included in the PROFILE 1005 and 1007 studies, cerebral response and disease control rate were only $18 \%$ and $53 \%$ respectively, and the CNS was the initial site of progression in $70 \%$ of patients. ${ }^{8}$ One can argue that in this patient population, cranial radiotherapy can be considered first.

Also, the place of the second and third generation TKI's (EGFR: afatinib, AZD9291, CO1686, ALK: ceritinib, alectinib) should be determined as these agents have a better penetration in the CSF compared to first generation TKI's and cranial responses are found with these agents in patients who develop brain metastases when they have already been treated with first generation TKI. ${ }^{15,60-62}$ Another option that could be explored in this patient population is the use of SRS without WBRT, even for multiple (five to ten) brain metastases. This because recently it was found that results for SRS alone did not differ between patients with two to four brain metastases compared to five to ten metastases. ${ }^{63}$ The advantages for SRS/SRT without WBRT are that both 
cognition and quality of life are superior with SRS/SRT alone. ${ }^{64}$ Moreover, local control rates are durable (12-month local control rate between 50 and more than $80 \%$ dependent on radiation dose and volume of brain metastases) and complication rate is low (grade $\geq 3$ adverse events less than $5 \%$ ). ${ }^{63,65,66}$ However, because of number and/or volume of brain metastases, not all patients are suitable for SRS/SRT and WBRT still is an option in this patient population. Although there are some studies investigating WBRT concurrently with an EGFR-TKI (overview in Table 9.5), there are currently no ongoing studies in patients with an activating EGFR-mutation oligoprogressive in the brain while on EGFR-TKI treatment.

In summary, although there are arguments that EGFR-TKI can be safely applied concurrent with WBRT, there is no high-level evidence to support this. With the addition of SRS/SRT to WBRT, severe (grade 3-5) toxicities may increase, although further studies are needed. ${ }^{34}$ For $A L K$-rearranged patients no data are available. This review stresses the need for high quality studies evaluating the use of TKI with concurrent radiotherapy in patients with an activating EGFR-mutation and/or $A L K$ rearrangement as well as for the further evaluation of the place of second and third generation TKI's and SRS/SRT in this selected patient population. 


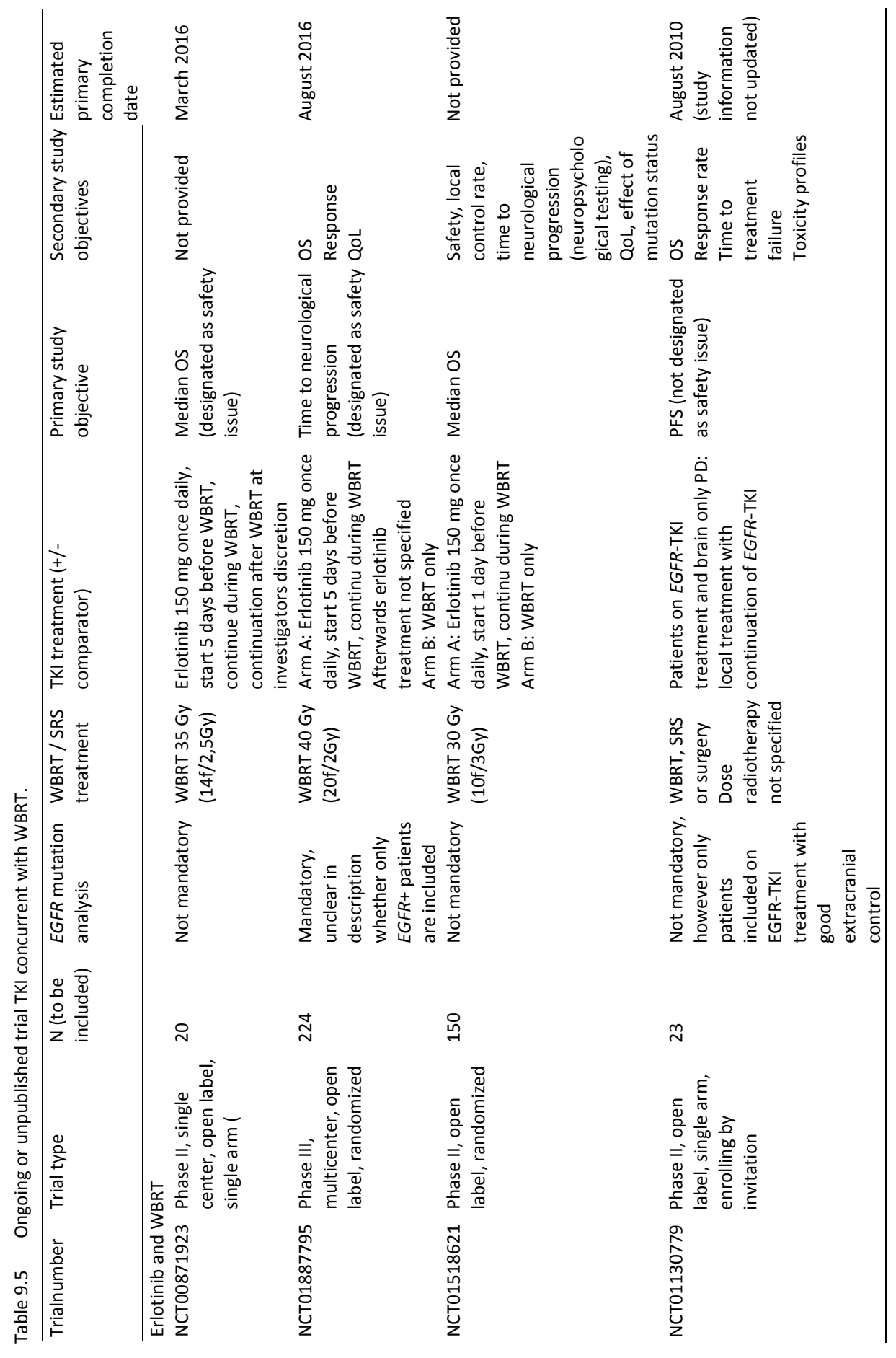




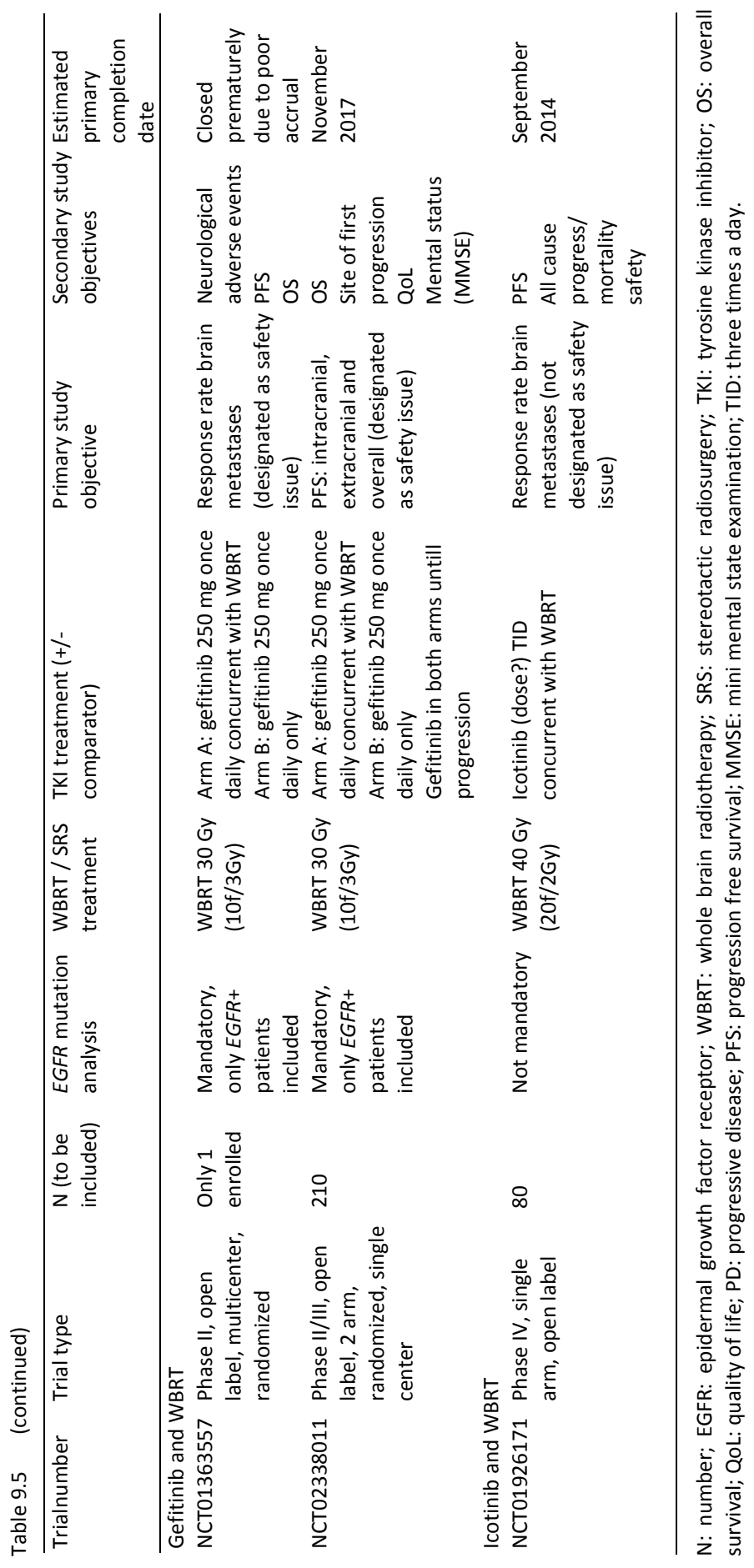




\section{REFERENCES}

1. Stella GM, Luisetti M, Pozzi E, Comoglio PM. Oncogenes in non-small-cell lung cancer: emerging connections and novel therapeutic dynamics. Lancet Respir Med 2013;1:251-61.

2. NCCN Guidelines version 1.2015 Non-Small Cell Lung Cancer. 2014.

3. Reck M, Popat S, Reinmuth $\mathrm{N}$ et al. Metastatic non-small-cell lung cancer (NSCLC): ESMO Clinical Practice Guidelines for diagnosis, treatment and follow-up. Ann Oncol 2014;25 Suppl 3:iii27-39.

4. Doebele RC, Lu X, Sumey C et al. Oncogene status predicts patterns of metastatic spread in treatmentnaive nonsmall cell lung cancer. Cancer 2012;118:4502-11.

5. Shaw AT, Kim DW, Nakagawa $\mathrm{K}$ et al. Crizotinib versus chemotherapy in advanced ALK-positive lung cancer. N Engl J Med 2013;368:2385-94.

6. Rangachari D, Yamaguchi N, VanderLaan PA et al. Brain metastases in patients with EGFR-mutated or ALK-rearranged non-small-cell lung cancers. Lung Cancer 2015;88:108-11.

7. Zimmermann S, Dziadziuszko R, Peters S. Indications and limitations of chemotherapy and targeted agents in non-small cell lung cancer brain metastases. Cancer Treat Rev 2014;40:716-22.

8. Costa DB, Shaw AT, Ou SH et al. Clinical experience with crizotinib in patients with advanced ALKrearranged non-small-cell lung cancer and brain metastases. J Clin Oncol 2015.

9. Heon S, Yeap BY, Britt GJ et al. Development of central nervous system metastases in patients with advanced non-small cell lung cancer and somatic EGFR mutations treated with gefitinib or erlotinib. Clin Cancer Res 2010;16:5873-82.

10. Heon S, Yeap BY, Lindeman NI et al. The Impact of Initial Gefitinib or Erlotinib versus Chemotherapy on Central Nervous System Progression in Advanced Non-Small Cell Lung Cancer with EGFR Mutations. Clin Cancer Res 2012;18:4406-14.

11. Patel S, Rimner A, Foster A et al. Risk of brain metastasis in EGFR-mutant NSCLC treated with erlotinib: A role for prophylactic cranial irradiation? Int J Radiat Oncol Biol Phys 2014;90:S643-4.

12. Weickhardt AJ, Scheier B, Burke JM et al. Local ablative therapy of oligoprogressive disease prolongs disease control by tyrosine kinase inhibitors in oncogene-addicted non-small-cell lung cancer. J Thorac Oncol 2012;7:1807-14.

13. Park SJ, Kim HT, Lee DH et al. Efficacy of epidermal growth factor receptor tyrosine kinase inhibitors for brain metastasis in non-small cell lung cancer patients harboring either exon 19 or 21 mutation. Lung Cancer 2012;77:556-60.

14. Nishie K, Kawaguchi T, Tamiya A et al. Epidermal growth factor receptor tyrosine kinase inhibitors beyond progressive disease: a retrospective analysis for Japanese patients with activating EGFR mutations. J Thorac Oncol 2012;7:1722-7.

15. Hoffknecht $P$, Tufman A, Wehler $T$ et al. Efficacy of the irreversible ErbB family blocker afatinib in epidermal growth factor receptor (EGFR) tyrosine kinase inhibitor (TKI)-pretreated non-small-cell lung cancer patients with brain metastases or leptomeningeal disease. J Thorac Oncol 2015;10:156-63.

16. Ou SH, Janne PA, Bartlett $\mathrm{CH}$ et al. Clinical benefit of continuing ALK inhibition with crizotinib beyond initial disease progression in patients with advanced ALK-positive NSCLC. Ann Oncol 2014;25:415-22.

17. Chinnaiyan $P$, Huang $S$, Vallabhaneni $G$ et al. Mechanisms of enhanced radiation response following epidermal growth factor receptor signaling inhibition by erlotinib (Tarceva). Cancer Res 2005;65: 3328-35.

18. Zhuang $\mathrm{HQ}$, Sun J, Yuan ZY et al. Radiosensitizing effects of gefitinib at different administration times in vitro. Cancer Sci 2009;100:1520-5.

19. Bokobza SM, Jiang $\mathrm{Y}$, Weber $\mathrm{AM}$ et al. Short-course treatment with gefitinib enhances curative potential of radiation therapy in a mouse model of human non-small cell lung cancer. Int J Radiat Oncol Biol Phys 2014;88:947-54.

20. Dai Y, Wei Q, Schwager C et al. Synergistic effects of crizotinib and radiotherapy in experimental EML4ALK fusion positive lung cancer. Radiother Oncol 2015;114:173-81.

21. Das $A K$, Sato $M$, Story $M D$ et al. Non-small-cell lung cancers with kinase domain mutations in the epidermal growth factor receptor are sensitive to ionizing radiation. Cancer Res 2006;66:9601-8.

22. NCCN guidelines Version 2.2014 Central Nervous System Cancers. 2014. 
23. Tsao MN, Rades D, Wirth A et al. Radiotherapeutic and surgical management for newly diagnosed brain metastasis(es): An American Society for Radiation Oncology evidence-based guideline. Pract Radiat Oncol 2012;2:210-25.

24. Lilenbaum R, Samuels M, Wang X et al. A Phase II Study of Induction Chemotherapy Followed by Thoracic Radiotherapy and Erlotinib in Poor-Risk Stage III Non-Small-Cell Lung Cancer: Results of CALGB 30605 (Alliance)/RTOG 0972 (NRG). J Thorac Oncol 2015;10:143-7.

25. $\mathrm{Xu} \mathrm{Y,} \mathrm{Zhang} \mathrm{Y}, \mathrm{Ma}$ S. EGFR inhibitors with concurrent thoracic radiation therapy for locally advanced non-small cell lung cancer. Lung Cancer 2011;73:249-55.

26. Koh PK, Faivre-Finn C, Blackhall FH, De Ruysscher D. Targeted agents in non-small cell lung cancer (NSCLC): clinical developments and rationale for the combination with thoracic radiotherapy. Cancer Treat Rev 2012;38:626-40.

27. Ramella S, Alberti AM, Cammilluzzi E et al. Erlotinib and concurrent chemoradiation in pretreated NSCLC patients: radiobiological basis and clinical results. Biomed Res Int 2013;2013:403869.

28. Chaft JE, Oxnard GR, Sima CS et al. Disease flare after tyrosine kinase inhibitor discontinuation in patients with EGFR-mutant lung cancer and acquired resistance to erlotinib or gefitinib: implications for clinical trial design. Clin Cancer Res 2011;17:6298-303.

29. Pop O, Pirvu A, Toffart AC, Moro-Sibilot D. Disease flare after treatment discontinuation in a patient with EML4-ALK lung cancer and acquired resistance to crizotinib. J Thorac Oncol 2012;7:e1-2.

30. da Costa Santos CM, de Mattos Pimenta CA, Nobre MR. The PICO strategy for the research question construction and evidence search. Rev Lat Am Enfermagem 2007;15:508-11.

31. Lee SM, Lewanski CR, Counsell $\mathrm{N}$ et al. Randomized trial of erlotinib plus whole-brain radiotherapy for NSCLC patients with multiple brain metastases. J Natl Cancer Inst 2014;106.

32. Lind JS, Lagerwaard FJ, Smit EF, Senan S. Phase I study of concurrent whole brain radiotherapy and erlotinib for multiple brain metastases from non-small-cell lung cancer. Int J Radiat Oncol Biol Phys 2009;74:1391-6.

33. Olmez I, Donahue BR, Butler JS et al. Clinical outcomes in extracranial tumor sites and unusual toxicities with concurrent whole brain radiation (WBRT) and Erlotinib treatment in patients with non-small cell lung cancer (NSCLC) with brain metastasis. Lung Cancer 2010;70:174-9.

34. Sperduto PW, Wang $\mathrm{M}$, Robins $\mathrm{HI}$ et al. A phase 3 trial of whole brain radiation therapy and stereotactic radiosurgery alone versus WBRT and SRS with temozolomide or erlotinib for non-small cell lung cancer and 1 to 3 brain metastases: Radiation Therapy Oncology Group 0320. Int J Radiat Oncol Biol Phys 2013; 85:1312-8.

35. Welsh JW, Komaki R, Amini A et al. Phase II trial of erlotinib plus concurrent whole-brain radiation therapy for patients with brain metastases from non-small-cell lung cancer. J Clin Oncol 2013;31: 895-902.

36. Zhuang H, Yuan Z, Wang J et al. Phase II study of whole brain radiotherapy with or without erlotinib in patients with multiple brain metastases from lung adenocarcinoma. Drug Des Devel Ther 2013;7: 1179-86.

37. Ma S, Xu Y, Deng Q, Yu X. Treatment of brain metastasis from non-small cell lung cancer with whole brain radiotherapy and Gefitinib in a Chinese population. Lung Cancer 2009;65:198-203.

38. Pesce GA, Klingbiel D, Ribi $K$ et al. Outcome, quality of life and cognitive function of patients with brain metastases from non-small cell lung cancer treated with whole brain radiotherapy combined with gefitinib or temozolomide. A randomised phase II trial of the Swiss Group for Clinical Cancer Research (SAKK 70/03). Eur J Cancer 2012;48:377-84.

39. Wang F, Ning F, Liu C et al. Comparison of gefitinib versus VMP in the combination with radiotherapy for multiple brain metastases from non-small cell lung cancer. Cell Biochem Biophys 2015;71:1261-5.

40. Zeng YD, Zhang L, Liao $\mathrm{H}$ et al. Gefitinib alone or with concomitant whole brain radiotherapy for patients with brain metastasis from non-small-cell lung cancer: a retrospective study. Asian Pac J Cancer Prev 2012;13:909-14.

41. Cai Y, Wang JY, Liu H. Clinical observation of whole brain radiotherapy concomitant with targeted therapy for brain metastasis in non-small cell lung cancer patients with chemotherapy failure. Asian Pac J Cancer Prev 2013;14:5699-703. 
42. Inamasu E, Toyokawa G, Shiraishi $Y$ et al. A feasibility of concurrent whole brain radiation plus epidermal growth factor receptor-tyrosine kinase inhibitor for non-small cell lung cancer. J Thorac Oncol 2012;7:S479.

43. Lee HL, Chung TS, Ting LL et al. EGFR mutations are associated with favorable intracranial response and progression-free survival following brain irradiation in non-small cell lung cancer patients with brain metastases. Radiat Oncol 2012;7:181.

44. Yun F, Huang ZY, Gong L et al. Icotinib and whole brain radiotherapy (WBRT) for patients with brain metastases from non-small cell lung cancer (NSCLC): Preliminary results of a phase II study. J Clin Oncol 2015;76:517-23.

45. Zhou L, He J, Xiong W et al. Phase I trial of icotinib combined with whole brain radiotherapy for EGFRmutated non-small cell lung cancer patients with brain metastases. J Clin Oncol 2014; 32: Suppl1.

46. Costa DB, Shaw AT, Ou SHI et al. Clinical experience with crizotinib in patients with advanced ALKrearranged nonsmall cell lung cancer and brain metastases in profile 1005 and profile 1007. J Thorac Oncol 2013;8:S294-5.

47. Costa DB, Kobayashi S, Pandya SS et al. CSF concentration of the anaplastic lymphoma kinase inhibitor crizotinib. J Clin Oncol 2011;29:e443-5.

48. Deng $\mathrm{Y}$, Feng $\mathrm{W}, \mathrm{Wu} J$ et al. The concentration of erlotinib in the cerebrospinal fluid of patients with brain metastasis from non-small-cell lung cancer. Mol Clin Oncol 2014;2:116-20.

49. Togashi $Y$, Masago K, Masuda S et al. Cerebrospinal fluid concentration of gefitinib and erlotinib in patients with non-small cell lung cancer. Cancer Chemother Pharmacol 2012;70:399-405.

50. Andrews DW, Scott CB, Sperduto PW et al. Whole brain radiation therapy with or without stereotactic radiosurgery boost for patients with one to three brain metastases: phase III results of the RTOG 9508 randomised trial. Lancet 2004;363:1665-72.

51. Shi L, Tang J, Tong L, Liu Z. Risk of interstitial lung disease with gefitinib and erlotinib in advanced nonsmall cell lung cancer: a systematic review and meta-analysis of clinical trials. Lung Cancer 2014;83: 231-9.

52. Melosky B, Hirsh V. Management of Common Toxicities in Metastatic NSCLC Related to Anti-Lung Cancer Therapies with EGFR-TKIs. Front Oncol 2014;4:238.

53. Reck M, Mok T, Wolf J et al. Reviewing the safety of erlotinib in non-small cell lung cancer. Expert Opin Drug Saf 2011;10:147-57.

54. Yoshida T, Yamada K, Azuma K et al. Comparison of adverse events and efficacy between gefitinib and erlotinib in patients with non-small-cell lung cancer: a retrospective analysis. Med Oncol 2013;30:349.

55. Cao KI, Lebas N, Gerber S et al. Phase II randomized study of whole-brain radiation therapy with or without concurrent temozolomide for brain metastases from breast cancer. Ann Oncol 2015;26:89-94.

56. Lu JF, Eppler SM, Wolf J et al. Clinical pharmacokinetics of erlotinib in patients with solid tumors and exposure-safety relationship in patients with non-small cell lung cancer. Clin Pharmacol Ther 2006;80: 136-45.

57. Ranson M, Hammond LA, Ferry D et al. ZD1839, a selective oral epidermal growth factor receptortyrosine kinase inhibitor, is well tolerated and active in patients with solid, malignant tumors: results of a phase I trial. J Clin Oncol 2002;20:2240-50.

58. Li C, Alvey C, Bello A et al. Pharmacokinetics (PK) of crizotinib (PF-02341066) in patients with advanced non-small cell lung cancer (NSCLC) and other solid tumors. J Clin Oncol 2011;29:(suppl; abstr e13065).

59. Feng $Y$, Masson E, Dai D et al. Model-based clinical pharmacology profiling of ipilimumab in patients with advanced melanoma. Br J Clin Pharmacol 2014;78:106-17.

60. Kim DW, Mehra R, Tan D et al. Ceritinib in advanced anaplastic lymphoma kinase (ALK)-rearranged $(A L K+)$ non-small cell lung cancer (NSCLC): Results of the ASCEND-1 trial. J Clin Oncol 2014;32:(suppl; abstr 8003).

61. Sequist L, Soria J-C, Gadgeel S et al. First-in-human evaluation of CO-1686, an irreversible, highly selective tyrosine kinase inhibitor of mutations of EGFR (activating and T790M). J Clin Oncol 2014;32: (suppl; abstr 8010)

62. Nakagawa K, Hida T, Seto T et al. Antitumor activity of alectinib (CH5424802/RO5424802) for ALKrearranged NSCLC with or without prior crizotinib treatment in bioequivalence study. J Clin Oncol 2014; 32:(suppl; abstr 8103) 
63. Yamamoto $M$, Serizawa $T$, Shuto $T$ et al. Stereotactic radiosurgery for patients with multiple brain metastases (JLGK0901): a multi-institutional prospective observational study. Lancet Oncol 2014;15: 387-95.

64. Chang EL, Wefel JS, Hess KR et al. Neurocognition in patients with brain metastases treated with radiosurgery or radiosurgery plus whole-brain irradiation: a randomised controlled trial. Lancet Oncol 2009;10:1037-44.

65. Rodrigues G, Zindler J, Warner A, Lagerwaard F. Recursive partitioning analysis for the prediction of stereotactic radiosurgery brain metastases lesion control. Oncologist 2013;18:330-5.

66. Wiggenraad R, Verbeek-de Kanter A, Kal HB et al. Dose-effect relation in stereotactic radiotherapy for brain metastases. A systematic review. Radiother Oncol 2011;98:292-7. 


\section{APPENDIX 9.1}

\section{SEARCH STRATEGY}

\begin{tabular}{|c|c|c|c|}
\hline \multirow{2}{*}{$\frac{\text { PICO }}{\text { Patient }}$} & \multicolumn{3}{|c|}{ Search terms } \\
\hline & & $\begin{array}{l}\text { NSCLC } \\
\text { Non-small cell lung cancer }\end{array}$ & OR \\
\hline \multirow[t]{2}{*}{ Intervention } & AND & $\begin{array}{l}\text { EGFR-TKI } \\
\text { erlotinib } \\
\text { gefitinib } \\
\text { afatinib } \\
\text { icotinib } \\
\text { ALK } \\
\text { ALK-inhibitor } \\
\text { crizotinib } \\
\text { ceritinib } \\
\text { LDK378 } \\
\text { alectinib } \\
\text { R05424802 }\end{array}$ & OR \\
\hline & AND & $\begin{array}{l}\text { whole brain radiotherapy } \\
\text { WBRT } \\
\text { whole brain irradiation } \\
\text { cranial radiotherapy } \\
\text { cranial irradiation } \\
\text { stereotactic radiotherapy } \\
\text { SRT } \\
\text { stereotactic radiosurgery } \\
\text { SRS } \\
\text { radiosurgery }\end{array}$ & OR \\
\hline Comparator & & not specified in search strat & \\
\hline Outcome & & $\begin{array}{l}\text { not specified in search st } \\
\text { safety was not a primary ou }\end{array}$ & \\
\hline
\end{tabular}




\section{APPENDIX 9.2}

\section{DATA EXTRACTION SHEET}

Titel

first author

year of publication

description of study (retrospective or prospective)

Phase study

number of arms in study

if applicable, randomization

if applicable, blinding

time period

number of patients included (and planned when different)

EGFR mutation status tested

number of patients tested, results

WBRT/SRS dose (Gy)

targeted treatment (drug, dose, start, how long)

if applicable, same for comparator arm(s)

primary objective(s) study

secondary objective(s) study

neurological safety outcome, as specified as possible

other safety outcomes

efficacy outcomes 


\section{Chapter 10}

\section{Treatment and survival of patients}

with EGFR-mutated non-small cell lung

cancer and leptomeningeal metastasis:

a retrospective cohort analysis

Justine L. Kuiper, Lizza E.L. Hendriks, Anthonie J. van der Wekken, Adrianus J. de Langen, Idris Bahce, Erik Thunnissen, Daniëlle A.M. Heideman, Yvonne Berk, Ed J.M. Buijs, Ernst-Jan M. Speel, Frans H. Krouwels, Hans J.M. Smit, Harry J.M. Groen, Anne-Marie C. Dingemans, Egbert F. Smit 


\section{ABSTRACT}

\section{Objectives}

Development of leptomeningeal metastasis (LM) in non-small cell lung cancer (NSCLC)-patients is associated with a poor prognosis. It has been suggested that LM-patients with epidermal growth factor receptor mutated (EGFR+) NSCLC have a superior prognosis compared to EGFR wild-type NSCLC. Studies in EGFR+ NSCLC-patients with LM are scarce. We retrospectively evaluated a multi-institutional cohort of EGFR+ NSCLC-patients for LM to assess clinical outcome in relation to patient characteristics and treatment modalities.

\section{Material and methods}

Medical records of advanced-stage EGFR+ NSCLC-patients (diagnosed between August 2000 and June 2014) from 11 Dutch hospitals were evaluated for LM as diagnosed by MRI and/or cytopathological liquor analysis. Data on patient characteristics, treatment and outcome were collected.

\section{Results}

Thirty-two of 356 (9.0\%) advanced-stage EGFR+ NSCLC-patients (median follow-up 21.0 months), were diagnosed with LM between 2006 and 2014. LM was diagnosed by MRI (59.4\%), liquor analysis $(9.4 \%)$ or by both MRI and liquor analysis (31.3\%). Median survival after LM-diagnosis was 3.1 months (95\% $\mathrm{Cl} 0.0-7.3)$. Six- and twelve-month survival rates were $43.8 \%$ and $18.8 \%$, respectively. Patients with performance status (PS) $0-1$ at time of diagnosis of LM had a significantly higher chance to be alive after six months and had a significantly longer survival after diagnosis of LM compared to patients with PS $\geq 2$. Age, treatment with high-dose EGFR-TKI, radiotherapy and whether $L M$ was the only site of progressive disease did not influence survival after LM-diagnosis.

\section{Conclusion}

Although median survival after LM-diagnosis in EGFR-mutated NSCLC-patients was poor, a substantial part of the patients had a prolonged survival of more than six months. PS of $0-1$ at time of diagnosis of LM was associated with prolonged survival. No other patient- or treatmentrelated characteristics were identified. Further research is warranted to identify treatment strategies that improve survival in EGFR+ NSCLC-patients with LM. 


\section{INTRODUCTION}

Neoplastic meningitis, or leptomeningeal metastasis (LM), is the result of spread of malignant cells to the subarachnoid space within the compartment of the cerebrospinal fluid (CSF). ${ }^{1}$ It occurs in many types of cancer, including non-small cell lung cancer (NSCLC). LM is associated with poor prognosis and rapid deterioration of performance status. ${ }^{1}$ Radiotherapy, surgery and intrathecal chemotherapy all have been described as treatment options for NSCLC-patients with LM. However, the efficacy of these treatments for LM-patients is unclear and there is no consensus which (combination) provides the optimal therapeutic strategy. ${ }^{2,3}$ Treatment should be discussed in a multidisciplinary team involved in the treatment of this complication of cancer. It has been reported that central nervous system (CNS) metastases (including LM) are more often diagnosed in epidermal growth factor receptor (EGFR)-mutated (EGFR+) NSCLC-patients. ${ }^{4}$ This may be due to the prolonged survival of EGFR+ NSCLC-patients and/or the poor penetration of first generation tyrosine kinase inhibitors (TKIS) across the blood-brain barrier (BBB) into the CSF. ${ }^{5}$ Several studies have reported on LM in NSCLC-patients. However, in most studies, EGFR-mutation status was not provided or only in a small subset ( $\mathrm{N}=6-23)$ of patients. ${ }^{2,3,6-15}$

Small series suggest that EGFR-TKI naïve EGFR+ patients who received EGFR-TKI treatment after diagnosis of LM may experience a better survival than patients who do not receive EGFR-TKI treatment after diagnosis of $L M{ }^{3,6,15}$ However, since $L M$ is usually a late event, most EGFR+ NSCLC-patients have already been treated with EGFR-TKIs prior to diagnosis of LM. In addition to the previous mentioned treatment modalities for LM, high-dose EGFR-TKIs and switch of EGFR-TKI-treatment have been described as treatment option for EGFR+ NSCLC-patients with LM.,14,16,17

Altogether, data on LM in EGFR+ NSCLC are scarce. We therefore retrospectively evaluated a multi-institutional cohort of EGFR+ NSCLC-patients for diagnosis of LM. The purpose of this study was to describe diagnosis of LM and treatment modalities and survival after diagnosis of LM, in EGFR+ NSCLC-patients.

\section{MATERIALS AND METHODS}

Medical records of EGFR+ NSCLC-patients from 11 Dutch hospitals (4 academic and 7 non-academic) who were diagnosed with advanced-stage (stage IIIB or IV) NSCLC between August 2000 and June 2014 were retrospectively reviewed for diagnosis of LM. A diagnosis of LM was defined as focal or diffuse enhancement of leptomeninges, nerve roots or ependymal surface diagnosed by magnetic resonance imaging (MRI) and/or a cytopathological diagnosis of malignant cells in the CSF. Detection of atypical and/or suspicious cells in the liquor did not qualify for the diagnosis of LM. All patients were tested for the presence of EGFR-mutations in their tumor as standard of care. An 
EGFR-mutation was defined as any mutation detected in exon 18, 19, 20 and/or 21 of the EGFR-gene. Data on demographics, clinical and tumor-related features, treatments and clinical outcomes were extracted from the medical records. The medical ethical committee of the VU University Medical Center approved the protocol.

Follow-up was extended through October 2014 and was calculated from first diagnosis of advanced-stage NSCLC until death or last day of follow-up. Objective response rate (ORR) of extracranial lesions on standard-dose EGFR-TKI treatment was calculated as the proportion of patients with complete or partial response according to Response Evaluation Criteria in Solid Tumors (RECIST) $1.1^{18}$ Disease control rate (DCR) on standard-dose EGFR-TKI treatment was calculated as the proportion of patients with an objective response or stable disease for at least 6 weeks according to RECIST 1.1.18 Progression-free survival (PFS) on standard-dose EGFR-TKI treatment was calculated as the time from first day of EGFR-TKI treatment until progression of disease or death. Overall survival (OS) was calculated from first diagnosis of advanced-stage NSCLC until date of death or patients were censored at last follow-up. Survival after diagnosis of LM was calculated as the time from date of diagnosis of LM until date of death or patients were censored at last follow-up.

Comparison of categorical variables was performed with Pearson's $\chi^{2}$ test. Comparison of continuous variables was performed with independent T-test. Survival analyses were performed according to the Kaplan-Meier method and tested for significance with the log rank test. Two-sided $p$-values $\leq 0.05$ were considered significant and confidence intervals $(\mathrm{Cl})$ were calculated at a $95 \%$ confidence level. Statistical analyses were performed using SPSS for Windows (version 20; SPSS Inc., Chicago, II, USA).

\section{RESULTS}

\section{LEPTOMENINGEAL METASTASES IN EGFR+ NSCLC-PATIENTS}

Medical records of 356 advanced-stage NSCLC-patients with an EGFR-mutation were screened for diagnosis of LM. Median follow-up of these patients was 21.0 months (range 0.2-144.9). Two patients were lost to follow-up after 24.5 and 44.5 months. LM was diagnosed in $9.0 \%$ of the patients (32 patients). Patient and tumor characteristics are provided in Table 10.1.

In 19 patients (59.4\%) LM was diagnosed by MRI, in three patients (9.4\%) by CSF cytology and in 10 patients (31.3\%) by both MRI and CSF cytology (Table 10.2). In one patient, LM was detected on MRI but CSF analysis was negative twice for malignant cells. In three patients in whom LM was detected by CSF cytology, there was no confirmation of LM by MRI; in one patient only a CT-scan was performed and in two patients LM could not be detected on MRI. 
Table 10.1 Patient characteristics.

\begin{tabular}{|c|c|c|c|c|c|c|}
\hline \multicolumn{2}{|c|}{ Patient characteristics } & \multicolumn{2}{|c|}{$\begin{array}{c}E G F R+N S C L C-p a t i e n t s \\
\text { without LM }(\mathrm{N}=324)\end{array}$} & \multicolumn{2}{|c|}{$\begin{array}{l}E G F R+N S C L C \text {-patients } \\
\text { with LM }(\mathrm{N}=32)\end{array}$} & \multirow{2}{*}{$\begin{array}{c}P \\
0.014\end{array}$} \\
\hline Median age $^{\alpha}$ & (years) & 61.0 (ran & e 30.0-90.7) & 54.0 (rang & e 29.2-78.6) & \\
\hline \multirow{2}{*}{$\begin{array}{l}\text { Median } \\
\text { overall } \\
\text { survival }^{\beta}\end{array}$} & (months) & $25.4(95 \%$ & Cl 22.3-28.5) & $19.9(95 \%$ & Cl 11.6-28.2) & 0.476 \\
\hline & & Frequency & (percentage) & Frequency & (percentage) & $P$ \\
\hline \multirow[t]{2}{*}{ Gender } & Male & 98 & $(30.2 \%)$ & 14 & $(43.8 \%)$ & 0.117 \\
\hline & Female & 226 & (69.8\%) & 18 & $(56.2 \%)$ & \\
\hline \multirow[t]{4}{*}{ Smoking } & Current smoker & 31 & $(9.6 \%)$ & 2 & $(6.2 \%)$ & 0.925 \\
\hline & Former smoker & 117 & $(36.1 \%)$ & 12 & $(37.5 \%)$ & \\
\hline & Never-smoker & 152 & (46.9\%) & 16 & $(50.0 \%)$ & \\
\hline & Unknown & 24 & $(7.4 \%)$ & 2 & $(6.2 \%)$ & \\
\hline Performance & PSO & 126 & (38.9\%) & 16 & $(50.0 \%)$ & 0.511 \\
\hline \multirow[t]{5}{*}{ Status (PS) ${ }^{\alpha}$} & PS 1 & 139 & (42.9\%) & 10 & $(31.3 \%)$ & \\
\hline & PS 2 & 23 & $(7.1 \%)$ & 1 & $(3.1 \%)$ & \\
\hline & PS 3 & 8 & $(2.5 \%)$ & 2 & $(6.3 \%)$ & \\
\hline & PS 4 & 2 & $(0.6 \%)$ & 0 & $(0.0 \%)$ & \\
\hline & Unknown & 26 & $(8.0 \%)$ & 3 & (9.4\%) & \\
\hline \multirow[t]{6}{*}{ Histology } & Adenocarcinoma & 297 & (91.7\%) & 32 & $(100 \%)$ & 0.577 \\
\hline & Adenosquamous & 1 & $(0.3 \%)$ & 0 & $(0.0 \%)$ & \\
\hline & carcinoma & & & & & \\
\hline & Squamous cell carcinoma & 1 & $(0.3 \%)$ & 0 & $(0.0 \%)$ & \\
\hline & Large-cell lung cancer & 23 & $(7.0 \%)$ & 0 & $(0.0 \%)$ & \\
\hline & $\begin{array}{l}\text { Non-small cell neuro- } \\
\text { endocrine carcinoma }\end{array}$ & 2 & $(0.6 \%)$ & 0 & $(0.0 \%)$ & \\
\hline \multirow[t]{8}{*}{ Mutation } & EGFR-exon 18 & 9 & $(2.8 \%)$ & 1 & $(3.1 \%)$ & 0.730 \\
\hline & EGFR-exon $18+20$ & 12 & $(3.7 \%)$ & 1 & $(3.1 \%)$ & \\
\hline & EGFR-exon $18+21$ & 2 & $(0.6 \%)$ & 0 & $(0.0 \%)$ & \\
\hline & EGFR-exon 19 & 169 & $(52.2 \%)$ & $17^{v}$ & (53.1\%) & \\
\hline & EGFR-exon $19+21$ & 2 & $(0.6 \%)$ & 0 & $(0.0 \%)$ & \\
\hline & EGFR exon $20^{\delta}$ & 42 & $(13.0 \%)$ & 1 & $(3.1 \%)$ & \\
\hline & EGFR-exon $20+21$ & 3 & $(0.9 \%)$ & 0 & $(0.0 \%)$ & \\
\hline & EGFR-exon 21 & 85 & $(26.2 \%)$ & 12 & (37.5\%) & \\
\hline
\end{tabular}

${ }^{\alpha}$ At time of $1^{\text {st }}$ diagnosis of advanced-stage NSCLC; ${ }^{\beta}$ From date of diagnosis of stage IV untill date of death or last day of follow-up; ${ }^{\gamma}$ All Exon 19 deletions; ${ }^{\delta}$ All non-T790M mutations; ${ }^{\varepsilon}$ All exon 21 L858R mutations. LM: leptomeningeal metastasis. EGFR: epidermal growth factor receptor.

In six patients, mutation analysis was performed on the liquor specimen. In all six patients the identical EGFR driver mutation was detected in the CSF as detected in the diagnostic biopsy from a systemic lesion (four patients with an exon 19 deletion, one patient with an exon 21 L858R and one patient with an exon 20 insertion). In one patient with an exon 19 deletion who was progressive while on EGFR-TKI treatment, the T790M mutation was detected in both a re-biopsy from an extracranial lesion as well as in the liquor. 


\section{CHARACTERISTICS OF EGFR+ NSCLC-PATIENTS WITH LEPTOMENINGEAL METASTASES}

LM was diagnosed between November 2006 and March 2014. The majority of EGFR+ NSCLC-patients with LM was female (56.2\%) and most patients were never- $(50.0 \%)$ or former smokers (37.5\%), alike EGFR+ NSCLC-patients without LM (Table 10.1). At time of first diagnosis of advanced-stage NSCLC, median age was 54.0 years (range 29.2-78.6), being significantly younger than EGFR+ NSCLC-patients without LM (61.0 (range 30.0-90.7), $p=0.014$ ). Median time from diagnosis of advanced-stage NSCLC until diagnosis of LM was 13.6 months (95\% Cl 7.7-19.5, range 0.0-61.4) (Table 10.2). ECOG performance status (PS) at time of diagnosis of LM was PS 1 in 15 patients (46.9\%), PS 2 in ten patients (31.3\%) and PS 3 in seven patients (21.9\%). Twenty-six patients $(81.3 \%)$ presented with symptoms of cerebral LM, five patients (15.6\%) with symptoms of thoracic and/or lumbar LM and one patient (3.1\%) with symptoms of both cerebral and thoracic LM. In 15 patients (46.9\%) LM was the only site of progression; in these patients all extra-CNS lesions were controlled at time of diagnosis of LM. In 17 patients (53.1\%) LM was diagnosed while extra-CNS lesions were progressive as well. Among patients with cerebral LM, the most frequent presenting symptom was headache $(48.1 \%)$, followed by confusion (33.3\%), weakness in limbs (29.6\%), nausea/vomiting (29.6\%) and dizziness (25.9\%). Diplopia occurred in three patients (11.1\%) and seizure in one patient (3.7\%). All six patients with thoracic or lumbar LM presented with back pain. One of these patients also presented with a cauda equina syndrome. Apart from LM, parenchymal brain metastases were detected in $71.9 \%$ of the patients at some time point in the course of their disease (Table 10.2).

Table 10.2 Leptomeningeal metastasis.

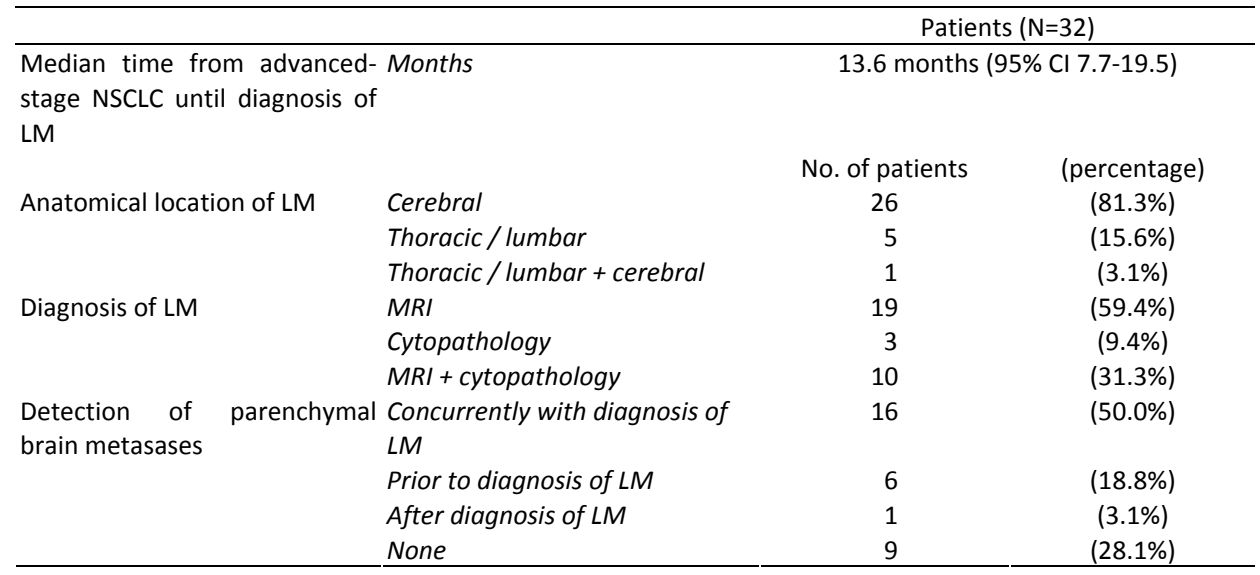

NSCLC: non-small cell lung cancer, LM: leptomeningeal metastases. MRI: magnetic resonance imaging. 


\section{PREVIOUS EGFR-TKI TREATMENT IN EGFR-MUTATED NSCLC-PATIENTS WITH LEPTOMENINGEAL METASTASES}

Treatments and outcome of individual EGFR-mutated NSCLC-patients who developed LM are provided in Figure 10.1. Patients received a median of 2 systemic lines of treatment prior to diagnosis of LM (range 0-3). Twenty-seven patients (84.4\%) were treated with at least one line of EGFR-TKI treatment prior to diagnosis of LM, three patients $(9.4 \%)$ received only cytotoxic chemotherapy as systemic treatment prior to diagnosis of LM and in two patients (6.3\%) LM-diagnosis coincided with first diagnosis of NSCLC. As first EGFR-TKI treatment prior to diagnosis of LM, 17 patients $(63.0 \%)$ received erlotinib and ten patients (37.0\%) received gefitinib. In two patients there was no documented progression on EGFR-TKI treatment prior to diagnosis of LM, as these patients underwent a pneumonectomy after treatment with erlotinib. The remaining 25 patients had developed progression on EGFR-TKI treatment and median PFS was 10.1 months (95\% Cl 8.9-11.2). Median PFS on EGFR-TKI treatment of these patients was not significantly different compared to EGFR+ patients who were treated with EGFR-TKI ( $\mathrm{N}=239$ ) who did not develop LM (9.8 months (95\% Cl, 8.3-11.3), $p=0.885$ ).

Six patients (24.0\%) were diagnosed with LM at time of first progression on EGFR-TKI treatment and 19 patients (76.0\%) had developed progression on EGFR-TKI treatment prior to diagnosis of LM. Among 27 patients who received EGFR-TKI treatment prior to diagnosis of $L M$, the ORR was $92.6 \%$ and DCR was $100.0 \%$. In patients who did not develop LM ORR was $72.1 \%(p=0.021)$ and DCR was $88.9 \%(p=0.069)$.

\section{TREATMENT OF EGFR-MUTATED NSCLC-PATIENTS WITH LEPTOMENINGEAL METASTASES}

At the time of diagnosis of LM most patients (62.5\%) were on (re-)treatment with an EGFR-TKI (Table 10.3). After LM had been diagnosed, six different types of systemic treatment regimens were applied: continuation of current EGFR-TKI treatment $(\mathrm{N}=9)$, continuation of current chemotherapy $(\mathrm{N}=2)$, start of EGFR-TKI treatment $(\mathrm{N}=4)$, switch of EGFR-TKI treatment ( $\mathrm{N}=4)$, high-dose EGFR-TKI treatment $(\mathrm{N}=8)$ and high-dose EGFRTKI treatment in combination with chemotherapy $(\mathrm{N}=4)$ (Figure 10.1, Table 10.3). Fourteen patients were treated with radiotherapy; eleven with WBRT and three with thoracic and/or lumbar RT (Figure 10.1). 


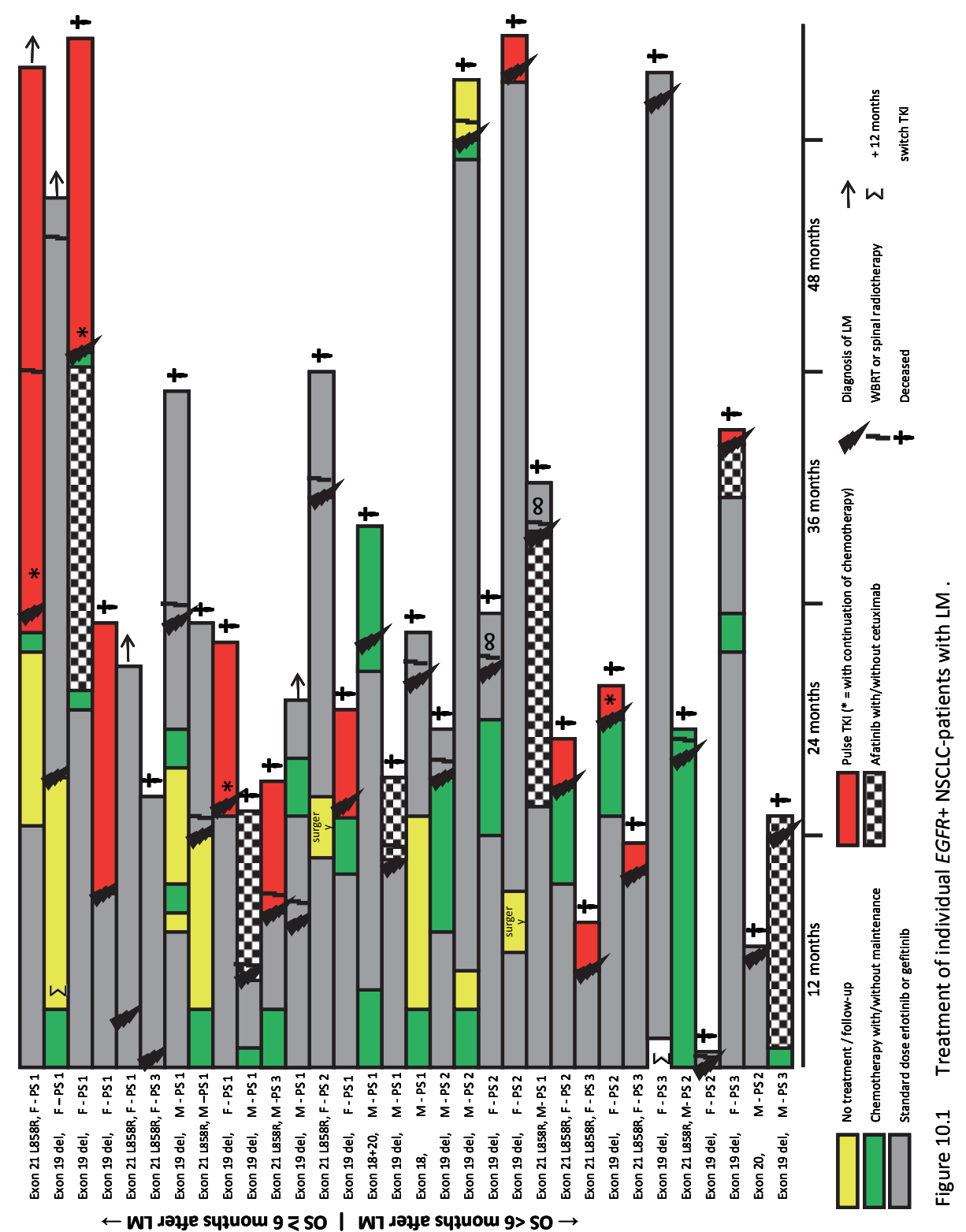


Table 10.3 Treatment prior to and after diagnosis of LM

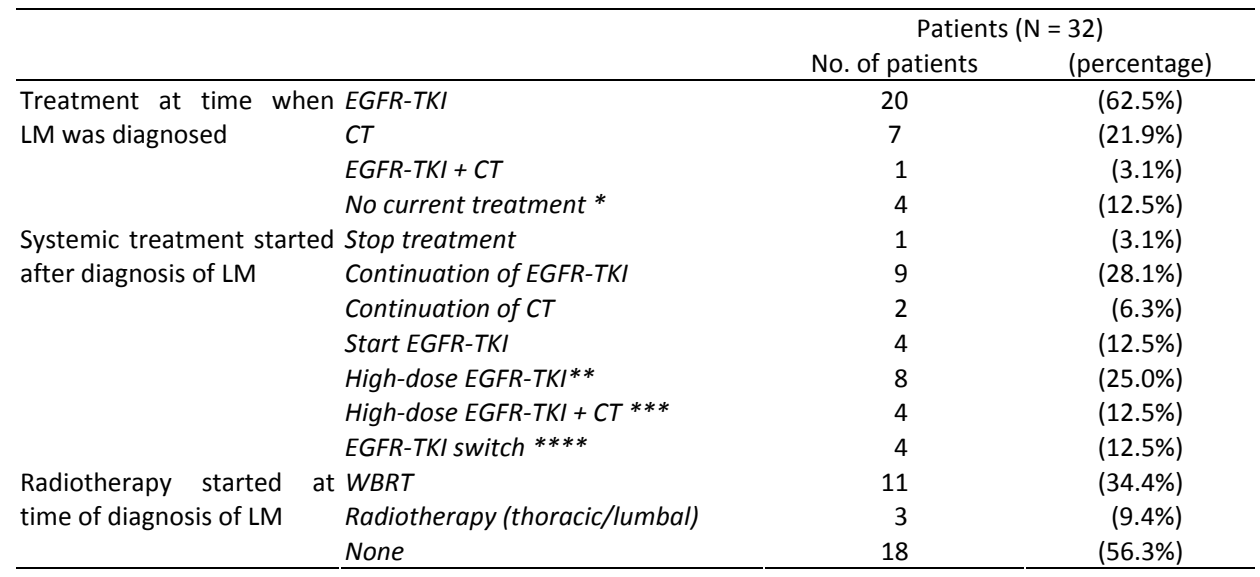

* Two patient had finished previous chemotherapy; ** Two patients were treated with erlotinib 600 mg every 4 days, 6 patients were treated with erlotinib 1500 mg once weekly; ${ }^{* * *}$ All patients received erlotinib 1500 mg once weekly; $* * * *$ TKI-switch: in 1 patient gefitinib $\rightarrow$ erlotinib, in 1 patient afatinib $\rightarrow$ gefitinib and in 2 patients gefitinib $\rightarrow$ afatinib. LM: leptomeningeal metastases. EGFR: epidermal growth factor receptor. TKI: tyrosine kinase inhibitor. CT: chemotherapy. WBRT: whole brain radiotherapy.

\section{SURVIVAL AND RESPONSE OF EGFR-MUTATED NSCLC-PATIENTS WITH LEPTOMENINGEAL METASTASES}

At the time of analysis of this cohort of EGFR+ NSCLC-patients with LM, 28 patients (87.5\%) had died and median follow-up was 20.0 months (range 0.8-67.2).

Median survival after diagnosis of LM was 3.1 months (95\% $\mathrm{Cl} 0.0-7.3$, range $0.2-29.9$ ) (Figure 10.2). One-year survival rate was $18.8 \%$ (six patients) and six-month survival was $43.8 \%$ (14 patients) after diagnosis of LM.

Patients with PS $0-1$ at time of diagnosis of $L M(N=15)$ had a significantly longer survival after diagnosis of LM compared to patients with PS $\geq 2(\mathrm{~N}=17)(11.0$ months $(95 \% \mathrm{Cl}$ 7.7-14.3) and 2.1 months $(95 \% \mathrm{Cl} 1.4-2.8)$ respectively, $\mathrm{p}=0.0001)$. Patients in whom LM was the only site of disease progression $(\mathrm{N}=15)$ had a longer median survival compared to patients in whom there was evidence of synchronous extra-CNS progression of disease ( $\mathrm{N}=17) ; 6.5$ months $(95 \% \mathrm{Cl} 0.9-12.1)$ versus 2.6 months $(95 \% \mathrm{Cl}$ 1.9-3.3) respectively, but this difference was not statistically significant $(p=0.499)$. 


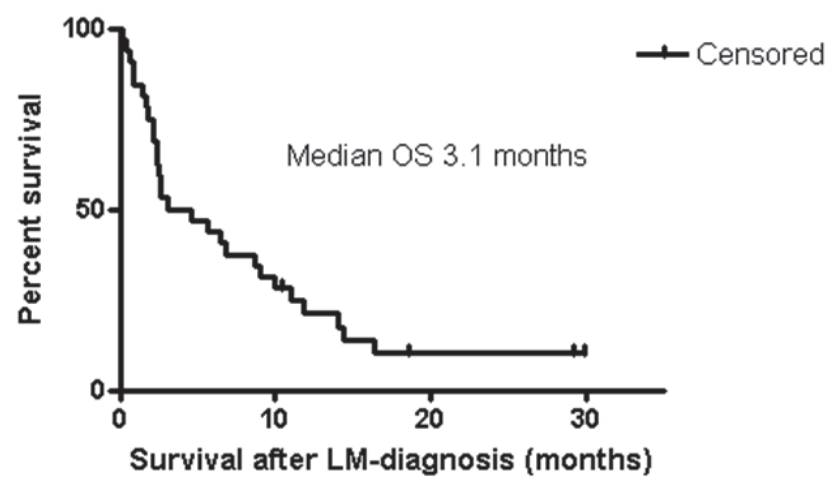

Figure 10.2 Survival of EGFR+ NSCLC-patients after diagnosis of LM.

Patients who were treated with high-dose EGFR-TKI treatment after diagnosis of LM $(\mathrm{N}=12)$ did not survive longer than patients who were not $(\mathrm{N}=20)$; median 2.4 months (95\% $\mathrm{Cl} 0.0-8.3)$ versus 3.1 months $(95 \% \mathrm{Cl} 0.0-7.3)$ respectively $(p=0.863)$. There was no difference between patients who received radiotherapy $(\mathrm{N}=14)$ and patients who did not ( $\mathrm{N}=18)$; median 3.1 months (95\% Cl 0.0-6.6) versus 2.4 months (95\% $\mathrm{Cl} 0.0-9.7$ ), respectively $(p=0.359)$. There was a trend for a longer survival after $L M$-diagnosis in patients who were $<60$ years old at time of LM-diagnosis $(\mathrm{N}=18)$ compared to patients who were $>60$ years old $(\mathrm{N}=14)$; median 5.7 months $(95 \% \mathrm{Cl} 1.6-9.7)$ and 2.4 months (95\% Cl 0.6-4.2), respectively ( $p=0.064)$.

Survival after diagnosis of LM was not statistically significantly different in patients in whom LM was the only site of progression who were treated with pulsatile EGFR-TKI treatment compared to patients who were not; 5.6 months $(95 \% \mathrm{Cl} ., 0.00-11.8)$ and 6.5 months (95\% Cl., 0.00-17.1), respectively ( $p=0.737)$.

Patients with PS of $0-1$ at time of diagnosis of LM had a significantly higher chance to be alive after six months compared to patients with $P S \geq 2(p=0.002)$. Gender, smoking status, type of EGFR-mutation, treatment with high-dose EGFR-TKIs, treatment with radiotherapy and whether extra-CNS lesions were controlled were not related to sixmonth survival (Supplement Table S10.1).

Fourteen patients were radiologically evaluated after treatment for LM had been initiated; in 10 patients (31.3\%) there was a radiological response of LM, in 3 patients $(9.4 \%)$ there was no radiological response and no radiological progression of LM and in 1 patient (3.1\%) LM was progressive at re-evaluation. In the remaining 18 patients (56.3\%), no radiological follow-up was performed. Five patients had not been treated with an EGFR-TKI prior to diagnosis of LM; four started EGFR-TKI treatment in standard dose after diagnosis of LM. Three of these patients had a prolonged survival of 11.0, 14.4 and 29.9 months after diagnosis of LM (Figure 10.1). Two of these patients were evaluated for response of LM and both experienced a partial response. 


\section{DISCUSSION}

In this cohort of EGFR+ NSCLC-patients LM was detected in $9.0 \%$, comparable to the previously reported rate of LM in EGFR-wild type NSCLC-patients. ${ }^{19}$ To the best of our knowledge, this report describes the largest group of EGFR+ NSCLC-patients with LM. The median survival after diagnosis of LM was a disappointing 3.1 months, which is similar to unselected NSCLC-patients with LM. ${ }^{2,3}$ Interestingly, a considerable part of the patients had a longer than expected survival with $43.8 \%$ and $18.8 \%$ still being alive six months and one year after diagnosis of LM, respectively. Patients with PS of 0-1 at time of diagnosis of LM had a higher chance to be alive after six months and had longer median survival after diagnosis of LM.

Only one other study that included more than twenty EGFR+ patients with LM has been published $(\mathrm{N}=23)$, however all of these patients were treated for the first time with EGFR-TKIs after diagnosis of LM, which does not represent current practice. ${ }^{15}$ Another study of Lee et al [8] compared erlotinib with gefitinib for control of LM in 25 NSCLCpatients. It was suggested that erlotinib had a better LM control rate, however 16 patients were EGFR-TKI naïve at diagnosis of LM and only 17 patients had a confirmed EGFR-mutation. Although several treatment strategies for LM in EGFR+ NSCLC have been described, it is at present unclear which is the best treatment to be preferred. In the present study no superior treatment could be identified either, although due to the small sample size and retrospective design no firm conclusions can be drawn. High-dose EGFR-TKI treatment (erlotinib $1500 \mathrm{mg}$ once weekly, or erlotinib $600 \mathrm{mg}$ every 3-4 days) is a strategy that has been described for EGFR+ NSCLC-patients with CNS-metastases. ${ }^{7}$ Due to the BBB, the concentration of available EGFR-TKIs is considerably lower in the intra-CNS compartment as compared to systemic concentrations. ${ }^{20}$ Clarke et al demonstrated that once the systemic concentration of EGFR-TKIs is high enough, therapeutic concentrations can be achieved in the CSF. ${ }^{21}$ Toxicity of this 'pulsatile' treatment strategy is generally acceptable. ${ }^{7,22,23}$ At present, only a few reports have described this treatment strategy for EGFR+ NSCLC-patients with LM, with both positive and negative results. ${ }^{7,24,25}$ In this retrospective study survival did not seem to improve by treatment with high-dose EGFR-TKIs as compared to other treatment strategies. To answer this question, a randomized controlled trial is urgently needed.

Afatinib is a second generation EGFR-TKI and irreversible blocker of the ErbB receptor tyrosine kinase family. In a recent study that evaluated patients who progressed on standard dose erlotinib or gefitinib, $66 \%$ had CNS disease control with afatinib. ${ }^{26}$ However, there was no discrimination between patients with brain metastases or LM in this study. In our study, three patients were treated with afatinib (and cetuximab) after diagnosis of LM. One of these patients had been on afatinib treatment prior to LMdiagnosis and survived for 0.2 months after LM-diagnosis. Survival of the other two patients was 4.6 and 8.7 months (Figure 10.1). Data regarding the efficacy of the third 
generation EGFR-TKIs, AZD9291 and CO-1686 on CNS metastases are very scarce. ${ }^{27,28}$ Further investigation on the efficacy of these agents in EGFR+ NSCLC-patients with LM is warranted.

Radiotherapy is another treatment modality that is commonly applied after diagnosis of LM. However, evidence for the efficacy of radiotherapy in NSCLC-patients with LM is limited. ${ }^{3}$ It has been suggested that this may be caused by the fact that only one compartment of the CNS is irradiated, while LM is a disorder that affects all compartments of the CNS. ${ }^{29}$ In this study we did not detect a difference in survival in patients who were or were not irradiated. Yet, due to the retrospective setting and small sample size, definite conclusions cannot be drawn. It is plausible that patients with a 'good' performance score are better candidates for an 'aggressive' treatment (i.e. high-dose EGFR-TKI treatment) and clinicians are more likely to advocate radiotherapy for patients who are in a poor clinical condition. As radiotherapy increases the BBB permeability and high-dose EGFR-TKI provides a better penetration of TKI into the brain ${ }^{21}$ a sequential combination of radiotherapy and high-dose EGFR-TKI could be an interesting treatment option for patients with LM. However, immediate toxicity of radiotherapy should be taken into account in this often-symptomatic patient population with a limited survival.

Intrathecal chemotherapy has been described as treatment option for NSCLC-patients with LM. ${ }^{2}$ However, this treatment strategy could not be incorporated in the analyses of this study, since none of the patients received this treatment. In the Netherlands, as in other European countries, this treatment is not routinely applied in NSCLC-patients, as the evidence is rather limited. ${ }^{30,31}$

It has been stated that classic EGFR-TKI resistance mechanisms, i.e. the T790Mmutation, develop under selective pressure of EGFR-TKI treatment. Given the fact that the BBB inhibits penetration of EGFR-TKIs into the CNS, these mechanisms of resistance would normally not be detected in tumor cells from the CNS. ${ }^{73}$ Interestingly, in this study, in one patient in whom mutation analysis was performed on malignant cells present in the CNS, the T790M mutation was detected.

Age above 60 years old was identified as a negative prognostic factor by Gwak et al. in a study of unselected NSCLC-patients. ${ }^{2}$ Also in the present study, patients younger than 60 had a trend to a better survival after diagnosis of LM. Patients in whom LM was the only site of progressive disease had longer survival compared with patients in whom there was also extracranial progression at time of LM-diagnosis, although this difference was not statistically significant. This is similar to NSCLC-patients with BM and uncontrolled extracranial disease who have a worse prognosis compared to patients with controlled extracranial disease. ${ }^{32-34}$

A strength of this study is that all patients were pathologically confirmed to carry an EGFR-mutation in their primary tumors. Also, the disease control rate of $100 \%$ to first EGFR-TKI treatment suggests that no patients with primary EGFR-TKI resistance were included. 
However, some limitations should be taken into account when interpreting the results of this study. First, the retrospective design and small sample size preclude strong conclusions. Second, due to its non-invasive character, MRI is the technique of choice to diagnose LM. However, the false-negative rate of MRI for detecting LM is approximately $30 \% .^{35}$ In this study, LM was diagnosed by MRI in most patients. The same is true for cytopathological evaluation of CSF; it has a low sensitivity (50-60\%) compared to autopsy-proven $\mathrm{LM}^{36}$ This may be caused by a low number of recognizable malignant cells in the liquor or by compartmentalization. Ideally, a negative lumbar puncture should be repeated at least twice to be able to exclude LM. ${ }^{37}$ Finally, in the non-LM group, more patients with an EGFR exon 20 mutation were included compared to the LM-group, which might have caused bias.

In conclusion, in this cohort of EGFR+ NSCLC-patients LM was diagnosed in $9.0 \%$ of the patients. This study describes the largest cohort of EGFR+ NSCLC-patients with LM. Survival after diagnosis of LM was disappointing (3.1 months) and is comparable to EGFR wild type NSCLC-patients with LM. Nevertheless, $43.8 \%$ and $18.8 \%$ of the patients survived for at least 6 months and 1 year, respectively. Patients with PS 0-1 at time of diagnosis of LM had a better prognosis. Treatments associated with a superior survival after diagnosis of LM could not be identified. Further research is warranted to identify treatment strategies that improve survival in these patients. 


\section{REFERENCES}

1. Gleissner B, Chamberlain MC. Neoplastic meningitis. Lancet Neurol 2006;5:443-52.

2. Gwak HS, Joo J, Kim S, Yoo H, Shin SH, Han JY, et al. Analysis of treatment outcomes of intraventricular chemotherapy in 105 patients for leptomeningeal carcinomatosis from non-small-cell lung cancer. J Thorac Oncol 2013;8:599-605.

3. Morris PG, Reiner AS, Szenberg OR, Clarke JL, Panageas KS, Perez HR, et al. Leptomeningeal metastasis from non-small cell lung cancer: survival and the impact of whole brain radiotherapy. J Thorac Oncol 2012;7:382-5.

4. Omuro AM, Kris MG, Miller VA, Franceschi E, Shah N, Milton DT, et al. High incidence of disease recurrence in the brain and leptomeninges in patients with nonsmall cell lung carcinoma after response to gefitinib. Cancer 2005;103:2344-8.

5. Togashi Y, Masago K, Masuda S, Mizuno T, Fukudo M, Ikemi Y, et al. Cerebrospinal fluid concentration of gefitinib and erlotinib in patients with non-small cell lung cancer. Cancer Chemother Pharmacol 2012;70:399-405.

6. Du C, Hong R, Shi Y, Yu X, Wang J. Leptomeningeal metastasis from solid tumors: a single center experience in Chinese patients. J Neurooncol 2013;115:285-91.

7. Grommes C, Oxnard GR, Kris MG, Miller VA, Pao W, Holodny Al, et al. "Pulsatile" high-dose weekly erlotinib for CNS metastases from EGFR mutant non-small cell lung cancer. Neuro Oncol 2011;13: 1364-9.

8. Lee E, Keam B, Kim DW, Kim TM, Lee SH, Chung DH, et al. Erlotinib versus gefitinib for control of leptomeningeal carcinomatosis in non-small-cell lung cancer. J Thorac Oncol 2013;8:1069-74.

9. Lee SJ, Lee JI, Nam DH, Ahn YC, Han JH, Sun JM, et al. Leptomeningeal carcinomatosis in non-small-cell lung cancer patients: impact on survival and correlated prognostic factors. J Thorac Oncol 2013;8: 185-91.

10. Lee Y, Han JY, Kim HT, Yun T, Lee GK, Kim HY, et al. Impact of EGFR tyrosine kinase inhibitors versus chemotherapy on the development of leptomeningeal metastasis in never smokers with advanced adenocarcinoma of the lung. J Neurooncol 2013;115:95-101.

11. Park JH, Kim YJ, Lee JO, Lee KW, Kim JH, Bang SM, et al. Clinical outcomes of leptomeningeal metastasis in patients with non-small cell lung cancer in the modern chemotherapy era. Lung Cancer 2012;76: 387--92.

12. Riess JW, Nagpal S, Iv M, Zeineh M, Gubens MA, Ramchandran K, et al. Prolonged survival of patients with non-small-cell lung cancer with leptomeningeal carcinomatosis in the modern treatment era. Clin Lung Cancer 2014;15:202-6.

13. Shingyoji M, Kageyama H, Sakaida T, Nakajima T, Matsui $Y$, Itakura $M$, et al. Detection of epithelial growth factor receptor mutations in cerebrospinal fluid from patients with lung adenocarcinoma suspected of neoplastic meningitis. J Thorac Oncol 2011;6:1215-20.

14. Yi HG, Kim HJ, Kim YJ, Han SW, Oh DY, Lee SH, et al. Epidermal growth factor receptor (EGFR) tyrosine kinase inhibitors (TKIs) are effective for leptomeningeal metastasis from non-small cell lung cancer patients with sensitive EGFR mutation or other predictive factors of good response for EGFR TKI. Lung Cancer 2009;65:80-4.

15. Umemura S, Tsubouchi K, Yoshioka H, Hotta K, Takigawa N, Fujiwara K, et al. Clinical outcome in patients with leptomeningeal metastasis from non-small cell lung cancer: Okayama Lung Cancer Study Group. Lung Cancer 2012;77:134-9.

16. Katayama T, Shimizu J, Suda K, Onozato R, Fukui T, Ito S, et al. Efficacy of erlotinib for brain and leptomeningeal metastases in patients with lung adenocarcinoma who showed initial good response to gefitinib. J Thorac Oncol 2009;4:1415-19.

17. http://www.nccn.org/professionals/physician_gls/f_guidelines.asp. In: 2015.

18. Eisenhauer EA, Therasse P, Bogaerts J, Schwartz LH, Sargent D, Ford R, et al. New response evaluation criteria in solid tumours: revised RECIST guideline (version 1.1). Eur J Cancer 2009;45:228-47.

19. Eichler AF, Kahle KT, Wang DL, Joshi VA, Willers $H$, Engelman JA, et al. EGFR mutation status and survival after diagnosis of brain metastasis in nonsmall cell lung cancer. Neuro Oncol 2010; 12:1193-9. 
20. Masuda T, Hattori N, Hamada A, Iwamoto H, Ohshimo S, Kanehara M, et al. Erlotinib efficacy and cerebrospinal fluid concentration in patients with lung adenocarcinoma developing leptomeningeal metastases during gefitinib therapy. Cancer Chemother Pharmacol 2011;67:1465-9.

21. Clarke JL, Pao W, Wu N, Miller VA, Lassman AB. High dose weekly erlotinib achieves therapeutic concentrations in CSF and is effective in leptomeningeal metastases from epidermal growth factor receptor mutant lung cancer. J Neurooncol 2010;99:283-6.

22. Kuiper JL, Heideman DA, Thunnissen E, van Wijk AW, Postmus PE, Smit EF. High-dose, weekly erlotinib is not an effective treatment in EGFR-mutated non-small cell lung cancer-patients with acquired extracranial progressive disease on standard dose erlotinib. Eur J Cancer 2014;50:1399-1401.

23. Milton DT, Azzoli CG, Heelan RT, Venkatraman E, Gomez JE, Kris MG, et al. A phase I/II study of weekly high-dose erlotinib in previously treated patients with nonsmall cell lung cancer. Cancer 2006; 107:1034-41.

24. Kuiper JL, Smit EF. High-dose, pulsatile erlotinib in two NSCLC patients with leptomeningeal metastasesOne with a remarkable thoracic response as well. Lung Cancer 2013;80:102-5.

25. Jackman D, Mach S, Heng JC, Rabin MS, Barbie DA, Gandhi L, et al. Pulsed dosing of erlotinib for central nervous system (CNS) progression in EGFR-mutant non-small cell lung cancer (NSCLC). J Clin Oncol 31, 2013 (suppl; abstr 8116).

26. Hoffknecht P, Tufman A, Wehler T, Pelzer T, Wiewrodt R, Schutz M, et al. Efficacy of the Irreversible ErbB Family Blocker Afatinib in Epidermal Growth Factor Receptor (EGFR) Tyrosine Kinase Inhibitor (TKI)-pretreated Non-small Cell Lung Cancer Patients with Brain Metastases or Leptomeningeal Disease. J Thorac Oncol 2015;10: 156-63.

27. Janne PA, Ramalingam SS, Chih-Hsin Yang J, Kim DW, Kim SW, Planchard D, et al. Clinical activity of the mutant-selective EGFR inhibitor AZD9291 in patients (pts) with EGFR inhibitor-resistant non-small cell lung cancer (NSCLC). J Clin Oncol 2014 32:5s (suppl; abstr 8009).

28. Sequist LV, Soria JC, Gadgeel SM, Wakelee HA, Camidge DR, Varga A, et al. First in-human evaluation of CO-1686, an irreversible, highly selective tyrosine kinase inhibitor of mutations of EGFR (activating and T790M). J Clin Oncol 2014 32:5s (suppl; abstr 8010).

29. Chamberlain MC, Eaton K. Is there a role for whole brain radiotherapy in the treatment of leptomeningeal metastases? J Thorac Oncol 2012;7:1204-5.

30. Chamberlain MC. Leptomeningeal metastasis. Curr Opin Oncol 2010;22:627-35.

31. Chamberlain M, Soffietti R, Raizer J, Ruda R, Brandsma D, Boogerd W, et al. Leptomeningeal metastasis: a Response Assessment in Neuro-Oncology critical review of endpoints and response criteria of published randomized clinical trials. Neuro Oncol 2014;16:1176-85.

32. Niibe Y, Chang JY. Novel insights of oligometastases and oligo-recurrence and review of the literature. Pulm Med 2012;2012:261096.

33. Gaspar L, Scott C, Rotman M, Asbell S, Phillips T, Wasserman T, et al. Recursive partitioning analysis (RPA) of prognostic factors in three Radiation Therapy Oncology Group (RTOG) brain metastases trials. Int J Radiat Oncol Biol Phys 1997;37:745-51.

34. Hendriks LE, Troost EG, Steward A, Bootsma GP, De JK, van den Borne BE, et al. Patient selection for whole brain radiotherapy (WBRT) in a large lung cancer cohort: Impact of a new Dutch guideline on brain metastases. Acta Oncol 2014;53:945-51.

35. Chamberlain MC. Leptomeningeal metastasis. Semin Neurol 2010;30:236-44

36. Glass JP, Melamed M, Chernik NL, Posner JB. Malignant cells in cerebrospinal fluid (CSF): the meaning of a positive CSF cytology. Neurology 1979;29:1369-75.

37. Wasserstrom WR, Glass JP, Posner JB. Diagnosis and treatment of leptomeningeal metastases from solid tumors: experience with 90 patients. Cancer 1982;49:759-72. 


\section{SUPPLEMENTARY TABLE}

Table S10.1 1 -6 Month survival.

\begin{tabular}{|c|c|c|c|c|c|c|}
\hline & & \multicolumn{4}{|c|}{ Alive after 6 months } & \multirow[b]{3}{*}{ P-value } \\
\hline & & \multicolumn{2}{|c|}{ Yes } & \multicolumn{2}{|c|}{ No } & \\
\hline & & Frequency & (percentage) & Frequency & (percentage) & \\
\hline \multirow[t]{2}{*}{ Gender } & Male & 6 & $(42.9 \%)$ & 8 & $(44.4 \%)$ & 0.928 \\
\hline & Female & 8 & $(57.1 \%)$ & 10 & $(55.6 \%)$ & \\
\hline \multirow[t]{4}{*}{ Smoking } & Never & 5 & $(35.7 \%)$ & 11 & $(61.1 \%)$ & 0.103 \\
\hline & Former & 7 & $(50.0 \%)$ & 5 & $(27.8 \%)$ & \\
\hline & Current & 2 & $(14.3 \%)$ & 0 & $(0.0 \%)$ & \\
\hline & Unknown & 0 & $(0.0 \%)$ & 2 & $(11.1 \%)$ & \\
\hline \multirow[t]{5}{*}{ EGFR-mutation } & Exon 18 & 0 & $10.0 \%$ & 1 & $(5.6 \%)$ & 0.358 \\
\hline & Exon 19 & 6 & $(42.9 \%)$ & 11 & (61.1\%) & \\
\hline & Exon 20 & 0 & $(0.0 \%)$ & 1 & $(5.6 \%)$ & \\
\hline & Exon 21 & 7 & $(50.0 \%)$ & 5 & $(27.8 \%)$ & \\
\hline & Exon $18+20$ & 1 & (7.1\%) & 0 & $(0.0 \%)$ & \\
\hline \multirow[t]{2}{*}{ PS at LM-diagnosis } & PS 0-1 & 11 & $(78.6 \%)$ & 4 & $(22.2 \%)$ & 0.002 \\
\hline & $P S \geq 2$ & 3 & $(21.4 \%)$ & 14 & $(77.8 \%)$ & \\
\hline \multirow[t]{2}{*}{ Pulsatile for LM } & Yes & 5 & $(35.7 \%)$ & 7 & $(38.9 \%)$ & 0.854 \\
\hline & No & 9 & $(64.3 \%)$ & 11 & (61.1\%) & \\
\hline \multirow{4}{*}{$\begin{array}{l}\text { Extra-CNS disease } \\
\text { under control } \\
\text { Radiotherapy for LM }\end{array}$} & Yes & 8 & (57.1\%) & 7 & $(38.9 \%)$ & 0.305 \\
\hline & No & 6 & $(42.9 \%)$ & 11 & (61.1\%) & \\
\hline & Yes & 6 & $(42.9 \%)$ & 8 & $(44.4 \%)$ & 0.928 \\
\hline & No & 8 & $(57.1 \%)$ & 10 & $(55.6 \%)$ & \\
\hline
\end{tabular}




\title{
Chapter 11
}

\author{
General discussion and
}

future perspectives

- x. 
Chapter 11 


\section{INTRODUCTION}

Brain metastases are diagnosed in approximately $40 \%$ of lung cancer patients during the course of their disease. ${ }^{1}$ Known risk factors for the development of brain metastases are adenocarcinoma histology, advanced nodal status, tumor stage and younger age..$^{2-5}$ Brain metastases can have a negative impact on quality of life (QoL) and overall survival (OS) is often poor after diagnosis of brain metastases. ${ }^{6-8}$

Aims of this thesis were to explore controversies regarding the screening for brain metastases in stage III non-small cell lung cancer (NSCLC), risk factors for brain metastases (treatment related as well as molecular phenotype related), as well as in the treatment of brain metastases and prognosis after diagnosis of brain and leptomeningeal metastases. This to provide a more evidence-based management of lung cancer brain metastases.

The following section will summarize the highlights of the thesis in perspective of the currently available (lung cancer) brain metastases literature. Ideas for future research will also be discussed.

\section{MAIN FINDINGS}

\section{PART 1: BRAIN METASTASES IN STAGE III NSCLC}

\section{Screening for brain metastases in stage III NSCLC: imaging}

Brain magnetic resonance imaging (MRI) has marginally additive value above a contrast enhanced computed tomography (CE-CT) performed during ${ }^{18}$ fluorodeoxyglucosepositron emission tomography $\left({ }^{18}\right.$ FDG-PET)-CE-CT in detecting occult brain metastases in stage III NSCLC. However, although the screening MRI did not show evidence of brain metastases, approximately $15 \%$ of patients developed mostly symptomatic brain metastases within one year after NSCLC diagnosis.

Although MRI of the brain is recommended in neurologically asymptomatic stage III NSCLC patients to exclude asymptomatic brain metastases, ${ }^{9-12}$ its value above a CE-CT of the brain performed during ${ }^{18}$ FDG-PET-CE-CT is not known. Time (as well as money) could be saved when only an ${ }^{18}$ FDG-PET-CE-CT would be needed for staging purposes in this patient population.

In part one, chapter two and three we evaluated this question in a retrospective study and a prospective observational study, respectively. With up-to-date imaging techniques, no additional value of brain MRI was found in the 45 patients in the retrospective study described in chapter two. In the prospective observational study described in chapter three an additional 2.5\% of patients (three out of 118) was diagnosed with brain metastases on MRI after a CE-CT without suspect findings. However, in one patient a brain metastasis was in retrospect identified on CE-CT after a 
blinded review of these three CE-CTs by an experienced neuroradiologist. As we defined "clinically relevant" as an additional $2 \%$ of patients with brain metastases found on MRI, MRI has in daily practice, without extra review of the CE-CT, a (marginally) additional value after a negative CE-CT. In 3.0 and $3.3 \%$ of cases asymptomatic brain metastases were detected on CE-CT, as was found in chapter two and three, respectively. Chapter two also stresses the need for adequate brain imaging in this patient population, as $16 \%$ "extracranial stage III NSCLC" patients in whom only a low dose CT (LD-CT) of the brain was performed had subsequent occult brain metastases on MRI. It is important to realize that in most hospitals only a LD-CT for attenuation correction is performed during a ${ }^{18}$ FDG-PET that is not suitable for excluding asymptomatic brain metastases. Furthermore, in most hospitals, comparable to the participating hospitals in chapter two and three, a LD-CT is performed when there is already a CE-CT of the thorax available.

Moreover, access to MRI proved often difficult, as in the prospective study described in chapter three $29.8 \%$ of patients did not underwent a brain MRI within three weeks of the ${ }^{18}$ FDG-PET. Problems with timely access to MRI are not unique for the participating hospitals, as in a United Kingdom survey (2014) CE-CT was preferred above MRI, presumably due to lack of access to MRI. ${ }^{13}$ From an economical point of view the costeffectiveness of an additional MRI when already a CE-CT of the brain has been performed is interesting.

Despite up-to-date brain imaging before start of intensive therapy, we have shown in part one chapter two and four that $10.5-13 \%$ of stage III NSCLC patients will develop (mainly symptomatic) brain metastases within a year of NSCLC diagnosis. Percentages of brain metastases diagnosis after treatment for stage III NSCLC are varying in the literature. In two retrospective studies ( $\mathrm{N}=177$ and $\mathrm{N}=51)$ including stage III NSCLC patients with negative brain imaging at initial diagnosis, $34 \%$ and $43 \%$ had brain metastases as the first site of progression. ${ }^{14,15}$ It is possible that this higher percentage is caused by undetected asymptomatic brain metastases at initial diagnosis because of the older imaging techniques used (patients included from 1988-2000 and 1990-2004 respectively). However, a retrospective review from four SWOG studies ( $N=422$ stage III NSCLC patients with negative brain imaging at initial diagnosis, all studies closed for accrual in the 1990's) found that $16.8 \%$ developed brain metastases and $11.8 \%$ had brain metastases within a year of NSCLC diagnosis. ${ }^{2}$ In a more recent retrospective study ( $N=217$, stage III patients with baseline brain imaging included from 2003-2005), the 1-year risk for brain metastases was 9.2\%, 14.7\% had brain metastases as first site of relapse and for $6.9 \%$ this was the only site of relapse (both irrespective of timing). ${ }^{16}$ In all studies, despite improving imaging techniques, is it still possible that some of these metastases were already present at initial stage III diagnosis but were not detected by CE-CT and/or MRI. Maybe some of these already present micrometastases could have been detected with more sensitive MRI-techniques. However, in both chapter two and three MRI sensitivity was already increased with MTC prepulse 
(resulting in an increased enhancement equivalent to a double dose of gadolinium contrast) and the addition of a post-contrast fluid attenuated inversion recovery (FLAIR) sequence. ${ }^{17,18}$ Higher contrast doses also increase the possibility for false positive findings. ${ }^{19,20}$ It is possible that a 3.0 Tesla scanner would have detected brain metastases in more patients, but no studies exist showing increased sensitivity of these scanners in detecting the presence or absence of brain metastases.

An interesting new development for early visualisation of brain metastases is the use of a targeted MRI contrast agent that enables imaging of endothelial vascular cell adhesion molecule-1 (VCAM-1). VCAM-1 is upregulated on vessels closely associated with brain metastases, and in a murine model the use of this VCAM-1 targeted MRI contrast agent enabled the visualisation of a tumour two to three times smaller compared to the minimum detectable tumour $(2-5 \mathrm{~mm})$ on a standard gadolinium contrast-enhanced MRI. ${ }^{21}$ Unfortunately, this contrast agent is non-biodegradable and not suitable for use in humans. Comparable contrast agents suitable for use in humans are in development. ${ }^{21}$ Moreover, as VCAM-1 is also upregulated in non-tumour associated inflammation, this technique could lead to false positive cases. ${ }^{21}$ To visualise a brain metastasis with a gadolinium contrast enhanced MRI requires permeability of the blood brain barrier (BBB) located near the tumour. The BBB integrity starts to fail when a brain metastasis reaches a diameter of $2-5 \mathrm{~mm} .{ }^{22}$ Earlier local permeabilisation of the BBB would enable earlier detection of a brain metastasis with gadolinium contrast enhanced MRI. In a mouse model, local expression of tumour necrosis factor receptor 1 (TNFR1) was found only on the vascular endothelium of blood vessels associated with brain metastases and administration of TNF permeabilized the BBB selectively at sites of brain metastases. TNFR1 expression was also found in human brain metastases, but clinical translation of this technique has yet to be made. ${ }^{23}$ It is also possible that despite more sensitive imaging techniques the brain metastasis will not be detected at an early stage. In a mouse model it has been described that lung cancer cells can invade the brain and remain dormant as single cells in the perivascular spaces for some time before they develop into detectable brain metastases. ${ }^{24}$ These single cells will escape detection with all the imaging modalities described above.

Strategies to reduce incidence of (symptomatic) brain metastases in the follow-up of radically treated stage III NSCLC patients: systemic therapy

The specific chemotherapy used in a chemoradiation regimen for stage III NSCLC does not have an impact on the subsequent development of brain metastases and $10.5-13 \%$ of the patients will develop (mainly symptomatic) brain metastases within a year of NSCLC diagnosis

The risk factors for the development of brain metastases described in the retrospective multicentre study in chapter four were found to be consistent with the literature (i.e. adenocarcinoma histology, advanced tumour stage, younger age). ${ }^{2-5}$ However, the 
specific chemotherapy regimen used within a CRT treatment had no impact on the diagnosis of brain metastases in the follow up.

There are two explanations for this brain metastases development. The first is that these metastases were already present at initial stage III NSCLC diagnosis but were not detected by MRI. Strategies to improve brain metastases diagnosis are discussed above, strategies to prevent outgrowth of these metastases are described below. The other explanation is that the seeding and subsequent development of brain metastases occurred during or after treatment for stage III NSCLC but that these metastases were not present at the time of initial brain imaging.

As microscopic brain metastases are not detected with current up-to-date imaging techniques, it would also be a good option to prevent outgrowth of these micrometastases, for example with chemotherapy. However, in the retrospective study described in chapter four, the specific chemotherapeutic regimen during CRT had no impact on the development of brain metastases. Still, chemotherapy does have some effect on the development of metastases in general. From older retrospective stage III studies ( $\mathrm{N}=267$ and $\mathrm{N}=1765$ ) without routine ${ }^{18}$ FDG-PET-scan or brain imaging, a decrease in extracranial (but not cranial) metastases was observed with the addition of systemic dose, cisplatin based chemotherapy to local radical treatment. ${ }^{3,25}$ To also prevent outgrowth of micrometastases in the brain, the drug used has to penetrate the intact BBB. Although not many data exist for chemotherapy penetration through an intact BBB, from current literature it is clear that the chemotherapeutics used in a CRT regimen do not penetrate this $B B B$. They are all substrates for brain efflux pumps such as the P-glycoprotein (PgP) pump or the multidrug-resistance-associated protein (MRP) efflux pump family. ${ }^{26-28}$ New strategies are necessary to prevent active efflux of these drugs. An option could be to redesign a drug to take advantage of innate influx transporter systems expressed at the BBB. Angiopeps are an example. They are transported into the brain via low-density lipoprotein receptor-related protein (LRP1). Angiopep-2 conjugated to paclitaxel has been tested in a phase I trial including patients with solid tumors. It was well tolerated and showed some activity in patients with already diagnosed brain metastases. ${ }^{29}$ A trial with the same drug tested in NSCLC patients diagnosed with brain metastases was prematurely closed because of slow accrual (NCT01497665). Another option to transport drugs to the brain is conjugation to transferrin, which is actively transported through the $\mathrm{BBB}^{30}$ Changing the drug formula to a liposomal based form is also an option to increase brain delivery. ${ }^{30}$ Another possible way to prevent outgrowth of micrometastases is to target the vascular endothelial growth factor (VEGF). Angiogenesis is necessary for NSCLC brain metastases to grow and is mainly driven by VEGF activation. VEGF blockade with the humanized monoclonal anti-VEGF antibody bevacizumab has been shown to inhibit brain metastases formation in an experimental setting in mice injected with a lung cancer, but not melanoma cell line. ${ }^{24,31}$ Whether bevacizumab prevents brain metastases formation has only been retrospectively studied in cancer patients although 
there are prospective data that it has an effect on established brain metastases in NSCLC. In an exploratory phase II study including NSCLC patients with untreated asymptomatic brain metastases a bevacizumab based regimen (first line carboplatinpaclitaxel-bevacizumab or second line erlotinib-bevacizumab) was safe and elicited an intracranial response (intracranial overall response rate (ORR) 61.2\%). ${ }^{32}$ Furthermore, in an unplanned retrospectively analysis of the randomized first line phase III AVAil study a lower risk for (symptomatic) brain metastases as site of first relapse was found for the bevacizumab arm compared to the control arm. This study included 1043 metastasized non-squamous NSCLC patients and excluded those with brain metastases at baseline (imaging only required when symptomatic). Patients were randomized to receive gemcitabine $1250 \mathrm{mg} / \mathrm{m}^{2}$ plus cisplatin $80 \mathrm{mg} / \mathrm{m}^{2}$ for up to six cycles plus bevacizumab $7.5 \mathrm{mg} / \mathrm{kg}$, bevacizumab $15 \mathrm{mg} / \mathrm{kg}$ or placebo every three weeks until disease progression. $2.6 \%$ of bevacizumab treated patients developed brain metastases as site of first relapse compared to $5.8 \%$ in the control arm $(p<0.001)$. Time to development of these brain metastases was also longer in the bevacizumab arm: median [95\% confidence interval] 7.8 [1.1-16.2] months compared to 4.5 [0.3-12.1] months in the control arm (hazard ratio 0.36 [0.19-0.68]) No difference was found for the development of extracranial metastases. ${ }^{31,33}$ Unfortunately, the addition of bevacizumab to thoracic radiotherapy is not feasible, as in a phase I study four out of six patients developed $\geq$ grade 2 radiation pneumonitis after which the study was closed. $^{34}$ Moreover, tracheoesophageal fistulas have been described after (chemo)radiation combined with bevacizumab. ${ }^{35,36}$ However, it should be evaluated whether low dose bevacizumab treatment started after completion of chemoradiotherapy for NSCLC is safe and effective in preventing brain metastases formation in NSCLC patients with a high risk of brain metastases development (adenocarcinoma patients). A low dose of bevacizumab would be of interest from an economical point of view, and preclinical data show that low dose bevacizumab still inhibits brain metastases formation in non-squamous NSCLC. ${ }^{31}$

Recently, it has been suggested that low dose chemotherapy administered on a frequent regular schedule with no drug-free break periods ("metronomic" chemotherapy) can exert a broad range of antitumor activity different from systemic chemotherapy. It is suggested that metronomic chemotherapy can inhibit cancer stem cells, stimulate the immune system, cause anti-vascular effects and prevent the acquisition of epithelial-to-mesenchymal transition which is necessary for tumour cells to metastasize. ${ }^{37-39}$ In contrast, some cyclic systemic dose chemotherapies seem to cause a rebound in circulating endothelial progenitor cells (CEP) which supply cells that may participate in tumour angiogenesis. ${ }^{40-42}$ CEP rebound has been described especially for taxane-based chemotherapy, but also for anthracyclines (although conflicting results exist for doxorubin). ${ }^{40,42}$ Cancer stem cells are thought to be the most probable cause for the seeding of (brain) metastases. ${ }^{43}$ Metastases development is also dependent on epithelial-to-mesenchymal transition and angiogenesis. ${ }^{44}$ Therefore, it is 
possible that metronomic chemotherapy is superior in preventing the development of brain metastases compared to regular cyclic systemic dose chemotherapy. However, in chapter four, daily low dose cisplatin (a possible metronomic schedule) was not superior in preventing brain metastases as compared to systemic dose chemotherapy. The most probable explanation is that the daily low dose cisplatin regimen used did not act as metronomic chemotherapy. There are few data on metronomic chemotherapy in lung cancer patients, and none of these data are regarding low dose cisplatin or stage III NSCLC. One study ( $\mathrm{N}=40$ advanced NSCLC) evaluated the anti-angiogenic effects of a maximum-tolerated dose (MTD) regimen of a single dose cisplatin $75 \mathrm{mg} / \mathrm{m}^{2}$ plus docetaxel $75 \mathrm{mg} / \mathrm{m}^{2}$ (both day 1) versus a "metronomic" dose of cisplatin $25 \mathrm{mg} / \mathrm{m}^{2}$ plus docetaxel $25 \mathrm{mg} / \mathrm{m}^{2}$ (both day 1 of week 1, 2 and 3). The anti-angiogenic effect (measured with serum VEGF, VEGFR1 and thrombospondin-1 (TSP1)) was not superior in the metronomic dose group. ${ }^{45}$ To our best knowledge there are no other clinical data for NSCLC using a purely metronomic regimen and neither there are data for other tumors using a metronomic cisplatin schedule. In an urothelial carcinoma cell line, metronomic cisplatin $(2 \mathrm{mg} / \mathrm{kg} / 3$ days a week) was not superior in inhibiting tumor growth as compared to standard cisplatin (6 mg/kg/once a week), although the metronomic dosing showed some anti-cell-migratory activity. ${ }^{46}$ In contrast, data from a hepatocarcinoma cell line combined with data in mice suggest that daily low dose cisplatin $(0.6 \mathrm{mg} / \mathrm{kg} /$ day) has a superior anti-angiogenic effect as compared to a single MTD dose $(9 \mathrm{mg} / \mathrm{kg}$ ) (measured in vitro with human umbilical vascular endothelial cells (HUVECs) and the hepatocarcinoma cell line, in mice with VEGF and matrix metallopeptidase 2 (MMP-2) expression, microvessel density and tumor growth). ${ }^{47}$ Few and only preclinical data exist regarding immunomodulatory effects of cisplatin. As opposed to topo-isomerase inhibitors (e.g. etoposide) and anti-microtubule agents (e.g. vinblastin, paclitaxel, docetaxel) cisplatin had in vitro no effect on the maturation of dendritic cells which are necessary for presenting tumor-associated antigens to effector T-cells. ${ }^{48}$ And although data exist that metronomic chemotherapy can reduce the cancer stem cell population, neither data exist for a cisplatin based regimen nor for lung cancer patients specifically. ${ }^{37-39}$ It is also possible that daily low dose cisplatin acts as metronomic chemotherapy, but that the duration (only concurrent with radiotherapy) was not long enough.

As is has been described that especially taxane-based chemotherapy causes a rebound in CEP, and if it is assumed that a CEP rebound increases the risk for brain metastases development, one can also argue that patients treated with a taxane-based chemotherapy regimen would have the highest risk for brain metastases development. $^{40,42}$ However, no increased risk was found in chapter four. The CEP rebound for taxanes was found when paclitaxel or docetaxel were given at the maximum tolerable dose (MTD) and it is possible that the taxane based CRT regimen used (weekly docetaxel) has less CEP rebound because of the lower weekly dose. It is also possible that the taxane subgroup $(\mathrm{N}=60)$ was not large enough to demonstrate a 
difference, or that CEP rebound has no influence on the subsequent development of brain metastases.

Strategies to reduce incidence of (symptomatic) brain metastases in the follow-up of radically treated stage III NSCLC patients: prophylactic cranial irradiation

Prophylactic cranial irradiation $(\mathrm{PCl})$ to prevent the outgrowth of microscopic brain metastases is also an option and is an accepted treatment for SCLC patients with a response to initial therapy. In the non-metastasized as well as in the metastasized setting, $\mathrm{PCl}$ reduced the incidence of symptomatic brain metastases. $\mathrm{PCl}$ also prolonged disease free survival (DFS) and OS. ${ }^{49,50}$ However, in the randomized phase III RTOG0214 study ( $\mathrm{PCl}$ versus observation after radical treatment for stage III NSCLC) no difference was found for OS, the primary endpoint of this trial. A significant difference was found for the 1-year rate of brain metastases diagnosis ( $\mathrm{PCl} 7.7 \%$, observation $18 \%$ ). In this study, regular brain imaging in the follow-up was mandatory. The study was prematurely closed due to slow accrual (planned 1058 patients, accrued 356). ${ }^{51}$ Regular brain imaging after radical treatment for stage III NSCLC is not recommended in current NSCLC guidelines, in contrast to the RTOG0214 study. An approach more resembling routine clinical practice regarding follow up is the phase III randomized NVALT11/DLCRG 02 study (NCT01282437). This study has as a primary endpoint the proportion of patients developing symptomatic brain metastases. The study is closed for accrual and the results are awaited for. The downside of $\mathrm{PCl}$ is the risk for neurocognitive decline. In the RTOG0214 study, no significant differences were found with respect to QoL, Mini Mental State Examination (MMSE) and the Activities of Daily Living Scale (ADLS). However, a trend for a greater decline in patient reported cognitive functioning as well as a significant decline in memory (Hopkins Verbal Learning Test (HVLT) was found for the $\mathrm{PCl}$ group. ${ }^{52}$ As, despite the relatively high risk for brain metastases development, most patients will not develop brain metastases. Moreover, $\mathrm{PCl}$ comes at a cost of a risk of neurocognitive decline especially in the long-term (3-year OS after CCRT 23.8\%, 5-year OS 15.1\%). ${ }^{53}$ Thus, a risk stratification tool before commencement of $\mathrm{PCl}$ would be ideal.

Strategies to improve diagnosis of brain metastases in the follow-up of radically treated stage III NSCLC patients: identifying high risk patients

As micrometastases in the brain are not diagnosed with current staging techniques, and the current treatment applied does not seem to reduce the development of brain metastases, another strategy would be to diagnose the brain metastases before they become symptomatic. Routine brain imaging during follow up after CRT is not advised in current guidelines. ${ }^{11,12}$ Only the ESMO guideline on locally advanced NSCLC suggests that for selected high risk patients (adenocarcinoma) routine brain imaging is an option for the early detection and possible radical treatment of brain metastases (level of evidence: $\mathrm{V}, \mathrm{C}) .{ }^{9}$ Despite these known risk factors, it is difficult to predict on an individual patient level which patient will develop brain metastases and which one will 
not. As such a better risk stratification tool would be useful. The easiest method would be a serum-based test. However, currently known serum tumour markers such as CEA, CYFRA21-1 and CA-125 were not associated with the development of brain metastases, ${ }^{54}$ although an elevated CEA-level was associated with already present brain metastases in two other studies. ${ }^{55,56}$ In a recent study, Single Nucleotide Polymorphisms in the PI3K-PTEN-AKT-mTOR pathway were associated with the development of brain metastases in the follow-up. ${ }^{57}$ Another option is testing the available tissue from the primary tumour. The expression of three genes (CDH2, KIFC1 and FALZ) in the primary tumour had predictive value for the development of symptomatic brain metastases in $\operatorname{NSCLC~}\left(\mathrm{N}=142\right.$, stage I-IV). ${ }^{58}$ As one micro-RNA (miRNA) regulates several hundred genes, miRNA profiling could be superior in predicting the development of brain metastases compared to single gene profiling. miRNA-328 expression was in a small series of NSCLC patients ( $N=6$ with brain metastases, $\mathrm{N}=6$ without brain metastases) associated with a diagnosis of brain metastases. $^{59}$ miRNA-378 was also differentially expressed in a small series of NSCLC patients ( $\mathrm{N}=21$ with brain metastases, $\mathrm{N}=8$ without brain metastases). ${ }^{60}$ In a large study ( $N=272$ stage I NSCLC patients) 10 miRNA's correlated with the development of brain metastases. The above described miRNA-378 and miRNA-328 were not among these miRNAs. $^{61}$

\section{PART 2 BRAIN METASTASES IN STAGE IV DISEASE (ALL COMERS).}

\section{Impact of the organ(s) affected in stage IV NSCLC on prognosis}

In stage IV NSCLC, number of organ sites affected has a prognostic value. In single organ disease, local disease status has an impact on prognosis. Besides the TNM7 M1a group, no other organ sites were consistently associated with a favourable prognosis. The prognostic value of number of organ sites affected and local disease status did not change in the ${ }^{18}$ FDG-PET-staged subgroup.

Although the concept of a superior prognosis in patients with single organ metastasis is not new, available studies are not population based and they included a smaller, sometimes very selected number of patients. ${ }^{62-67}$ Moreover, except for one study, $\left(\mathrm{N}=186\right.$ oligometastatic NSCLC patients) ${ }^{66}$ information on ${ }^{18}$ FDG-PET scanning was not available or was not used for subgroup analysis. In chapter five we describe the first large population based study (including a large subgroup analysis ( $N=1517$ ) of ${ }^{18} \mathrm{FDG}$ PET staged patients) in which number of organs with metastases, the actual organ with metastases as well as the prognostic value of local disease status is evaluated in stage IV NSCLC at diagnosis. Results were validated in a substantial subgroup analysis with ${ }^{18}$ FDG-PET staged patients and patients receiving active anticancer treatment. Single organ metastasis and a low TN-status were associated with a superior OS in the total cohort as well as in the subgroups. 
$\mathrm{N}$-status in stage IV NSCLC is evaluated in only three other studies. ${ }^{66,68,69}$ In these studies a low $\mathrm{N}$-status was also prognostic. However, one study included a relatively small number $(\mathrm{N}=186)^{66}$ of oligometastatic NSCLC patients, one $(\mathrm{N}=67149)$ evaluated $\mathrm{N}$ status only in T4 and M1a patients and did not include information obtained from ${ }^{18}$ FDG-PET staging. ${ }^{69}$ The third study $(\mathrm{N}=850)$ evaluated a selected group of nonsquamous NSCLC patients with a good PS (ECOG 0/1), without brain metastases, receiving first line carboplatin plus paclitaxel with/without bevacizumab, but did not include information on single organ metastasis or ${ }^{18}$ FDG-PET staging. ${ }^{68}$

We did not have information regarding number of metastases per organ or the total volume of NSCLC in a patient. It could be that a patient with multiple organs affected with single or small lesions per organ has a different prognosis compared to a patient with bulky metastases in multiple organs. It is also possible that a patient with a high tumour burden in one organ (e.g. multiple lesions in one organ) has a different prognosis compared to a patient with a only one metastasis in one organ. The latter is suggested in the proposals for the revision of the $M$ descriptors for the eight edition of the TNM classification for lung cancer. Based on an analysis of 1025 patients (registered in multiple centres between 1999-2012) the authors advise to maintain the current M1a category, and to divide the current M1b category into a new M1b (single metastasis in a single organ) and M1c (multiple metastasis in a single organ/ single or multiple metastases in multiple organs). ${ }^{70}$ In chapter six we discussed in a letter this proposal with regard to a possible selection bias and an uncertainty regarding imaging modalities performed for staging work-up.

${ }^{18}$ FDG-PET-scanning is a good method to evaluate both number of lesions per organ (except for the brain) as well as the total volume of (lung) cancer in a patient. The prognostic value of the metabolic tumour volume (MTV) and the total lesion glycolysis (TLG) of the primary tumour in NSCLC has recently been reviewed. ${ }^{71}$ Thirteen studies (all retrospective, all stages) with in total 1581 patients were included and a high MTV and TLG were associated with a poor prognosis in stage I/II as well as stage III/IV disease. ${ }^{71}$ Especially in stage IV NSCLC the whole-body MTV and TLG would be of interest, as this would be a better reflection of the total tumour burden. Indeed, in a recently published retrospective study ( $N=328$ NSCLC, 111 stage IV) the addition of whole-body MTV to the TNM classification enabled a better discrimination between poor and good prognosis patients across all TNM stages. However, number of organs affected was not incorporated in the stage IV subgroup. ${ }^{72}$ Despite the usually poor prognosis of stage IV NSCLC patients, further stratification into relatively good or poor prognosis groups would be useful. These differences in prognosis could cause bias in clinical trials and should be taken into account as a stratification factor. Whether aggressive therapy could improve prognosis should be studied especially in the good prognosis patients as is discussed below. 
Local disease status is not frequently studied in stage IV NSCLC. However, despite a metastasized setting, local disease still had a prognostic impact in chapter five. This was also found in two other studies. ${ }^{73,74}$ As patients with single organ metastases and low TN-status had the highest OS, it is tempting to speculate whether a subgroup of these patients with single or oligometastases in one organ would achieve an even better OS when treated radically. Radical treatment is often aimed at in patients with oligometastases in the brain or adrenal(s). However, it is not clear whether these patients by nature have a superior OS or that OS can be improved with radical treatment, as was also discussed in a recent review. ${ }^{75}$ Hopefully this answer will be provided with one ongoing trial (NCT01725165) and one trial in preparation (SARON, NCT02417662). In the ongoing randomized phase II trial, oligometastatic (one to three metastases) NSCLC patients are allocated to local ablative therapy or surveillance/maintenance therapy after completion of 4 cycles of induction platinum doublet chemotherapy (or TKI in case of an EGFR-mutation or ALK-rearrangement). Primary endpoint is progression free survival (PFS). In the randomized phase III SARON study, oligometastatic (one to three metastases) NSCLC patients, staged with ${ }^{18} \mathrm{FDG}$ PET-scan and MRI brain, are randomized to either standard platinum based chemotherapy (4 cycles) or standard platinum based chemotherapy and radical radiotherapy to the primary tumour as well as the metastases. Primary endpoint is OS. Another interesting topic in oligometastatic stage IV NSCLC is the location of the adrenal metastasis (ipsilateral side as the primary tumour or the contralateral side). It is suggested that an ipsilateral adrenal metastasis occurs via lymphatic spreading and a contralateral via hematogenous spreading. In small series it is suggested that an ipsilateral adrenal metastasis has a superior prognosis compared to a contralateral one. $^{76}$ This would be of interest to evaluate in the SARON trial as well as in the population based Dutch database (IKNL) (in the fully staged patients treated with radical intent).

\section{Prognosis of lung cancer patients with brain metastases}

In general, prognosis of lung cancer patients diagnosed with brain metastases is dismal. The advised treatment for patients with multiple brain metastases is whole brain radiotherapy (WBRT). As the prognosis of Recursive Partitioning Analysis (RPA) class III is very poor, it is advised in the revised Dutch guideline on brain metastases to withhold WBRT in this patient population. However, in daily clinical practice 11.3-21.3\% of WBRT treated patients is classified as RPA class III and this did not significantly decrease after implementation of the guideline

In the retrospective study described in chapter seven, a large cohort of Dutch lung cancer patients undergoing WBRT was studied. The existing RPA classes were validated and except for a longer OS in the NSCLC RPA class I cohort, median OS was dismal and comparable to the original RTOG analysis. ${ }^{7}$ Moreover, in the RPA class II cohort patient groups with a different survival were found when evaluating the presence or absence 
of extracranial metastases. Median OS of the RPA class III cohort was only 1.7 months. In the revised Dutch guideline on brain metastases it is advised to withhold WBRT in this poor prognosis group. However, we found that this advice had no impact on daily clinical practice, and we could not identify factors possibly associated with a decision to pursue active treatment (e.g. younger age, option to receive first line chemotherapy, brain metastases as the only site of disease activity). The most probable explanation for active treatment despite a dismal prognosis is that both physicians as well as patients/relatives overestimate the effect of a palliative treatment with respect to symptoms as well as OS. ${ }^{77-79}$ In a survey including 384 lung cancer patients treated with palliative radiotherapy, $67 \%$ of patients believed that radiotherapy would improve symptoms associated with their cancer, $78 \%$ of them believed that radiotherapy would help them to live longer and $64 \%$ did not understand that the radiotherapy administered had no curative intent. ${ }^{79}$ Comparable results were found in a study with palliative chemotherapy $169 \%$ of lung cancer patients did not understand that the chemotherapy administered was not likely to cure their cancer). ${ }^{80}$ However, the majority of oncologists (98\%) stated in another survey that they explain to their patients that their disease is incurable although they are more unwilling to disclose a specific time period till death. ${ }^{81}$ The easiest explanation for the discrepancy between patients' expectations about the effects of palliative treatment is stating that the involved physicians did not adequately discuss treatment effects and prognosis with their patients. In contrast, it was found that patients who rated the communication with their physician as good (defined as a physician who listens carefully, explains in an understandable way, gives as much information as a patient wanted, in other words probably gives all the necessary information to understand the treatment effect) were also at an increased risk for incorrect expectations. ${ }^{80}$ However, in this study it was not asked whether the physician provided a specific estimation of the effect of the planned treatment or whether the patient wanted to hear this information. In contrast, in another recent study, prognostic disclosure was associated with more realistic patient expectations. Importantly, this was not associated with a reduced patient emotional well-being or a reduced patient-physician relationship. ${ }^{82}$ It is also possible that the physician correctly explains the dismal prognosis and possible treatment (side-)effects but that the timing of the conversation was not right, e.g. directly after breaking the bad news, without time for processing this news. By switching directly from disclosing the fact that the disease is incurable to treatment options patients focus eagerly on these options and do not want to acknowledge that all the treatment efforts made are with a palliative intention. ${ }^{83}$ By focusing on offered treatments the patients and physicians often ignore the dismal future due to a focus on short-term goals (e.g. make it to the next treatment or test. ${ }^{83}$ Moreover, supportive care was often not viewed as a real alternative compared to active treatment (WBRT) in a survey on decision making in palliative radiation therapy including 19 brain metastases patients and 20 caregivers. ${ }^{84}$ By just being offered treatment, patients and caregivers retained some hope for 
symptom improvement, an increased life expectancy and sometimes even cure while on the same time most of them acknowledged that they had an incurable disease. ${ }^{84}$ Possibly a team-based consult service through a multidisciplinary integrated palliative oncology clinic would have improved this decision making process. In a recent study (2013) this team consisted of one clinical nurse specialist, one spiritual care counselling consultant, one palliative care physician and one radiation oncologist (unfortunately no medical oncologist/pulmonologist). The team focused on reviewing patient- and cancer-related characteristics and QoL but also on patients' understanding and expectations including spiritual care. Prognosis, advanced care planning (including palliative and home care services) and goals of care are discussed in the consultation, supplemented with printed and/or online resources and referral when necessary. ${ }^{84}$ When there was doubt of the patients' eligibility for WBRT, the decision was deferred for one or two weeks pending reassessment. By introducing this multidisciplinary team, end-of-life WBRT (defined as WBRT within 30 days of death) was reduced from a historical $19 \%$ to $9 \%{ }^{84}$

Till recently, no randomized studies were available evaluating whether a poor overall prognosis is not only a poor prognostic factor for OS but also translates into a predictive factor for a poor effect of WBRT (on symptoms as well as OS). One retrospective study $(\mathrm{N}=113)$ in patients with brain metastases and adverse prognostic factors found that withholding WBRT did not harm these patients. ${ }^{85}$ Comparable results were found in a prospective randomized study in RPA class III patients (N=91). ${ }^{86}$ At the 2015 ASCO annual meeting, QoL and OS data from the QUARTZ randomised non-inferiority clinical trial (NCT00403065) were presented. In this trial, NSCLC patients with inoperable brain metastases for whom clinician and patient were uncertain of the benefit of WBRT were included. They were randomised between WBRT and BSC versus BSC only. Primary outcome measure was quality adjusted life years (QALY). It was shown that WBRT provided no additional clinically significant benefit to BSC for this group of patients. ${ }^{87}$ Till now, results are only available in abstract-form and some critical comments need to be made about this trial. Recruitment was slow: the trial duration was from 2007-2014 with 72 participating hospitals in order to recruit 538 patients (i.e. approximately one patient per year per hospital included). This can have resulted in selection bias. Only $38 \%$ of patients had a Karnofsky Performance Score (KPS) of $<70$ (i.e. RPA class III) and it is not clear from the abstract whether there was a difference in QALY between RPA class III and the other patients. $30 \%$ of patients had a solitary brain metastasis and it is not clear why these patients were ineligible for stereotactic radiotherapy or surgery. Furthermore, histology (squamous cell versus non-squamous cell carcinoma) and the presence or absence of driver mutations were not specified in the abstract. It is possible that patients with a driver mutation in the non-squamous group would have had a different prognosis or neurological outcome when treated with WBRT as for example EGFR-mutations and $A L K$-rearrangements have a radio sensitising effect. ${ }^{88-91}$ 
Moreover, the last years effective tyrosine kinase inhibitors (TKI) have become available and good responses have been noted in poor performance patients with (even when withholding cranial radiotherapy) and without central nervous system metastases. ${ }^{92-96}$ As such, it is not clear whether the results from the QUARTZ trial can be extrapolated to a patient in the clinic, although in general a lung cancer patient without a targetable driver mutation diagnosed with brain metastases, classified as RPA III should receive $\mathrm{BSC}$ only.

RPA class II applies to the largest group of NSCLC patients with brain metastases, and it is stated in the revised Dutch guideline that in this class the effects of WBRT are uncertain. In chapter seven the RPA class II category could be further subdivided by the presence or absence of extracranial metastases. It would be interesting to evaluate whether prognosis could be even further refined by evaluating the number of organs with metastases, a prognostic factor which we have found in chapter five. Although the presence or absence of extracranial metastases is taken into account in prognostic classifications number of organs with metastases is not. Furthermore, it is not taken into account whether an effective systemic treatment is available for the extracranial disease (especially first line chemotherapy for SCLC and TKI for patients with molecular drivers, but in a lesser extent also first line chemotherapy for NSCLC) and whether this systemic treatment also penetrates the (compromised) BBB to also have an effect on the brain metastases. Ideally, prognostic classification, patient preferences, available systemic options and patient outcome (symptoms and OS) should be incorporated into a decision aid that continues to improve by the input it receives.

\section{PART 3: BRAIN METASTASES IN STAGE IV NSCLC PATIENTS WITH DRIVER MUTATIONS (ESPECIALLY EGFR) AND CENTRAL NERVOUS SYSTEM INVOLVEMENT}

Brain metastases incidence as well as survival after brain metastases diagnosis are not significantly different for EGFR-mutated, KRAS-mutated or EGFR/KRAS wildtype patients. The diagnosis of leptomeningeal metastasis confers a poor prognosis in most EGFR-mutated patients although exceptions occur. There are arguments that EGFR-TKI can be safely combined with WBRT although no high-level evidence exists. For ALK-TKI no data exist.

\section{Incidence and survival after brain metastases diagnosis}

NSCLC patients with an activating EGFR-mutation have a superior OS as compared to EGFR-wild type patients. ${ }^{97}$ However, in the literature controversies exist whether these patients have a higher risk of central nervous system (CNS) metastases compared to EGFR-wild type patients and whether they still have a superior OS when diagnosed with CNS metastases. ${ }^{96,98-102}$ This is an important question because of need for screening or (preventive) treatment options. The possible higher risk for brain metastases can be subdivided into two parts. The first part is the question whether EGFR-mutated patients have a higher biological tendency to develop brain metastases, i.e. whether the EGFR- 
mutation by itself is a risk factor for the development of brain metastases. If this is true, screening would be useful in order to subsequently choose a treatment modality with cranial as well as extracranial activity. The second part is whether the systemic treatment given to an EGFR-mutated patient influences the development of brain metastases in the follow up (i.e. brain as a sanctuary site due to pharmacological failure). Then, treatment should be aimed at the prevention of (symptomatic) brain metastases development. Again, screening could play a role.

The first part is best studied in treatment naïve stage IV patients. We could not demonstrate a difference in percentage of patients diagnosed with brain metastases for EGFR-mutated patients compared to KRAS-mutated and EGFR/KRAS wildtype patients in the retrospective study described in chapter eight. This was also found in another retrospective study by Doebele et al. ${ }^{98}$ although percentage of patients diagnosed with brain metastases at initial stage IV diagnosis was higher in this study (EGFR-mutated $23 \%$ versus $8.1 \%$ in our study). Percentage of EGFR-mutated patients diagnosed with brain metastases at stage IV diagnosis ranges from $10-33 \%$ in other studies ( $\mathrm{N}=49-155)$. In these studies no comparison was made between EGFR-mutated and EGFR-wildtype patients. ${ }^{101,103-105}$ In part two chapter five, the percentage of patients with brain metastases ( $23 \%$ in adenocarcinoma) was not different compared to those EGFR-studies. The varying percentage of (EGFR-mutated) patients diagnosed with brain metastases probably reflects the (lack of) imaging performed at initial diagnosis as screening for brain metastases is not recommended in stage IV NSCLC not eligible for therapy with curative intent. ${ }^{11,106,107}$ Percentage of patients with brain imaging ranged from $60 \%$ in chapter eight (and less than half of these patients had a MRI) to $69 \%$ (Doebele et al. ${ }^{98}$, over $90 \% \mathrm{MRI}$ ) and even $100 \%$ in two other studies (method not specified). ${ }^{103,104}$ Other studies did not mention the percentage of patients with baseline brain imaging. ${ }^{101,105}$ The optimal method to study whether there is a difference in brain metastases at initial stage IV diagnosis in EGFR-mutated patients compared to other molecular drivers and wildtype patients would be a prospective population based study in which imaging modality, presence or absence of molecular drivers and diagnosis of brain metastases is recorded. At the moment we are discussing a retrospective pilot and a prospective registration of these data in order to provide an answer.

It has been described that time to development of brain metastases in EGFR-mutated patients is influenced by the systemic treatment given. In a retrospective study including only EGFR-mutated patients $(\mathrm{N}=155)$ first-line EGFR-TKI reduced the risk for CNS progression with $40 \%$ compared to first line chemotherapy. ${ }^{104}$ This is something we could not demonstrate in chapter eight, probably because of a limited number of patients $(\mathrm{N}=15)$ diagnosed with brain metastases in the follow-up. Often it is stated that EGFR-mutated patients have a higher risk to develop brain metastases compared to EGFR-wildtype patients and that in these patients the brain frequently is the first (and only) site of progression. However this statement is based on studies including only patients with already diagnosed brain metastases in which, in at least a subgroup of 
patients, molecular analysis is performed. ${ }^{96,99,100}$ When EGFR-mutated patients from stage IV diagnosis to development of brain metastases are documented, the brain is the first and only site of progression in less than $10 \% .{ }^{96,104,105}$ In one study $16 \%$ has been described, however in this study all patients were regularly screened for brain metastases. ${ }^{108}$ Furthermore, control of already diagnosed brain metastases is not lower compared to extracranial disease control as was summarized in a recent (2014) review and brain response rate was $74-89 \%$ with first-generation EGFR-TKI. ${ }^{109}$ Because of a longer OS compared to EGFR-wildtype patients, brain metastases eventually will become a problem in EGFR-mutated patients. In long-term survival patients the cumulative incidence of brain metastases is $28 \%-52.9 \%{ }^{103,104,110,111}$ With the development of third-generation EGFR-TKI (rociletinib and AZD9291) OS will be extended in a substantial proportion of patients, especially the T790M resistance mutation patients. ${ }^{112,113}$

Survival is significantly superior when a first-generation EGFR-TKI is given after diagnosis of brain metastases. ${ }^{96,100,114}$ This is not current practice as these are usually given as first line treatment. ${ }^{11,107}$ Survival is dismal when brain metastases develop during EGFR-TKI therapy, as we have shown in chapter eight. This is also described in another study. ${ }^{103}$ Brain metastases have a negative impact on $\mathrm{QoL}^{8}$ and therefore it remains important to develop strategies to prevent the development or progression of brain metastases and to extent survival post brain metastases diagnosis. It is possible that survival would have been longer when EGFR-TKI had been continued after progression in the patients described in chapter eight. This relatively new treatment strategy was neither incorporated in chapter eight nor in the study by Heon et al. ${ }^{103} \mathrm{By}$ continuing the first generation EGFR-TKI after RECIST defined progression (with/without local therapy), PFS2 was 3.7 -7.1 months, with the highest PFS2 found in patients with brain-only progression treated with local therapy. ${ }^{111,115}$ Another interesting concept is EGFR-TKI pulse therapy. It has been demonstrated for pulse therapy erlotinib that therapeutic concentrations can be reached in the central nervous system fluid (CSF). ${ }^{116}$ Currently this concept is used in series to treat brain metastases that developed during standard dose EGFR-TKI. Erlotinib dose is usually $1500 \mathrm{mg}$ once a week. ${ }^{117}$ It is also interesting to evaluate whether EGFR-TKI pulse therapy can prevent the development of brain metastases. This has been tested in a phase I trial presented at the ASCO 2015. By using a mathematical model the best treatment predicted was erlotinib pulse twice weekly (day 1 and 2, MTD $1200 \mathrm{mg}$ ) and $50 \mathrm{mg}$ daily on days 3-7. ORR and PFS were similar to standard dose erlotinib, however none of the 34 patients included (16 treated at the MTD) had CNS progression at the time of extracranial progression (including 35\% with already present CNS disease). ${ }^{118}$ For afatinib, a second generation EGFR-TKI it has been described that although CSF concentration is only $1 \%$ of the systemic concentration, this percentage is around the IC50 for afatinib. ${ }^{94}$ However, this was measured in a patient already diagnosed with brain metastases (i.e. BBB more permeable). CNS responses for afatinib have been described after 
progression on a first-generation EGFR-TKI. Of the 31 patients with evaluable CNS lesions, $42 \%$ had a partial response, 39\% had stable disease and the others had progressive disease. Disease control rate was four months (range 1-13 months). ${ }^{94}$ It might be that afatinib would be a better option for pulse therapy to control or prevent CNS lesions but this has never been studied. New EGFR-TKI specifically developed to penetrate the BBB and the third generation EGF-TKI are more promising. AZD3759 is an EGR-TKI specifically developed to penetrate the BBB and is not a substrate for PgP or BCRP efflux pumps. In vitro a very good BBB penetration was found and in the subsequent phase I trial it was effective in treating CNS as well as extracranial disease. ${ }^{119}$ For the third generation EGFR-TKI not many data exist regarding effect on brain metastases. In a case report, a brain response was noted for a patient treated with rociletinib. ${ }^{120}$ In the subgroup of patients with central nervous system involvement $(\mathrm{N}=170)$ in the phase I/II TIGER-X study (NCT01526928) the RECIST 1.1 overall response rate was $41 \%$ (brain response not specifically mentioned). ${ }^{121}$ AZD9291 showed significant exposure in the brain (approximately ten times higher than gefinitib) in preclinical studies and simulations predicted that a dose of $80 \mathrm{mg}$ (the currently recommended dose) would be sufficient to elicit a brain response. In the subsequent phase I study, brain responses have been observed. ${ }^{122}$ In the AURA phase II extension cohort and the AURA2 phase II study (NCT01802632 and NCT02094261) patients with asymptomatic and stable brain metastases were eligible and $39 \%$ of included patients $(\mathrm{N}=162)$ had brain metastases. Overall response rate was $56 \%$ compared to $64 \%$ for patients without brain metastases. Shrinkage of brain metastases has been observed, and CSF concentration in one patients was comparable to the predicted plasma free circulating AZD9291 concentration. ${ }^{123}$ It is not clear whether these third generation EGFR-TKI are superior in preventing brain metastases development or treating brain metastases compared to first line EGFR-TKI. Both drugs are currently tested in the first line and hopefully this will provide an answer (AZD9291: NCT02296125, rociletinib NCT02186301 (TIGER-1)). The combination of erlotinib plus bevacizumab to prevent brain metastases development is worthwhile to investigate. In a randomized phase II study ( $\mathrm{N}=154)$ EGFR-mutated patients were treated with erlotinib monotherapy or erlotinib plus bevacizumab. Patients with brain metastases at baseline were excluded. Median PFS [95\% confidence interval] significantly improved with the combination therapy: 16.0 [13.9-18.1] months versus 9.7 [5.7-11.1] months for the erlotinib monotherapy arm (hazard ratio 0.54 [0.36-0.79], $p=0.0015) .{ }^{124}$ Differences in incidence of brain metastases during treatment were not described but would be interesting to evaluate.

\section{Leptomeningeal metastases in EGFR-mutated patients}

For EGFR-mutated patients diagnosed with leptomeningeal metastasis it has also been suggested that incidence is higher and that survival is longer compared to wildtype patients. However in the retrospective study described in chapter ten we described the 
percentage of patients diagnosed with leptomeningeal metastases in a cohort of EGFRmutated patients and percentage (9\%) was not substantially higher compared to a historical cohort (7.7\%). ${ }^{96}$ For most of the patients survival was dismal after diagnosis of leptomeningeal metastasis (median OS of 3.1 month). Only a WHO PS of 0-1 was associated with a longer survival and no treatment related factors could be identified. This dismal survival reflects the fact that in chapter ten $84.4 \%$ of patients already had received treatment with an EGFR-TKI before development of leptomeningeal metastases. For these patients, the same treatment options remain as discussed above in the brain metastases section (although in most clinical trials patients with leptomeningeal metastases are excluded). Although pulse therapy EGFR-TKI did not result in a substantial survival (median OS 2.4 months for the 12 patients treated with pulse therapy) in chapter ten, half of these patients seemed to benefit as OS was clearly prolonged. The use of third generation EGFR-TKI in this patient population would be interesting; the effect of AZD9291 on leptomeningeal metastases is currently tested, including CSF penetration rate and CSF response rate (NCT02228369).

\section{TKI concurrent with cranial irradiation}

When brain metastases develop during EGFR-TKI treatment there is often no effective systemic treatment available or the effect of a new systemic treatment cannot be awaited as the brain metastases are symptomatic. Furthermore, in oligoprogressive patients continuing the EGFR-TKI beyond progression combined with a local ablative therapy has been found to be effective especially when the progression occurs in the brain. Time to second progression was 7.1 months in a small series. ${ }^{111}$ Although cranial radiotherapy (WBRT as well as stereotactic radiotherapy/radiosurgery (SRT/SRS) is an accepted treatment for brain metastases, ${ }^{106,107,125}$ controversies exist regarding the safety of cranial radiotherapy concurrent with EGFR-TKI. Continuing the EGFR-TKI during cranial radiotherapy would decrease the risk of an extracranial flare-up. In a series of 61 patients treated with a TKI, 23\% of patients experienced a flare-up after TKI discontinuation with a median time to disease flare-up of only eight days (range 3-21). Patients with CNS disease were among those with the highest risk of a flare-up. ${ }^{126}$ In the systematic review chapter nine we evaluated the available literature. There are arguments that EGFR-TKI (erlotinib, gefitinib and icotinib, no data found for other EGFRTKI) can be safely combined with WBRT although no high-level evidence exists. Besides the prevention of a flare-up, another possible advantage would be a synergistic effect of the WBRT and the EGFR-TKI on brain metastases response. Preclinical data indicate that TKIs enhance radiation effects. ${ }^{88-91}$ EGFR-mutated cells also respond better to radiation therapy compared to EGFR-wildtype cells. ${ }^{127}$ There are no trials evaluating whether an EGFR-mutated patient diagnosed with brain metastases during EGFR-TKI treatment has a superior outcome (i.e. higher cranial response rate, no increased neurotoxicity, lower percentage of extracranial flare-up) when treated with concurrent EGFR-TKI and WBRT compared to temporarily discontinuing this EGFR-TKI. A study to 
evaluate this question would have to randomize these patients to one of the treatment arms and document cranial response rate, neurotoxicity and percentage of flare-up in the follow-up. Another option would be to treat at least some of these patients with SRS/SRT without WBRT as this is a short-course treatment which obviates the need for a long EGFR-TKI discontinuation. SRS results alone did not differ between (molecularly unselected) patients with two to four brain metastases compared to five to ten

metastases. ${ }^{128}$ The advantages for SRS/SRT without WBRT are that both cognition and quality of life are superior with SRS/SRT alone. ${ }^{129}$ In a recent (2015) prospective series it was found that SRS concurrent with a TKI was safe. Among the 112 NSCLC patients treated with SRS, 19 were treated concurrently with a TKI, and adverse radiation effects were not significantly different (all grades $7 \%$ versus $5 \%$ ). ${ }^{130}$ In contrast, in chapter nine we described a higher incidence of neurotoxicity when erlotinib was combined with WBRT and SRT. This discrepancy between toxicities is possibly caused by the combination of WBRT and SRT in the study described in chapter nine.

\section{GENERAL CONCLUSION}

Brain metastases are a frequent problem in NSCLC. However, there is still a gap in knowledge on treatment as patients diagnosed with brain metastases are often excluded from clinical trials because of symptoms or a poor performance status. Several clinical trials were prematurely closed due to slow accrual. Brain metastases research remains a niche and often has no priority in lung cancer research. Strategies are needed that can predict and reduce the risk of brain metastases development. There should be more awareness among clinicians as well as patients that survival after brain metastases diagnosis is often dismal and that only best supportive care is a valid option in poor prognosis patients without a targetable molecular alteration like EGFR or $A L K$. A multidisciplinary team could provide a role in providing support in these brain metastases management decisions.

Incidence and prevalence of CNS involvement increases in EGFR-mutated patients. EGFR-mutation status per se does not seem to be a risk factor for brain metastases as these are diagnosed especially in patients with prolonged survival. Unfortunately, when brain metastases develop during EGFR-TKI treatment survival in EGFR-mutated patients is as poor as in wildtype patients. However, new treatment options (EGFR-TKI treatment beyond progression with (concurrent) local therapy, pulse therapy EGFR-TKI, third generation EGFR-TKI) are promising for EGFR-mutated patients with brain as well as leptomeningeal metastases.

Stage IV NSCLC patients with single organ metastases have a superior OS compared to patients with multiple organs with metastases and local disease status has prognostic impact in the single organ metastases group. The specific organ with metastases (except the current M1a category) has no prognostic impact. Number of organs with metastases could be a stratification factor in clinical trials, when validated. 
The results described in this thesis indicate that there are opportunities for additional research that hopefully will improve outcome in this patient population. 


\section{REFERENCES}

1. Yawn BP, Wollan PC, Schroeder C, Gazzuola L, Mehta M. Temporal and gender-related trends in brain metastases from lung and breast cancer. Minn Med. 2003;86:32-7.

2. Gaspar LE, Chansky K, Albain KS, Vallieres E, Rusch V, Crowley JJ, et al. Time from treatment to subsequent diagnosis of brain metastases in stage III non-small-cell lung cancer: a retrospective review by the Southwest Oncology Group. J Clin Oncol. 2005;23:2955-61.

3. Andre F, Grunenwald D, Pujol JL, Girard P, Dujon A, Brouchet L, et al. Patterns of relapse of N2 nonsmall-cell lung carcinoma patients treated with preoperative chemotherapy: should prophylactic cranial irradiation be reconsidered? Cancer. 2001;91:2394-400.

4. Carolan H, Sun AY, Bezjak A, Yi QL, Payne D, Kane G, et al. Does the incidence and outcome of brain metastases in locally advanced non-small cell lung cancer justify prophylactic cranial irradiation or early detection? Lung Cancer. 2005;49:109-15.

5. Ceresoli GL, Reni M, Chiesa G, Carretta A, Schipani S, Passoni P, et al. Brain metastases in locally advanced nonsmall cell lung carcinoma after multimodality treatment: risk factors analysis. Cancer. 2002;95:605-12.

6. Kepka L, Cieslak E, Bujko K, Fijuth J, Wierzchowski M. Results of the whole-brain radiotherapy for patients with brain metastases from lung cancer: the RTOG RPA intra-classes analysis. Acta Oncol. 2005;44:389-98.

7. Gaspar L, Scott C, Rotman M, Asbell S, Phillips T, Wasserman T, et al. Recursive partitioning analysis (RPA) of prognostic factors in three Radiation Therapy Oncology Group (RTOG) brain metastases trials. Int J Radiat Oncol Biol Phys. 1997;37:745-51.

8. Steinmann D, Schafer C, van Oorschot B, Wypior HJ, Bruns F, Bolling T, et al. Effects of radiotherapy for brain metastases on quality of life (QoL). Prospective pilot study of the DEGRO QoL working party. Strahlenther Onkol. 2009;185:190-7.

9. Eberhardt WE, De Ruysscher D, Weder W, Le Pechoux C, De Leyn P, Hoffmann H, et al. 2nd ESMO Consensus Conference in Lung Cancer: locally advanced stage III non-small-cell lung cancer. Ann Oncol. 2015;26:1573-88.

10. Fruh M, De Ruysscher D, Popat S, Crino L, Peters S, Felip E, et al. Small-cell lung cancer (SCLC): ESMO Clinical Practice Guidelines for diagnosis, treatment and follow-up. Ann Oncol. 2013;24 Suppl 6: vi99-105.

11. NCCN Guidelines version 1.2015 Non-Small Cell Lung Cancer. 2014.

12. VIKC. Dutch guideline on non-small cell lung cancer. 2011.

13. Hudson BJ, Crawford MB, Curtin JJ. Brain imaging in lung cancer patients without symptoms of brain metastases: a national survey of current practice in England. Clin Radiol. 2015;70:610-3.

14. Chen AM, Jahan TM, Jablons DM, Garcia J, Larson DA. Risk of cerebral metastases and neurological death after pathological complete response to neoadjuvant therapy for locally advanced nonsmall-cell lung cancer: clinical implications for the subsequent management of the brain. Cancer. 2007;109: 1668-75.

15. Mamon HJ, Yeap BY, Janne PA, Reblando J, Shrager S, Jaklitsch MT, et al. High risk of brain metastases in surgically staged IIIA non-small-cell lung cancer patients treated with surgery, chemotherapy, and radiation. J Clin Oncol. 2005;23:1530-7.

16. Ding X, Dai H, Hui Z, Ji W, Liang J, Lv J, et al. Risk factors of brain metastases in completely resected pathological stage IIIA-N2 non-small cell lung cancer. Radiat Oncol. 2012;7:119.

17. Finelli DA, Hurst GC, Gullapali RP, Bellon EM. Improved contrast of enhancing brain lesions on postgadolinium, T1-weighted spin-echo images with use of magnetization transfer. Radiology. 1994;190:553-9.

18. Terae S, Yoshida D, Kudo K, Tha KK, Fujino M, Miyasaka K. Contrast-enhanced FLAIR imaging in combination with pre- and postcontrast magnetization transfer T1-weighted imaging: usefulness in the evaluation of brain metastases. Journal of magnetic resonance imaging : JMRI. 2007;25:479-87.

19. Sze G, Johnson C, Kawamura Y, Goldberg SN, Lange R, Friedland RJ, et al. Comparison of single- and triple-dose contrast material in the MR screening of brain metastases. Am J Neuroradiol. 1998;19: 821-8. 
20. Yuh WT, Tali ET, Nguyen HD, Simonson TM, Mayr NA, Fisher DJ. The effect of contrast dose, imaging time, and lesion size in the MR detection of intracerebral metastasis. Am J Neuroradiol. 1995;16: 373-80.

21. Serres S, Soto MS, Hamilton A, McAteer MA, Carbonell WS, Robson MD, et al. Molecular MRI enables early and sensitive detection of brain metastases. Proc Natl Acad Sci U S A. 2012;109:6674-9.

22. Nomoto Y, Miyamoto T, Yamaguchi Y. Brain metastasis of small cell lung carcinoma: comparison of GdDTPA enhanced magnetic resonance imaging and enhanced computerized tomography. Jpn J Clin Oncol. 1994;24:258-62.

23. Connell JJ, Chatain G, Cornelissen B, Vallis KA, Hamilton A, Seymour L, et al. Selective permeabilization of the blood-brain barrier at sites of metastasis. J Natl Cancer Inst. 2013;105:1634-43.

24. Kienast $Y$, von Baumgarten L, Fuhrmann M, Klinkert WE, Goldbrunner R, Herms J, et al. Real-time imaging reveals the single steps of brain metastasis formation. Nat Med. 2010;16:116-22.

25. Cox JD, Scott CB, Byhardt RW, Emami B, Russell AH, Fu KK, et al. Addition of chemotherapy to radiation therapy alters failure patterns by cell type within non-small cell carcinoma of lung (NSCCL): analysis of radiation therapy oncology group (RTOG) trials. Int J Radiat Oncol Biol Phys. 1999;43:505-9.

26. Bart J, Groen HJ, Hendrikse NH, van der Graaf WT, Vaalburg W, de Vries EG. The blood-brain barrier and oncology: new insights into function and modulation. Cancer Treat Rev. 2000;26:449-62.

27. Li L, Agarwal S, Elmquist WF. Brain efflux index to investigate the influence of active efflux on brain distribution of pemetrexed and methotrexate. Drug Metab Dispos. 2013;41:659-67.

28. Steeg PS, Camphausen KA, Smith QR. Brain metastases as preventive and therapeutic targets. Nat Rev Cancer. 2011;11:352-63.

29. Kurzrock R, Gabrail N, Chandhasin C, Moulder S, Smith C, Brenner A, et al. Safety, pharmacokinetics, and activity of GRN1005, a novel conjugate of angiopep-2, a peptide facilitating brain penetration, and paclitaxel, in patients with advanced solid tumors. Mol Cancer Ther. 2012;11:308-16.

30. Parrish KE, Sarkaria JN, Elmquist WF. Improving drug delivery to primary and metastatic brain tumors: strategies to overcome the blood-brain barrier. Clin Pharmacol Ther. 2015;97:336-46.

31. Ilhan-Mutlu A, Osswald M, Liao Y, Goemmel M, Reck M, Miles D, et al. Bevacizumab prevents brain metastases formation in lung adenocarcinoma. Mol Cancer Ther. 2016.

32. Besse B, Le Moulec S, Mazieres J, Senellart H, Barlesi F, Chouaid C, et al. Bevacizumab in patients with nonsquamous non-small cell lung cancer and asymptomatic, untreated brain metastases (BRAIN): A nonrandomized, phase II study. Clin Cancer Res. 2015;21:1896-903.

33. Reck M, von Pawel J, Zatloukal P, Ramlau R, Gorbounova V, Hirsh V, et al. Phase III trial of cisplatin plus gemcitabine with either placebo or bevacizumab as first-line therapy for nonsquamous non-small-cell lung cancer: AVAil. J Clin Oncol. 2009;27:1227-34.

34. Lind JS, Senan S, Smit EF. Pulmonary toxicity after bevacizumab and concurrent thoracic radiotherapy observed in a phase I study for inoperable stage III non-small-cell lung cancer. J Clin Oncol. 2012;30: e104-8.

35. Gore E, Currey A, Choong N. Tracheoesophageal fistula associated with bevacizumab 21 months after completion of radiation therapy. J Thorac Oncol. 2009;4:1590-1.

36. Spigel DR, Hainsworth JD, Yardley DA, Raefsky E, Patton J, Peacock N, et al. Tracheoesophageal fistula formation in patients with lung cancer treated with chemoradiation and bevacizumab. J Clin Oncol. 2010;28:43-8.

37. Kareva I, Waxman DJ, Lakka Klement G. Metronomic chemotherapy: an attractive alternative to maximum tolerated dose therapy that can activate anti-tumor immunity and minimize therapeutic resistance. Cancer Letters. 2015;358:100-6.

38. Kerbel RS. A Decade of experience in developing preclinical models of advanced- or early-stage spontaneous metastasis to study antiangiogenic drugs, metronomic chemotherapy, and the tumor microenvironment. Cancer J. 2015;21:274-83.

39. Gnoni A, Silvestris N, Licchetta A, Santini D, Scartozzi M, Ria R, et al. Metronomic chemotherapy from rationale to clinical studies: a dream or reality? Crit Rev Oncol Hematol. 2015;95:46-61.

40. Stoelting S, Trefzer T, Kisro J, Steinke A, Wagner T, Peters SO. Low-dose oral metronomic chemotherapy prevents mobilization of endothelial progenitor cells into the blood of cancer patients. In Vivo. 2008;22:831-6. 
41. Bertolini F, Paul S, Mancuso P, Monestiroli S, Gobbi A, Shaked Y, et al. Maximum tolerable dose and low-dose metronomic chemotherapy have opposite effects on the mobilization and viability of circulating endothelial progenitor cells. Cancer Res. 2003;63:4342-6.

42. Shaked Y, Henke E, Roodhart JM, Mancuso P, Langenberg MH, Colleoni M, et al. Rapid chemotherapyinduced acute endothelial progenitor cell mobilization: implications for antiangiogenic drugs as chemosensitizing agents. Cancer Cell. 2008;14:263-73.

43. Ali AS, Ahmad A, Ali S, Bao B, Philip PA, Sarkar FH. The role of cancer stem cells and miRNAs in defining the complexities of brain metastasis. J Cell Physiol. 2013;228:36-42.

44. Sampieri K, Fodde R. Cancer stem cells and metastasis. Semin Cancer Biol. 2012;22:187-93.

45. Tas F, Duranyildiz D, Soydinc HO, Cicin I, Selam M, Uygun K, et al. Effect of maximum-tolerated doses and low-dose metronomic chemotherapy on serum vascular endothelial growth factor and thrombospondin-1 levels in patients with advanced nonsmall cell lung cancer. Cancer Chemother Pharmacol. 2008;61:721-5.

46. Levitt JM, Jian W, Lerner SP, Sonpavde G. A conventional preclinical schedule of cisplatin is more effective than a metronomic frequent bolus schedule for urothelial carcinoma. Urol Oncol. 2013;31:234-40.

47. Shen FZ, Wang J, Liang J, Mu K, Hou JY, Wang YT. Low-dose metronomic chemotherapy with cisplatin: can it suppress angiogenesis in H22 hepatocarcinoma cells? Int J Exp Pathol. 2010;91:10-6.

48. Tanaka H, Matsushima H, Mizumoto N, Takashima A. Classification of chemotherapeutic agents based on their differential in vitro effects on dendritic cells. Cancer Res. 2009;69:6978-86.

49. Auperin A, Arriagada R, Pignon JP, Le Pechoux C, Gregor A, Stephens RJ, et al. Prophylactic cranial irradiation for patients with small-cell lung cancer in complete remission. Prophylactic Cranial Irradiation Overview Collaborative Group. N Engl J Med. 1999;341:476-84.

50. Slotman B, Faivre-Finn C, Kramer G, Rankin E, Snee M, Hatton M, et al. Prophylactic cranial irradiation in extensive small-cell lung cancer. N Engl J Med. 2007;357:664-72.

51. Gore EM, Bae K, Wong SJ, Sun A, Bonner JA, Schild SE, et al. Phase III comparison of prophylactic cranial irradiation versus observation in patients with locally advanced non-small-cell lung cancer: primary analysis of radiation therapy oncology group study RTOG 0214. J Clin Oncol. 2011;29:272-8.

52. Sun A, Bae K, Gore EM, Movsas B, Wong SJ, Meyers CA, et al. Phase III trial of prophylactic cranial irradiation compared with observation in patients with locally advanced non-small-cell lung cancer: neurocognitive and quality-of-life analysis. J Clin Oncol. 2011;29:279-86.

53. Auperin A, Le Pechoux C, Rolland E, Curran WJ, Furuse K, Fournel P, et al. Meta-analysis of concomitant versus sequential radiochemotherapy in locally advanced non-small-cell lung cancer. J Clin Oncol. 2010;28:2181-90.

54. Cedres S, Nunez I, Longo M, Martinez P, Checa E, Torrejon D, et al. Serum tumor markers CEA, CYFRA21-1, and CA-125 are associated with worse prognosis in advanced non-small-cell lung cancer (NSCLC). Clinical Lung Cancer. 2011;12:172-9.

55. Arrieta O, Saavedra-Perez D, Kuri R, Aviles-Salas A, Martinez L, Mendoza-Posada D, et al. Brain metastasis development and poor survival associated with carcinoembryonic antigen (CEA) level in advanced non-small cell lung cancer: a prospective analysis. BMC Cancer. 2009;9:119.

56. Lee DS, Kim YS, Jung SL, Lee KY, Kang JH, Park S, et al. The relevance of serum carcinoembryonic antigen as an indicator of brain metastasis detection in advanced non-small cell lung cancer. Tumour Biol. 2012;33:1065-73.

57. Li Q, Yang J, Yu Q, Wu H, Liu B, Xiong H, et al. Associations between single-nucleotide polymorphisms in the PI3K-PTEN-AKT-mTOR pathway and increased risk of brain metastasis in patients with non-small cell lung cancer. Clin Cancer Res. 2013;19:6252-60.

58. Grinberg-Rashi H, Ofek E, Perelman M, Skarda J, Yaron P, Hajduch M, et al. The expression of three genes in primary non-small cell lung cancer is associated with metastatic spread to the brain. Clin Cancer Res. 2009;15:1755-61.

59. Arora S, Ranade AR, Tran NL, Nasser S, Sridhar S, Korn RL, et al. MicroRNA-328 is associated with (nonsmall) cell lung cancer (NSCLC) brain metastasis and mediates NSCLC migration. Int J Cancer. 2011;129:2621-31. 
60. Chen LT, Xu SD, Xu H, Zhang JF, Ning JF, Wang SF. MicroRNA-378 is associated with non-small cell lung cancer brain metastasis by promoting cell migration, invasion and tumor angiogenesis. Med Oncol. 2012;29:1673-80.

61. Lu Y, Govindan R, Wang L, Liu PY, Goodgame B, Wen W, et al. MicroRNA profiling and prediction of recurrence/relapse-free survival in stage I lung cancer. Carcinogenesis. 2012;33:1046-54.

62. Albain KS, Crowley JJ, LeBlanc M, Livingston RB. Survival determinants in extensive-stage non-small-cell lung cancer: the Southwest Oncology Group experience. J Clin Oncol. 1991;9:1618-26.

63. Jeremic B, Milicic B, Dagovic A, Aleksandrovic J, Nikolic N. Pretreatment clinical prognostic factors in patients with stage IV non-small cell lung cancer (NSCLC) treated with chemotherapy. J Cancer Res Clin Oncol. 2003;129:114-22.

64. Oh Y, Taylor S, Bekele BN, Debnam JM, Allen PK, Suki D, et al. Number of metastatic sites is a strong predictor of survival in patients with nonsmall cell lung cancer with or without brain metastases. Cancer. 2009;115:2930-8.

65. Paralkar VR, Li T, Langer CJ. Population characteristics and prognostic factors in metastatic non-smallcell lung cancer: a Fox Chase Cancer Center retrospective. Clin Lung Cancer. 2008;9:116-21.

66. Parikh RB, Cronin AM, Kozono DE, Oxnard GR, Mak RH, Jackman DM, et al. Definitive primary therapy in patients presenting with oligometastatic non-small cell lung cancer. Int J Radiat Oncol Biol Phys. 2014;89:880-7.

67. Sanchez de Cos Escuin J, Abal Arca J, Melchor Iniguez R, Miravet Sorribes L, Nunez Ares A, Hernandez Hernandez JR, et al. Tumor, node and metastasis classification of lung cancer--M1a versus M1b-analysis of $\mathrm{M}$ descriptors and other prognostic factors. Lung Cancer. 2014;84:182-9.

68. Hoang T, Dahlberg SE, Sandler AB, Brahmer JR, Schiller JH, Johnson DH. Prognostic models to predict survival in non-small-cell lung cancer patients treated with first-line paclitaxel and carboplatin with or without bevacizumab. J Thorac Oncol. 2012;7:1361-8.

69. William WN, Jr., Lin HY, Lee JJ, Lippman SM, Roth JA, Kim ES. Revisiting stage IIIB and IV non-small cell lung cancer: analysis of the surveillance, epidemiology, and end results data. Chest. 2009;136:701-9.

70. Eberhardt W, Mitchell A, Crowley J, Kondo H, Kim Y, Turrisi A, et al. The IASLC lung cancer staging project: Proposals for the revision of the $M$ descriptors in the forthcoming eighth edition of the TNM classification of lung cancer. J Thorac Oncol. 2015;10:1515-22.

71. Im HJ, Pak K, Cheon GJ, Kang KW, Kim SJ, Kim IJ, et al. Prognostic value of volumetric parameters of (18)F-FDG PET in non-small-cell lung cancer: a meta-analysis. Eur J Nucl Med Mol Imaging. 2015;42: 241-51.

72. Zhang H, Wroblewski K, Jiang Y, Penney BC, Appelbaum D, Simon CA, et al. A new PET/CT volumetric prognostic index for non-small cell lung cancer. Lung Cancer. 2015;89:43-9.

73. Hendriks LE, Derks JL, Postmus PE, Damhuis RA, Houben RM, Troost EG, et al. Single organ metastatic disease and local disease status, prognostic factors for overall survival in stage IV non-small cell lung cancer: Results from a population-based study. Eur J Cancer. 2015;51:2534-44.

74. Ashworth $A B$, Senan S, Palma DA, Riquet $M$, Ahn YC, Ricardi U, et al. An individual patient data metaanalysis of outcomes and prognostic factors after treatment of oligometastatic non-small-cell lung cancer. Clin Lung Cancer. 2014;15:346-55.

75. Palma DA, Salama JK, Lo SS, Senan S, Treasure T, Govindan R, et al. The oligometastatic state-separating truth from wishful thinking. Nat Rev Clin Oncol. 2014;11:549-57..

76. Bazhenova L, Newton P, Mason J, Bethel K, Nieva J, Kuhn P. Adrenal metastases in lung cancer: clinical implications of a mathematical model. J Thorac Oncology. 2014;9:442-6.

77. Barnes EA, Chow E, Tsao MN, Bradley NM, Doyle M, Li K, et al. Physician expectations of treatment outcomes for patients with brain metastases referred for whole brain radiotherapy. Int J Radiat Oncol Biol Phys. 2010;76:187-92.

78. Extermann M, Albrand G, Chen H, Zanetta S, Schonwetter R, Zulian GB, et al. Are older French patients as willing as older American patients to undertake chemotherapy? J Clin Oncol. 2003;21:3214-9.

79. Chen AB, Cronin A, Weeks JC, Chrischilles EA, Malin J, Hayman JA, et al. Expectations about the effectiveness of radiation therapy among patients with incurable lung cancer. J Clin Oncol. 2013;31:2730-5.

80. Weeks JC, Catalano PJ, Cronin A, Finkelman MD, Mack JW, Keating NL, et al. Patients' expectations about effects of chemotherapy for advanced cancer. N Engl J Med. 2012;367:1616-25. 
81. Daugherty CK, Hlubocky FJ. What are terminally ill cancer patients told about their expected deaths? A study of cancer physicians' self-reports of prognosis disclosure. J Clin Oncol. 2008;26:5988-93.

82. Enzinger AC, Zhang B, Schrag D, Prigerson HG. Outcomes of prognostic disclosure: Associations with prognostic understanding, distress, and relationship with physician among patients with advanced cancer. J Clin Oncol. 2015;33:3809-16.

83. The AM, Hak T, Koeter G, van Der Wal G. Collusion in doctor-patient communication about imminent death: an ethnographic study. BMJ. 2000;321:1376-81.

84. Sze J, Marisette S, Williams D, Nyhof-Young J, Crooks D, Husain A, et al. Decision making in palliative radiation therapy: reframing hope in caregivers and patients with brain metastases. Support Care Cancer. 2006;14:1055-63.

85. Nieder C, Norum J, Dalhaug A, Aandahl G, Pawinski A. Radiotherapy versus best supportive care in patients with brain metastases and adverse prognostic factors. Clin Exp Metastasis. 2013;30:723-9.

86. Komosinska K, Kepka L, Niwinska A, Pietrzak L, Wierzchowski M, Tyc-Szczepaniak D, et al. Prospective evaluation of the palliative effect of whole-brain radiotherapy in patients with brain metastases and poor performance status. Acta Oncol. 2010;49:382-8.

87. Mulvenna P, Nankivel M, Barton R, Faivre-Finn C, Wilson P, Moore B, et al. Whole brain radiotherapy for brain metastases from non-small lung cancer: Quality of life (QoL) and overall survival (OS) results from the UK Medical Research Council QUARTZ randomised clinical trial (ISRCTN 3826061). J Clin Oncol. 2015;33( (suppl; abstr 8005)).

88. Zhuang HQ, Sun J, Yuan ZY, Wang J, Zhao LJ, Wang P, et al. Radiosensitizing effects of gefitinib at different administration times in vitro. Cancer Sci. 2009;100:1520-5.

89. Bokobza SM, Jiang Y, Weber AM, Devery AM, Ryan AJ. Short-course treatment with gefitinib enhances curative potential of radiation therapy in a mouse model of human non-small cell lung cancer. Int J Radiat Oncol Biol Phys. 2014;88:947-54.

90. Dai Y, Wei Q, Schwager C, Moustafa M, Zhou C, Lipson KE, et al. Synergistic effects of crizotinib and radiotherapy in experimental EML4-ALK fusion positive lung cancer. Radiother Oncol. 2015;114:173-81.

91. Chinnaiyan P, Huang S, Vallabhaneni G, Armstrong E, Varambally S, Tomlins SA, et al. Mechanisms of enhanced radiation response following epidermal growth factor receptor signaling inhibition by erlotinib (Tarceva). Cancer Res. 2005;65:3328-35.

92. Lee CK, Wu YL, Ding PN, Lord SJ, Inoue A, Zhou C, et al. Impact of specific epidermal growth factor receptor (EGFR) mutations and clinical characteristics on outcomes after treatment with EGFR tyrosine kinase inhibitors versus chemotherapy in EGFR-mutant lung cancer: A meta-analysis. J Clin Oncol. 2015;33:1958-65.

93. Biya J, Caramella C, Lindsay CR, Planchard D, Besse B. A Long-Term Spinal Intramedullary Response to Ceritinib in ALK Rearranged Non-Small-Cell Lung Cancer. J Thorac Oncol. 2015;10(6):e44-5.

94. Hoffknecht P, Tufman A, Wehler T, Pelzer T, Wiewrodt R, Schutz M, et al. Efficacy of the irreversible ErbB family blocker afatinib in epidermal growth factor receptor (EGFR) tyrosine kinase inhibitor (TKI)pretreated non-small-cell lung cancer patients with brain metastases or leptomeningeal disease. J Thorac Oncol. 2015;10:156-63.

95. Gainor JF, Sherman CA, Willoughby K, Logan J, Kennedy E, Brastianos PK, et al. Alectinib salvages CNS relapses in ALK-positive lung cancer patients previously treated with crizotinib and ceritinib. J Thorac Oncol. 2015;10:232-6.

96. Eichler AF, Kahle KT, Wang DL, Joshi VA, Willers H, Engelman JA, et al. EGFR mutation status and survival after diagnosis of brain metastasis in nonsmall cell lung cancer. Neuro Oncol. 2010;12:1193-9.

97. Mok TS, Wu YL, Thongprasert S, Yang CH, Chu DT, Saijo N, et al. Gefitinib or carboplatin-paclitaxel in pulmonary adenocarcinoma. N Engl J Med. 2009;361:947-57.

98. Doebele RC, Lu X, Sumey C, Maxson DA, Weickhardt AJ, Oton AB, et al. Oncogene status predicts patterns of metastatic spread in treatment-naive nonsmall cell lung cancer. Cancer. 2012;118:4502-11.

99. Matsumoto S, Takahashi K, Iwakawa R, Matsuno Y, Nakanishi Y, Kohno T, et al. Frequent EGFR mutations in brain metastases of lung adenocarcinoma. Int J Cancer. 2006;119:1491-4.

100. Welsh JW, Komaki R, Amini A, Munsell MF, Unger W, Allen PK, et al. Phase II trial of erlotinib plus concurrent whole-brain radiation therapy for patients with brain metastases from non-small-cell lung cancer. J Clin Oncol. 2013;31:895-902. 
101. Lee YJ, Choi HJ, Kim SK, Chang J, Moon JW, Park IK, et al. Frequent central nervous system failure after clinical benefit with epidermal growth factor receptor tyrosine kinase inhibitors in Korean patients with nonsmall-cell lung cancer. Cancer. 2010;116:1336-43.

102. Omuro AM, Kris MG, Miller VA, Franceschi E, Shah N, Milton DT, et al. High incidence of disease recurrence in the brain and leptomeninges in patients with nonsmall cell lung carcinoma after response to gefitinib. Cancer. 2005;103:2344-8.

103. Heon S, Yeap BY, Britt GJ, Costa DB, Rabin MS, Jackman DM, et al. Development of central nervous system metastases in patients with advanced non-small cell lung cancer and somatic EGFR mutations treated with gefitinib or erlotinib. Clin Cancer Res. 2010;16:5873-82.

104. Heon S, Yeap BY, Lindeman NI, Joshi VA, Butaney M, Britt GJ, et al. The impact of initial gefitinib or erlotinib versus chemotherapy on central nervous system progression in advanced non-small cell lung cancer with EGFR mutations. Clin Cancer Res. 2012;18:4406-14.

105. Al-Halabi H, Sayegh K, Digamurthy SR, Niemierko A, Piotrowska Z, Willers H, et al. Pattern of failure analysis in metastatic EGFR-mutant lung cancer treated with tyrosine kinase inhibitors to identify candidates for consolidation stereotactic body radiation therapy. J Thorac Oncol. 2015;10:1601-7.

106. NICE clinical guideline 121: The diagnosis and treatment of lung cancer. 2011:103-4.

107. Reck M, Popat S, Reinmuth N, De Ruysscher D, Kerr KM, Peters S, et al. Metastatic non-small-cell lung cancer (NSCLC): ESMO Clinical Practice Guidelines for diagnosis, treatment and follow-up. Ann Oncol. 2014;25 Suppl 3:iii27-39.

108. Yoshida T, Yoh K, Niho S, Umemura S, Matsumoto S, Ohmatsu H, et al. RECIST progression patterns during EGFR tyrosine kinase inhibitor treatment of advanced non-small cell lung cancer patients harboring an EGFR mutation. Lung Cancer. 2015;90:477-83.

109. Zimmermann S, Dziadziuszko R, Peters S. Indications and limitations of chemotherapy and targeted agents in non-small cell lung cancer brain metastases. Cancer Treat Rev. 2014;40:716-22.

110. Patel S, Rimner A, Foster A, Zhang Z, Woo KM, Yu HA, et al. Risk of brain metastasis in EGFR-mutant NSCLC treated with erlotinib: A role for prophylactic cranial irradiation? Int J Radiat Oncol Biol Phys. 2014;90:S643-S4.

111. Weickhardt AJ, Scheier B, Burke JM, Gan G, Lu X, Bunn PA, Jr., et al. Local ablative therapy of oligoprogressive disease prolongs disease control by tyrosine kinase inhibitors in oncogene-addicted non-small-cell lung cancer. J Thorac Oncol. 2012;7:1807-14.

112. Sequist LV, Soria JC, Goldman JW, Wakelee HA, Gadgeel SM, Varga A, et al. Rociletinib in EGFR-mutated non-small-cell lung cancer. N Engl J Med. 2015;372:1700-9.

113. Janne PA, Yang JC, Kim DW, Planchard D, Ohe Y, Ramalingam SS, et al. AZD9291 in EGFR inhibitorresistant non-small-cell lung cancer. N Engl J Med. 2015;372:1689-99.

114. Mak KS, Gainor JF, Niemierko A, Oh KS, Willers H, Choi NC, et al. Significance of targeted therapy and genetic alterations in EGFR, ALK, or KRAS on survival in patients with non-small cell lung cancer treated with radiotherapy for brain metastases. Neuro Oncol. 2015;17:296-302.

115. Park K, Ahn MJ, Yu C, Kim S, Lin M, Sriuranpong V, et al. ASPIRATION: first-line erlotinib (E) until and beyond RECIST progression (PD) in Asian patients (pts) with EGFR mutation-positive (mut+) NSCLC. Ann Oncol. 2014;25:(suppl_4): iv426-iv70.

116. Clarke JL, Pao W, Wu N, Miller VA, Lassman AB. High dose weekly erlotinib achieves therapeutic concentrations in CSF and is effective in leptomeningeal metastases from epidermal growth factor receptor mutant lung cancer. J Neurooncol. 2010;99:283-6.

117. Grommes C, Oxnard GR, Kris MG, Miller VA, Pao W, Holodny Al, et al. "Pulsatile" high-dose weekly erlotinib for CNS metastases from EGFR mutant non-small cell lung cancer. Neuro Oncol. 2011;13:13649.

118. Yu HA, Sima CS, Reales D, Jordan S, Rudin CM, Kris M, et al. A phase I study of twice weekly pulse dose and daily low dose erlotinib as initial treatment for patients (pts) with EGFR-mutant lung cancers. J Clin Oncol. 2015;33:suppl; abstr 8017.

119. Kim D-W, Yang CH, Chen K, Cheng Z, Yin L, Martin PD, et al. AZD3759, an EGFR inhibitor with blood brain barrier (BBB) penetration for the treatment of non-small cell lung cancer (NSCLC) with brain metastasis (BM): Preclinical evidence and clinical cases. J Clin Oncol. 2015;33:suppl; abstr 8016. 
120. Sequist L, Soria J-C, Gadgeel S, Wakelee H, Camidge D, Varga A, et al. First-in-human evaluation of CO1686, an irreversible, highly selective tyrosine kinase inhibitor of mutations of EGFR (activating and T790M). J Clin Oncol. 2014;32(5s):(suppl; abstr 8010)

121. Varga A, Camidge D, Sequist L, Wakelee H, Ou SH, Goldman JW, et al. Activity of rociletinib in EGFR mutant NSCLC patients with a history of CNS involvement. Eur J Cancer. 2015;51(S3).

122. Kim D, Yang J, Cross D, Ballard P, Yang P, Yates J, et al. Preclinical evidence and clinical cases of AZD9291 activity in EGFR-mutant non-small cell lung cancer (NSCLC) brain metastases (BM). Ann Oncol. 2014;25:(suppl_4): iv146-iv64.

123. Ahn MJ, Tsai CM, Yang JC, Shepherd F, Satouchi M, Kim DW, et al. AZD9291 activity in patients with EGFR-mutant advanced non-small cell lung cancer (NSCLC) and brain metastases: Data from Phase II studies. Eur J Cancer. 2015;51(S3).

124. Seto T, Kato T, Nishio M, Goto K, Atagi S, Hosomi Y, et al. Erlotinib alone or with bevacizumab as firstline therapy in patients with advanced non-squamous non-small-cell lung cancer harbouring EGFR mutations (JO25567): an open-label, randomised, multicentre, phase 2 study. Lancet Oncol. 2014;15:1236-44.

125. NCCN guidelines Non-Small Cell Lung Cancer. version 1.2012. 2012 MS14.

126. Chaft JE, Oxnard GR, Sima CS, Kris MG, Miller VA, Riely GJ. Disease flare after tyrosine kinase inhibitor discontinuation in patients with EGFR-mutant lung cancer and acquired resistance to erlotinib or gefitinib: implications for clinical trial design. Clin Cancer Res. 2011;17:6298-303.

127. Das AK, Sato M, Story MD, Peyton M, Graves R, Redpath S, et al. Non-small-cell lung cancers with kinase domain mutations in the epidermal growth factor receptor are sensitive to ionizing radiation. Cancer Res. 2006;66:9601-8.

128. Yamamoto M, Serizawa T, Shuto T, Akabane A, Higuchi $Y$, Kawagishi J, et al. Stereotactic radiosurgery for patients with multiple brain metastases (JLGK0901): a multi-institutional prospective observational study. Lancet Oncol. 2014;15:387-95.

129. Chang EL, Wefel JS, Hess KR, Allen PK, Lang FF, Kornguth DG, et al. Neurocognition in patients with brain metastases treated with radiosurgery or radiosurgery plus whole-brain irradiation: a randomised controlled trial. Lancet Oncol. 2009;10:1037-44.

130. Shin SM, Cooper BT, Chachoua A, Butler J, Donahue B, Silverman JS, et al. Survival but not brain metastasis response relates to lung cancer mutation status after radiosurgery. J Neurooncol. 2016;126:483-91. 


\section{ENGLISH SUMMARY}

Lung cancer patients are frequently diagnosed with brain metastases. These patients often have a poor quality of life and a poor survival. In this thesis we tried to unravel clinical questions regarding screening for and prevention of development of brain metastases in stage III non-small cell lung cancer (NSCLC). We also evaluated the prognosis of patients already diagnosed with brain metastases and whether clinicians adhered to the revised Dutch guideline on brain metastases from solid tumours with respect to offering patients whole brain radiotherapy (WBRT). The last part focused on patients with a driver mutation (especially the epidermal growth factor receptor (EGFR)-mutation).

\section{PART 1: DIAGNOSIS AND PREVENTION OF BRAIN METASTASES IN STAGE III NSCLC}

The recommendation in guidelines is to stage all NSCLC patients eligible for therapy with curative intent with ${ }^{18}$ Fluodeoxyglucose positron emission tomography computed tomography $\left({ }^{18}\right.$ FDG-PET-CT). In stage III NSCLC it is also advised to perform a magnetic resonance imaging (MRI) scan of the brain to exclude asymptomatic brain metastases. It is unknown whether this MRI has an additional clinically relevant value if there is already a contrast enhanced CT (CE-CT) of the brain performed during this ${ }^{18}$ FDG-PETCT. This question is evaluated in chapter $\mathbf{2}$ and $\mathbf{3}$ in a retrospective monocentre study and a prospective multicentre study, respectively. Chapter 2 shows that a ${ }^{18}$ FDG-PET is insufficient to exclude brain metastases, as $16 \%$ of these patients (5 out of 32 ) had brain metastases on the MRI. When a CE-CT of the brain was performed during the ${ }^{18}$ FDG-PET-CT, no additional brain metastases were found on MRI (45 patients). In the prospective chapter 3 these results do change a little: in this chapter 3 out of 118 patients $(2.5 \%)$ who underwent a CE-CT of the brain during the ${ }^{18}$ FDG-PET-CT were diagnosed with brain metastases on MRI. In retrospect, in one of these three patients a solitary brain metastasis could be identified on the ${ }^{18}$ FDG-PET-CE-CT. We defined a difference of more than $2 \%$ clinically relevant. So, in daily practice, without review of the ${ }^{18}$ FDG-PET-CE-CTs, MRI is superior to CE-CT in detecting asymptomatic brain metastases in stage III NSCLC. Despite a MRI without brain metastases during initial staging, 9 patients $(12.5 \%)$ were diagnosed with brain metastases within a year of this $\mathrm{MRI}$ in chapter 2 . For more than $75 \%$ of these patients the brain was the first site of progression. Also in retrospect, revision of the original baseline MRIs revealed no brain metastases.

The findings of both chapters show that screening for asymptomatic brain metastases is useful in stage III NSCLC and that LD-CT is insufficient for screening. Also, MRI is (marginally) clinically relevant superior to CE-CT.

As brain metastases are frequently diagnosed in stage III NSCLC patients after chemoradiotherapy, we evaluated in the retrospective multicentre study described in chapter 4 whether the specific chemotherapeutic regime during this chemoradio- 
therapy has an influence on the development of brain metastases in the follow up. Focus is on the diagnosis of brain metastases within a year of stage III NSCLC diagnosis and whether the brain is the first and only site of progression. Diagnosis of brain metastases irrespective of timing is also evaluated. In this study only adequately staged stage III NSCLC were included $\left({ }^{18}\right.$ FDG-PET-CT and CE-CT or MRI of the brain) who completed their chemoradiotherapy treatment and who did not receive prophylactic cranial irradiation within a trial. 838 patients were eligible: 737 were treated with concurrent chemoradiotherapy and 101 with sequential chemoradiotherapy. 153 out of these 838 patients (18\%) were diagnosed with brain metastases, for $93 \%$ these were symptomatic. No significant difference was found with respect to the diagnosis of (symptomatic) brain metastases for patients treated with concurrent or sequential chemoradiotherapy (both 18\%). Median time to diagnosis of these brain metastases did not differ either. Compared to patients not diagnosed with brain metastases, patients diagnosed with brain metastases were significantly younger, were more often female and were more often diagnosed with an adenocarcinoma. $11 \%$ was diagnosed with brain metastases within a year of NSCLC diagnosis. Approximately half of these patients had only brain metastases as first site of progression. No significant differences were found for concurrent versus sequential chemoradiotherapy. Also within the concurrent chemoradiotherapy group $11 \%$ of patients was diagnosed with brain metastases within a year of NSCLC diagnosis and also for approximately half of them the brain was the only site of first progression. In logistic regression analysis the type of chemotherapy (cyclic dosed doublet chemotherapy or daily low dose cisplatin) had no influence on the development of brain metastases. Furthermore, the specific type of chemotherapy within the doublet chemotherapy group (regression analysis performed for all groups with $\geq 50$ patients) versus the daily low dose cisplatin group had no significant influence. In all analyses it was found that patients with a squamous cell carcinoma had a lower risk on the development of brain metastases compared to patients with an adenocarcinoma. Moreover, in most of the analyses it was found that younger patients had a higher risk, and in some of the analyses it was found that a higher T-and/or $\mathrm{N}$-stage increased the risk of brain metastases development.

In conclusion: approximately 1 out of 10 stage III NSCLC patients treated with chemoradiotherapy will develop brain metastases within a year of NSCLC diagnosis. The specific chemotherapy used within a chemoradiotherapy regimen has no influence on this. As brain metastases significantly reduce the quality of life as well as the prognosis, it remains important to identify strategies to reduce brain metastases development.

\section{PART 2: BRAIN METASTASES IN STAGE IV LUNG CANCER (“ALL-COMERS”)}

Within the current $\left(7^{\text {th }}\right)$ tumour, node, metastasis (TNM) classification for lung cancer, stage IV disease is separated into M1a (intrathoracic metastases) and M1b (extrathoracic metastases), as the latter group has a worse prognosis. It is unknown whether in the general population the specific organ affected (with the exception of 
M1a disease) has an influence on prognosis: in other words it is unknown whether for example patients with metastases in the brain have a worse prognosis compared to patients with another extrathoracic organ affected. It is also unknown whether local disease status (T- and $\mathrm{N}$-status) and number of organs affected influences prognosis.

In chapter $\mathbf{5}$ these questions are evaluated with data of the IKNL, in which almost all (98\%) of the NSCLC patients diagnosed in the Netherlands are registered. The median overall survival (OS) was significantly longer for patients with one organ affected (6.7 months) compared to those with 2 organs affected (4.3 months) or 3 or more organs affected (2.8 months). This was irrespective of age, gender, histology, M1a status and low local disease status. Younger age, female gender, adenocarcinoma, M1a status and low local disease status were independently associated with a longer OS. In subgroup analyses of patients with a documented ${ }^{18}$ FDG-PET-CT (more accurate staging) and in subgroup analyses of patients receiving active anticancer treatment, a superior OS was found compared to those without a documented ${ }^{18}$ FDG-PET-CT or active treatment. However, differences in OS regarding the number of organs affected remained significant. Within the group of patients with one organ affected, a low local disease status (T1-2 and N0-1) had a significant predictive value for a superior OS. In this group median OS was 8.5 months compared to 6.5 months for patients with a high TN-status. These differences remained when only ${ }^{18}$ FDG-PET-CT staged patients or those receiving active anticancer treatment were selected. Except for the current M1a organs and extrathoracic lymph node metastases, no organs were found that were consistently associated with a worse or superior OS.

As a result, the proposal is to subdivide the stage IV NSCLC group into three distinct groups: the current M1a, a new group for patients with one extrathoracic organ affected and a group with more than one extrathoracic organ affected.

The proposals for the M-categories for the 8th TNM classification for lung cancer also comprises three groups, but these are slightly different from the groups proposed in chapter 5. The proposal for the TNM8 is a subdivision into M1a (same as current M1a), M1b (solitary metastasis in one organ) and M1c (multiple metastases in one organ or multiple organs, or solitary metastasis in multiple organs). In chapter 6 this proposal is discussed. The proposal for the TNM8 is based on a relatively small group of patients $(\mathrm{N}=1025)$ from multiple hospitals, representing a risk for selection bias. It is also unclear which staging methods were used and it is possible that this has influenced the diagnosed number of organs affected as well as the number of diagnosed metastases per organ. As approximately a quarter of patients included was Asian, it is likely that these patients have influenced the results as the percentage of patients with a driver mutation is higher among Asians which results in a superior OS. Furthermore, in the proposals for the TNM8 it is unclear whether local disease status has a prognostic impact.

In chapter $\mathbf{7}$ it is evaluated whether clinicians adhere to the revised Dutch guideline on brain metastases. This with respect to lung cancer patients diagnosed with brain 
metastases not eligible for surgery or stereotactic radiotherapy. In this retrospective study we evaluated whether the percentage of recursive partitioning analysis (RPA) class III patients treated with WBRT decreased after the release of the updated guideline (2011). Furthermore, the median OS per RPA class was compared to data from the original RTOG analysis. $11.3-21.3 \%$ of treated patients was classified as RPA class III and this percentage did not decrease significantly after the release of the guideline. Reasons for WBRT despite a poor RPA class were not found. Median OS was 11.4, 4.0 and 1.7 months for NSCLC patients in RPA class I, II and III, respectively. For SCLC patients this was 7.9, 4.7 and 1.7 months, respectively. We concluded that the median OS in especially RPA class III is poor. Clinicians as well as patients should be aware of this to avoid unnecessary treatment.

\section{PART 3: STAGE IV NSCLC PATIENTS WITH CENTRAL NERVOUS SYSTEM METASTASES AND A DRIVER MUTATION, WITH A FOCUS ON EGFR-MUTATIONS}

Approximately $10 \%$ of the Caucasian patients with a non-squamous NSCLC has an EGFR-mutation. It is unclear whether these patients have a higher risk of developing brain metastases compared to patients without an EGFR-mutation. It is also unclear whether these patients have a superior OS after diagnosis of brain metastases. The current literature does not provide a clear answer.

In chapter 8 we tried to answer these questions in a retrospective, multicentre casecontrol study. All patients diagnosed with metastasized NSCLC and an EGFR-mutation (exon 19 or 21) were selected from two pathology databases (MUMC and VUMC). The consecutive patient with a KRAS-mutation and the consecutive EGFR/KRAS wildtype patient with a metastasized NSCLC were selected. These patients were compared. The percentage of patients diagnosed with brain metastases was not significantly different: $32 \%, 35 \%$ and $40 \%$, respectively. No significant difference was found regarding the percentage of patients with brain metastases at initial stage IV NSCLC diagnosis. The time to development of brain metastases (if not already diagnosed at initial stage IV diagnosis) was significantly longer for EGFR-mutated patients compared to KRASmutated patients (mean 20.4 months versus 10.8 months), but not compared to EGFR/KRAS wildtype patients (16.4 months). Median survival after brain metastases diagnosis was not significantly different and was 12.1, 7.6 and 10.7 months, respectively. All EGFR-mutated patients were treated with a first generation EGFR-TKI somewhere during the course of their disease and $80 \%$ of these patients were already treated with an EGFR-TKI before diagnosis of brain metastases. Time to development of brain metastases was not significantly different for those EGFR-mutated patients only treated with chemotherapy before brain metastases diagnosis compared to these treated with an EGFR-TKI. Also, survival after diagnosis of brain metastases was not significantly different, however number of patients per group was small.

To prolong survival in EGFR-mutated patients after diagnosis of brain metastases, local treatment and continuation of the EGFR-TKI or pulse EGFR-TKI is an option (in 
oligoprogressive patients). When a patients has a more generalised progression, second or third generation EGFR-TKIs are an option. Both treatments were not administered to the patients included in chapter 8.

An accepted strategy in oligoprogressive (brain only) EGFR-mutated patients is to treat locally with radiotherapy (WBRT or stereotactic radiotherapy) with a temporarily discontinuation and afterwards re-initiation of the EGR-TKI. It is possible that extracranial disease is still dependent on EGFR-inhibition and the risk exists that an extracranial flare up of the disease occurs with this discontinuation of the EGFR-TKI during cranial radiotherapy. Preclinical data indicate that TKIs augment the sensitivity for radiotherapy. The same is noted for EGFR-mutated cells. So, it is possible that EGFRTKI concurrent with cranial radiotherapy has a superior outcome compared to temporal discontinuation of the EGFR-TKI. A disadvantage is the possible increased risk of (neuro)toxicity. In current guidelines no recommendation is made regarding patients on (EGFR-)TKI treatment who develop brain metastases and have an indication for cranial radiotherapy. In daily practice the TKI is often discontinued because of the fear for (neuro-)toxicity.

In chapter 9 we evaluated in a systematic review whether this fear for increased toxicity is justified. The systemic search comprised EGFR-TKI's (erlotinib, gefitinib, icotinib, afatinib) and anaplastic lymphoma kinase (ALK)-TKI's (crizotinib, ceritinib, alectinib). 15 articles were included. In 6 articles erlotinib concurrent with WBRT was evaluated (one study also stereotactic radiotherapy after the WBRT), in 4 articles gefitinib concurrent with WBRT was evaluated, 3 articles evaluated gefinitib or erlotinib concurrent with WBRT and 2 articles evaluated icotinib concurrent with WBRT. For the other drugs no studies were found. Five of the 15 studies were retrospective and in 9 studies the EGFR-mutation status was evaluated in at least some of the patients (EGFR-mutation present in $1.3 \%$ to $100 \%$ ). Only one study was a randomised phase III study (erlotinib concurrent with WBRT and stereotactic radiotherapy) and 3 out of 7 phase II studies were randomised 2-arm studies. No study was found evaluating only EGFR-mutated patients who developed brain metastases during EGFR-TKI treatment and who were treated with radiotherapy concurrent with EGFR-TKI. Primary outcomes of the studies varied and where reported in a non-uniform way. Based on the results it seems safe to combine erlotinib, gefitinib or icotinib with WBRT although no highquality data exist. The combination of erlotinib with WBRT and stereotactic radiotherapy seems to increase the percentage of severe neurological complications.

Patients diagnosed with leptomeningeal metastases usually have a very poor survival. In chapter $\mathbf{1 0}$ we evaluated whether this is also true for EGFR-mutated NSCLC patients and whether we could identify factors associated with a superior survival. Data from 356 EGFR-mutated patients were retrospectively evaluated. 32 of these patients $(9.0 \%)$ were diagnosed with leptomeningeal metastases. Median survival was only 3.1 months and this was comparable to historical data from EGFR-wildtype patients. Only a good clinical condition was associated with a superior survival. After diagnosis of 
leptomeningeal metastases patients were treated with, among others: an EGFR-TKI (or switch of EGFR-TKI), pulse therapy EGFR-TKI, EGFR-TKI in combination with chemotherapy and/or radiotherapy. $75 \%$ of the patients (three out of four) not treated with an EGFR-TKI before diagnosis of leptomeningeal metastases had a relatively long survival (11.0-29.9 months). No other treatment could be identified that was associated with a significantly longer survival. In conclusion: EGFR-mutated patients do not have a superior survival compared to (historical data of) EGFR-wildtype patients when diagnosed with leptomeningeal metastases during or after EGFR-TKI treatment. It is possible that the third generation EGFR-TKIs can change this survival.

In chapter 11 the findings summarized above are discussed. 


\section{Samenvatting}

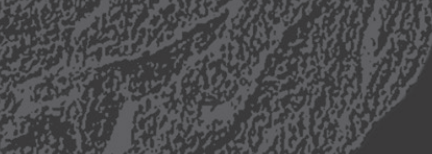

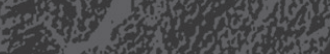

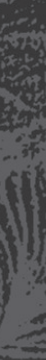

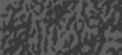




\section{NEDERLANDSTALIGE SAMENVATTING}

Hersenmetastasen komen frequent voor bij longkanker patiënten. Patiënten met hersenmetastasen hebben vaak een slechtere kwaliteit van leven en een kortere overleving. In dit proefschrift wordt getracht klinische vraagstellingen te beantwoorden met betrekking tot screening op en preventie van ontwikkeling van hersenmetastasen bij patiënten met stadium III niet-kleincellig longkanker (NSCLC). Tevens wordt er naar de prognose gekeken van patiënten met hersenmetastasen en of na diagnose de richtlijn hersenmetastasen is gevolgd met betrekking tot het aanbieden van totale schedelbestraling (Whole Brain Radiotherapy (WBRT)). Het laatste deel focust op patiënten met een driver-mutatie (met name de epidermal growth factor receptor (EGFR)-mutatie).

\section{DEEL 1: DIAGNOSTIEK EN PREVENTIE VAN HERSENMETASTASEN BIJ STADIUM III NSCLC}

Het advies in richtlijnen is om alle NSCLC patiënten die in aanmerking komen voor curatieve behandeling te stadiëren middels ${ }^{18}$ Fluodeoxyglucose positron emission tomography computed tomography $\left({ }^{18} \mathrm{FDG}-\mathrm{PET}-\mathrm{CT}\right)$ en om bij stadium III ook een magnetic resonance imaging (MRI)-scan van het brein te maken om asymptomatische hersenmetastasen uit te sluiten. Het is echter niet bekend of deze MRI nog een klinisch relevante meerwaarde heeft indien er al een contrast CT (CE-CT) van het brein is gemaakt tijdens deze ${ }^{18}$ FDG-PET-CT. Deze vraagstelling wordt in hoofdstuk 2 en 3 geëvalueerd in respectievelijk een retrospectief monocenter onderzoek en een prospectief multicenter onderzoek. Uit hoofdstuk 2 blijkt dat een ${ }^{18}$ FDG-PET onvoldoende is om hersenmetastasen uit te sluiten, aangezien bij $16 \%$ van deze patiënten ( 5 van de 32 ) alsnog hersenmetastasen werden gevonden op MRI. Indien er een CT van het brein met contrast (CE-CT) werd gemaakt tijdens de ${ }^{18}$ FDG-PET-CT, werd er bij niemand hersenmetastasen gevonden op de MRI (45 patiënten). In het prospectieve hoofdstuk 3 worden deze resultaten iets bijgesteld: hier hadden 3 van de 118 patiënten (2.5\%) die een CE-CT van het brein hadden gehad tijdens de ${ }^{18}$ FDG-PET$\mathrm{CT}$ alsnog hersenmetastasen op MRI. Echter, bij geblindeerde revisie van de CE-CT's kon bij een van deze 3 patiënten alsnog een hersenmetastase worden gediagnosticeerd op de CE-CT. Vooraf hadden we $2 \%$ patiënten met hersenmetastasen op MRI die niet gevonden waren op CE-CT als klinisch relevant gedefinieerd. In de dagelijkse praktijk, zonder een extra revisie van de CE-CT's is MRI dus net klinisch relevant beter. Ondanks een MRI zonder hersenmetastasen bij initiële diagnose van het stadium III NSCLC werden in hoofdstuk 29 patiënten (12.5\%) alsnog gediagnosticeerd met hersenmetastasen binnen een jaar na deze MRI. Voor ruim driekwart van deze patiënten was het brein de eerste plek van progressie. Revisie van de oorspronkelijke MRI's liet ook in retrospectie geen hersenmetastasen zien. 
De bevindingen van beide hoofdstukken samen laten zien dat screenen op asymptomatische hersenmetastasen bij stadium III NSCLC noodzakelijk is, en dat MRI (net) klinisch relevant beter dan CE-CT.

Aangezien hersenmetastasen vaak voorkomen na chemoradiotherapie voor stadium III NSCLC, wordt in de retrospectieve multicenter studie beschreven in hoofdstuk 4 onderzocht of het specifieke chemotherapie schema dat tijdens deze behandeling wordt gebruikt van invloed is op het ontstaan van hersenmetastasen binnen een jaar na diagnose van stadium III NSCLC en of het brein de eerste en enige plek van progressie is. Er wordt verder ook gekeken naar de diagnose van hersenmetastasen ongeacht het tijdstip van diagnose. In deze studie werden alleen adequaat gestadieerde stadium III NSCLC patiënten geïncludeerd ( ${ }^{18}$ FDG-PET-CT plus CE-CT of MRI van het brein) die de gehele behandeling met chemoradiatie afgerond hadden en die geen profylactische schedelbestraling hadden gehad in studieverband. Van de 838 geschikte patiënten werden er 737 behandeld met concurrente chemoradiatie en 101 met sequentiële chemoradiatie. Bij 153 van deze 838 patiënten (18\%) werden binnen een jaar hersenmetastasen vastgesteld, bij $93 \%$ van hen waren deze symptomatisch. Er was geen verschil tussen de patiënten die behandeld worden met concurrente of sequentiële chemoradiatie (beiden 18\%) en mediane tijd tot de diagnose van hersenmetastasen was niet significant verschillend. De patiënten die gediagnosticeerd werden met hersenmetastasen waren significant jonger dan degenen zonder, waren vaker vrouw en hadden vaker adenocarcinoma histologie. $11 \%$ werd gediagnosticeerd met hersenmetastasen binnen een jaar na NSCLC diagnose. Ongeveer de helft van deze patiënten had alleen hersenmetastasen als eerste plek van progressie. Ook hier werd er geen significant verschil gevonden tussen concurrente en sequentiële chemoradiatie. Binnen de concurrente chemoradiatie groep werden eveneens bij $11 \%$ van de patiënten binnen een jaar na NSCLC diagnose hersenmetastasen gediagnosticeerd, en ongeveer de helft van deze patiënten had alleen maar hersenmetastasen als enige plek van eerste progressie. In logistieke regressie analyse had de soort chemotherapie (cyclisch gedoseerde doublet chemotherapie of dagelijks lage dosis cisplatinum) geen invloed op het ontwikkelen van hersenmetastasen. Ook wanneer er specifiek naar de soort chemotherapie binnen de polychemotherapie groep werd gekeken (regressie analyse verricht voor alle groepen met $\geq 50$ patiënten) en deze werd vergeleken met de lage dosis cisplatinum groep, werden er geen verschillen gevonden. Wel werd er in alle analyses gevonden dat patiënten met een plaveiselcelcarcinoom een lager risico hadden op het ontwikkelen van hersenmetastasen dan patiënten met een adenocarcinoom. Tevens werd in het merendeel van de analyses gevonden dat jongere patiënten een hoger risico hadden, en werd in sommige analyses gevonden dat een hoger T- en /of N-stadium het risico op hersenmetastasen verhoogde.

Concluderend kan gezegd worden dat ongeveer een op de tien patiënten met een stadium III NSCLC die behandeld wordt middels chemoradiatie gediagnosticeerd wordt 
met hersenmetastasen binnen een jaar na NSCLC diagnose, en dat het specifieke chemotherapie regime dat gebruikt wordt tijdens deze chemoradiatie geen invloed hierop heeft. Aangezien hersenmetastasen de kwaliteit van leven en de prognose beduidend verminderen blijft het belangrijk om een strategie te vinden om het ontwikkelen van hersenmetastasen tegen te gaan.

\section{DEEL 2: HERSENMETASTASEN BIJ STADIUM IV LONGKANKER (“ALL-COMERS”)}

Binnen de huidige $\left(7^{\mathrm{e}}\right)$ tumor, nodus, metastase (TNM) classificatie voor longkanker wordt bij stadium IV ziekte een onderscheid gemaakt tussen M1a (intrathoracale metastasen) en M1b (extrathoracale metastasen), omdat de laatste groep een slechtere prognose heeft. Het is onbekend of binnen de algehele populatie het specifieke orgaan dat aangedaan is (met uitzondering van de M1a ziekte) invloed heeft op de prognose, m.a.w. het is onduidelijk of hersenmetastasen bij stadium IV NSCLC de prognose verminderen, vergeleken met andere extrathoracale organen die aangedaan zijn. Het is ook onduidelijk of de lokale ziektestatus (T- en N-status) en de hoeveelheid organen die aangedaan zijn invloed heeft op de prognose.

In hoofdstuk 5 wordt dit geëvalueerd met data van het IKNL, waarin vrijwel alle (98\%) NSCLC patiënten die in Nederland zijn gediagnosticeerd in worden opgenomen. De mediane overleving was significant langer voor patiënten met 1 orgaan aangedaan (6.7 maanden) vergeleken met degenen met 2 (4.3 maanden) of 3 of meer organen (2.8 maanden) aangedaan. Dit was onafhankelijk van leeftijd, geslacht, histologie, M1a status en lage lokale ziekte status. Jongere leeftijd, adenocarcinoom, M1a status en lage lokale ziekte status waren ook geassocieerd met een langere overleving. In subgroep analyses van patiënten met een gedocumenteerde ${ }^{18}$ FDG-PET-CT (accuratere stadiering) en in subgroep analyses van patiënten die actief behandeld werden (waarschijnlijk patiënten met betere klinische conditie), werd een betere overleving gevonden dan bij degenen waarbij dit niet het geval is, maar de verschillen in overleving met betrekking tot het aantal organen aangedaan blijven bestaan. Binnen de groep patiënten met metastasen in 1 orgaan, had een lage lokale ziektestatus (T1-2 en N0-1) een significant voorspellende waarde voor een betere overleving. In deze groep was de mediane overleving 8.5 maanden vergeleken met 6.5 maanden voor de patiënten met een hoge TN-status. Deze verschillen bleven bestaan indien alleen ${ }^{18}$ FDG-PET-CT gestadieerde patiënten of degenen met actieve oncologische behandeling werden geselecteerd. Behalve de huidige M1a organen en extrathoracale lymfkliermetastasen werden er geen organen gevonden die consistent geassocieerd waren met een betere of slechtere overleving.

Het voorstel is dan ook om binnen de stadium IV NSCLC groep een onderverdeling te maken in drie groepen: de huidige $\mathrm{Mla}$, en dan een nieuwe groep met patiënten waarbij een extrathoracaal orgaan is aangedaan en een groep waarbij meerdere extrathoracale organen zijn aangedaan. 
Het voorstel voor de M-categorieën voor de $8^{\mathrm{e}}$ TNM classificatie bevat ook drie groepen, maar deze verschillen enigszins van de groepen die in hoofdstuk 5 worden voorgesteld. Het voorstel voor de TNM8 is een onderverdeling in M1a (conform huidige M1a), M1b (solitaire metastase in een orgaan) en M1c (meerdere metastasen in een orgaan of meerdere organen, of solitaire metastasen in meerdere organen). In hoofdstuk 6 worden discussiepunten bij dit voorstel aan de orde gesteld. Het voorstel voor de TNM8 is gebaseerd op een relatief kleine groep van patiënten (1025) uit meerdere ziekenhuizen, waardoor de kans op selectiebias groot is. Ook is onduidelijk hoe deze patiënten gestadieerd zijn en dit kan van invloed zijn op zowel het aantal organen dat aangedaan is als op het aantal metastasen per orgaan. Aangezien ongeveer een kwart van de patiënten van Aziatische komaf is, is er een reële kans dat deze patiënten de uitkomsten beïnvloedt hebben aangezien het percentage patiënten met een driver-mutatie hoger ligt in deze groep met als resultaat een betere overleving. Ook is het in het voorstel voor de TNM8 onduidelijk of lokale ziektestatus nog een rol speelt in de prognose.

In de retrospectieve multicenter studie hoofdstuk 7 wordt geëvalueerd of men zich aan de Nederlandse richtlijn hersenmetastasen houdt indien er bij een longkanker patiënt hersenmetastasen worden gediagnosticeerd die niet geschikt zijn voor chirurgie of stereotactische radiotherapie. In deze studie wordt gekeken of na het invoeren van de richtlijn (2011) het percentage Recursive Partitioning Analysis (RPA) klasse III patiënten dat behandeld werd met WBRT daalt. Tevens wordt de overleving van de patiënten per RPA klasse vergeleken met data uit de originele RTOG analyse. 11.3-21.3\% van de behandelde patiënten kon als RPA klasse III geclassificeerd worden en dit percentage daalde niet na invoering van de richtlijn. Een oorzaak voor behandelen met WBRT ondanks een ongunstige RPA klasse wordt niet gevonden. Mediane overleving was 11.4, 4.0 en 1.7 maanden voor NSCLC patiënten in RPA klasse I, II en III respectievelijk. Voor SCLC was dit 7.9, 4.7 en 1.7 maanden respectievelijk. Dit was grotendeels in lijn met de originele RTOG analyse. Geconcludeerd kan worden dat overleving in met name RPA klasse III slecht is, en dat clinici en patiënten hiervan beter op de hoogte zouden moeten zijn om onnodige behandeling te voorkomen.

\section{DEEL 3: STADIUM IV NSCLC PATIËNTEN MET CENTRAAL ZENUWSTELSEL BETROKKENHEID MET EEN DRIVER-MUTATIE, MET DE FOCUS OP EGFR-MUTATIES}

Ongeveer $10 \%$ van de Caucasische patiënten met een niet-plaveiselcelcarcinoom NSCLC heeft een EGFR-mutatie. Het is onduidelijk of deze patiënten een hoger risico hebben op het ontwikkelen van hersenmetastasen vergeleken met patiënten zonder een EGFRmutatie. Het is ook onduidelijk of deze patiënten een langere overleving hebben na diagnose van hersenmetastasen. De bestaande literatuur is tegenstrijdig.

In hoofdstuk $\mathbf{8}$ wordt geprobeerd deze vragen te beantwoorden in een retrospectieve, multi-center case-control studie. Alle patiënten met gemetastaseerd NSCLC en een EGFR-mutatie (exon 19 of 21) werden geselecteerd uit twee pathologie databases 
(MUMC en VUMC). De daaropvolgende KRAS-gemuteerde en EGFR/KRAS wildtype patiënt met een gemetastaseerd NSCLC werd geselecteerd. Deze patiënten werden vergeleken. Het percentage patiënten dat werd gediagnosticeerd met hersenmetastasen was niet significant verschillend: $32 \%$, 35\% en $40 \%$, respectievelijk. Er was ook geen significant verschil in percentage patiënten met hersenmetastasen bij initiële diagnose van het gemetastaseerde NSCLC. Tijd tot ontwikkelen van hersenmetastasen (indien niet al gediagnosticeerd bij initiële diagnose) was significant langer voor EGFR-gemuteerde patiënten vergeleken met KRAS-gemuteerde patiënten (mean 20.4 maanden versus 10.8 maanden), maar niet vergeleken met EGFR/KRAS wildtype patiënten (16.4 maanden). Mediane overleving na diagnose van hersenmetastasen was niet significant verschillend en was respectievelijk 12.1, 7.6 en 10.7 maanden. Alle EGFR-gemuteerde patiënten werden ergens in het beloop van hun ziekte behandeld met een eerste generatie EGFR-TKI, en $80 \%$ van hen kreeg deze al voor diagnose van de hersenmetastasen. Tijd tot ontwikkelen van hersenmetastasen was niet significant verschillend voor de EGFR-gemuteerde patiënten die alleen chemotherapie hadden gekregen voor diagnose van hersenmetastasen vergeleken met degenen die behandeld werden met een EGFR-TKI. Ook overleving na diagnose van hersenmetastasen was niet significant verschillend, maar aantallen per groep waren erg klein.

Om overleving na diagnose van hersenmetastasen te verlengen bij EGFR-gemuteerde patiënten, is (indien oligoprogressie) lokaal behandelen en continueren van de eerste generatie EGFR-TKI of pulse EGFR-TKI een optie. Bij meer gegeneraliseerde progressie zijn tweede of derde generatie EGFR-TKI's een optie. Deze behandelingen werden niet toegepast op de patiënten die geïncludeerd werden in hoofdstuk 8.

Zeker indien er oligoprogressie cerebraal is, is lokaal behandelen met radiotherapie (WBRT of stereotaxie) met hierbij alleen tijdelijk onderbreken van de EGFR-TKI een geaccepteerde behandelingsstrategie. Extracraniele ziekte kan echter nog goed reageren op de EGFR-TKI, en het risico bestaat dat er een extracraniele opflakkering van de ziekte optreedt indien de EGFR-TKI rondom de radiotherapie wordt onderbroken. Preklinische data wijzen er verder op dat TKI's de gevoeligheid voor radiotherapie verhogen. Ditzelfde wordt gezien voor EGFR-gemuteerde cellen. Het is dus mogelijk dat gelijktijdige behandeling met radiotherapie en een EGFR-TKI een betere uitkomst geeft. Nadeel is dat de (neuro-)toxiciteit mogelijk toeneemt. In huidige richtlijnen staat geen advies wat te doen met een (EGFR)-TKI indien een patiënt die hiermee behandeld wordt hersenmetastasen ontwikkeld en een indicatie heeft voor craniale radiotherapie. In de praktijk wordt deze vaak tijdelijk gestopt wegens de angst voor (neuro-)toxiciteit. In hoofdstuk 9 wordt in een systematisch review onderzocht of deze angst voor toegenomen toxiciteit terecht is. De systemische literatuursearch omvatte EGFR-TKI's (erlotinib, gefitinib, icotinib, afatinib) en anaplastic lymphoma kinase (ALK)-TKI's (crizotinib, ceritinib, alectinib). 15 artikelen werden geïncludeerd. In 6 artikelen werd gekeken naar erlotinib tegelijkertijd met WBRT (een studie ook nog stereotaxie na 
WBRT), in 4 werd gekeken naar gefitinib tegelijkertijd met WBRT, 3 artikelen evalueerden gefinitib of erlotinib tegelijkertijd met WBRT en 2 artikelen evalueerden icotinib met WBRT. Voor de andere medicijnen werden geen studies gevonden. Vijf van de 15 studies waren retrospectief, en in 9 studies werd (in een deel van de patiënten) de EGFR-mutatie bepaald (EGFR-mutatie aanwezig variërend van 1.3 tot $100 \%$ ). Maar een studie was een gerandomiseerde fase III studie (erlotinib plus WBRT en stereotaxie), en 3 van de 7 fase II studies waren gerandomiseerde 2-arm studies. Geen enkele studie evalueerde alleen EGFR-gemuteerde patiënten, die hersenmetastasen ontwikkelen gedurende EGFR-TKI behandeling en die dan behandeld werden met radiotherapie met continueren van de EGFR-TKI. Primaire uitkomsten van de studies varieerden en werden niet uniform weergegeven. Gebaseerd op de resultaten lijken erlotinib, gefitinib en icotinib veilig met WBRT gegeven te kunnen worden maar er zijn geen harde data. De combinatie van erlotinib met WBRT en stereotaxie lijkt het aantal ernstige neurologische complicaties te verhogen.

Patiënten die gediagnosticeerd worden met leptomeningeale metastasen hebben meestal een zeer slechte overleving. In de retrospectieve multicenter cohortstudie beschreven in hoofdstuk 10 onderzochten we of dit ook het geval was voor EGFRgemuteerde NSCLC patiënten, en of we factoren konden vinden die geassocieerd waren met een betere overleving. Hiervoor bekeken we retrospectief de data van 356 EGFRgemuteerde patiënten. 32 van hen $(9.0 \%)$ werd gediagnosticeerd met leptomeningeale metastasen. Mediane overleving was maar 3.1 maanden en dit is vergelijkbaar met historische data van de overleving van EGFR-wildtype patiënten. Alleen een goede klinische conditie was geassocieerd met een betere overleving. Patiënten werden na diagnose van de leptomeningeale metastasen behandeld met onder andere: een EGFRTKI (of switch van EGFR-TKI), pulstherapie EGFR-TKI, EGFR-TKI in combinatie met chemotherapie en/of radiotherapie. Driekwart (drie van de vier) patiënten die nog niet waren behandeld met een EGFR-TKI voor diagnose van leptomeningeale metastasen hadden een relatief lange overleving (11.0 -29.9 maanden). Verder kon er geen behandeling geïdentificeerd worden die voor een significant langere overleving zorgde. Concluderend hebben EGFR-gemuteerde patiënten geen langere overleving vergeleken met (historische data van) EGFR-wildtype patiënten indien ze deze leptomeningeale metastasen ontwikkelen tijdens of na EGFR-TKI behandeling. Mogelijk dat de derde generatie EGFR-TKIs hier verandering in aan kunnen brengen.

In hoofdstuk 11 wordt een algemene discussie over deze thesis gehouden. 


\section{VALORIZATION}

In 2013 in the Netherlands, 12,660 patients were diagnosed with lung cancer. ${ }^{1}$ Approximately $30 \%$ was diagnosed in a locally advanced state (i.e. stage III) and $50 \%$ in an already metastatic state (stage IV). ${ }^{2}$ Non-small cell lung cancer (NSCLC) and small cell lung cancer (SCLC) account for $80-85 \%$ and $15-20 \%$ of lung cancer cases, respectively. ${ }^{3}$ Approximately $40 \%$ of lung cancer patients will develop brain metastases during the course of their disease. ${ }^{4}$ These brain metastases often have a negative impact on quality of life (QoL). ${ }^{5}$ In this thesis we tried to unravel clinical questions regarding screening, prevention and treatment of brain metastases. As a result of the scientific content of this thesis several recommendations have been made in chapter 11 . However, besides a scientific analysis of these studies, there are some socioeconomical applications and the possibility to develop clinical decision aid tools.

The percentage of the "Gross Domestic Product" spend on health care in the Netherlands is approximately $14 \%$ and is still increasing. ${ }^{6}$ From an economical point of view, the results described in this thesis can aid in reducing the costs of treating lung cancer patients in several possible ways. Examples are omitting unnecessary imaging procedures (brain magnetic resonance imaging (MRI) in stage III NSCLC), omitting endof-life-whole brain radiotherapy (WBRT) and using population based databases for prognostic information and concepts for validation in future studies.

The first to be discussed is the MRI of the brain in neurologically asymptomatic stage III NSCLC patients. Depending on the specific MRI protocol and the hospital, one brain MRI costs around 300-400 euros. In the Netherlands, approximately 3000 patients per year are diagnosed with stage III NSCLC . Depending on clinical condition, comorbidities and patient's wishes, these patients are candidates for therapy with curative intent. As brain MRI was found to be only marginally superior to a dedicated computed tomography (CT) of the brain, a significant amount of money can be saved by omitting a brain MRI in every stage III NSCLC patient staged with ${ }^{18}$ fluorodeoxyglucose-positron emission tomography contrast-enhanced CT ( ${ }^{18}$ FDG-PET-CE-CT). Moreover, as timely access to MRI was difficult for the participating hospitals, time to start of treatment can also be shortened by omitting a brain MRI. Problems with timely access to MRI are not unique for the participating hospitals, as in a United Kingdom survey (2014) CE-CT was preferred above MRI, presumably due to lack of access to MRI. ${ }^{7}$

The second example to reduce health care costs is the prevention of end-of-life-WBRT. For one patient, WBRT costs are $€ 9886.01$ (MAASTRO data). ${ }^{8}$ In general, it is advised to withhold active treatment in patients with a very poor prognosis and to pursue only optimal supportive care as these patients do not benefit from active treatment. ${ }^{9}$ This thesis describes the results of a large group of lung cancer patients diagnosed with brain metastases and treated with WBRT. As is shown, the overall survival in the recursive partitioning analysis (RPA) class III group is dismal and no prognostic factors could be identified that were associated with an improved survival. Moreover, in the 
QUARTZ study, it was shown that omitting WBRT in a poor prognosis group does not harm patients. ${ }^{10}$

The third example is the use of population based databases. Clinical trials are becoming more and more expensive and it is not always clear whether results found within a clinical trial / registry based on data from selected patients treated at a referral center can be extrapolated to the general population. Population based registries, like we have used in chapter five can aid in validating clinical trial results or providing data for future clinical trials without additional costs. For example, number of organs with metastases could be used to stratify patients in clinical trials. Furthermore, the concept of oligometastatic disease should be further explored especially in the patients with a low local disease status as we have described that these patients have the best survival. Population based results can also provide prognostic factors such as the ones described above. These factors should be validated in the 9th tumour, node, metastasis (TNM) classification for lung cancer.

This thesis has also some social implications. An example is that it should not matter in which hospital in a certain region a patient is diagnosed with lung cancer: work-up and treatment should not be different. However, as is clear from chapter three, chemotherapy regimens within a chemoradiotherapy regimen vary widely across hospitals. There are no head to head clinical trials comparing these regimens, but from published clinical trials it seems that there is no superior one. ${ }^{11}$ Moreover, we have shown that there is no impact of the chemotherapy used on the diagnosis of brain metastases after treatment completion. As there are no significant differences for these regimens (also no difference for overall survival), this thesis provides evidence to adopt one single regimen within the Netherlands. This would also prevent miscommunication with referred patients because of different treatment regimens applied in different hospitals. Moreover, there is no consensus whether NSCLC patients with a driver mutation, treated with a tyrosine kinase inhibitor (TKI) and diagnosed with brain metastases, can be treated with cranial irradiation concurrent with the TKI. In a short survey among pulmonologists and radiation oncologists, practice varied between continuation of the TKI, discontinuation of the TKI only for the days of cranial irradiation to discontinuation of the TKI for five half-times before and after the cranial irradiation (personal communication). This thesis provides evidence that it is safe to combine a first generation epidermal growth factor receptor (EGFR)-TKI and WBRT. These data also provide evidence that can be used in a new guideline on cranial radiotherapy concurrent with systemic treatment.

Another social aspect is that cancer patients do not want to lose hope. However, sometimes the definition of hope needs to be rephrased, e.g. in poor prognosis lung cancer patients diagnosed with brain metastases. ${ }^{12}$ By focusing on offered treatments the patients and physicians often ignore the dismal future due to a focus on short-term goals (e.g. make it to the next treatment or test. ${ }^{13}$ Moreover, in a survey supportive 
care was often not viewed as a real alternative compared to active treatment. ${ }^{12}$ Possibly a team-based consult service through a multidisciplinary integrated palliative oncology clinic would have improved this decision making process as was shown in a recent study. ${ }^{12}$ The results described in this thesis provide additional grounds to have such a multidisciplinary approach including physician and patient education in every hospital as it seems that the prognosis of the RPA class III patients was overestimated. Another translational of these results would be the development of a clinical decision aid.

This thesis can also aid in improving the ongoing revision of the Dutch guideline on brain metastases. Examples already mentioned are the value of $\mathrm{MRI}$ in diagnosing asymptomatic brain metastases in stage III NSCLC and omitting end-of-life-WBRT in poor prognosis brain metastases patients. However, more factors should be taken into account when deciding whether a patient is eligible for cranial radiotherapy and this should be described in the revised guideline. Prognostic examples found in this thesis are the presence or absence of extracranial metastases and number of organs with metastases. Furthermore, today it is not taken into account whether an effective systemic treatment is available for the extracranial disease (especially first line chemotherapy for small cell lung cancer (SCLC) and TKIs for patients with molecular drivers, but in a lesser extent also first line chemotherapy for NSCLC) and whether this systemic treatment also penetrates the (compromised) blood-brain barrier (BBB) to also have an effect on the brain metastases. Ideally, prognostic classification, patient preferences, available systemic options and patient outcome (symptoms and survival) should be incorporated into the guidelines and preferably into a decision aid that continues to improve by the input it receives.

In conclusion, this thesis has a socio-economical relevance and provides opportunities to develop decision support tools. The economical relevance is demonstrated by possibilities to reduce costs by sometimes omitting imaging and by omitting end-of-life WBRT. The social relevance comes from described possibilities to make uniform treatment decisions (chemotherapy regimens within a chemoradiotherapy regimen, TKI concurrent with WBRT) and education of physicians and patients about poor prognosis in RPA class III patients. It also provides opportunities to develop new clinical decision aid tools and might have impact on the revision of the Dutch guideline on brain metastases from solid tumours. 


\section{REFERENCES}

1. www.cijfersoverkanker.nl [Internet]. [cited 27-Oct-2015]. Available from:

http://www.cijfersoverkanker.nl/selecties/Incidentie_long_en_luchtpijpkanker/img54d0ecb34ed7b.

2. SEER database: SEER Stat Fact Sheets: Lung and Bronchus Cancer, Percent of Cases \& 5-Year Relative Survival by Stage at Diagnosis: Lung and Bronchus Cancer [Internet]. Available from: http://seer.cancer.gov/statfacts/html/lungb.html.

3. SEER database table 15.28 Cancer of the Lung and Bronchus (invasive) [Internet]. Available from: seer.cancer.gov/csr/1975_2012/results_single/sect_15_table.28.pdf.

4. Yawn BP, Wollan PC, Schroeder C, Gazzuola L, Mehta M. Temporal and gender-related trends in brain metastases from lung and breast cancer. Minn Med. 2003;86(12):32-7.

5. Steinmann D, Schafer C, van Oorschot B, Wypior HJ, Bruns F, Bolling T, et al. Effects of radiotherapy for brain metastases on quality of life (QoL). Prospective pilot study of the DEGRO QoL working party. Strahlenther Onkol. 2009;185(3):190-7.

6. Mot E, Stuut K, Westra P, Aalbers R. Een raming van de zorguitgaven 2018-2021: Centraal PlanBureau; 2016 [cited 2016]. Available from: http://www.cpb.nl/publicatie/een-raming-van-de-zorguitgaven2018-2021.

7. Hudson BJ, Crawford MB, Curtin JJ. Brain imaging in lung cancer patients without symptoms of brain metastases: a national survey of current practice in England. Clin Radiol. 2015;70(6):610-3.

8. Passantentarieven 2016v2 [Internet]. MAASTRO. 2016 [cited June 1th 2016]. Available from: https://www.maastro.nl/nl/1/444/standaard-prijslijst.aspx.

9. LWNO/ IKL guideline: "brain metastases from solid tumors" version 3.0 July 2011. 2011:17-22.

10. Mulvenna P, Nankivel M, Barton R, Faivre-Finn C, Wilson P, Moore B, et al. Whole brain radiotherapy for brain metastases from non-small lung cancer: Quality of life (QoL) and overall survival (OS) results from the UK Medical Research Council QUARTZ randomised clinical trial (ISRCTN 3826061). J Clin Oncol. 2015;33( (suppl; abstr 8005)).

11. Santana-Davila R, Devisetty K, Szabo A, Sparapani R, Arce-Lara C, Gore EM, et al. Cisplatin and etoposide versus carboplatin and paclitaxel with concurrent radiotherapy for stage III non-small-cell lung cancer: an analysis of Veterans Health Administration data. J Clin Oncol. 2015;33(6):567-74.

12. Sze J, Marisette S, Williams D, Nyhof-Young J, Crooks D, Husain A, et al. Decision making in palliative radiation therapy: reframing hope in caregivers and patients with brain metastases. Supportive Care in Cancer. 2006;14(10):1055-63.

13. The AM, Hak T, Koeter G, van Der Wal G. Collusion in doctor-patient communication about imminent death: an ethnographic study. BMJ. 2000;321(7273):1376-81. 


\section{DANKWOORD}

Het is zover, het wetenschappelijk deel van dit proefschrift is afgerond. Dit was niet mogelijk geweest zonder de hulp van vele mensen, die ik hieronder wil bedanken.

Allereerst alle patiënten. De klinische vraagstellingen in dit proefschrift berusten veelal op een praktisch probleem dat we tegenkwamen gedurende de dagelijkse patiëntenzorg. Hopelijk wordt met dit proefschrift de zorg weer een stukje beter.

Allereerst Anne-Marie Dingemans. Anne-Marie, toen ik nog in Heerlen werkte heb je me enthousiast gemaakt voor longkanker onderzoek en je hebt me "binnengehaald" in het longartsenteam in Maastricht. Bedankt voor alle nuttige, opbouwende en snelle feedback. Begonnen zonder al te veel onderzoekservaring kon ik altijd binnen komen vallen met vragen en problemen. Ook qua combinatie van patiëntenzorg en onderzoek ben je een voorbeeld van een betrokken longarts die net een stapje (grote stap!) verder gaat voor haar patiënten. Deze waarderen dat dan ook ten zeerste. Verder verheug ik me op zowel klinische als onderzoekssamenwerking de komende jaren. Ik zal de dropjespot op mijn kamer nog vaak moeten bijvullen......

Beste prof. dr. Wouters, beste Miel. Dank voor het opnemen in de staf longziekten en het geloof in mij dat ik de combinatie deels kliniek en deels onderzoek aan kon. Tevens dank voor de ruimte die ik kreeg om aan mijn onderzoek te werken binnen de staf longziekten.

Verder wil ik de leden van de beoordelingscommissie, prof. dr. Tjan-Heijnen, prof. dr. Lambin, prof. dr. Van Meerbeeck, prof. dr. Ramaekers en dr. Gijtenbeek, bedanken voor de kritische beoordeling van het proefschrift.

Prof. dr. De Ruysscher, beste Dirk. Ondanks je drukke schema heb je altijd binnen korte tijd zeer bruikbare feedback gegeven op mijn manuscripten, ze zijn er veel beter van geworden. Je kritische kijk op zowel de dagelijkse praktijk als onderzoeksresultaten is een voorbeeld van hoe het zou moeten. Je inbreng op het longoncologie MDO en ons "kleine MDO" is waardevol, en dat je terug bent in Maastricht is zeker een aanwinst.

Prof. dr. Troost, beste Esther, helaas werk je nu in Duitsland, maar in de gezamenlijke tijd in Maastricht heb ik je ervaren als een fijne collega, altijd klaar staand voor zowel patiënten als onderzoek. Dank voor je bijdrage aan dit proefschrift.

Prof. dr. Smit, beste Egbert. Je waarschuwde me de eerste keer toen je feedback op een manuscript terugstuurde dat "het een beetje rood was geworden en dat ik hier niet 
van moest schrikken". Ik heb er veel van geleerd (en ben er niet van geschrokken) en de artikelen zijn er alleen maar beter van geworden.

Prof. dr. Hofman, beste Paul, dank voor alle radiologische feedback, revisie van beeldvorming en de adviezen met betrekking tot ons volgende gezamenlijke MRIonderzoek.

Alle collega longartsen, AIOS en radiotherapeuten die me gefaciliteerd hebben om data op te komen zoeken of ze zelf geregistreerd hebben voor mij. Zonder jullie zou dit proefschrift niet mogelijk zijn geweest. Gerben, dankjewel voor het enthousiasmeren voor de longoncologie, het aanleveren van patiënten data en het warme welkom in Heerlen als ik weer eens langs kwam, met of zonder collega's die ook data nodig hadden. Marcel, Vivian, ik weet niet hoe vaak ik jullie om weer wat informatie heb gevraagd, maar jullie hebben het altijd zonder problemen of vertraging aangeleverd. Cordula, Ragnar, de patiënten in Roermond boffen met jullie! Ben en Katrien, ook in Eindhoven ben ik met open armen ontvangen, op naar nog meer ONCOZON samenwerking. Michel, Wilma, José, dank voor het mogen gebruiken van jullie AvLdatabase en het kritische commentaar op het uiteindelijke manuscript. En wat een service voor het case report. Jos, het was een stukje rijden, maar wat een positieve indruk kregen we van de longziekten in Zwolle. Dank voor alle medewerking. Robin, Mohammad, Bonne, ik ben erg blij met alle data en feedback die jullie hebben geleverd. Anita en Janna, op naar jullie eigen proefschrift!

Jules, je bent mijn redding geweest met SPSS of Adobe problemen. We hebben twee mooie artikelen samen en ik ben blij dat je mijn paranimf wil zijn. Heel veel succes bij je volgende manuscripten en het afronden van je eigen proefschrift. Het wordt goed! En ooit leer ik zelf mooie figuren maken.....

Monique Hochstenbag, dank voor de kritische noot en de taalkundige ondersteuning. Op naar nog veel samenwerking met de drie (inmiddels vier) long oncologie dames.

Ruud Houben, dank voor de statistische ondersteuning bij de manuscripten.

Justine en Wouter. De samenwerking met jullie was prettig in het VUMC. Wouter, je proefschrift is goed geworden. Justine, succes met de laatste loodjes.

Marlies, je hebt binnen 2.5 jaar je proefschrift afgerond, wat een prestatie. Dank voor alle praktische feedback rondom studies opzetten. Karin, ook jij gaat als een speer! Hopelijk kunnen we genoeg patiënten enthousiast maken voor jouw onderzoeken. Janna, het begin van je promotietraject is er, ik ben blij dat je er bent en verder gaat met waar ik gebleven was. 
Alle andere coauteurs. Het zijn er teveel om allemaal op te noemen. Bedankt dat jullie de tijd vrijmaakten om mijn manuscripten kritisch door te lezen.

De oncologie/researchverpleegkundigen, datamanagers en researchcoördinator. Desiree, beide Gerry's, Erna, Anneke, Esther, Michelle, Lianne, Lilian, Esmee: niets is jullie te veel als het om het welzijn van de patiënten gaat. Hetzelfde geldt voor de medewerkers van het oncologiecentrum: jullie hebben hart voor de patiënten maar staan ook altijd klaar voor de artsen. Ik kom nog steeds graag naar jullie toe.

Alle longartsen, arts-assistenten, verpleegkundigen en ondersteunend personeel van de afdeling longziekten. Het is een prettige groep om in te werken. Janine, zonder jou zou de afdeling niet functioneren. Als ik zie wat we allemaal aan je vragen, en het is nooit een probleem...

Tiny Wouters. Bedankt voor het goede en snelle verzorgen van de editing van dit proefschrift.

Daan Janssen, de lay-out is dankzij jou mooi geworden. Op naar een mooie carrière als medisch illustrator (of toch sportarts).

Sanne, fijn dat je mijn paranimf wilt zijn. Heel veel plezier en geluk met de kleine Samuel en met Javier natuurlijk. Op naar nog veel ijs eten samen!

Tjeu, Truus, Ingrid, Jeroen. Dank voor de uitstekende verzorging van Jourie, zonder jullie had ik niet rustig in Maastricht gezeten. Ik heb me altijd en nog steeds welkom gevoeld bij jullie en ik hoop dat ik nog lang kan blijven komen. Misschien krijg ik de hond nog eens slank met mijn gewandel.

Mijn ouders. Jullie staan altijd voor me klaar en stiekem ben ik best een beetje verwend, zeker met alles wat jullie de afgelopen jaren voor me gedaan hebben. Hopelijk heb ik ook wat terug kunnen doen. Papa, ik hoop dat ik nog lang veel langzamer fiets dan jij en dat we nog veel samen kunnen fietsen, beiden weer eens op een nieuwe fiets. Dank voor jullie liefde.

Donné, dankjewel voor alle begrip als ik weer eens 's avonds of in het weekend achter de laptop zat en verder ook nog wilde wielrennen, naar het paard, de hond uitlaten. En slapen natuurlijk, daar ben ik goed in.... Je kent me beter dan dat ik mezelf ken. Je hebt altijd alle vertrouwen in me gehad en me ondersteund, niet alleen psychisch maar ook met erg lekker eten. Ik kan iedereen zo'n goede kok als vriend aanraden. Op naar nog vele jaren samen! 


\section{Curriculum vitae}

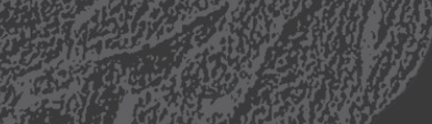

ons

(5)

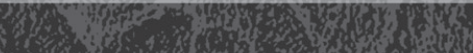

3

sine

Now

Q

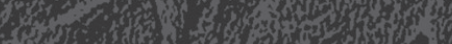

1

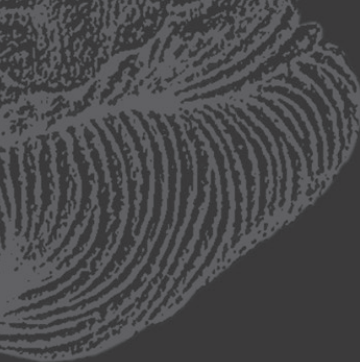

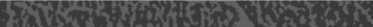




\section{CURRICULUM VITAE}

Lizza Hendriks was born on February $3^{\text {th }}, 1981$ in Weert, the Netherlands. In 1999 she finished her secondary education cum laude at the Gymnasium of the Philips van Horne Scholengemeenschap, Weert. In the same year, she started her medical studies at the Maastricht University, the Netherlands. She obtained her medical degree cum laude in 2005. Subsequently, she worked as a resident at the pulmonary departments of the Orbis Medical Center,

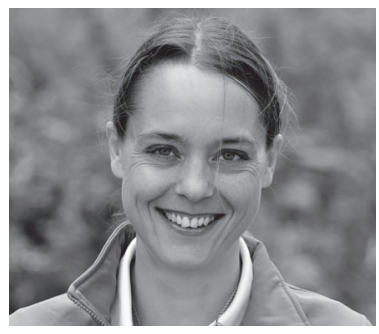
Sittard and the Atrium Medical Center, Heerlen, the Netherlands. In the latter, she started her training as a pulmonologist in 2006 and finished this training in September 2012. In October 2012, she started working as a pulmonologist in the Maastricht University Medical Centert, combined with a PhD trajectory on brain metastases in lung cancer patients (promotores: A-M. Dingemans, E. Wouters). Lizza is subinvestigator in several phase I, II and III lung cancer trials in the MUMC. She has participated in trainings for "rising stars in pulmonary oncology" and she has won the lung cancer award for best WCLC abstract by a resident/junior staff member of the "opleidingsregio Zuid-Oost Nederland" in 2013. She has been awarded several travel grants for abstracts presented at international oncology conferences. Lizza Hendriks is a member of the NVALT (and oncology subgroup), ERS, IASLC, ASCO, ESMO, EORTC lung cancer group and NRS. She is the coordinator of the young investigator group of the EORTC lung cancer group. She is a member of the committee for the revision of the Dutch guideline "brain metastases from solid tumours" and is a speaker on regional and national conferences and educational sessions. She lives together with Donné in Maastricht. 


\section{List of publications}

and

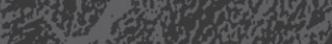

(1) 


\section{LIST OF PUBLICATIONS}

\section{THIS THESIS}

L Hendriks, A Brouns, M Amini, W Uyterlinde, R Wijsman, J Bussink, B Biesma, B Oei, J Stigt, G Bootsma, J Belderbos, D De Ruysscher, $M$ van den Heuvel, A-M. Dingemans. Development of symptomatic brain metastases after chemoradiotherapy for stage III NSCLC: does the type of chemotherapy regimen matter? Submitted.

L Hendriks, A-M Dingemans, D De Ruysscher. Proposals for the M-descriptors of the eight TNM classification for non-small cell lung cancer: more data needed? J Thorac Oncol 2016;11(3):e42-3.

L Hendriks, J Schoenmaekers, J Zindler, D Eekers, A Hoeben, D De Ruysscher, A-M Dingemans. Safety of cranial radiotherapy concurrent with tyrosine kinase inhibitors in non-small cell lung cancer: a systematic review. Cancer Treat Rev. 2015;41(7):634-45.

L Hendriks, J Derks, P Postmus, R Damhuis, R Houben, E Troost, M Hochstenbag, E Smit, A-M Dingemans. Single organ metastatic disease and local disease status, prognostic factors for overall survival in stage IV Non-Small Cell Lung Cancer: results from a population based study. European Journal of Cancer 2015;51(17):2534-44.

J Kuiper, L Hendriks, A van der Wekken, A de Langen, I Bahce, E Thunnissen, D Heideman, Y Berk, E Buijs, E-J Speel, F Krouwels, H Smit, H Groen, A-M Dingemans, E Smit. Treatment and survival of patients with EGFR-mutated non-small cell lung cancer and leptomeningeal metastases: a retrospective cohort analysis. Lung Cancer. 2015;89(3):255-61.

L Hendriks, E Troost, A Steward, G Bootsma, K de Jaeger, B vd Borne, AM Dingemans. Patient selection for whole brain radiotherapy (WBRT) in a large lung cancer cohort: Impact of a new Dutch guideline on brain metastases. Acta Oncologica 2014;53(7):94551.

L Hendriks, E Smit, B Vosse, W Mellema, D Heideman, G Bootsma, M Westenend, C Pitz, G de Vries, R Houben, K Grunberg, M Bendek, E Speel, AM Dingemans. EGFR mutated non-small cell lung cancer patients: More prone to development of bone and brain metastases? Lung Cancer 2014;84(1):86-91.

L Hendriks, G Bootsma, D de Ruysscher, N Scheppers, P Hofman, B Brans, AM Dingemans. Screening for brain metastases in patients with stage III non-small cell lung cancer: is there additive value of magnetic resonance imaging above a contrastenhanced computed tomography of the brain? Lung Cancer 2013;80(3):293-7. 


\section{OTHER PUBLICATIONS}

A van der Wekken, R Pelgrim, N 't Hart, N Werner, M Mastik, L Hendriks, E van der Heijden, M looijen-Salamon, A de Langen, J Staal-van den Brekel, S Riemersma, B van den Borne, E Thunnissen, E-J Speel, A-M Dingemans, T Hiltermann, A van den Berg, W Timens, E Schuuring, $H$ Groen. Dichotomous ALK-IHC is a better predictor for ALK inhibition outcome than traditional ALK-FISH in advanced non-small cell lung cancer. Submitted.

L Hendriks, J Aerts, M van den Heuvel, A-M Dingemans. Ervaring van de expertisecentra met het compassionate use programma nivolumab voor het niet-kleincellig longcarcinoom. Submitted.

A. Brouns, L Hendriks, M. de Booij, P. Theunissen, M. van Vliet. A simple aspiration? Submitted.

M Verduin, H Martinussen, R Janssen, S Croes, L Hendriks, J Jager, J Zindler, D Eekers, A Hoeben. Use of targeted agents and chemotherapy concurrent with stereotactic or whole brain radiotherapy for cerebral metastases of solid tumors: a review of the literature. Submitted.

E Driessen, G Bootsma, L Hendriks, F vd Berkmortel, B Bogaarts, J van Loon, A-M Dingemans, M Heijnen-Janssen. Stage III NSCLC in the elderly: patient characteristics predictive for tolerance and survival of chemoradiation in daily clinical practice. Submitted.

K Sanders, L Hendriks, E Troost, G Bootsma, R Houben, A Schols, A-M Dingemans. Early weight loss during chemoradiotherapy has detrimental impact on outcome in NSCLC. $J$ Thorac Oncol. 2016;11(6):873-9.

L Hendriks, B Hermans, M vd Beuken, M Hochstenbag, A-M Dingemans. Effect of bisphosphonates, denosumab and radioisotopes on bone pain and quality of life in patients with non-small cell lung cancer and bone metastases: a systematic review. J Thorac Oncol. 2016;11(2):155-73.

J Derks, L Hendriks, W Buikhuizen, H Groen, E Thunnissen, R van Suylen, R Houben, R Damhuis, E-J Speel, A-M Dingemans. Clinical features of Large Cell Neuroendocrine Carcinoma: a population based overview. Eur Respir J. 2016;47(2):615-24.

W Mellema, L Masen-Poos, E Smit, L Hendriks, J Aerts, A Termeer, M Goosens, H Smit, $M$ van den Heuvel, A van der Wekken, G Herder, $F$ Krouwels, J Stigt, B van den Borne, $T$ Haitjema, A Staal-van den Brekel, R van Heemst, E Pouw, A-M Dingemans. Comparison 
of clinical outcome after first-line platinum-based chemotherapy in different types of KRAS mutated advanced non-small-cell lung cancer. Lung Cancer 2015;90(2):249-54.

L Hendriks, A-M Dingemans, $M$ Lammens, M Anten, M vd Heuvel, A Postma. An uncommon presentation of brain metastases in a lung cancer patient. $J$ Thor Oncol 2015;10(11):1655-65.

L Hendriks, A-M Dingemans. Hersenmetastasen (brain metastases). Case report www.ipulmonologist.eu September 2015.

L Hendriks, A-M Dingemans. Journal Scan: eerstelijns behandeling met crizotinib versus pemetrexed-platinum bij stadium 4 niet-kleincellig longkankerpatiënten met een $A L K$ translocatie (first-line crizotinib versus chemotherapy in $A L K$-positive lung cancer). Ned Tijdschr Oncol 2015;12:166-7.

L Hendriks, M Gronenschild, E van Haren. A man with persisting dyspnea. Ned Tijdschr Geneeskd 2013;157(3):A5158.

L Hendriks, M Drent, E van Haren, J Verschakelen, G Verleden. Lung cancer in idiopathic pulmonary fibrosis patients diagnosed during or after lung transplantation. Resp Med CME 2012(5):37-9.

L Hendriks, M Hochstenbag, U Lalji, A-M Dingemans. A pulmonary abscess - beware of lung cancer! Resp Med CME 2011(4);157-9.

L Hendriks, E van Haren. 18-year old male with fever and dyspnea. Interactive case ERS website, September 2011.

L Hendriks, M. van Vliet. Pleurisy and splenic abscess from Salmonella serotype Enteritidis: case report and review of the literature. Tijdschrift voor Infectieziekten 2011;8:64-8.

L Hendriks, California digging. Breathe 2010;6(3):267-71.

L Hendriks, B Looij. Hyperthyroidism caused by excessive consumption of sausages. Neth J Med 2010;68(3):135-7.

Th van der Waart, L Hendriks, M ljland. Verzakkingsgevoel. Huisarts en wetenschap 2004;47(4):763-768. 


\section{BOOK CHAPTERS}

L Hendriks, E van Haren. Recidiverende luchtweginfecties. In: Probleemgeoriënteerd denken in de longgeneeskunde (2010), hoofdstuk 19: Pag 195-206.

Th van der Waart, L Hendriks, M IJland. Verzakkingsgevoel. In: Diagnostiek van alledaagse klachten (2004). Pag 615-23. 

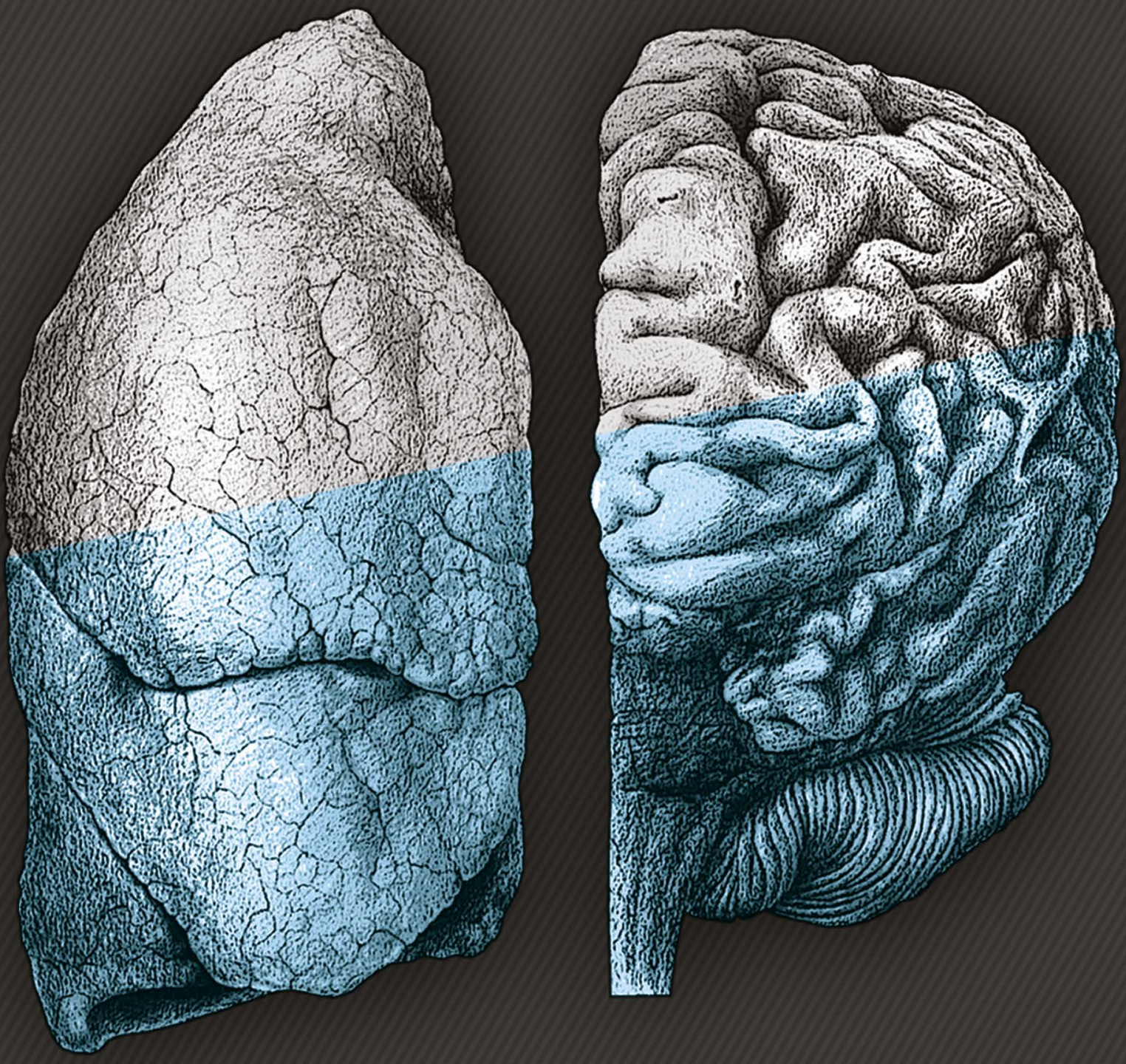